\title{
Navigating Uncharted Waters: Teachers collaborating across difference
}

\author{
Anne Hynds
}

A thesis

submitted to the Victoria University of Wellington

in fulfilment of the requirements for the degree of

Doctor of Philosophy

in Education

Victoria University of Wellington

2007 


\section{Abstract}

This thesis provides a unique navigational story which describes my own careful exploration of a collaborative dynamic when culturally diverse teachers worked together on a unique professional development initiative. Between 2001 and 2003 the Ministry of Education in Aotearoa/New Zealand funded the first phase of an action research initiative, Te Kauhua/Māori in the Mainstream Pilot Project, in a number of schools across the country. This initiative aimed to improve teaching practice and outcomes for Māori students through the development of collaborative partnerships ${ }^{1}$ between Māori and non-Māori within participating school communities ${ }^{2}$.

I worked to gather the stories of teachers' collaborative partnership work, from various perspectives over a period of two years, in two schools which had taken part in this first phase of this government funded project. The immediate result of such collective work was a commitment to work together for change and improvement in practice, and an apparent transformation in the thinking and practices of many teachers. My initial analysis highlighted partnership mechanisms and processes which held much promise and which had enabled the beginnings of change within and across both school communities. However as I continued my investigation over time I came to realise that sustaining change and development in schools, targeted at student groups who have been marginalised in the education system for a long time, was more complex than I first realised. Beneath the surface, in both schools, were submerged influences which militated against continuation and acceptance of such collaborative partnership work within and across both cultural communities. It became increasingly clear that a lack of shared vision across the schools generally, together with active resistance on the parts of particular groups, contributed to destroying the respect, trust and partnership that I thought had been established within the staff communities.

This thesis therefore outlines the opportunities, challenges and threats to collaborative partnership work that aims to improve practice and outcomes for culturally diverse students.

\footnotetext{
${ }^{1}$ Partnership work between Māori and non-Māori has particular significance in Aotearoa/New Zealand and usually refers to the partnership principle in the Treaty of Waitangi. This treaty was signed in 1840, and formed an agreement between Māori and the British Crown about governance of the country.

${ }^{2}$ It is important to note that when I use terms such as teachers, students, parents/caregivers etc., unless otherwise stated I am referring to Māori and non-Māori participants in these category groups. Māori are the indigenous people of our islands; the tangata whenua of Aotearoa/New Zealand.
} 


\section{Acknowledgements}

Like most successful journeys, this study would not have been possible without the help and assistance of others. There are many people I want to thank and acknowledge: people who generously gave of their time and were able to give directions, comfort, encouragement and advice as I entered uncharted waters. What I have learned on my travels I learnt through my participation with you.

First of all and most importantly, I would like to acknowledge all of the participants (the teachers, students, parents/caregivers, whānau members, principals, inschool facilitators, Resource Teachers of Learning and Behaviour and others) who took part in this study. Thank you for your time, honesty and willingness to engage in ongoing research discussions with me. Without your participation, your honesty and openness this study would not have been possible.

I would like to thank my invaluable research supervisors, Deborah Willis and Barbara Craig from Victoria University of Wellington. Thank you for encouraging me to continue and not to give up, particularly when I felt I was lost in the complexity of the data: your support and critical feedback were important contributions in this research journey. To Ginny Sullivan who also provided me with navigational tools to re-check my bearings when I felt lost.

To my reference group - Marama Tuuta, Cheree Shortland-Nuku, Lynette Bradnam, Trisha Turner and Joanna Higgins - thank you. You provided me with guidance and important reference points, which encouraged me to undertake this research journey. I would also like to thank and acknowledge the Ministry of Education which allowed me to have access to the Te Kauhua context, and especially Fred Bishop and Heleen Visser from the Ministry of Education.

A special thank you to my husband Derek, whose patience and reassurance enabled me to complete this research journey. Thanks also to my whānau: to Verna and Percy, John and Leonie, Max and Dyanne, Julie, Maree, Andrew, Alan and Terry as well as other members of my extended family (past and present) who have engaged me in debate and challenged me to think about my own practice as a teacher and to refine my social vision for Aotearoa/New Zealand. 
Thanks and acknowledgements must also be made to friends and colleagues: to Prue, Helen, Pip, Liz, Lizzie and Jen who kept me going with timely breakfast meetings, who gladly read draft chapters, gave important feedback and who kept telling me that I could finish and do justice to this research. Thanks also to Dr Lex McDonald, Dr Don Brown and Lottie Thompson who initially encouraged me to start this research journey. Acknowledgements also to Susan Kaiser from publishing and to the research librarians from the College of Education, Victoria University of Wellington, who willingly gave their time to assist me in this endeavour.

Tēnā koutou 


\section{Glossary}

A simple ${ }^{3}$ translation of Māori-English words is provided here.

\begin{tabular}{|c|c|}
\hline $\begin{array}{l}\text { Aotearoa } \\
\text { aroha } \\
\text { arohanui }\end{array}$ & $\begin{array}{l}\text { whole of New Zealand } \\
\text { love } \\
\text { big love }\end{array}$ \\
\hline hapū & sub-tribe, clan \\
\hline harakeke & flax leaf \\
\hline hīkoi & step out, pace, \\
\hline hui & meeting \\
\hline iwi & tribe \\
\hline kai & food \\
\hline kaiāwhina & helper \\
\hline kanohi te kanohi & face to face \\
\hline kaumātua & elder \\
\hline kaupapa & strategy, theme \\
\hline kina & sea egg \\
\hline kia kaha & be strong \\
\hline koha & donation, gift \\
\hline kōhanga reo & language nest, nursery for the language \\
\hline kōrero & speak, talk \\
\hline koru & opening fern frond, spiral pattern \\
\hline kotahitanga & as one, unity \\
\hline kuia & older woman \\
\hline kōwhai & $\begin{array}{l}\text { an indigenous tree of Aotearoa/New Zealand known for its bright } \\
\text { yellow flowers }\end{array}$ \\
\hline kura & school \\
\hline mai & give to me, this direction \\
\hline mahi & job, activity, work \\
\hline mana & integrity, prestige \\
\hline Māori & indigenous people of Aotearoa/New Zealand \\
\hline marae & meeting area of whānau or iwi \\
\hline mihimihi & greeting, introductions \\
\hline mokopuna & grandchild, young generation \\
\hline Pākehā & non-Maori, European, Caucasian \\
\hline pohutakawa & $\begin{array}{l}\text { indigenous tree often seen in costal areas of the North Island, } \\
\text { which flowers late in the year }\end{array}$ \\
\hline rātā & $\begin{array}{l}\text { an indigenous tree vine of Aotearoa/New Zealand known for its } \\
\text { red or white flowers }\end{array}$ \\
\hline
\end{tabular}

3 As words are always open to different, multiple, regional and localised interpretations, other excellent resources will help the reader with translation. For example, refer to Ryan, P. M. (1994). Dictionary of Modern Mãori. Auckland: Heinemann Education. 


\author{
tamariki \\ tangata whenua \\ Te Kauhua
}

Te Ara Reo

te ao Māori

tēnā koutou

te reo

Te reo me ona tikanga

tikanga

tipuna

tohu

Treaty of Waitangi children

local people, indigenous people of Aotearoa/New Zealand

the supports on a waka; used by participants as a metaphor for the professional development pilot project undertaken within the two school communities (I was told that it means supporting teachers to undertake the same journey together)

pathway to the language (a language course)

the Māori world

greetings and acknowledgements to you all

the language

The language, the customs and protocols behind the language go together and cannot be separated.

custom, obligations and conditions

ancestor, grandparent

navigational signs or messages from guardian spirits

This treaty was signed in 1840 and formed an agreement between Māori and the British Crown about the governance of Aotearoa/New Zealand.

waka
wairua
whāea
whakapapa -
whakataukī
whānaungatanga
wharenui
whānau
whānau hui

waka

canoe

spirit

madam, aunt, nanny

genealogy, cultural identity, family tree

proverb

relationsip, kinship

big house

extended family

family meeting 


\section{Contents}

Abstract

Acknowledgements ii

Glossary iv

$\begin{array}{ll}\text { Introduction } & 1\end{array}$

Chapter 1. Mihi: Initiation, Terminology, Methodology, 4 Context and Data

Initiation: An Explanation of the Research Approach 4

Who am I? Researcher, Collaborator, Friend or Foe? 5

Two Journeys: An Investigation into Teachers' Collaborative Partnership Work 6

The Goals of My Inquiry $\quad 10$

Terminology: Defining Teachers' Collaborative Partnership Work 11

The Dimensions of Collaborative Work 12

Partnership Work in the Context of Educational Reform 14

Teacher Collaboration and Collegiality 15

My Own Definition of Collaborative Partnership Work $\quad 17$

$\begin{array}{ll}\text { Methodology } & 21\end{array}$

The Protocols of Collaborative Research Methodology 21

$\begin{array}{ll}\text { The Issue of Legitimacy } & 21\end{array}$

The Process of Establishing Research Relationships 22

The Process of Entry: A Series of Negotiated Invitations 23

The Process of Conducting Interviews 26

The Issue of Accountability 28

The Issue of Benefit $\quad 30$

The Issue of Representation 31

The Context $\quad 32$

The Research Participants $\quad 32$

The Two Schools $\quad 34$

The Wider Context: Race Relations within Aotearoa/New Zealand 42

During the Time of This Research

$\begin{array}{ll}\text { The Data } & 45 \\ \text { Research Questions } & 48\end{array}$

Chapter 2. The Existing Navigational Charts That Outline 49 Teachers' Collaborative Partnership Work

The Need for Teachers to Fix the Problem of Underachievement 49

The State of Educational Achievement in Aotearoa/New Zealand 49

Teachers' Attitudes and Deficit Theorising $\quad \mathbf{5 0}$

The Importance of Teachers' Agency and Effective Learning Relationships $\quad 55$

Teacher Collaboration and Collegiality: Mechanisms for Improving $\quad 60$

the Quality of Teachers' Practice For Culturally Diverse Learners 
$\begin{array}{ll}\text { Enhancing Teacher Agency Through Collaboration } & 61\end{array}$

Collective Efficacy $\quad 62$

Collegiality and Other Forms of Collaborative Teacher Behaviour 63

Uncovering Turbulent Waters: Tensions in Creating and Sustaining 66

Collaborative Teacher Cultures

Contextual Influences on Teachers' Collaborative Behaviour 68

The Impact of Reform - Is It Good for Teachers?

Collaboration and the Presence of Conflict $\quad 71$

The Cultural Map: Opting In or Opting Out 73

The Function of Aroha in Teachers' Collaborative Partnership Work 73

Muddying the Waters: A Search for Evidence within Aotearoa/New Zealand 75

on Culturally Diverse Teachers' Experiences of Collaboration and

Partnership Work

Māori Teachers' Experiences of Collaborative Partnership Work 77

in Mainstream Schools

Conflicting and Incomplete Navigational Charts $\quad 80$

Chapter 3. Interpreting Signs and Messages $\quad 82$

The Blessings: Exploring Mindsets, Beliefs and Values 83

The Blessings: Establishing the Right Environment $\quad 87$

The Blessings: Awakening, Understanding and Listening $\quad 89$

The Blessings: Real/Honest Heart-felt Stories $\quad 91$

The Blessings: Examining Contradictions of Practice in a Context of 93

Collaborative Inquiry

The Blessings: Ownership, Voice and Choice $\quad 99$

The Blessings: Valuing Voices Not Usually Heard 102

The Gathering of Blessings $\quad 106$

Mixed Messages: Different, Contradictory Signs within the Context of 118

Teachers' Collaborative Partnership Work

Chapter 4. The Tip of the Iceberg and What Lies Beneath 122

The Second Interviews $\quad 122$

Signs and Messages: Emotionally-charged Discussions $\quad 124$

Trust and Respect: Less Visible and/or Examined Beliefs and Practices 127

Warning Signs: Submerged Beliefs, Revealed Prejudice 131

Differences in Teachers' Beliefs: Trust, Respect, Status, Leadership and Mana 135

Diversity of Teachers' Identities, Beliefs and Values $\quad 139$

Power-sharing Strategies in the Work of Reform 145

Messages About Established Listening and Partnership Practices 153 with Culturally Diverse Stakeholder Groups

Chapter 5. Warning Signs About Resistance to Collaborative 157 Partnership Approaches: The Internal Dynamic

Resistance to Teachers' Collaborative Partnership Work 159

The Dominant Discourses of Resistance: Identity and Equity 167

The Undercurrents of Resistance: Deficit Thinking, Prejudice, 171 
Racism and Identity

Resistant and Automatic Learnt Behaviour $\quad \mathbf{1 8 1}$

A Lack of Openness, Transparency and Honesty and the Presence of Subterfuge 181

Creating High Trust Environments: School Leadership 187

Issues of Teacher Niceness and Unexplored Social Class Values 192

$\begin{array}{ll}\text { A Lack of Listening } & 198\end{array}$

Chapter 6. Warning Signs About the Schooling Environment 205 and Beyond: The External Dynamic

Established Hierarchies and the Issue of Leadership 206

Staff Divisions and Disputes $\quad 210$

Bullying and Subversive Practices $\quad 216$

Ways of Dealing with Diversity in a Closed System 222

Transparency and Outcomes for Students $\quad 227$

Power Relationships and Identity Formation 231

The Impact of the Wider Schooling Environment on Teachers' and 235

Principals' Knowledge

What Counts as Culturally Responsive Practice? 238

Chapter 7. Charting the Journey: A Slow and Careful Navigation 246 of the Collaborative Dynamic

Searching Out and Interpreting Different Signs and Messages within the 246

Context of Teachers' Collaborative Partnership Work

A Return to the Blessings 249

Developing New Types of Collective Consciousness and Political Activism 251

Engaging Culturally Diverse Participants in Dialogue and 254

Critical Collective Enquiry

The Need for Preparation $\quad 257$

$\begin{array}{ll}\text { Recommendations } & \mathbf{2 6 3}\end{array}$

Teachers' Professional, Personal and Learning Identities 263

The Development of Non-negotiable Principles and Protocols in Practice 264

Knowledge, Skills and Dispositions Needed 264

The Cultural, Emotional, Political and Spiritual Dimensions of 265

Collective Reform Work

Racism, Prejudice \& Bullying Practices in the Context of Reform 265

The Internal and External Dynamics of Teachers' Collaborative 265

Partnership Work

In My Own Educational Practice $\quad 266$

$\begin{array}{ll}\text { References } & 268\end{array}$

$\begin{array}{ll}\text { Appendices } & 279\end{array}$

A Consent Forms and Participant Information Sheets 280

B Characteristics of Participants 290

C Interview Questions $\quad 293$

D Summary of Research Design, Methods and Findings 295 


\section{Introduction}

In this thesis I use personal narrative in order to illustrate the 'turning points' (Bruner, 1990) in my understanding of what influences, sustains and constrains teachers' collaborative partnership work within a context of cultural diversity and educational reform. From a Kaupapa Māori perspective it was appropriate that narrative should underpin my methodological approach in order to privilege participants' own stories of teachers' collaborative partnership work:

Cultural preference for story as a medium of education is widespread, not only among Māori and Polynesian cultures, but among indigenous cultures generally.... Stories enable the listeners to identify with, and learn from, the experience of storytellers (Bishop \& Glynn, 1999; p. 180)

Therefore the thesis itself is presented as an account of what I passed through; my own slow and careful navigation of the collaborative dynamic, when a group of Māori and non-Māori teachers work together for change and reform.

Chapter 1 starts the journey with a mihimihi, a process of introduction into the research methodology which begins by explaining how the research was initiated, the participants involved and the protocols which I attempted to follow. This first chapter describes the unique political context within Aotearoa/New Zealand as two very different schools launched their own collaborative journeys in an attempt to improve current teaching practice and outcomes for Māori children and young people within their communities. Here the reader will find my own definition of teachers' collaborative partnership work, a definition which emerged as a result of careful navigation and critical interpretation of the collaborative dynamic. This chapter provides an account of the collaborative partnership process which underpinned my own learning journey, as well as descriptions of some of the challenges that I encountered, and the points at which I had to double back and re-chart my course.

Chapter 2 gives an account of the readily available literature on teachers' collaborative partnership work, which I found to be largely inadequate for preparing culturally diverse partners (particularly teachers and principals) to undertake such a 
journey. This chapter starts, however, with a description and review of literature which explains why a sea-change is needed within our current mainstream schooling practice in Aotearoa/New Zealand. Here, I explore and critique the available literature on teachers' collaborative partnership work as a potential reform mechanism. I found a lack of stories about such work told from the perspectives of culturally diverse participants, and much of what was available remained silent on issues of culture and identity.

Chapters 3, 4, 5 and 6 provide an account of my own careful navigation and critical interpretation of the visible and less visible dimensions of teachers' collaborative partnership work, and how I was able over time to identify the influence of these dimensions on the practice, acceptance and efficacy of such work. Chapter 3 begins the process of interpretation and gives an account of the various tohu (signs and messages) which emerged as both 'blessings' (highlighting a way forward) and 'warnings' (revealing potential threats). Although I came to understand such signs, they were largely ignored, unexamined and unacknowledged by participants (particularly teachers and principals) within and across both school communities.

Over time I came to see the 'tip of the iceberg and what lies beneath'. Chapter 4 provides an account of the less visible, submerged and hidden influences on the practice and acceptance of teachers' collaborative partnership work within and across both school communities. Signs and messages emerged from participant stories and revealed to me the less conscious values, beliefs, identities and practices that teachers bring into their work (and in this context their collaborative partnership work). Over time, warning signs revealed to me a lack of trust and respect for difference and diversity within a context of teachers' collaborative partnership work, which included the presence of deficit theorising, racism and prejudice. I came to see the unacknowledged power relationships and discourses which influenced the acceptance and efficacy of teachers' partnership work within and across both school communities.

Chapters 5 and 6 outline other messages which continued to emerge over time. I interpreted these as warning signs, revealing the hidden and unacknowledged values, beliefs and practices that contributed to each of the school's cultures and which fed resistance to teachers' collaborative partnership work. These signs pointed to resistance, including (internally) the presence of 'forced' identities and learnt behaviours, which 
contributed to deficit thinking, racism and prejudice, within an environment (externally) of established micro-politics, staff divisions and disputes, bullying and subversive practices as well as hierarchies and power relationships within each school community, but which also extended beyond the school gates.

Chapter 7 completes the final stage in my own learning journey. In this chapter I return to the messages which I interpreted as 'blessings', an account of the signs which initially created so much hope for teachers' collaborative partnership work within and across both school communities. It was these messages which I believe contributed to an awakening in many teachers' consciousness, yet they remained ignored and unacknowledged within and across both school communities. By returning to the blessings, I emphasise the need for more radical, inclusive and political forms of teachers' collaborative partnership work, which I have come to realise must be developed and sustained if we are truly to work together for change and transformation in Aotearoa/ New Zealand. 


\section{Chapter 1. Mihimihi: Initiation, Terminology, Methodology, Context and Data}

Ehara taku toa i te toa takitahi, engari he toa takitini.

My strength is not that of a single warrior but that of many.

I open this chapter with a whakatauki ${ }^{4}$ to position myself as researcher within a much wider learning community (past and present) concerned with theory and practice that is "connected to the advancement and development of Māori children" (Bishop \& Glynn, 1999, p. 102). This study presents the product of my learning: what I have learned from conversations with others.

The thesis gives a partial snapshot of the multi-dimensional nature of the collaborative dynamic when Māori and non-Māori teachers from two very different mainstream schools worked together for reform. In the course of carrying out this research, I collected interview data from 77 culturally diverse participants across two unique school communities. The issues addressed in this study emerged from data analysis that occurred within a specific time-frame; this analysis was limited by the time requirements and restraints of the thesis process. I have attempted to provide enough information about the research methodology and the research context for these words to paint a picture of the dynamics of teachers' collaborative partnership work and to begin a process of unveiling the dynamics informing this work.

\section{Initiation: An Explanation of the Research Approach}

There is a growing consensus that research involving Māori and their knowledge should be conducted in culturally appropriate ways (Bishop \& Glynn, 1999; McFarlane, 2004) and promote new forms of consciousness and transformative action (Smith, L. T., 1999; Smith, G., 2002). I have been particularly motivated by Bishop and Glynn's call for nonMāori researchers to engage in inquiry as Treaty ${ }^{5}$ partners, so long as their research is guided by Kaupapa Māori research protocols (1999).

4 This whakatauki was used within the Te Kauhua Evaluation conducted by Tuuta, Bradnam, Hynds, Higgins and Broughton (2004), and is presented here as part of my mihimihi to position myself within the context of this work on teachers' collaboration.

5 That is, Treaty of Waitangi partners. 
The Kaupapa Māori research protocols as described by Bishop and Glynn (1999, p. 129) include the following:

1. initiation (how was the research initiated?);

2. benefits (what benefits will there be from the research?);

3. representation (whose voice is heard within the text?);

4. legitimation (what authority does the text have?); and

5. accountability (who is the researcher accountable to?).

In this study, I have attempted to follow these protocols within a qualitative research process, using inductive analysis (Janesick, 2000). Each of these protocols is addressed in more depth within this chapter as I explain the research methodology. I want to start by describing the initiation process (protocol 1), placing myself, as a Pakeha researcher, in a wider context of relationship building and co-construction of meaning with particular participant groups. I begin by stating my motivations, biases and assumptions because "all texts are personal statements" (Lincoln \& Denzin, 2000, p. 1051). My voice, as participant/researcher, is positioned within this collaborative story.

\section{Who am I? Researcher, Collaborator, Friend or Foe?}

I am a Pakeha woman, born in Manurewa, South Auckland, in the 1960s. I strongly identify with a group of Pakeha researchers who "signal difference from other European settlers who ignore or deny the status of Māori as tangata whenua", but who still acknowledge that they are part of the "empowered group" (McCreanor, 2005, p. 53). Within this research text, I am a co-participant, occupying space in the context of a qualitative inquiry conceptualised as "civic, participatory" and "collaborative", which "joins the researchers and researched in an ongoing moral dialogue" (Lincoln \& Denzin, 2000, p. 1049).

My motivation for undertaking this study grew from my reading of Bishop (1996) who argues that there is a need to develop theory which evolves out of and is connected to the educational contexts within Aotearoa/New Zealand. Although considerable research has documented the inequalities of the New Zealand education system, there remains a need for research to inform change and transformation across mainstream education (Bishop \& Glynn, 1999; Shields, Bishop \& Mazawi, 2005; Smith, L. T., 1999; Smith, G., 2002). Some Māori researchers have argued that interested and well-meaning 
Pakeha conduct research with indigenous people which maintains a colonial discourse of Māori as the 'other' (Bishop \& Glynn, 1999; Smith, L. T., 1999). I have attempted to avoid this. In my research, culturally diverse participants from two very different mainstream schools (teachers, principals, specialist teachers and in-school facilitators, students and parents/caregivers) talk about their experiences of teachers' collaborative partnership work, the purpose of which is to work together to improve classroom practice and outcomes for Māori students. I wanted to take part in research that addresses the issues of benefits and representation (protocols 2 and 3) in particular, and that ascribes legitimation (protocol 4) to the participatory and collaborative nature of the research, in which accountability (protocol 5) is a given part of the research dynamic (Bishop, 1996). I have been motivated to carry out this inquiry as an educator and as a citizen of Aotearoa/New Zealand.

\section{Two Journeys: An Investigation into Teachers' Collaborative Partnership Work}

My interest in teacher collaboration and partnership as reform mechanisms developed through my experiences as a classroom teacher, as a facilitator involved in delivering professional development workshops in schools, and more recently as a lecturer and researcher working within the context of teacher education programmes. Two teachers, myself and a teacher-trainee, were part of an earlier investigation into the impact of a collaborative inquiry project on individual educators' professional learning. We were Pakeha middle-class women interested in working together for change (Hynds, 2000). Although as educators we thought we supported each other in our efforts to implement simple cooperative learning strategies (e.g. 'think-pair-share', 'numbered heads together'), I found that educators can experience considerable difficulty in giving and receiving specific, honest and constructive feedback, particularly when it is radical and challenges their biases and beliefs (Hynds, 2000). The process of uncovering and confronting practices (and assumptions which underpinned them) was unsettling. The fear of over-burdening colleagues and of conflict, feelings of isolation, failure and guilt, the changing nature of the inquiry process, and competing roles and responsibilities, all resulted in reduced commitment to the collaborative process, and ultimately the inquiry was abandoned (Hynds, 2000). I now had first-hand knowledge of some of the dilemmas educators face when attempting classroom reform through collective action.

While I was aware of these dilemmas, I was optimistic about the benefits of such work because teacher collaboration and partnership as reform mechanisms are so widely 
touted in professional practice literature. ${ }^{6}$ Although I was unable to find any research literature within Aotearoa/New Zealand which spoke directly to such collaborative partnership work from culturally diverse perspectives (involving teachers, students and parents/caregivers), I felt it was important to address the issue of educational collaboration and reform within the specific context of the New Zealand education system and thus to ascertain the particular cultural and contextual dynamics of this setting and to identify the gaps in experience, knowledge, scholarship and policy formation that result. I was convinced that further study could address some of these important gaps.

I then became involved in a research whānau created to undertake an evaluation of a programme called Te Kauhua: Māori in the Mainstream pilot project (henceforward referred to as Te Kauhua). Te Kauhua was a three-year professional development exploratory pilot project, created and supported by the Ministry of Education (MoE). As part of Budget 2000, funding was secured for 2000-2003 to enable selected schools to "pilot new and innovative approaches to professional development to enhance teacher effectiveness for teachers working with Māori students in mainstream educational settings" (Tuuta, Bradnam, Hynds, Higgins \& Broughton, 2004). It was intended that Te Kauhua (meaning the supports on a waka and used as a metaphor for people supporting each other on a journey) would provide schools with opportunities, in partnership with their Māori communities, to explore professional development approaches that would enable teachers to improve classroom practice and outcomes for their Māori students.

Seventeen voluntary schools were selected by the MoE to be involved in the Te Kauhua pilot project. These schools, from the primary, intermediate and secondary settings, were divided into ten school clusters located across Aotearoa/New Zealand. The project used action research/collaborative research methodologies as a means to enhance teachers' professional development and knowledge of Māori student needs. An underlying assumption of the Te Kauhua pilot project was that Māori students were more likely to achieve "when they see themselves reflected in a curriculum, and when their teachers are supported to be reflective about their practice and to be agents of change for Māori students" (Tuuta et al., 2004, pvii).

Each school cluster had a 'teacher-leader' seconded to facilitate the project within the school/school cluster (Tuuta et al., 2004, pvii). These people were often referred to as in-school facilitators and their role "was to facilitate professional development

6 This literature on teachers' collaborative partnership work is covered in more depth in Chapter 2. 
opportunities and assist with the development of school strategic plans for building teacher capacity that would contribute towards improving student academic and social outcomes" (Tuuta et al., 2004, pvii). Another important part of the in-school facilitator's role was to assist teachers/principals to liaise and work in partnership with each school's Māori community in order to explore professional development approaches that enabled teachers to work to improve outcomes for Māori students. The Te Kauhua Evaluation highlighted evidence that teachers/principals were attending unique professional development hui, conducted in new and very different settings such as on the marae. Professional development sessions on the marae involved teachers' adherence to important Māori protocols, and in some situations involved important local Māori community members: kaumātua and kuia who would facilitate professional development discussions in partnership with Te Kauhua in-school facilitators. In some schools these appeared as one-off hui ${ }^{7}$ and in others it appeared that teachers/principals met with / and consulted whānau and community members over time.

As part of the Te Kauhua funding teachers were given planned release time to participate in the professional development activities. According to contract details, each school conducted action research by:

- collecting base-line data on Māori student achievement and identifying students' learning needs;

- developing appropriate interventions (and professional development programmes for teachers in partnership with whānau) to address the most significant of these;

- implementing the interventions;

- observing and recording changes in Māori student outcomes; and

- assessing the impact the programme had on Māori student outcomes and whānau school relationships.

\footnotetext{
${ }^{7}$ I found conflicting evidence within my own study as to the amount of time that teachers spent working in partnership and/or consulting whānau members. Some teachers who were interviewed told me that they attended and / or participated in different Te Kauhua professional development experiences to those of their teaching peers. For example, in Rata Primary it appeared that a group of teachers working in the Senior Syndicate worked closely with the Te Kauhua in-school facilitator on a very structured action research project, within their own classes. Some teachers from Kowhai College also told me that teachers attended professional development hui on marae at different times, and that some activities involved smaller groups of teachers working more closely with the Te Kauhua facilitator and others involved the entire staff.
} 
Wellington College of Education (WCE) was contracted to evaluate the effectiveness of these professional development initiatives. I was a member of the Research and Evaluation whānau (Te Kauhua), along with the two Directors of Te Kura Māori (Marama Tuuta and Lynette Bradnam), another Māori researcher (Robina Broughton) and the Manager of Research and Development (Joanna Higgins).

The WCE evaluation process included gathering data over the two-year period from:

- interviews with Māori students, their parents/caregivers, their teachers, principals and Te Kauhua facilitators;

- questionnaires completed by teachers, Te Kauhua facilitators, kaiawhina/teacher aides and specialist support staff (Resource Teachers of Learning and Behaviour [RTLBs], Resource Teachers of Māori);

- documentation from the schools involved in Te Kauhua, including milestone reports.

I refer to some of this data in the body of this thesis. The Te Kauhua Evaluation indicated evidence of the "beginning of change" and positive signs of progress towards reframing the mainstream school experience for Māori students within several schools (Tuuta et al., 2004). Participant groups had reported increased whānau/hapū involvement in schools, for example, whānau members undertaking professional development in order to work in home-school literacy programmes. Increased Māori representation was reported by different participant groups as new Māori staff members were employed (kaiawhina, teachers, senior management team members), and through increased Māori representation within school governance groups, such as boards of trustees. Māori parents and caregivers who were interviewed as part of the Te Kauhua Evaluation reported that schools were attempting to gather information on Māori stakeholder views through surveys on issues regarding effective school/classroom practice for their children (Tuuta et al., 2004). There was also evidence of teachers (Māori and non-Māori) working together more effectively within some schools. Although the Te Kauhua Evaluation noted progress in collaborative work, it also highlighted contested definitions of Māori students' achievement, as different stakeholders held varying ideas about the goal of improved practice (Tuuta et al., 2004). At the end of 2002, I was keen to find out more about the potential and challenges associated with collaborative partnerships, where 
culturally diverse teachers worked together to improve practice for equally diverse children and young people.

After the evaluation process for Te Kauhua had finished and the Evaluation Report was written, I approached the Ministry of Education for permission to use Te Kauhua as a context for further inquiry. Once approval was given, I set up a Research Advisory Group for my $\mathrm{PhD}$ thesis to guide me on the selection of two schools that had been involved in Te Kauhua and to give me advice on appropriate research with Māori stakeholder groups. The members of the Research Advisory Group consisted of three Māori and one non-Māori researcher who had previous experience and involvement with the Te Kauhua Evaluation. The Advisory Group suggested four Te Kauhua schools and I chose two randomly from this list. All four initial schools had been recognised through the Te Kauhua Evaluation process as attempting to work closely with Māori whānau, and there was evidence that they had emphasised encouraging collaboration and partnership between teachers in an attempt to improve practice and outcomes for Māori children and young people. These were also schools that had reported improvements in practice and Māori student outcomes as a result of their involvement in Te Kauhua.

\section{The Goals of My Inquiry}

This current study developed out of these two journeys and recommendations stated in the Executive Summary of the Te Kauhua Evaluation report:

Increased research is needed on processes that encourage or discourage teacher collegiality and their impact on school improvement and student achievement.

Further research is needed on partnership processes between Māori and non-Māori in schools. (Tuuta et al., 2004, p. ix)

I was interested in extending the process of collaborative inquiry, with my own study being part of an ongoing conversation on classroom reform in Aotearoa/New Zealand. I felt that as the research questions for this current study emerged directly from the Te Kauhua Evaluation, I was addressing Bishop and Glynn's (1999) concerns about initiation in research conducted in Māori contexts: "Who initiates the project? What are the goals of the project? Who sets the goals?" (Bishop \& Glynn, 1999, p. 129). One of the findings of the Te Kauhua Evaluation Report was the importance of developing 
effective collaborative partnerships within classrooms and across the school community (Tuuta et al., 2004). This was emphasised as a means of improving teachers' classroom practice and the health of the school culture, and as a way to address unequal power relationships among Māori and non-Māori in educational settings (Bishop, Berryman, Tiakiwai \& Richards, 2003; Bishop \& Glynn, 1999; McFarlane, 2004; Tuuta et al., 2004).

I was very interested in conducting research that would inform our understandings of collaborative partnership work between culturally diverse teachers within a context of reform. I wanted to investigate such work from a variety of views and diverse perspectives, for example the perspectives of indigenous and non-indigenous teachers, students, parents and caregivers, and others involved in the work of reform. My key concern was to understand the value and impact of teachers' collaborative partnership work from the insiders' (emic) perspective; I wanted to address issues of voice, particularly the voices of indigenous participants.

\section{Terminology: Defining Teachers’ Collaborative Partnership Work}

I already knew that there were different and competing definitions related to teachers' collaborative work through my reading of the available research literature. I found that although the term 'collaboration' is widely used in the literature on teacher professional learning and school reform, it is a contested term and is used in relation to other definitions of collaborative work, including teacher collegiality and/or partnership work (Fielding, 1999; Fullan \& Hargreaves, 1996; Head, 2003; Lieberman \& Miller, 1999; Little, 1990; Marzano, 2003; Stoll, Fink \& Earle, 2003; Timperley \& Robinson, 2002).

I found that some authors describe collaboration as a concept (Head, 2003) with different and interacting dimensions or levels (Head, 2003; Timperley \& Robinson, 2002). Some stress the developmental nature of collaborative work as a social learning process (Head, 2003; Lieberman \& Miller, 1999; Stoll, Fink \& Earle, 2003) influenced by the social context, including the existing patterns of staff relationships and teacher cultures (Fullan \& Hargreaves, 1996; Hargreaves, 1994; Stoll \& Fink, 1996). Many authors emphasise the complexity of the collaborative process as a social reform mechanism, and identify the knowledge, skills and dispositions that collaborators would need in order to work effectively together, and learn how to achieve shared goals through 


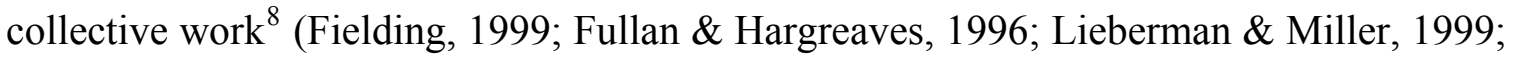
Little, 1990; Marzano, 2003; Stoll \& Fink, 1996; Stoll, Fink \& Earle, 2003; Timperley \& Robinson, 2002).

It appeared to me that a confusing array of terms was used within the discourse on teachers' collaborative work. Although different authors argued strongly for their descriptions and definitions, there was a lack of agreement within the literature. There were also noticeable gaps within the research texts on issues related to teachers' ethnic and cultural identities and the influence of diverse participant values, beliefs and practices that those involved bring into the collaborative dynamic. I was particularly interested in a definition that I found in the Concise Oxford English Dictionary: "Collaborate - to work jointly on an activity or project. Co-operate traitorously with an enemy" (1995, p. 280). This definition encapsulates the contradictory and opposing dynamics which often underlie collaborative work, particularly if there is a history of warfare between groups, as well as the contexts (historical and present) which may influence the development of collaborative partnership work.

\section{The Dimensions of Collaborative Work}

A few authors stress the importance of recognising the varying levels or dimensions of collaborative or partnership work (Head, 2003; Timperley \& Robinson, 2002). For example, Head (2003) argues that collaboration involves social activities or functions which may occur simultaneously within groupings, as "an individual cannot collaborate on her/his own" (p. 50). He states,

... collaboration is essentially multi-dimensional: its meaning is derived from the range of activities involved in the act of collaboration and from the subsequent effects of such activities. At the simplest level, collaboration comprises a range of closely related acts such as coordinating, consulting, communicating and co-operating. (2003, p. 50)

Head emphasises that collaboration has a multi-faceted nature which can impact on the development of the process and on the task at hand. He highlights that collaboration may involve an intermediary process, whereby something may have

\footnotetext{
${ }^{8}$ These arguments are discussed in more depth in Chapter 2.
} 
happened first "which suggests people need to work together collaboratively in order to deal with it" (Head, 2003, p. 51). Head argues for a recognition of the complexity of the collaborative process, including the need to recognise the diversity of people who cooperate in the act, and "the antecedent-activity-result process" (2003, p. 51).

Head notes that collaboration is a complex and problematic concept to examine because it may involve operations occurring simultaneously at more than one level. The first and most identifiable level relates to the functional or procedural elements of collaboration (Head, 2003). This entails the 'routine' and more 'immediate' aspects of collaborative work, for example, the coming together of participants, the formation of group work, and the exchange of information or knowledge between participants. However, Head states that this type of activity tends to remain at a material and/or technical level and benefits individuals within the group differently (2003). At the 'functional' level, participants may gather together for a common purpose, but in reality "they behave as individuals and only carry out the roles expected of them" (2003, p. 53). Head notes that collaboration provides participants with a chance to work at a different 'deeper' level of collaboration, something which he calls "effective collaboration" (2003, p. 49). He argues that "effective collaboration" involves a group of participants behaving in ways that produce shared understandings and collective benefits through new learning. This "leads to a degree of success belonging to the group" and "can only be achieved by group members working together" (Head, 2003, p. 50). Head notes that this deeper level shifts the focus from the learning of the individual to the "social aspects of learning" (2003, p. 50). Head argues that "effective collaboration is an integral element of the learning process", a "desirable and essential part" because it helps create community through the development of new learning (2003, p. 49).

Head states that effective collaboration requires individuals to "employ a repertoire of skills", including negotiation, communication and interpersonal skills (2003, p. 49). He notes that participants need to acknowledge and reflect collectively on the "surface manifestations" that are visible as participants work together over time (2003, p. 51). According to Head, this requires a "meta-cognitive" rather than a "functional" process, as there is a "deeper", "complex reality" operating between individuals when they come together with different experiences, backgrounds and knowledge. Head states that it is only when these are made "explicit" that potential barriers to effective collaboration, such as misunderstandings and misconceptions, can be addressed (2003, p. 49). Head argues that collaboration must be viewed as a complex concept because 
participants who work together are required to create meanings that "are shared rather than imposed" (2003, p. 48). It appeared to me that effective collaboration, as Head defines it, could only be achieved through participants working 'metacognitively' in a trusting, safe learning environment.

Head's (2003) arguments interested me and reflected the results which emerged from my current study, as he recognised that there are visible and less visible interacting aspects of collaborative work to which participants may not be attuned. There would need to be an acknowledgement of the ripples, currents and undertow which influence the collaborative dynamic, along with the visible surface expression of it.

\section{Partnership Work in the Context of Educational Reform}

Some authors stress that there are different dimensions of partnership work within the context of educational reform (Head, 2003; Timperley \& Robinson, 2002). According to Timperley and Robinson (2002), partnership means the sharing of tasks when working collaboratively. These authors argue that partnerships are about relationships, and the ways relationships develop often determine the success of the partnership.

Partnerships within educational contexts are often formed to carry out particular tasks that have a specific aim, such as improving classroom practice in order to raise student outcomes (Timperley \& Robinson, 2002). In their discussion, these authors note a lack of clarity around definitions of partnership and highlight the fact that the term can mean different things to different people. They argue that definitions of partnership often ignore the complex dimensions of such collaborative approaches, for example, they emphasise both the task and relationship dimensions. These authors note that partners need to integrate the relationship and task dimensions in ways which allow participants to work together and learn from one another. Effective partnerships ensure that shared responsibility to achieve stated goals is underpinned by mutual values of trust and respect, which in turn encourage differing beliefs and values to be brought to the work. Partnership work can be undermined if shared tasks become dominated by one partner's biases and beliefs (Timperley \& Robinson, 2002). These authors also state that a complex hierarchy may operate as partners work together, and they prefer to describe partnership as joint-work rather than as power-sharing (Timperley \& Robinson, 2002).

Their theory of partnership was developed through close study, over a four-year period, of the Ministry of Education's initiative, 'Strengthening Education in Mangere and Otara' (SEMO). Within this study, they investigated the development and success of 
a range of partnerships between teachers, parents, boards of trustee members, early childhood educators and the Ministry of Education. The overall conclusion of this study was that less successful partnerships focus exclusively on improving aspects of partner relationships, while the more successful partnerships balance the relationship and task dimensions in productive and creative ways.

\section{Teacher Collaboration and Collegiality}

I found that much of the research literature on teachers' professional learning linked teacher collaboration with collegiality, which is a finer and more specific expression of relationship. Fielding has argued that teacher collegiality is "invariably partnered" with collaboration and that, despite all the rhetoric of such partnership approaches, "we do not often manage to actually work in these desirable ways" (1999, p. 1).

I found different authors focusing on the behaviours of collegial teachers as well as different functions of collegiality. For example, Marzano (2003) emphasises teachers' collegial behaviours and interactions:

Collegial behaviour is demonstrated by teachers who are supportive of one another. They openly enjoy professional interactions, are respectful and courteous of each other's needs. (Marzano, 2003, p. 61)

A number of authors emphasise the need for respect amongst teachers in their discussion of teacher collegiality and/or collaboration (Fullan \& Hargreaves, 1996; Lieberman \& Miller, 1999; Marzano, 2003; Stoll, Fink \& Earle, 2003). However, Fullan and Hargreaves (1996) also argue that collegial behaviour, including respect, must occur within a context of open and constructive critique and review of current classroom and/or school practices and procedures. These authors appear to see a function of teacher collegiality as improving instruction and outcomes for students. Other authors highlight the spontaneous nature of collegiality. For example, Stoll emphasises teacher collegiality as a process of "mutual sharing and assistance; and orientation towards the school as a whole; and is spontaneous, voluntary, development orientated, unscheduled and unpredictable" (2000). I found some agreement in the literature that teacher collegiality means teachers taking collective responsibility for improvement across their school (Lieberman \& Miller, 1999; Stoll, 2000; Stoll \& Fink, 1996). 
Some authors stress that little is known about the inner workings of teacher collaboration within a context of social reform (Fielding, 1999; Fullan, 1999; Fullan \& Hargreaves, 1996; Head, 2003; Little, 1990; Little, 2001; Stoll, 2000). Little states that "The term collegiality has remained conceptually amorphous and ideologically sanguine" (1990, p. 509). This point is echoed by Lieberman and Miller who argue that teacher collegiality is "more complex than previously portrayed" (1999, p. 90). Fullan and Hargreaves, noted writers in the area of teachers' professional learning, assert that while teacher collegiality is touted as "one of the premier improvement strategies for schools", it comes with problems (1996, p. 7) and there is nothing automatically efficacious about it.

Key questions arose in my mind as I read through the available research literature on teacher collaboration, collegiality and partnership work. While different writers stress the need for respect and trust between teaching partners (Fullan \& Hargreaves, 1996; Lieberman \& Miller, 1999; Marzano, 2003; Stoll, Fink \& Earle, 2003; Timperley \& Robinson, 2002), the colonial history of Aotearoa/New Zealand (Smith, L. T., 1999) and the deficit attitude of many teachers towards their Māori students (Bishop \& Glynn, 1999) make it clear that establishing and sustaining mutual trust and respect between culturally diverse partners, particularly Māori and non-Māori, may be challenging.

Much of the research literature that I found on teachers' collaborative partnership work appears to reflect a monocultural or dominant Eurocentric perspective, which ignores the perspectives of culturally diverse participants. I found no direct research literature which speaks of Māori and non-Māori teachers' partnership work and I wondered about the impact this may have on the practice of partnership work and its acceptance into a school's culture.

In my own study, I found in the end that teachers' collaborative partnership work was largely superficial and contrived, influenced by 'visible' and 'less visible' factors. As I listened to culturally diverse participants tell their stories, I became aware of largely hidden, unacknowledged and 'less conscious' values, beliefs, identities and practices that those involved brought into their work, and in this context their collaborative partnership work. I found that these less visible influences had contributed to each of the school's existing cultures and fed resistance to teachers' collaborative partnership work. This resistance focused on a breakdown of any single-mindedness of vision the schools may have tried to achieve, and on interpretations of identity and equity. These 'less visible' internal and external factors worked to influence the practice of teachers' collaborative 
partnership work as well as its acceptance and place within each school's culture. However, it was 'I' as qualitative researcher who became aware of the influencing, interacting nature of such themes and related activities: participant stories and subsequent member checks emphasised the lack of awareness that those involved bring into the collaborative dynamic. I found there was an absence of the knowledge, skills, dispositions and contexts which would have enabled teachers to make sense of the 'emotionally charged conversations' which appeared as surface manifestations of the fact that something deeper was stirring, and would have encouraged teachers to work with other partners for change and transformation. It began to seem as if collaboration could realise its own energy and interactive dynamic only if it became conscious and active both in practice and in reflective analysis.

My own study results reveal that teachers' collaborative partnership work may be accepted, owned, embraced and adopted to many and varying degrees, but the dynamics underlying its acceptance and practice can only be ascertained through critical, collective inquiry and dialogue over time. I have come to the conclusion that change and reform for culturally diverse learners (Māori and non-Māori) can be achieved only if partners work together to identify the internal and external influences that affect the collaborative dynamic and the creation of culturally inclusive and responsive learning communities.

Transformation and change can occur only through a slow navigation of our thinking and behaviour as we engage in collaborative partnership work over time. I believe that we will be able to reframe the mainstream schooling experience for culturally diverse groups of students (Māori and non-Māori) only once a new form of collective, critical consciousness develops. This growing awareness of unconscious behaviour and hidden practices is needed to emancipate us from tradition (Carr \& Kemmis, 1986; Lather, 1986). Awareness is viewed as an essential preliminary to bringing about emancipation (Carr \& Kemmis, 1986; Hammersley, 1993; Lather, 1986).

\section{My Own Definition of Collaborative Partnership Work}

In this study, I have therefore interpreted teachers' collaborative partnership work as a collective activity involving indigenous and non-indigenous partners journeying together, one which is best expressed through the metaphor of sailing and navigation. I chose this metaphor for a number of reasons. Firstly, the metaphor is useful when considering the different tohu (navigational signs and messages) that emerged in the course of this study. Secondly, different participants who were interviewed talked about the importance of 
teachers being "on the waka together", in reference to the title of the professional development initiative Te Kauhua, which was the catalyst for these teachers' collaborative reform work. Te Kauhua was used as a metaphor within teachers' schools to describe a process of supporting teachers on a collective journey.

As a researcher, I have been warned that "change is a process not an event" (Fullan \& Stiegelbauer, 1991). It appeared from my readings that authentic and sustainable educational change or reform may be 'sailed' rather than 'driven'. Part of this 'sailing' metaphor recognises the changing dynamics, dimensions and complexity of any change process. It has been argued that change-agents find themselves facing unforeseen challenges and unanticipated dilemmas as they attempt to disrupt the status quo and work for improvement over time (Johnston \& Bush, 2005; Senge, Cambron-McCabe, Lucas, Smith, Dutton, \& Kleiner, 2000; Stoll, Fink \& Earle, 2003).

I found that Durie has argued for a recognition of the metaphor of navigation, because Māori (as a collective) have sailed tides of endurance and of change over time. He states that navigation requires Māori partners to work with others interculturally (across cultural groups) and intraculturally (within cultural groups):

Navigating a way forward will require Māori leadership to place greater emphasis on the alliances and opportunities that can be forged within te ao Māori (p. 250) ... [and later] ... Navigating the future will also require leadership to look outside te ao Māori, to the wider New Zealand society, and further still to other countries and peoples. (Durie, 2005, p. 251)

If we accept these metaphors of sailing and navigation within educational change contexts, then it would appear to me that culturally diverse teachers would need to be excellent navigators as they journey together; able to scan their environments, share and make good use of their collective knowledge, but also be conscious of the need to recognise and interpret different signs and messages as they enter uncharted waters. Such work would demand teachers to become self-aware and to recognise the cultural, spiritual, political, emotional and intellectual dimensions of their collaborative partnership work. It would require partners to be alert to, understand, recognise and collectively interpret different tohu. In this definition, tohu can be interpreted as blessings or warnings, highlighting potential navigational points, both safe passage and the presence of hazards. In other words, partners would need to become conscious of the 
'visible' and 'less visible' influences; the internal and external dynamics that affect the practice of their collaborative partnership work as well as its efficacy. As sailors and navigators in uncharted territory, partners would also need to be aware of and alert to the hidden influences: the 'less visible' features, revealing unseen depths, undertows, potential rips and submerged dangers, which could fuel resistance and the threat of mutiny and disrupt the collective journey.

In this thesis, I therefore define teachers' collaborative partnership work as a process which requires time and resilience, in order to conduct a careful and sustained navigation of the self and of the environment: a consciousness-raising political journey over a life-time of collective work. It also requires teachers to understand that this collective journey must include other partners if it is to be successful. In other words, collaborative partnership work must extend beyond teachers if the current mainstream schooling system is to be dismantled. I have come to agree with Bishop (1996) that we need to "bring" others "on board" (p. 233).

Partnership work must then involve indigenous and non-indigenous participants (Māori and non-Māori) in a process of more radical and inclusive work (Fielding, 1999). It requires teachers to re-position themselves as co-learners within a cooperative learning environment with culturally diverse children and young people, their teachers, parents, caregivers and whānau. Such collaborative work would require partners working together to recognise and analyse the internal and external dynamic, and to understand how knowledge is constructed, benefiting certain groups through privileging and powerful (but largely hidden and unacknowledged) discourses. At the end of this learning journey, I have come to agree with certain others that change will develop through critical consciousness, a process of de-colonisation involving culturally diverse groups (Bishop \& Glynn, 1999; Smith, L. T., 1999). This would require partners to acknowledge and examine the way historical power relations have shaped mainstream schooling practice, cultural identity, thought processes, learnt behaviour and legitimate knowledge in Aotearoa/New Zealand (Bishop \& Glynn, 1999; Penetito, 2001; Shields, Bishop \& Mazawi, 2005; Smith, G., 1990; Smith, L. T., 1999). The mainstream schooling system within this country has been developed through colonising processes (Bishop \& Glynn, 1999; Smith, G., 1990; Smith, L. T., 1999) and perpetuates pathologising practices, deficit thinking, and destructive images of Māori and others who are culturally diverse (Shields, Bishop \& Mazawi, 2005). 
My definition and understanding of collaborative partnership work therefore extends Durie's (2005) metaphor of navigation to include a process of moving back and forth between the internal and external (the self located within historical, cultural and political environments); and between the visible and less visible dimensions - the personal theories, world-views and practices that each of us bring into the context of our work. It will require us to be excellent navigators and interpreters of our selves and of our environment, aware both of what we see and what we do not see: the hidden, taken for granted, less conscious signs or messages that emerge as we engage in collaborative partnership work over time.

This process of navigation will be possible only if indigenous and non-indigenous teachers re-position themselves as learning partners in the joint work of change, through more radical and inclusive forms of collaboration and partnership, which extends to children and young people, their parents/caregivers and community elders. The process of learning through such partnerships will be possible only through dialogue, and open, collective and critical inquiry: a collaborative journey which must include a process of storying and counter-storying. Such a journey will not be easy, and will require us to be resilient, open-hearted and courageous over time, as the journey will be painful at points, and will require commitment and patience, partly because of the uncomfortableness and the turbulence of navigating uncharted waters and partly because of the as-yet unseen shadow self. The process of navigation, of moving back and forth, must reveal the hidden power dimensions which influence our schooling system and privilege some voices over others.

At the end of this stage in my own learning journey, I have come to the conclusion that collaborative partnership work must navigate the divide between theory and practice, a process which includes critical perspectives and discourses. It was critical theory which eventually helped me to make sense of the contradictory signs and messages contained within participant stories, and which also encouraged me to acknowledge and examine my own biases and assumptions which I too have carried into my analysis of teachers' collaborative partnership work. Finally, at the end of this stage in my journey of learning, I have come to the realisation that a new type of collaborative partnership work is needed if we are to work together to transform the mainstream schooling system for culturally diverse groups of Māori and non-Māori children and young people. This will categorically require political work. 


\section{Methodology}

\section{The Protocols of Collaborative Research Methodology}

The following section outlines important methodological practices related to the process of establishing relationships with culturally diverse groups of participants, and conducting interviews with them in order to be able to examine the etic and emic character of teachers' collaborative partnership work.

An essential part of this research process has been ensuring that I followed the protocols described by Bishop and Glynn (1999, p. 129). I have attempted to do this by committing myself to addressing the issues of initiation, benefits, representation, legitimation and accountability, and to create a text which is part of an ongoing narrative record (Bishop \& Glynn, 1999). I have described the process of initiation by identifying myself in the context of this research and by giving an account of my own voyage of discovery as I embarked on the research journey (pp. 1-8). I have also been careful to define the terms of this journey so that its signs and markers are known and its range is limited spatially, temporally and spiritually (pp. 8-18). These protocols inform the methodology and whole practice of this research and the thesis that is its end product, and are supports to and underpinnings of the methodological procedures that I relied on for this journey.

\section{The Issue of Legitimacy}

In my own study I found that the issue of legitimacy was closely tied to issues of representation and accountability, within a wider context of relationship-building, participation and co-construction of meaning. Bishop and Glynn note that in Kaupapa Māori educational research, legitimation is directly related to the validity of the data and the final results emerging from the overall research process. It is therefore important to address questions of accuracy, truth and completeness, as well as engagement and participation of others in theorising about the findings (1999, p. 129).

It was important for me to ensure that I represented participants' stories appropriately and truthfully (Bishop \& Glynn, 1999) and because of this I returned to individual participants and participant communities over time. This was achieved through an ongoing process of member checking to negotiate meaning, particularly as I revised my analysis. By sharing emerging themes and receiving feedback from participants on these findings, a process of storying and re-storying developed, something which Bishop 
and Glynn call a co-construction of knowledge (1999). Member checking involved 'giveand-take', a mutual negotiation of "meaning and power" (Bishop \& Glynn, 1999). This reciprocity operated at two primary points in the study: the junctures between the researcher and researched, and between data and theory (Lather, 1986, p. 263). I wanted to ensure my interpretations were trustworthy and were "credible portrayals" to those who participated (Kincheloe \& McLaren, 1994).

As Bishop (1996) notes, the research process is not 'ad hoc'; rather, it takes time to build trust and commitment. It is necessary for participants within cross-cultural contexts to have "cultural consciousness" in order to ensure that issues of power and control are adequately addressed (Bishop, 1996). I wanted to capture stories of participants' experiences within a context of inter- and intra-cultural partnership work, and as a Pakeha woman working with culturally diverse groups knew that in order to do so I would have to be accountable to my research participants, for both the process and product of this research (Bishop \& Glynn, 1999). Establishing and maintaining trusting relationships with diverse participant groups was an important and challenging part of my methodology, a process that occurred over time.

\section{The Process of Establishing Research Relationships}

Bishop (1996) uses the term 'whānau' metaphorically to describe those people whose relationship to one another is not formed through kinship or bloodlines. He argues that 'whānau' can be used as a metaphor for describing a group of people committed to a common kaupapa, for example a whānau of interest. Bishop (1996) identifies the process of "weaving people together" in order to solve a problem, or to "bring on board" people necessary to ensure a project succeeds (p. 233). Bishop and Glynn (1999) have also drawn on metaphors generated from work in Kaupapa Māori research, kohanga reo and kura kaupapa. One of these includes whakawhānaungatanga as a metaphor for creating family-type relationships, and hui as a metaphor for collaborative storying from research settings (Bishop \& Glynn, 1999, p. 201). Durie (2003) also notes that 'whānau' can be used to describe a group of people who may not be descended from the same ancestor but who share a common mission. He goes on to examine the term 'kaupapa whānau': "Kaupapa whānau have more flexible rules for engagement and disengagement and do not necessarily expect a life-long relationship" (Durie, 2003, p. 10). Issues of representation, participation, shared ownership, accountability and benefits are all 
incorporated within the process of whakawhānaungatanga (Bishop, 1996; Bishop \& Glynn, 1999; Durie, 2003).

I was already known to many of the research participants. As I mentioned earlier, to a certain extent a relationship had been established with some key people within both schools (Kowhai College and Rata Primary) due to my prior involvement in the Te Kauhua Evaluation. During the time of the evaluation, I attended hui along with in-school facilitators, principals and teachers involved in the work of reform. I got to know individuals through conversations at breakfast, lunch and dinner during several evaluation hui, held between 2000 and 2002. As a member of a much larger whānau, I listened to various stories describing the breakthroughs and dilemmas that emerged in the process of instituting mainstream schooling reform that was needed to benefit Māori pupils. Some of these stories were told in structured settings during hui presentations, whilst others were relayed over coffee and meal breaks. I felt people shared a sense of excitement, urgency and exhaustion as they talked, discussed ideas and resources, and laughed and cried. During our last presentation at the Te Kauhua hui, members of the evaluation team were thanked and farewelled with koha, and a number of relationships had been established. After the Te Kauhua Evaluation ended, it was important for me to explain to various participant groups that my involvement in the evaluation process had finished and that this separate inquiry was part of a very new and different research journey. Rather than having distinct phases in the research project such as 'gaining access', 'data collection' etc., I was mindful of Bishop and Glynn's description of a koru "as one that describes the process of continually revisiting the kaupapa of the research" and the formation and cementing of relationships (1999, pp. 129-130).

\section{The Process of Entry: A Series of Negotiated Invitations}

My entry into the research context occurred through a long process of invitation and negotiation, which adhered to important protocols. Following the advice of my Advisory Group, I made contact with key people at both selected schools. A series of invitations was extended to me to talk about my research, which required me to front up to research participants, kanohi te kanohi. This was an important part of establishing and sustaining research relationships (Bishop \& Glynn, 1999; Smith, L. T., 1999).

Each invitation afforded me an opportunity to speak about my research and to answer any questions people had. The process of invitation was particular to the different school contexts and occurred over time, with specific groups or individuals acting as 
gatekeepers to other participant groups. For example, at Kowhai College ${ }^{9}$ an invitation was extended, after an initial discussion with the in-school facilitator and principal, to come and speak to the board of trustees. No promises were made over the phone; all I had was an invitation to talk to the board about the possibilities of further study of teacher collaboration as a reform mechanism. The board of trustees, made up of Māori and nonMāori members, was interested but also wanted the research process to help their stated goal of improving classroom practice and outcomes for Māori students. I was mindful of Bishop and Glynn's (1999) concern regarding the issues of research benefits and I agreed to write a separate report, as koha, for the school's board of trustees to ensure benefits were shared (Bishop \& Glynn, 1999). I felt this was another way to ensure the research was guided by Kaupapa Māori research protocols (Bishop \& Glynn, 1999). After talking to the board of trustees at Kowhai College, I was then invited to return to the school to talk to teachers at a staff meeting about my inquiry process.

At Rata Primary School, ${ }^{10}$ the process of entry was similar with one notable exception. Although I was invited to talk at a staff meeting initially by the principal, I was not given an invitation to meet with the school's board of trustees. I offered to write a separate report on the research findings for Rata School's board of trustees, which was accepted by the principal.

Further visits were made to each of the two schools, and after a series of hui, 17 teachers (7 Māori and 10 non-Māori from across both schools) then volunteered to take part in this study.

At Kowhai College, I was advised to attend a whānau hui. A Māori staff member, who led whānau involvement at the school through the Te Kauhua programme, guided me through a process of consultation so that I could meet and talk with individual whānau and their children about the proposed research. In order to gather Māori participants' views regarding their experiences of teacher collaboration at Kowhai College, it was decided that it would be best to talk with those students and their parents/caregivers who had been directly involved with the Te Kauhua class. ${ }^{11}$ It was also decided that one of the Māori members of my Research Advisory Group should accompany me to the first whānau hui. The process of meeting with whānau was lengthy and required many trips and hui over time. I was initially disappointed that my first trip

\footnotetext{
${ }^{9}$ Kowhai College is a pseudonym that I have used to protect the identity of the school.

${ }^{10}$ Rata Primary is also a pseudonym that I have used to protect the identity of the school.

${ }^{11}$ I found out that the Te Kauhua class had been set up through the Te Kauhua programme at this school.
} 
was not successful. Whānau did not attend this hui at the school's whare nui, because, I later found out, many were unclear about the purposes of my research. I was then given a long list of possible informants and advised that the best way to make contact initially would be through a phone call to students' parents/caregivers.

At Rata Primary School, I worked with Māori staff members who had been responsible for coordinating the Te Kauhua professional development, as well as the principal of the school, to decide on the best way to contact whānau. Again, it was decided that I should make contact individually to sound out whether Māori parents/caregivers and their children wanted to be involved in this separate research study.

Of the 20 whānau groups I contacted from across both schools, 15 extended an invitation for me to meet with them, and to discuss their possible involvement in this research and the involvement of their children. The process of contacting non-Māori families followed a parallel process to that of whānau. I was given a long list of names of non-Māori students at both schools and the process of speaking to individual family members about my research took time and a series of invitations. Fifteen non-Māori families agreed to take part in this research study and gave permission for their children to take part also.

I was then invited to meet with whānau members, parents and caregivers and their children kanohi te kanohi. In some situations, I was invited into the homes of participants; others asked that meetings and interviews occur at school. It was important for me that whānau/family members felt comfortable and made decisions within the research process. During these hui, I explained the purpose of the research and what involvement would mean. I also met with these participants' children and answered any questions that they had about their participation in this research. I explained that I was particularly interested in questions about teachers' collaborative work at school. I wanted to build in processes that would encourage participants to bring up their own questions to aid further inquiry. I wanted to address issues of power and accountability within the research design, and reflect on my own experience as researcher through participation within a much larger learning community. I believed that invitations were extended to me, particularly from whānau members, because these family members were passionate about the professional development occurring within their child's school, and because key staff members who had taken a lead role in facilitating change were supporting my research. 
The context of establishing relationships was unique to each school setting. On reflection, I felt I had built a stronger relationship with participant groups at Kowhai College than at Rata Primary School, probably because I was invited to attend specific events by whānau members at this school. For example, I was invited to attend a board of trustees meeting and whānau hui. At the whānau hui, I was asked my opinion about proposed changes to entry into the school. I felt as though I was accepted and had established legitimate peripheral participation within an established whānau of inquiry at Kowhai College.

\section{The Process of Conducting Interviews}

Two interviews ${ }^{12}$ were conducted with each participating teacher over the course of 12 months to track changes in their collaborative partnerships over time. The first interviews were conducted with teachers during the latter half of 2003 and the second towards the end of 2004. Interviews with parents/caregivers and their children were completed towards the end of 2004 to gauge the impact of teachers' collaborative work from multiple perspectives. I left it up to participants to decide on the venue for the interviews. The majority of teacher participants chose to be interviewed in private places within the school grounds. The majority of interviews with parents/caregivers and their children were conducted at people's houses. I asked participants (students and their parents/caregivers) whether they would like to be interviewed separately or with other family members. Some chose to be interviewed separately and others chose to be interviewed with other family members present.

It was easier to connect with some participants than others. Some opened up and wanted to reveal their own stories of teachers' collaborative work, and others did not. Some were eager to talk and others appeared less confident or more reticent. When I initially made contact with individuals across both school communities, some were genuinely surprised by the issues I raised as they had no knowledge that their child's school had taken part in the Te Kauhua professional development pilot project. It is important to note, therefore, that I found myself asking questions of these participants about their experiences of teachers' collaborative partnership work when some of them in fact had little or no knowledge of the work being undertaken by teachers within their child's school.

\footnotetext{
${ }^{12}$ The interview questions to all participants are included in Appendix C.
} 
One of the hardest challenges was establishing relationships with parents and caregivers of non-Māori children within both school communities at a time when tensions in race relations were apparent nationally. A number of participants who were interviewed, particularly parents/caregivers of non-Māori children, were quite hostile to what they perceived as educational 'privilege' for Māori students, even though they told me that they had no knowledge of the pilot project work. In one interview, the participant was so angry about what he perceived as 'racist behaviour' that he spat his words across the table at me. Although I was keen for participants to ask their own questions, I noted that many of them did not want to, and felt angry and/or upset about teachers' collaborative reform work that was being undertaken in their child's school. I found it difficult to listen and to conduct interviews at times, particularly when many stereotypes and racist beliefs were shared. However, I was familiar with these views as many of these participants could have been members of my own extended whānau.

I felt that some of the younger children from Rata Primary seemed shy during their interviews, whilst some teenagers from Kowhai College who had asked to be interviewed with their parent/caregivers present then seemed reluctant to talk openly. I felt as though different participants may have told different stories in different contexts to different people of their own choosing. I acknowledge these gaps and limitations within this inquiry process.

Another challenge involved the process of electronic recording. A few individual participants (one student, one teacher and two parents/caregivers) did not want the interviews to be taped electronically. In these cases, it was agreed that I would hand-write the notes, and that they would be read back at the end of the interview to ensure accuracy and to restate answers to questions. All interviews were typed up and sent to individual participants to give them a chance to check, change or alter their transcripts. Many adult participants did this, adding thoughts based on new experiences or new thoughts which had occurred to them; this aided the process of analysis. Interviews were sent back and finally signed off by participants once they were happy with them. Participants' agreements, disagreements and questions have been incorporated within the body of this thesis as part of a "wider conversation in which multiple interpretations flourish" (Fine \& Weiss, 2005).

The interviews themselves were semi-structured in nature and gradually developed into conversations or, as Bishop and Glynn describe it, as "chat" (1999, p. 125). Before each interview was conducted, there was a settling-in period, often over a 
cup of coffee or tea. At the beginning of each interview, I would spend some time talking with individual participants about my background, as well as the research and interview process. I also explained that their thoughts and ideas were very important to me, as well as any questions that they may have had.

Throughout the process of interviewing, I kept a detailed journal, as I often learned valuable information before the tape-recorder was turned on. Interview evidence revealed various stereotypes and assumptions that participants held. For example, one thing that I noticed as I talked to individual children, particularly at Rata Primary School, was children's ideas about their teachers' racial identity. Many of these children told me that they had been interviewed before, or had some experience of teachers or other adults asking them questions. As a warm-up activity, I asked each of them to tell me which of their teachers they thought were Māori. I found it interesting that many children appeared to judge their teacher's ethnicity on their teacher's skin colour. For example, 9/12 (4 Māori and 5 non-Māori) children from Rata Primary described a particular teacher (who identified herself as Māori) as being non-Māori. When I asked the children why they thought this, they told me it was because "she's white" or "paler than a Māori person".

Memos and notes were made and these formed the basis of further interview questions and potential areas for further investigation. The journal I kept provided an audit trail for recording hunches and decisions made about interview evidence and the research process over time. This proved invaluable, as I found myself moving back and forth, revisiting my notes as I compared different sets of data.

\section{The Issue of Accountability}

Throughout this research, I have attempted to treat "inquiry as a moral act" and to keep before me significant issues such as "ethics, vulnerability and truth" (Lincoln \& Denzin, 2000, p. 614). The participatory and collaborative nature of the research methodology, and the results which emerged, meant that accountability was an essential part of the research dynamic.

On a technical level, I followed the necessary ethical procedures. For example, ethical approval was sought and given, through an application to the necessary university committee, yet I knew I had a duty of care to the participants and actors whose involvement in this story went far beyond institutional approval. I made sure that the research participants were informed of the purpose of this study and understood that my involvement in the Te Kauhua Evaluation had finished and that this was a separate and 
quite different study. Written permission (or consent) was required from each of the participants. I also explained that they could withdraw their consent at any stage of the research process, without having to give a reason. I asked for parents'/caregivers' permission to interview their children, as well as seeking permission from children themselves.

Before I began interviewing, I made sure all participants were happy to give informed consent. I told them what participation in this study meant, how I would conduct the interviews, and how data were going to be analysed and stored. I explained that participants did not have to take part in the research and that they could withdraw at any time without explanation. ${ }^{13}$ I asked for and was given permission, by individual participants, to use information gathered during 2001-2003 as part of the Te Kauhua Evaluation. This included participant interviews and questionnaires that were collected within the two participant schools.

It is important to note that in order to protect the identity of participants who volunteered to take part in this research, I have changed their names and disguised their identities. I was particularly concerned that a number of Māori teachers and parents/caregivers would be instantly recognisable due to the smaller number of Māori participants working in both schools. I changed the gender and/or status (position of responsibility) of participants across both schools. I decided to give participants pseudonyms from my own extended family (sisters, brothers, cousins, in-laws, aunts and uncles) because of the many discussions, debates and arguments we have had regarding culturally responsive teaching practice, power, racism and privilege in Aotearoa/New Zealand.

\footnotetext{
${ }^{13}$ Copies of consent forms and information given to participants are included in Appendix A.
} 


\section{The Issue of Benefit}

I wanted the research process to be open and transparent as well as to give back something useful to the various communities. I was hopeful that the research could help assist the process of reform whilst being responsible for ensuring that 'no harm' was done to individuals. Because I had agreed to write a separate report as koha to each of the schools' boards to trustees, a process of negotiation for this separate research process was established. It was agreed that draft reports would be circulated amongst individuals (particularly teachers) and they would have editorial authority over this separate reporting process. At one school, I was asked to conduct an open staff meeting to provide feedback on the results of the research. Again, I sought permission from individual participants to use information for this very different purpose, ensuring that participants' identities were well disguised. Participant groups, particularly some of the teachers who had been involved in this study, welcomed this process, as there were renewed hopes expressed during this time that in examining their own stories of change new directions and collaborative actions would occur. However, study results highlighted a lack of teacher and principal knowledge related to quality teaching and culturally responsive and inclusive practice as defined by key authors (Alton-Lee, 2003; Banks, 2004; Bishop, Berryman, Tiakiwai \& Richards, 2003; Ladson-Billings, 2001; Penetito, 2001; Shields \& Sayani, 2005).

Although I became more conscious of the diverse identities, values, beliefs, experiences and practice that those involved bring into the collaborative dynamic, it was clear that such things remained unacknowledged and unexamined by participants themselves. There appeared to be a lack of political will to examine carefully the findings presented. I felt there was a 'learned helplessness' amongst participants, particularly teachers and principals, as such an examination would require a commitment to a new process of collaborative partnership work, not just a minimal response that would guard the status quo. In the end, I found myself wondering how some participants really viewed both my role and the product of the research process: Collaborator, friend or foe? I wondered how I could most usefully present my findings, showing the multiple layers of experience and interpretation within a context of shared journeying that also allowed rigorous analysis and the recognition of contradictions and complexities. 


\section{The Issue of Representation}

Throughout the research development, I was guided to include all the main participants in the schooling process, and within these groups (teachers, students, parents/caregivers etc.) to work with individuals from diverse ethnicities and backgrounds.

In addition, I devised a system of interview and data collection that was dynamic and revisionary, and that relied upon a process of revision, inclusion and checking of data that would occur over a long period of time. After the interviews, I met with individuals to check back with them and to gain their views on the emerging themes, which in turn forced me to reassess my initial analysis. It is important to note that the final verification was only partial. During my final member checks, conducted late in 2005, I found many participants within both school communities had left the school and/or the area. Some of these participants I was able to track down and meet with individually but others I could not locate. The participants with whom I did meet confirmed the trustworthiness of the research themes and told me that I had captured the complex and contradictory essence of their experiences.

I want to acknowledge the central voice of the teachers as I interviewed these participants twice, compared to only one interview with each of the other participants (students, parents/caregivers). Although I have attempted to capture the diverse perspectives of participants, I also acknowledge that there were fewer Māori participants interviewed than non-Māori over all, and more females than males.

At the final member checks, some Māori participants within both school communities expressed concerns about representation which I have written into the body of this research text. Some thought that the process should have been more inclusive, for example, many Māori students who were interviewed from the Te Kauhua class at Kowhai College felt that other Māori students at the college should have been included in this study. Some participants wanted me to interview Māori students in the work experience class and their parents/caregivers. During interviews with different whānau members across both school communities, many expressed concern that there were other groups of Māori parents/caregivers who were disengaged from the school community and that they should have been interviewed as well. Some members were concerned about the lack of representation of their kaumatua from particular hapu. I acknowledge these gaps and participants' expressed concerns about issues of representation, and regard them as relevant to the political themes which emerged from data analysis. I felt that as we got to know each other better, trusting relationships were established which encouraged open and honest dialogue. 


\section{The Context}

The context of this research is important, as it is the psychological, cultural and spiritual setting for participant stories of teachers' collaborative partnership work. Participants indicated that such partnerships were 'new' and 'strange' across both school communities; their stories highlighted important contextual issues and social activities which preceded teachers' collaborative partnership work.

\section{The Research Participants}

Participants in this study included teachers, students and their parents and caregivers, as well as the schools' principals and specialists working to support change within the school context (for example, in-school facilitators, RTLBs and consultants). In total, I interviewed 32 Māori participants and 45 non-Māori participants, from across the two school communities. I have attempted to provide a description of the characteristics of research participant groups, but there are gaps in the data related to participants' identities. I did not gather information related to socio-economic status, country of birth, iwi or hapu connections, or sexuality. In hindsight, this was important information and I consider its absence to be a weakness of my research methodology. However, at the time of designing this research, I did not think that participants' identities would be as fluid and diverse as I later discovered them to be. I found that in the process of interviewing participants, some opened up and were happy to reveal aspects of their identities to me. For example, two participants told me that they were in a same-sex relationship; they wanted me to know that they were Queer. Through the process of interviewing participants over time, I became aware of the diversity of participants' values, beliefs, identities and experiences that precede collaborative activities when Māori and nonMāori teachers work together, and that are brought into the collaborative dynamic.

The following section gives a brief description of participant groups. For further information, please refer to the tables related to participant characteristics in Appendix B.

\section{Characteristics of Teacher, Principal and Specialist Staff Participants}

I interviewed 17 teachers (seven Māori and ten non-Māori) from across the two schools. Of these teachers, six came from Rata Primary and eleven from Kowhai College. Some of these teachers had appeared in Ministry of Education material promoting effective teaching practice for Māori learners. I also interviewed: 
- $\quad$ two school principals, one from each school, who were both non-Māori;

- the Resource Teacher of Learning and Behaviour from each of the two schools sites, both of whom were non-Māori;

- two in-school facilitators (one Māori and one non-Māori) from each of two school sites. They were responsible for liaison with whānau and coordinating much of each school's Te Kauhua professional development contract. One of these facilitators was employed as a teacher within the school at the time Te Kauhua was introduced, and the other was brought into the school and was unknown to school staff members before the pilot started.

I also sought permission from a consultant (non-Māori) to use an interview this person had given as part of the Te Kauhua Evaluation process. This consultant was responsible for facilitating some change initiatives at one of the schools within the context of the Te Kauhua professional development activities.

\section{Characteristics of Student Participants}

In total, I interviewed 30 students across both schools to gather their experiences of and reflections on teachers' collaborative reform work. During the process of interviewing and talking to students (particularly Māori students), many told me that they had spoken to researchers before, or had been asked their views by people conducting interviews previously as part of their school's involvement in Te Kauhua.

After consultation with key school personnel, ${ }^{14}$ it was felt that I should interview students and their parents/caregivers who had had the most involvement in witnessing teachers' collaborative experiences and/or who would be most able to talk about the impact of teachers' collaborative partnerships. At Kowhai College, I interviewed Māori students who had spent the previous two years in the Te Kauhua class. I also interviewed these students' parents and caregivers. It was decided by key staff members involved in the work of reform that I should interview non-Māori students from across the school of the same age and year group to ascertain their views.

In the primary school, I was advised by key personnel, including the principal, the in-school facilitator and staff members who had taken an active part in the work of reform,

14 Consultation included the principal, the in-school facilitator and key staff members (Māori and nonMāori) who were involved in the work of reform at both schools. 
to interview children who had had the most experience of teachers working together in the Te Kauhua programme, and these turned out to be children in Years 5 and 6.

\section{Characteristics of Parent/Caregiver Participants}

I interviewed the parents and caregivers of the students involved in this study. Ten of these parents/caregivers identified as Māori and 20 identified as non-Māori. It is important to note that five of the parents and/or caregivers of Māori children who were interviewed told me that they were non-Māori, but had married or partnered Māori men or women.

\section{The Two Schools}

Both Kowhai College and Rata Primary are mainstream schools located within the North Island of Aotearoa/New Zealand. Both schools had previously taken part in the Te

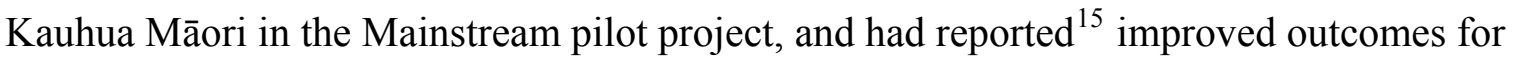
Māori students as a result of teachers participating in this professional development initiative. Interview evidence highlighted important contextual issues within and across both schools which impacted on the acceptance, efficacy and practice of teachers' collaborative partnership work.

\section{Rata Primary School}

Rata Primary School is situated in a small rural township, surrounded by farms and green pastures. The tranquil setting belies the bloody historical context which saw many Māori forcibly stripped of their land during the infamous land wars of the 1800s. Recently, there has been an attempt to address past injustices with the return of confiscated land through the Waitangi Tribunal.

The school itself is classified as a contributing primary school with a Decile ${ }^{16} 1$ rating, catering for 208 children between Year 1 and Year 6. According to the latest school figures, 59 percent of students enrolled at the school are Māori and 41 percent are identified as Pakeha; 52 percent of students currently at the school are male and 48 percent are female. Fifteen teachers were employed at the school at the time of my

15 This information was reported to the Ministry of Education in project milestone reports as part of each school's contract in the Te Kauhua project and was noted in the evaluation (Tuuta, Bradnam, Hynds, Higgins \& Broughton, 2004).

16 Decile 1 schools draw their students from areas of greatest socio-economic disadvantage and Decile 10 from areas of least socio-economic disadvantage. 
involvement, and I was told of Rata Primary's 'special features' including two partial immersion units, dedicated to te reo me ona tikanga Māori. I was interested to note that since 1997 Rata Primary had experienced a falling roll. During interviews with different participants from Rata Primary, I found out that many parents/caregivers chose to send their children out of town to schools located in the nearest city.

\section{The State of Staff Relationships Within Rata Primary}

Another notable feature of Rata Primary was the state of staff relationships before the school became involved in Te Kauhua. Evidence from interviews highlighted considerable staff divisions, as a result of a breakdown in relationships within the senior management team. Participant stories indicated that relationships had deteriorated which resulted in the resignation of the deputy principal. At the time that Te Kauhua was introduced into the school, it was evident that there were bitter staff divisions and disputes, and participant interviews indicated that staff tensions had impacted on the quality of teachers' practice and on student learning outcomes.

\section{The State of Race Relations Within the Wider School Community of Rata Primary}

It was clear from participant narratives that tensions existed between Māori and nonMāori groups within the local township surrounding Rata Primary. I was told that these tensions could be traced to historical events such as land wars, Treaty of Waitangi abuses and subsequent Treaty claims; and a high profile killing of a young Māori man by a local policeman several years earlier. It was evident that the state of local race relationships between Māori and non-Māori surrounding Rata Primary was a concern for many participants from within this community, although there were clear differences in the way participants chose to frame such issues:

Race relations in the town aren't that great. Like the sports teams are a problem in the town, and that's because the ball doesn't get passed to the white kids, well, not as much. The Māori kids don't treat the white kids with as much respect ... So race relationships aren't great here. But that's the influence and attitude out there, because there are so many Māori in the town, and they all have their cousins and it's not a good environment when there's too many Mâori here. And they need to be told that racism goes both ways. I know a lot of children in the town won't play for the 
town sports teams because the Mãori kids won't pass them the ball and so what's the point in playing? So the racism goes both ways. (Mrs Shelly, parent/caregiver of non-Māori child, 2004)

I've worked in the public eye for the last 3 to 4 years, and you can see attitudes of racism within the adults ... to break that cycle of racism we need to work with the children. Some of my friends, Pakeha friends, have said, 'Oh, what do you want to learn how to speak Māori for?', but that was my choice, I had no particular reason, I didn't want to be a teacher aide or anything, I just wanted to learn it for my own good, the good of my family and for my kids' future. I know now that if my children come and ask me something, I can answer them in te reo. But yeah, this community has had a bad rap, it's been through the newspapers and the kids saw that. It was really hard, being in the public eye. One person would run down the Māori and another person would run down the Pakeha and it was horrible. That attitude, it did come down to the schools and I think it was a hard road for the teachers to try and break that down. Kids have got eyes and ears and they heard things, and that went back to the playground and it was racism. It's a really hard thing to get through. (Mrs Huia, parent/caregiver of Māori child, 2004)

Some of the non-Màori parents just don't have the understanding of what the teachers are trying to do here at this school. Like I have a friend who's Pakeha, I think she forgets that my children are Māori. Her son was in this particular class and she felt he was the only Pakeha child and she wanted her son to be in a Pakeha class. I think she thought all the Māori kids were really naughty and her son wasn't going to learn while he was in that class. So he ended up being moved. But I think she forgets my children are Mäori. It's not just her, I have another friend and she is quite racist ... and she goes on about Pacific Islanders, but I've known her for 20 years so I just accept that. But when she's talking about 'Māori this and Māori that' and I think she forgets that my children are Māori. You know, she's talking about my kids as well and it is hurtful but I don't say anything. (Mrs Thompson, parent/caregiver of Māori child, 2004) 
Other participants who were interviewed explained that there were historical tensions between Māori and non-Māori groups, particularly within Rata Primary's local school community, that went back generations:

Just being classed as ... this sounds horrible, but you know I'd walk in somewhere and people would look at me, Màori people who don't know me, and all of a sudden they'd see my husband who is Màori and it's like everything eases. Yeah, it's a horrible feeling and yet my husband can have it on the opposite side. My husband is quite a big man and people may judge him by appearances, and then I'll walk in and it's like, 'Oh, he's Sarah's husband'. It's a horrible feeling ... . And I've found a lot of that here, in this community. It's a sort of a tension that goes through the room and it is a horrible feeling and I don't want that for my kids. There is a lot of tension here within the community, I don't know if it's the same in other areas. I think we're starting within the school. Hopefully, the children see that, the teachers working together and that there is another way of being together, interaction with people who have different cultures, and hopefully the children see the teachers are having better communication with each other and that respect for cultural differences. Having Pakeha and Māori children working together in the class ... you know, years ago I know that at that school you had Pakeha kids on one side of the playground and Màori kids on the other and so the generations before that then the interaction wasn't really there, it was worse ... there were barriers there. (Mrs Tito, parent/caregiver of Māori child, 2004)

Some participants talked about the pain and damage within the community as something that went back generations:

There has been so much hurt and damage in our community. People are hurting, families are hurting and there is a history here that goes back generations. I think it's awesome that the teachers are trying to improve their teaching for our mokopuna, but it's going to take time for some healing and an acknowledgement of that needs to happen first ... . Not all 
our families are involved in what is happening here at school. (Mrs Huia, parent/caregiver of Māori child, 2004)

Some of the young children who were interviewed were also conscious of the difficulties and problems with present race relations within the local school community:

I think it's good [Māori and non-Māori teachers working together].

Q. Can you tell me why you think it's good?

Well, because they don't get along that much.

$Q$. Why don't they get along?

When the Pakehas first came [here], they didn't get on with the Māoris and they started having wars. (Jeremy, Yr 5 non-Māori student, 2004)

Rata Primary appointed its first Māori deputy principal in 2002. Participant narratives emphasised the active and highly visible resistance amongst some parents/caregivers to collaborative reform efforts, resulting in a delegation of parents/caregivers who confronted the principal with their concerns. A group of nonMāori parents/caregivers had also withdrawn their children from this school.

\section{Kowhai College}

Kowhai College is situated on the outskirts of a bustling city, known as a tourist 'mecca'. The school is located close to many large lakes that surround the city, and the largest of these is visible from the school grounds. There are new housing developments surrounding the school, although large areas of land by the lake foreshore are untouched. I was interested to read in the local newspaper that some of the many local lakes and accompanying land were recently returned to local iwi as part of a Treaty of Waitangi claim and settlement.

Kowhai College itself is identified as an urban, co-educational secondary school, with a decile rating of 6 , catering for students from Year 9 up to Year 13. According to the latest school figures, there are 55 teachers employed at the school, and its 'special features' include a special education unit catering for students with intellectual and/or physical disability. The school roll is considered 'stable' with 726 pupils. According to the latest figures, 51 percent of students are classified as Pakeha, 37 percent are Māori, 10 percent are Asian and 2 percent are identified as 'other'; 52 percent of the students 
enrolled at Kowhai College are boys and 48 percent are girls. Recently the school has been attracting foreign (fee-paying) students, and there are 55 of these students currently enrolled at the school.

\section{The State of Staff Relationships Within Kowhai College}

Participant stories emphasised that teachers at Kowhai College were not used to working closely with colleagues from across subject departments at the time the school became involved in Te Kauhua. Although participant narratives revealed the evidence of personal vendettas between some staff members, the tension between teachers did not appear to be as overt and obvious as staff disputes at Rata Primary. A particular point of difference between the two schools appeared to be the formal staff hierarchy, with middle managers (Heads of Departments) being identified as having a particular influence on whether teachers felt supported to engage in collaborative partnership work to improve the quality of teaching practice for Māori students.

An important contextual feature, however, was the involvement of Kowhai College staff in another professional development initiative, aimed at improving the quality of teachers' practice for Māori students within their classrooms. Evidence indicated that a group of Kowhai College staff had initially volunteered to take part in $\mathrm{Te}$ Kauhua and then over time the school became involved in a different professional development initiative which 'piggy backed' onto the work already started.

\section{The State of Race Relationships Within the Kowhai College Community}

I became aware of clear differences between Kowhai College and Rata Primary related to the state of race relations when I was conducting interviews. There appeared to be less active and obvious resistance on the part of parents/caregivers of non-Māori children at Kowhai College to teachers' collaborative partnership work than at Rata Primary. In other words, there was no formal delegation to the principal's office.

However, there were obvious tensions related to race relations within the Kowhai College community. Many parents/caregivers expressed their concerns to me about the changes they perceived as occurring within the school as a result of teachers' collaborative partnership work. Many believed such work was 'racist' and favoured Māori students over their own children. It became apparent that these participants had little or no information about what teachers were actually doing. Their concerns became 
most evident when they talked about students' experiences of interactions and altercations within the school playground:

I mean my daughter, she got bashed over the head with a steel bar [at school] ... . It went to court, three Māori girls decided that Emma and her friend needed to be taught a lesson and Emma got bruising down one side of her face and her shoulder. We actually thought she may have had a cracked rib at one stage ... that was two years ago that she got attacked, we actually went to the police, .... I believe it happens in all the schools around here ... I asked her what happened ... most of Emma's friends are Māori girls ... I don't know why it happened ... she's still friends with most of them except for this one girl ... . But the school should have done more ... . (Mrs Brown, parent/caregiver of non-Māori student, 2004)

It was clear to me also from student interviews that tensions existed between Māori and non-Māori groups within the college. Eleven out of 18 students from Kowhai College (6 non-Māori and 5 Māori) talked during their interviews about racial divisions within the school grounds, racial tensions between groups and/or incidents of racism which they had witnessed:

... in some places in the school I think there's racism and it would be good to see less racism ... . There are some people who don't hang out with Māoris and stuff ... it's just how they act around Māori students ... they act as though they are better than students from other races like Mãoris and Asians in just in the way they talk about them like they're looking down at them ... so it's good to see the teachers mixing up and working together, it shows that it can happen ... that you can work with people who are from different cultures and it can work. I think that's important the teachers demonstrate that for us ... . (Louise, Yr 11 non-Māori student, 2004)

I was particularly concerned to note that teachers and other educators from this school community did not appear to be aware of and/or openly acknowledge these 
tensions amongst student groups within their school community (although some teachers must have been aware of such incidents):

Something that came up at one of the teacher-parent interviews was that there are a bunch of students who have come from a particular school in this area and moved in that there's a feeling that these students, nonMāori students, they seem to have an attitude towards Māori students and students from other cultures ... . (Mrs Kumu, parent/caregiver of nonMāori student, 2004)

A few parents/caregivers who were interviewed appeared to accept such tensions as a normal and inevitable part of school life. One parent/caregiver acknowledged the divisions that existed within the playground, but appeared to believe that such divisions gave her son some safety, because violence between culturally diverse groups was a fact of life that her son needed to prepare for:

I've heard about all the little cliquey groups at school but I think it's a cultural safety thing. They all need to group together to survive in the environment and there have been times when my son has walked past the wrong people and looked at them and you get a thump because you happen to be the wrong person walking past at the time and it's part of not being part of that group and being in the wrong place at the wrong time. It's just the mixture of the students and the different students that they [the teachers] have to cater for ... and it's life, isn't it. There are always a mix of different people out there. (Mrs Black, non-Māori parent/caregiver, 2004)

Some students believed that Kowhai College had a more inclusive atmosphere and that there was better acceptance of cultural diversity amongst students than at other secondary schools in the area:

I think mainly this school is all right ... and it's awesome seeing the teachers [Māori and non-Māori] working together, because that's like the Treaty of Waitangi and the partnership thing ... . Kowhai College has a 
much better rep [reputation] than other schools around here ... because the kids mainly get on well. Well, the cultures get on pretty much ... there's not so much fighting ... and stuff ... not like Trinity Secondary School. (Eru, Yr 11 Māori student, 2004)

As I listened to participants tell their own stories over time, I became more aware of the divisions and tensions which existed between groups, across both school communities.

\section{The Wider Context: Race Relations Within Aotearoa/New Zealand During the Time of This Research}

Another important contextual feature which had an impact on teachers' collaborative partnership work related to the specific time-frame of this study. During the year $2004,{ }^{17}$ several national incidents exposed the state of race relations between Māori and nonMāori groups within Aotearoa/New Zealand. This was captured in January 2005 when the Sunday Star-Times featured an article based on the findings of a study called '2005 Mood of the Nation':

In its 2005 Mood of the Nation report, .... UMR Research managing director Stephen Mills says the only cloud on the horizon has been public concern over race issues. "The last few years have been pretty positive, settled and optimistic. The one thing that disturbs that are the issues on the race relations front", says Mills ... In 2003 the foreshore and seabed issue ignited concern about racial issues. And 2004 started with a bang, with the racial debate that erupted after Don Brash's famous Orewa Speech ... Outrunning every other issue in 2004 was race relations and the Treaty of Waitangi ... . By February 40 percent of respondents were saying treaty and race issues were the biggest problem facing the country. (Laugesen, 2005, January 16)

The wider context had a bearing on this research. As I conducted interviews with participants, I was conscious of the debates which stormed across Aotearoa/New Zealand

17 I conducted the bulk of my interviews with participants during 2004. For further information on the interview process, refer to pp. 22-31. 
during 2004 and raged across election year (2005). Some of these related to the status of the Treaty of Waitangi; Don Brash's ${ }^{18}$ famous or infamous Orewa Speech; the Foreshore and Seabed legislation; the subsequent hikoi to parliament and the unifying protest against this legislation; and Tariana Turia's dramatic departure from the Labour Party and the formation of a new political force, the Māori Party. Media headlines remained hot about the social divisions exposed through these events, fuelled by a 'backlash' against perceived Māori privilege (McCreanor, 2005). During the research process, I collected Letters to the Editor in national newspapers as they revealed the macro-political context against which participants' experiences were framed.

One whānau member whom I had contacted via her cellphone told me that she was interested in taking part in this inquiry, but we would have to set a date later as she was travelling down to Wellington as part of the hikoi to protest against the proposed Foreshore and Seabed legislation. A number of participants who were interviewed for this study talked about how national events during this time impacted on teachers' collaborative partnership work within their children's school. These were clearly emotional and deeply political experiences for some participants, which highlighted social divisions, debates and arguments within and across participant groups. Consider the following comments gathered from participants from both school communities:

... with the foreshore and seabed forum, we had a great big sign supporting Tariana Turia and I came over to the school and I was just generally having a conversation with one of the teachers and she asked me was I getting paid for that. I said, 'Aroha mai, No! I don't expect that! Because to me that's awesome, because hello, finally we have someone who is standing up for our kaupapa'. And I just got this dirty look from her and it was like, 'Well, what is your kaupapa?' And I felt that from one teacher and I voiced my opinion to her and she says, 'Yeah, but it's just the legislation, it hasn't gone through yet has it?' But like I said to her, 'Yeah ... it's just the legislation, but watch out when it becomes real. What are you going to do then?' And she said, 'Well, you people, you just want

18 At this time, Don Brash was the Leader of the Opposition party: the National Party. In his Orewa speech he accused the government of employing 'racist policies', which targeted particular ethnic groups (such as Māori) in an attempt to close disparities between Māori and non-Māori groups in such areas as health and education. 
everything!' And I said, 'Well, but everything belonged to us before you came'. And she didn't like the fact that I was throwing it back at her like that. Another teacher said to me, 'Oh that wasn't very nice'. And I said, 'Well, what did she say to me? Did she sound very nice to me? No, it didn't, that my people want everything! Wrong! My people want what's rightfully theirs ...'. And this teacher she said, 'Yeah, but that sounds biased'. And I said, 'What I can be is who I am. And what I say is what I feel. And if you don't like it, there's the door'. And she did, she walked out, so I said, 'Well, I don't care, at the end of the day, I hope my party wins'. And again, a look says it all ... . (Mrs Huia, parent/caregiver of Māori child, 2004)

Actually I've had discussions recently about the Treaty of Waitangi with some of my son's friends, and their parents ... we've had discussions but then we're fairly liberal-minded ... some of the older members of my own family, for example, my son's grandparents would not think in the same way ... especially around the time of Don Brash's little speech ... when he was talking about equality but not equity ... . I think lots of times you get discussions around 'Everyone is equal so we should have equal opportunities', but that's quite different from being equitable ... so we've had lots of debates in our household recently. (Mrs Kumu, parent/caregiver of non-Māori child, 2004)

Some participants made reference to recent media reports on race relations and felt that collaborative partnership work between teachers would be fraught with difficulty and communication problems:

Why would non-Māori teachers want to work together with Māori teachers? They'd just be heaps of problems, 'cause they don't know how to speak the language ... . Like all the stuff in the newspapers [between Māori and non-Māori], there are heaps of problems ... . (Heath, Yr 11 non-Māori student, 2004) 
Although I was asking participants to talk about their experiences of teachers' collaborative partnership work, many framed their discussions by referring to macropolitical environments (past and present).

\section{The Data}

My main method of approaching the data was inductive analysis, which ensured that codes, themes and patterns emerged from the collected data (see Appendix D). The theory that evolved was grounded in interview evidence, and developed from statements of beliefs and behaviours of participants involved in the study (Janesick, 2000). After participant interviews were transcribed and returned to me, I read through each script and analysed participant responses to questions so that I was familiar with all of the data and also with its collective voice.

I isolated the beliefs that participants held before their involvement in this research project, along with participant identities, values and experiences that were brought into teachers' collaborative partnership work. I also searched for the visible activities of teachers' collaborative work, and over time as I analysed data and listened to participants tell their own stories I became more conscious of the less visible, the hidden, the unconscious and the unexamined 'identities', 'beliefs', 'values' and 'practices' that those involved bring into the collaborative dynamic.

I developed a system of colour coding which I used to make the analytical process easier, and I created large data tables or grids concerned with recording the experiences, beliefs and values that preceded teachers' collaborative activities. I noted the visible aspects of teachers' work: how they worked together, who they worked with and for what purposes. I examined the interview data with a focus on generating 'action codes' which gave an insight "into what people are doing, what is happening in the setting" (Charmaz, 2000, p. 515). I worked through each interview line by line, underlining key statements/terms in the interview texts. I restated key phrases keeping these as descriptive and literal as possible. Clusters of phrases were coded and formed initial patterns, however I also looked for examples that did not fit my initial analysis and for the ways that categories related to each other. This meant making constant comparisons as outlined in grounded theory methodology (Charmaz, 2000; Strauss \& Corbin, 1998). I compared different participants" "views, situations, action accounts and experiences" (Charmaz, 2000, p. 515). Another grid was created for the beliefs that preceded these 
collaborative activities and a separate one for participants' perceptions of the impact, which followed their experience of collaborative work. I repeated this process with each of the participant groups (teachers, students, parents/caregivers, and professional development facilitators, consultants and principals). After a long time and protracted process of analysis, particular patterns (cultural, emotional and political, visible and less visible) emerged from analysis.

I constantly compared data from the perspectives of the participants across these data tables and grids, moving back and forth, comparing one segment of data (and across data) to another in order to determine similarities and differences. This process prompted me to think of new questions to ask in the field as I looked for different interpretations of the activities of teachers' collaborative partnership work within the context of reform. The data analysis process continued as I started to write. I found myself constantly going back to participants' stories, checking, comparing and re-evaluating existing analysis. Although I started with particular codes, I found these were revised over time: as I rechecked the data I became more sensitive to the diverse identities (visible and less visible) that those involved brought into the collaborative dynamic, along with a recognition of the (visible and less visible) activities, experiences and contexts which had helped shaped such constructions. On reflection, I realised I had initially glossed "over meanings within respondents' stories" (Charmaz, 2000, p. 521). This is something noted within critical challenges to researchers undertaking grounded theory methodology (Charmaz, 2000). In my haste to classify participants' experiences, I found I had missed important meanings within the interview data, related to participants' diverse identities and the social contexts that shaped such constructions.

As I conducted member checks, some participants challenged me to rethink my analysis by emphasising the diversity of identity and the interplay of context. However, I found there was also an 'uncomfortableness' associated with checking back with participants, particularly in relation to comparing the visible and less visible beliefs, values and activities that preceded teachers' collaborative partnership work. Not all participants, particularly parents/caregivers of non-Māori children and young people, welcomed my analysis, especially that associated with the issues of 'forced identities'. I found myself confronted with messy text, “... where multiple voices speak .... often in conflict and where readers are left to sort out which experiences speak to their personal lives" (Lincoln \& Denzin, 2000, p. 1050). 
The process of listening and analysis took far more time than I had imagined. I can best describe this process as a slow navigation of the collaborative dynamic, a process that revealed my own haste to create something that was linear and followed neat, clearly defined collaborative interactions. Instead, I became more aware and conscious of a less visible dimension: the hidden beliefs, values and activities, and the unconscious and unexamined identities that preceded teachers' collaborative partnership work, but which also influenced its acceptance and practice within each school community. I found myself having constantly to go back to check the data, my own research journals and the available literature, and then to rethink and re-examine my interpretations. The process of conducting member checks with culturally diverse participants became a process of mutual story-telling, “... where participants are engaging in a discourse where meanings are contextually grounded and shift as discourse develops and is shaped by speakers" (Bishop \& Glynn, 1999, p. 127). By listening to different 'voices', my analysis started to become informed by what other authors have described as emic, existential, political and emotional criteria (Denzin, 1994; Lincoln \& Denzin, 2000).

As patterns and themes started to emerge from data analysis, I searched for new literature which would help me make sense of interview evidence. Interpreting and then writing about participant experiences have been enlightening but also highly uncomfortable experiences for me, particularly since I found the process of listening, analysing and reinterpreting to be lengthy and complex, highlighting specific contradictions, and visible and less visible aspects that those involved brought into the collaborative dynamic. I found that the experiences of participants did not "fit neatly into one general process", a factor noted by other qualitative researchers (Charmaz, 2000, p. 527).

However, I want to stress that the challenges I encountered encouraged metacognitive processes (thinking about my own thinking), and forced me to examine critically my own initial interpretations. I was encouraged to reclassify, categorise and describe the things people say (from various perspectives) about their involvement in this work, a unique opportunity to view participants' identities, beliefs and values. This was the process which guided the direction of my analysis, and although parts were uncomfortable, it provided me with new and unexpected opportunities to learn.

This was not the story I expected to tell when I first started this research journey. Through my engagement with others, I have come to understand the diversity and 
complexity of any process of change, where all the participants are brought together in a point of light with the enormity of their spiritual, cultural and personal identities in tow, often unconsciously, often unreflectively.

\section{Research Questions}

When I first started off on this research journey the questions which guided my analysis were:

- What are the experiences of participants in relation to Māori and non-Māori teachers' collaborative partnership work?

- What are the beliefs of participants, in relation to these experiences? And

- What are participants' perceptions of the impact of these experiences?

Although these were my starting points, more appropriate research questions developed over the course of data analysis and these include:

- What are the beliefs, values and experiences that precede the collaborative activities, when Māori and non-Māori teachers work together on a school reform project?

- What are the identities that those involved bring into the collaborative dynamic, when Māori and non-Māori teachers work together on a school reform project?

- What influences the acceptance and practice ${ }^{19}$ of teachers' collaborative partnership work, when Māori and non-Māori teachers work together on a school reform project?

Subset research questions which also guided data analysis include:

- What are the visible activities/aspects of teachers' collaborative partnership work, as Māori and non-Māori teachers work together on a school reform project?

- What are the less visible activities/aspects of teachers' collaborative partnership work, as Māori and non-Māori teachers work together on a school reform project?

19 The word 'practice' in this research question is defined as "the habitual action or custom, action or execution as opposed to theory" (The Concise Oxford Dictionary [ $9^{\text {th }}$ ed.], 1995, p. 1072). 


\section{Chapter 2. The Existing Navigational Charts That Outline Teachers' Collaborative Partnership Work}

This chapter describes the readily available literature which had mapped out the charted waters related to teachers' collaborative partnership work as a reform mechanism. It was literature which I referred to both before I started to interview participants about their experiences of teachers' collaborative partnership work, and subsequently as I analysed the data. Although it presents important arguments and debates within the educational discourse on issues related to, firstly, the responsiveness of the mainstream education system to cater for Māori students' learning needs, and, secondly, teacher collaboration and partnership work as potential reform mechanisms, my analysis of these existing texts revealed to me significant gaps and lost opportunities. It appeared to me that the majority of available texts reflected a largely Eurocentric, monocultural discourse and that this perspective saturated the information which would be readily available to teachers related to collaboration and/or partnership work. I felt this revealed a lack of acknowledgement and of respect for the journeys of culturally diverse (particularly indigenous) participants within the context of teachers' collaborative partnership work, and would fail to prepare many mainstream teachers adequately as they undertook their own collective reform work. However, it is important for me to maintain the sequence of this story, so I will return to my own exploration of the available research texts.

\section{The Need for Teachers to Fix the Problem of Underachievement The State of Educational Achievement in Aotearoa/New Zealand}

I was well aware of the arguments that urge mainstream teachers to improve the quality of their teaching practice so that students from diverse cultural groups experience academic success (Alton-Lee, 2003; Bishop, Berryman, Tiakiwai \& Richards, 2003; Bishop \& Glynn, 1999; Jenkins, 1994; Timperley, 2003). These arguments were reinforced by two OECD reports on achievement patterns of New Zealand students that highlighted disparities in educational achievement amongst groups of students and in particular a "long tail" of underachievement by Māori and Pacific Nations students (2001, 2002). A major government response to such statistics was significant policy innovations that were launched in an attempt to 'close the gaps'. These policies attempted to address cultural diversity and reduce educational disparities between Māori and non- 
Māori groups, particularly given that over 85 percent of Māori students are schooled in the mainstream (general) school system rather than in kura kaupapa or other Māori medium settings.

Society in Aotearoa/New Zealand, and subsequently in our school communities, is becoming increasingly culturally diverse as a result of population and social changes (Alton-Lee, 2003). In the 2001 Census, the resident population of Māori in New Zealand was recorded as 585,900, comprising 15.1 percent of the general population. Projections over the next 20 years based on the 2001 Census show that the Māori population will increase. In 2021, the projected number of Māori is expected to reach 749,300, an increase of 27.9 percent. Sixteen-and-a-half percent of the total population will then be Māori.

According to Alton-Lee (2003), there is an urgent requirement for education providers and policy-makers to accept the challenge created by the changing nature of our society, the call to recognise cultural diversity and our historical educational failure to cater for indigenous students, and to supply an education system that best supports the educational needs of all students. It appeared from my reading of the literature that teachers within mainstream schools are under pressure to transform their practice and provide quality learning environments for culturally diverse students, particularly Māori students.

\section{Teachers' Attitudes and Deficit Theorising}

Many Māori educators have long argued that the colonial history of Aotearoa/New Zealand has left an intergenerational legacy, including educational failure and unequal employment patterns for Māori (Bishop \& Glynn, 1999; Durie, 2005; Jenkins, 1994; Smith, L. T., 1999; Walker, 1991). The history of Māori and Pakeha relations since the signing of the Treaty of Waitangi has not been one of partnership, of two peoples developing a nation, but one of domination by Pakeha and marginalisation of Māori people (Bishop \& Glynn, 1999; Smith, L. T., 1999; Walker, 1991).

Ranginui Walker, a noted Māori academic, identified four factors over a decade ago that are relevant to the disparity between Māori and non-Māori student outcomes in mainstream educational schooling in Aotearoa/New Zealand. These are:

- the predominance of monocultural Pakeha teachers;

- the lack of relevance of school, as perceived by many Māori children;

- the monocultural framework of the curriculum; and

- the limited definition of 'success' (Walker, 1991). 
Walker (1991) warns that it is not enough to transfer the mainstream educational model of the dominant Pakeha culture, with its established practices and definitions of achievement, across to the Māori context, and then to measure the success of Māori students against this or to mould them to fit an educational model which cannot meet their learning needs. Penetito (2001)has also noted the unequal power relationships amongst Māori and non-Māori within the mainstream education system, and in particular the lack of responsiveness and inclusiveness of the education system towards Māori:

The New Zealand education system has always operated as though all its clients were either Pakeha or wanted to become Pakeha; Māori had much to learn from Pakeha but Pakeha had little to learn from Māori (p. 18) ... [and later] It can also be argued that Māori knowledge has always been 'managed' in the sense of being selected, interpreted, translated, co-opted and distributed by those who have the power to make the decisions; they have rarely if ever been Māori themselves. (2001, p. 24)

Historical attempts to address cultural diversity have been inadequate due to epistemological racism, "racism that is embedded in the fundamental practices of the dominant culture" (Bishop \& Glynn, 1999, p. 12).

Many Māori researchers have expressed their concerns that decades of reporting research findings about the failure of Māori children in mainstream schools have contributed to teachers' patterned responses to Māori children (Bishop, Berryman, Tiakiwai \& Richards, 2003; Bishop \& Glynn, 1999; Jenkins, 1994; Smith, L. T., 1999). Jenkins argued over ten years ago that the pattern of disparity has become so commonplace, "society has come to accept it as quite normal for Māori to fail" (1994, p. 150). Raising the achievement of Māori students in the general stream of education continues to be problematic due to the widespread deficit thinking of many educators towards Māori students' learning (Bishop, Berryman, Tiakiwai \& Richards, 2003). It is argued that the personal characteristics, beliefs and perspectives of many teachers may present considerable barriers to the achievement levels of diverse student groups (AltonLee, 2003; Bishop, Berryman, Tiakiwai \& Richards, 2003; Bishop \& Glynn, 1999).

Many participants who were interviewed for this study talked about their experiences of teacher expectations, beliefs and actions towards Māori students: 
I think that many kids are not succeeding because the teachers' strategies are unable to cope with the differences that these kids bring into the classroom. The teachers' cultures are different, they have different perceptions of these kids and maybe what's wrong is that they actually sometimes inadvertently think that these kids can't succeed. I don't think that applies to all the teachers that are working here at this school, but I think some of them probably think what they are doing is pretty good and OK and then therefore why would we need this project. (Consultant, ${ }^{20}$ 2002).

... a few years before my son was in this teacher's class, and my son he didn't like it, and I think that was because his teacher just didn't understand him and couldn't relate to him. His teacher didn't understand who my son was. And I was really unhappy about the way he was being taught. Like, my son didn't want to wear shoes inside the class because we don't do that at home and his teacher didn't understand that. Some of the things my son got into trouble for, he had to do lines and it wasn't for his behaviour ... it was more cultural differences and the teacher at that stage didn't have any understanding of that, and his teacher expected all the learning had to be writing pen to paper. There was no variation and my son, he just couldn't cope with that. (Mrs Thompson, parent/caregiver of Māori child, 2004)

I remember ... with my son, one day I found him at school and he was crying, he was actually outside the classroom and he didn't want to go back into the classroom. And I asked my son why, and it was because the teacher was bombarding him with questions ... and he was finding it hard to answer the teacher and the teacher was throwing these questions at him and saying, 'Come on. Come on'. And it was like quick-fire questions, but my son didn't understand these quick-fire questions, so I spoke to his

20 This quotation was gathered from an interview conducted with this participant as part of the Te Kauhua Evaluation process. Permission was given for me to use this interview in the context of this study. 
teacher and I explained to her, 'Hello, he's only like, c'mon, six years old. And you want him to answer quick-fire questions? We're not at the stage yet!' And she was like, 'Oh, oh'. And she felt like I was backing her into a corner and to me, like I said, 'Look lady, if you think I've just backed you into a corner, you've done it yourself. These are little kids, they are not seniors and if you want to fire off questions, go to the seniors and ask them'. And she was saying, 'Oh, oh, it wasn't so much that ...', and then she was trying to come at me, and I said, 'It doesn't matter at the end of the day. Look at what you've done to my son ... He needs to know what you're teaching him. At home I give him time to answer questions' ... I give him time and if he can't answer it, I say, 'Come back to it, son'. It's like a seat and we ride it out together. Like at home, we don't ask quickfire questions. (Ms Lynn, parent/caregiver of Māori child, 2004)

Individual teacher comments from questionnaire data collected during the evaluation process for Te Kauhua during 2001 also indicated that some teachers believed the problem of Māori student underachievement lay with students' backgrounds and family experiences. Consider these comments written by individual staff members at Rata Primary from questionnaires completed in 2001:

Most [Māori students] are underachievers, therefore it is possible to raise their achievement. [The main issues or challenges to this are] getting family to support students and promote positive attitude to school. Many chaotic, dysfunctional/solo parent families. Many lack basic language skills. (Te Kauhua data, $1^{\text {st }}$ questionnaire, 2001, School 2, Teacher response, T09, q. 10)

Of course, it is possible [to raise Māori student achievement]. But it needs to start a lot earlier than high school. Education needs to start with the home. [The main challenges or issues are] lack of stimulation as babies. Poor adult education, drinking, smoking, illiteracy, poor confidence and self-esteem levels. (Te Kauhua data, $1^{\text {st }}$ questionnaire, 2001, School 2, Teacher aide response, K09, p. 10) 
Bishop, Berryman, Tiakiwai \& Richards (2003) argue that existing teacher beliefs regarding disparity in the educational outcomes of Māori students often locate the problem with the learner. Teachers may believe Māori students require 'fixing' or 'curing' in some way, and so the problem of educational failure is located within the child and/or their background (Bishop, Berryman, Tiakiwai \& Richards, 2003; Bishop \& Glynn, 1999).

Te Kotahitanga was a research project based in a selection of secondary schools (Bishop, Berryman, Tiakiwai and Richards, 2003), and results from this study uncovered problems with teacher expectations of their Māori students and in particular teachers' assumptions about the causes of Māori student underachievement. These authors conducted a comprehensive study of Years 9 and 10 Māori students to investigate the main influences on their educational achievement. The study investigated Māori students' experiences in four non-structurally modified mainstream secondary schools, from the perspectives of engaged and non-engaged Māori students and from the perspectives of others such as those parenting these students, their principals and their teachers. It interested me that the majority of teachers who took part in this study believed that the beliefs and actions of other groups were the primary reason for lower Māori achievement, and so responsibility for overcoming learning and achievement problems did not rest with them.

This process of deficit thinking puts blame on the 'victim' and places learning problems outside of the teachers' control. This results in teachers lowering their expectations for student success and thinking they are unable to improve outcomes for Māori children (Bishop, Berryman, Tiakiwai \& Richards, 2003; Bishop \& Glynn, 1999), potentially creating a damaging, negative 'self-fulfilling prophecy' of Māori student failure in mainstream educational settings (Bishop, Berryman, Tiakiwai \& Richards, 2003; Bishop \& Glynn, 1999). In a review of research, Alton-Lee (2003) also reveals that teachers in mainstream schooling contexts had lower expectations of Māori students, were unable to identify or reflect effectively on how their practice impacts on the educational outcomes of Māori students, and had insufficient support and resources to address student diversity. Penetito (2001) adds that "knowing a child culturally" is not the same as "knowing a child psychologically" (p. 20). Penetito warns, 
Knowing a child culturally is not taken seriously enough because the content of the curriculum and the role of the teacher are considered culturally neutral and it is doubtful that they ever are. (2001, p. 20)

Previous research in mainstream schools within Aotearoa/New Zealand has identified the importance of teachers developing culturally responsive pedagogy (AltonLee, 2003; Bishop \& Glynn, 1999; Bishop, Berryman, Tiakiwai \& Richards, 2003). It has been argued that teachers improve the quality of their teaching by drawing on the diverse cultures of pupils they teach, respecting, valuing and connecting to students' prior knowledge and experiences (Alton-Lee, 2003; Bishop, Berryman, Tiakiwai \& Richards, 2003; Bishop \& Glynn, 1999). According to Alton-Lee (2003), honouring the diversity of all students is central to the notion of quality teaching in Aotearoa/New Zealand.

\section{The Importance of Teachers' Agency and Effective Learning Relationships}

In order for teachers to develop culturally responsive practice, they need to believe that they can make a difference to culturally diverse students' achievement, and to reflect critically on the causes of students' disengagement in learning (Bishop, Berryman, Tiakiwai \& Richards, 2003; Ladson-Billings, 2001). Classrooms need to be safe places where learners can bring 'who they are' to learning interactions, and know that their knowledge is acceptable and legitimate (Bishop, Berryman, Tiakiwai \& Richards, 2003; Ladson-Billings, 2001). Researchers in Aotearoa/New Zealand (Bishop, Berryman, Tiakiwai \& Richards, 2003; Bishop \& Glynn, 1999; Hawk, Tumama Cowley, Hill \& Sutherland, 2002; Jenkins, 1994; McFarlane, 2004; Penetito, 2001) have argued that Māori student outcomes will improve when Māori students see themselves reflected in the classroom curriculum. Developing more responsive teaching practice requires a teacher re-positioning in the classroom to one of co-learner or facilitator of learning experiences, according to Bishop and Glynn (1999). It has been argued that teacher repositioning is required so that the sense-making/knowledge construction processes of learners can be facilitated (Bishop \& Glynn, 1999, p. 158). Co-construction can be viewed as an activity concerned with knowledge creation and as a dynamic process, constructed by and between children and adults working together (Bishop, Berryman, Tiakiwai \& Richards, 2003; Bishop \& Glynn, 1999).

Educators must be sensitive to the diverse cultures of Māori students, because educators who are culturally sensitive and culturally knowledgeable will be more able to 
understand and respond to their Māori pupils (Alton-Lee, 2003; Bishop, Berryman, Tiakiwai \& Richards, 2003; Bishop \& Glynn, 1999; Penetito, 2001). The importance and recognition of social relationships in classrooms between teachers and their students and between students themselves within the learning process have been identified as crucial if teaching and learning are to be more inclusive (Bishop, Berryman, Tiakiwai \& Richards, 2003; Bishop \& Glynn, 1999; Tuuta, Bradnam, Hynds, Higgins \& Broughton, 2004).

I knew that the nurturing of effective learning relationships between Māori students and their teachers has been identified as crucial within recent research studies on effective teaching undertaken within Aotearoa/New Zealand (Bishop, Berryman, Tiakiwai \& Richards, 2003; Hawk, Tumama Cowley, Hill \& Sutherland, 2002; Tuuta, Bradnam, Hynds, Higgins \& Broughton, 2004). Hawk, Tumama Cowley, Hill \& Sutherland (2002) highlight three separate research studies which occurred over the period 1999-2000 and were conducted within different educational sectors: primary, secondary and tertiary. The students involved in two of the studies were Māori and Pasifika and were from schools in low socio-economic areas. The tertiary study involved Pasifika students only. Hawk, Tumama Cowley, Hill \& Sutherland (2002) report that a key theme to emerge from these very different and separate studies is the importance of the right kind of relationship between teachers and their Māori and Pasifika students, and the significance of such relationships to student success. The authors note that none of these studies was set up to investigate relationships between teachers and students; rather, they were investigating the links between what teachers do, student achievement and effective practice. The importance of relationships nevertheless emerged from the research findings.

Characteristics of effective relationships between teachers and Māori and Pasifika students were identified as the attributes of empathy, caring, respect, going the extra mile, passion to enthuse and motivate, patience and perseverance, and belief in students' ability (Hawk, Tumama Cowley, Hill \& Sutherland, 2002). I was interested in the points made by the researchers on how Māori and Pasifika students assess their relationships with teachers. Hawk, Tumama Cowley, Hill \& Sutherland (2002) state that teachers need to model the behaviour they want from their students and argue that students are very observant of teacher behaviour. I found myself wondering what types of behaviour culturally diverse teachers may model as they attempt to work together in school reform projects, and the messages (intentional or otherwise) that children and young people may receive. 
Hawk, Tumama Cowley, Hill \& Sutherland (2002) also observe that effective teachers within these studies were confident practitioners with high self-efficacy (belief that they can help their students to achieve). They also identify other features of the relationship:

- reciprocity, for example, if teachers are seen to work hard for their students then students are more likely to work hard in return;

- mutual loyalty;

- expecting a good work ethic, for example, teachers setting clear and high expectations for learning and behaviour and applying the right mixture of pressure and support to ensure students achieve; and

- modelling a good work ethic, for example, teachers setting high standards for themselves and working hard to achieve outcomes.

In my own study, I was interested to investigate teachers' collaborative partnership work from the different perspectives of students within classrooms, particularly since Hawk, Tumama Cowley, Hill \& Sutherland had noted that teacher modelling is important, and "students were aware of the effort teachers made" in improving classroom practice (Hawk, Tumama Cowley, Hill \& Sutherland, 2002, p. 48).

Other studies have emphasised the importance of classroom relationships in learning. For example, within the Te Kotahitanga study Bishop, Berryman, Tiakiwai \& Richards (2003) argue that classroom relationships and interactions are powerful influences on Māori students' achievement. The research project was divided into three phases:

- Phase 1: the construction of a series of narratives of experience, and their analysis.

- Phase 2: the development of a professional development model to implement change in classroom relationships and interactions.

- Phase 3: the measurement of changes in student achievement (Bishop, Berryman, Tiakiwai \& Richards, 2003, p. 3).

A key finding to emerge from Te Kotahitanga was the impact of teachers' total rejection of deficit theorising, the importance of quality in-class, face-to-face 
relationships and interactions between Māori students (as Māori people) and their teachers, and the impact these relationships and interactions have on Māori students' educational outcomes (Bishop, Berryman, Tiakiwai \& Richards, 2003). The findings of this study reinforce the importance of high expectations, effective relationships and quality learning interactions between teachers and Māori students which have been identified in other research (for example, Hawk, Tumama Cowley, Hill \& Sutherland, 2002). Bishop, Berryman, Tiakiwai \& Richards' findings indicate that as a result of changes in teacher-Māori student relationships, "Māori students' on-task engagement increases, their absenteeism reduces, their work completion increases, the cognitive levels of the classroom lessons are able to increase, and their short-term achievements increase; in many cases, dramatically so" (2003, p. 2).

In America, Ladson-Billings (1995) has examined the practices of successful teachers of African-American children in Northern California. The study examines the teaching practices of eight female teachers (five African American and three white) who were nominated through a process of community consultation. The study involved four phases including ethnographic interviewing around the teachers' teaching and learning philosophies, in-class observation of their practice, videotaping of their practice, and teachers' collaborative analysis on their own and other teachers' practice. A major observation of this study is that the teachers who took part helped all their students to be academically successful, culturally competent and socio-politically critical. The focus of the study was on the teachers' sense of self and others, social relationships in the classroom and the teachers' conception of knowledge. These teachers believed that all the students were capable of academic success. Ladson-Billings notes that these teachers took on the responsibility of ensuring their students' success, and focused on how they could improve teaching approaches if individual students were struggling. The teachers in the study were able to help their students perform at higher levels than their district counterparts. Teachers' participation in community life outside the school was also considered crucial, and teachers valued their connections with students' parents and with the wider community (Ladson-Billings, 1995).

Social relations within teachers' classrooms were also highlighted. The teachers in Ladson-Billings' study fostered effective and mutual learning relationships between the teacher and students, and between students in each class. Teachers encouraged cooperative learning arrangements and gave students opportunities to teach each other and seek help from peers with expertise. Responsibility for learning and teaching was 
fostered within the class. The teachers encouraged students to ask questions, to pose and solve problems actively, and to adopt a critical stance to forms of knowledge in a variety of ways - an approach teachers themselves modelled. Teachers in the Ladson-Billings study actively encouraged students to co-construct new knowledge through engaging in problem-based activities and enhancing students' critical thinking.

I was interested that Bishop, Berryman, Tiakiwai \& Richards (2003) and Bishop and Glynn (1999) both cite the Ladson-Billings study as having direct relevance for creating more culturally responsive classrooms for Māori students by describing teachers' commitment to connecting with learners' cultural aspirations, preferences and practices in ways which encourage academic success and foster important life skills. Bishop and Glynn (1999) note that although teachers in Ladson-Billings' study were encouraged to develop a critical stance to knowledge, they were also careful to help their students understand the difference between intellectual challenges and "a challenge to the authority of parents" (Bishop \& Glynn, 1999, p. 156).

As I read these statements, I wondered about parents/caregivers' perceptions of teachers' collaborative work as educators attempt to work together to improve classroom practice and outcomes for Māori learners. None of the studies reviewed above had investigated teachers' collaborative practices, from culturally diverse stakeholder perspectives, as teachers attempted to work together to improve classroom practice and outcomes for diverse learners. Most of the research studies I located appeared to describe the practice of teachers who were already considered 'effective' in their pedagogy, but I found there was a lack of research evidence on processes which had enabled 'ineffective' teachers to become more 'effective' in meeting the needs of culturally diverse learners. Bishop, Berryman, Tiakiwai \& Richards note within their own study that when teachers had peer support (more than one teacher engaged in the professional development) and were working with all or some of the same students, "teachers were able to work effectively as a cooperative team", focused on improving classroom practice and outcomes for Māori students (2003, p. 131).

There appeared to be some evidence within research literature that teacher collaboration could be an important partnership mechanism for improving classroom practice and outcomes for Māori students in mainstream schooling settings. However, the findings of Bishop, Berryman, Tiakiwai \& Richards (2003) appear to be based on particular groups of teachers who had willingly volunteered to take part in the professional development within selected schools, and I wondered what it would be like 
for teachers to work with 'willing' and 'unwilling' colleagues within the context of reform over time. Bishop, Berryman, Tiakiwai \& Richards also argue that improvement in classroom practice and outcomes for Māori students will come about "through reducing the degree of 'talking past each other' that is occurring among participants in the education process" between teachers, principals, those parenting Māori students and Māori students themselves (2003, p. 31). However, Bishop, Berryman, Tiakiwai \& Richards' study does not detail the experiences of culturally diverse participants (teachers, principals, students, parents/caregivers and in-school facilitators) as they engage in the process of trying to establish dialogue through a collaborative improvement process. There appeared to be a lack of research within Aotearoa/New Zealand on teachers' experiences of working collaboratively with diverse colleagues from across their schools on issues of practice for equally diverse students. It was at this stage that I turned my attention to research evidence and educational literature related to teacher collaboration and partnership as reform mechanisms.

\section{Teacher Collaboration and Collegiality: Mechanisms For Improving the Quality of Teachers' Practice For Culturally Diverse Learners}

As was stated earlier, I have been interested in theories related to teachers' collaborative work for some time (Hynds, 2000). According to research studies undertaken in Aotearoa/New Zealand and overseas, a number of authors have argued that teacher collaboration and collegiality can enhance teaching practice and ultimately student outcomes through teachers' participation in professional learning communities (Bishop, Berryman, Tiakiwai \& Richards, 2003; Lieberman \& Miller, 1999; Marzano, 2003; Stoll, Fink \& Earle, 2003; Timperley, 2003; Timperley \& Wiseman, 2003; Fullan \& Stiegelbauer, 1991). Over the past 20 years, educational reform literature has widely recognised that teachers are at the centre of instructional improvement and that staff development is central to school reform focused on improving student social and academic outcomes (Alton-Lee, 2003; Lieberman \& Wood, 2001; Louis \& Ingram, 2003; Louis \& Marks, 1998; Stoll, Fink \& Earle, 2003). It has been argued that "solutions" in educational reforms targeted at instructional practice, "must come through the development of shared meaning. The interface between individual and collective meaning and action in everyday situations is where change stands or falls" (Fullan \& Stiegelbauer, 1991, p.5) 
Alton-Lee (2003), in her analysis of what constitutes best practice in teaching within Aotearoa/New Zealand, notes that teachers make more difference to students' achievement levels than any other factor, including the backgrounds of students or school resources. Hattie (2003) argues that the most powerful way to raise student achievement is to foster excellence in teaching. Teachers can make a greater contribution in their schools when they take part in collaborative development work which can result in improved learning outcomes for their students (Bishop, Berryman, Tiakiwai \& Richards, 2003; Frost, Durrant, Head \& Holden, 2000). The significance of the quality and impact of teachers' professional relationships within schools is especially identified within school improvement and professional learning literature (Darling-Hammond, 1997; Frost, Durrant, Head \& Holden, 2000; Fullan, 1999; Fullan \& Hargreaves, 1996; Little, 1990; Little, 2001; Little \& McLaughlin, 1993; Louis \& Ingram, 2003; Louis \& Marks, 1998; Marzano, 2003; Rosenholtz, 1989; Stoll, 2000; Stoll \& Fink, 1996; Stoll, Fink \& Earle, 2003; Timperley, 2003; Timperley \& Wiseman, 2003).

Educational improvement and effectiveness in any context appears to be dependent on people working collaboratively and in partnership for a shared purpose (Bishop, Berryman, Tiakiwai \& Richards, 2003; Bishop \& Glynn, 1999; Fullan, 1999; Stoll, 2000; Timperley \& Robinson, 2002; Tuuta, Bradnam, Hynds, Higgins \& Broughton, 2004; Fullan \& Stiegelbauer, 1991). However, Penetito (2001) warns that participatory learning partnerships within schools, that intend to make a difference to the quality of teaching and learning outcomes for Māori students, must include whānau, hapū and iwi, through a collaborative and reciprocal learning process which pays close attention to local Māori knowledge. It will be these types of participatory learning opportunities that will be important if the goal is to improve mainstream teachers' practice for Māori students (Penetito, 2001).

\section{Enhancing Teacher Agency Through Collaboration}

I discovered that feelings of teacher confidence and certainty are often linked to improved practice and outcomes for students (Frost, Durrant, Head \& Holden, 2000; Fullan \& Hargreaves, 1996; Ladson-Billings, 2001; Roth \& Tobin, 2002; Stoll, Fink \& Earle, 2003). Teacher agency or efficacy, a belief that one can make a difference to the educational outcomes of diverse groups of students, is a key mechanism for improvement (Alton-Lee, 2003). The concept of agency derived from Giddens' (1984) theory of structuration explains that human capacity can make a difference. Giddens argues that 
people can play a significant part in shaping the conditions, structures, organisations, rules and agreements that shape their lives. There is a fundamental relationship between structure and agency in that individual actors can exercise bottom-up power to alter structures that constrain and/or shape their practices (Frost, Durrant, Head \& Holden, 2000; Sewell, 1992). Being able to contribute ideas and opinions in discussion with colleagues as part of reflective professional inquiry can enable teachers to develop confidence and take the necessary risks to disrupt the status quo (Frost, Durrant, Head \& Holden, 2000). Developing confidence is important in turbulent change environments, because people who believe that they have a sphere of influence in any given situation, and do believe they can make a difference, exercise agency (Frost, Durrant, Head \& Holden, 2000). Systematic and critical inquiry in schools by teachers can be uncomfortable when they "confront resistance, but it also enables teachers to acknowledge the wider picture and deal with problematic issues" (Frost, Durrant, Head \& Holden, 2000, p. 118).

\section{Collective Efficacy}

Social cognitive theory asserts that the control individuals and collectives exert over their lives is influenced by perceptions of efficacy and agency (Goddard, 2001). Collective efficacy extends the concept of human agency and is linked to people's shared beliefs in their collective power to produce desired results (Bandura, 1997; Bandura, 2000; Goddard, 2001). Collective efficacy is associated with judgements, tasks, levels of effort, persistence, stress levels and achievements of groups (Bandura, 1997) and, as is increasingly highlighted in educational literature, is related to school reform (Caprara, Barbaranelli, Borgogni \& Steca, 2003; Goddard, 2001). Collective efficacy has been linked to factors which account for differences in student achievement levels between different schools (Caprara, Barbaranelli, Borgogni \& Steca, 2003; Goddard, 2001). A key ingredient of collective efficacy is a shared belief in collective power to produce desired results (Bandura, 1997). According to Bandura, collective efficacy fosters,

... a sense of mission and purpose of a system, the strength of common commitment to what it seeks to achieve, how well its members work together to produce results, and the groups' resiliency in the face of difficulties. (1997, p. 469) 
It has been argued that collective efficacy can transform practice as teachers enhance changes in practice through forming a collective belief across their school that teachers can make a difference (Caprara, Barbaranelli, Borgogni \& Steca, 2003; Goddard, 2001; Goddard, Hoy \& Hoy, 2004). I wondered about this concept of collective efficacy, particularly as it related to Māori and non-Māori teachers' experiences of collaborative partnership work. As highlighted earlier, many Māori academics have warned us about the presence of teachers' deficit theorising and the impact of colonising schooling practices which had traditionally tried to 'cure' Māori of their cultural differences within a wider process of assimilation. I found a lack of attention in the available research literature on the efficacy of teachers' collaborative partnership work, when indigenous and non-indigenous teachers attempt to work together for change. I wanted to ascertain whether the issue of teachers opting out of collaborative work and the presence of teachers' deficit theorising about cultural diversity had been examined in greater detail and acknowledged as factors having a dynamic impact on the practice and efficacy of collaborative partnership work.

I returned back to the library and continued with literature searches in an attempt to address these gaps. I located a handful of studies that are dealt with later in the chapter. As I had to wait for these studies to arrive by interloan, I immersed myself in the readily available literature. The following section describes the debates and disagreements which I felt dominated the discourse regarding teacher collaboration and partnership work as a reform mechanism.

\section{Collegiality and Other Forms of Collaborative Teacher Behaviour}

As indicated in the previous chapter, different authors define aspects of teachers' collaborative work and/or behaviour differently. For example, Lieberman and Miller have drawn a distinction between teacher "collegiality" and teacher "congeniality" (1999). They argue that teacher collegiality refers to the quality and impact of professional relationships whereby teachers openly and continually investigate and critique school and classroom practice and take collective responsibility for improvements in student outcomes. In contrast, teacher congeniality refers to the 'comfortableness' of teacher relationships whereby the nature of teacher relationships may be more social (Lieberman \& Miller, 1999). Lieberman and Miller also note that the new social realities of teaching require teachers to move from norms of individualism, isolation and privatism to emerging norms of collegiality, openness and trust. However, a number of authors stress 
that these 'new norms' of teaching may be difficult to enact due to the amount of teacher isolation and individualism within schools (Darling-Hammond, 1997; Fullan \& Hargreaves, 1996; Hynds, 2000; Lieberman \& Miller, 1999; Little, 2001; Stoll, Fink \& Earle, 2003).

Hargreaves (1994) has highlighted different forms of teacher cultures that have "characteristic patterns of relationship and forms of association ${ }^{21}$ between members" (p. 166). He identifies five different forms of teacher culture related to distinct forms of association, and argues that each holds very different implications for teachers' work and educational change. The five identified forms include:

- fragmented individualism;

- balkanisation;

- contrived collegiality;

- collaborative culture; and

- the moving mosaic.

According to Hargreaves, fragmented individualism includes forms of teacher isolation, which may seek protection from outside interferences, but which also includes habitual patterns of working alone and structures which support teacher autonomy and isolation (1994). The second form of association is balkanisation, where teachers are neither isolated nor work as a whole school. In this form, teachers develop into smaller group associations, for example, in departments or syndicates, and their patterns of relationship are largely inconsistent, aligned to particular loyalties and/or identities tied to particular groups within the school. The third form, contrived collegiality, may be a strategy for creating collegiality in an attempt to develop more collaborative relationships, but is often a strategy for controlling teachers' work. In this form, teachers' collaborative working relationships are compulsorily imposed with fixed times and places set for such partnership work. Teachers may collaborate with one another for the sake of collaboration, and/or be forced into collaborative work. It has been argued that contrived collegiality will not produce the actions necessary to transform classroom practice over time in schools because teachers lack a sense of ownership in the process. However,

\footnotetext{
${ }^{21}$ The author's emphasis.
} 
Hargreaves has noted that teachers may initially engage in contrived collegial activities which may develop into more effective collegial practice.

The fourth form, collaborative culture, appears to hold promise. This pattern of teacher relationship includes spontaneous and voluntary forms of partnership work, without an external control agenda, and may involve both comfortable 'sharing' activities and more 'rigorous' processes such as mutual observation and focused reflective enquiry. Hargreaves notes that this form is characterised by trusting, sharing and supportive norms needed for joint work which are more likely to lead to improved student learning outcomes as teachers are encouraged to take risks in their teaching practice. Finally, Hargreaves identifies the moving mosaic, a postmodern form characterised by blurred boundaries, overlapping categories, and memberships which are flexible and dynamic. He notes that this form includes more responsive patterns of relationships which are also uncertain, vulnerable and contested.

I was interested to find that Fielding (1999) criticises Hargreaves (1994) for missing "important opportunities" to identify and understand the "underlying values, principles and dispositions which support and enhance those forms of association" (Fielding, 1999, p. 16). Fielding argues that what is needed is,

... an account of collegiality that opens up debate in a manner which openly acknowledges that it is (a) saturated with values, (b) external to, or at least not bounded by, the particularities of specific schools, (c) committed to education, not just teaching, (d) transgressive of the present by drawing in the past and future, (e) cognisant of the contexts of postmodernity, and (f) part of a participatory democratic project in which the voices of students, parents and community have an increasing resonance and legitimacy. (1999, p. 16)

I started to view the literature as outlining different and competing navigational charts. I could see that there was a lack of agreement within the educational texts I had read about the purposes and/or goals of teachers' collaborative partnership work and the forms of association and collaborative behaviour, beliefs and values that would be needed in order to challenge the status quo and enable transformation. 
Other authors and researchers use other terms to describe different types of teacher collaborative behaviour. For example, Little (1990) identifies four different kinds of collegial relations among teachers. These include:

1. scanning and story-telling;

2. help and assistance;

3. sharing; and

4. joint work.

The first three forms of teacher relations are considered by Little to be relatively weak forms of collegiality because they tend simply to confirm the status quo. Little argues that it is the last form, joint work, that is the strongest expression of teacher collaboration. Activities involved in joint work could involve reciprocal peer observation and feedback, peer critique of student work, team teaching and planning, and sustained peer coaching. Joint work implies and creates stronger independence, shared responsibility for improvement, and a greater readiness to participate in the difficult business of review and critique, according to Little (1990). Joint work between teachers is seen to make more of a difference in improving and sustaining classroom practice and outcomes for students.

I found that there was considerable over-lap between the results of the Little (1990) study and other findings that stress the need for critique and review within teachers' partnership work (Fullan \& Hargreaves, 1996; Lieberman \& Miller, 1999; Stoll, 2000; Stoll, Fink \& Earle, 2003; Timperley \& Robinson, 2002). However, Fielding $(1999)^{22}$ also criticises Little's (1990) account of teacher collaboration as failing to make enough of a distinction between collaboration and collegiality, and to "articulate the nature of the relationship between the two" (Fielding, 1999, p. 13).

\section{Uncovering Turbulent Waters: Tensions in Creating and Sustaining Collaborative Teacher Cultures}

Most of the readily available navigational charts emphasise turbulent waters, which outline some of the challenges for which participants would need to be prepared as they

22 Fielding also levelled this criticism at Hargreaves (1994). 
attempt to create and sustain collaborative teacher cultures within schools (Fullan \& Hargreaves, 1996; Fullan \& Hargreaves, 1998; Hargreaves, 1994; Little, 2001; Senge, Cambron-McCabe, Lucas, Smith, Dutton, Kleiner, 2000; Stoll, Fink \& Earle, 2003).

I felt that much of this literature highlighted enduring tensions in creating and sustaining truly collaborative teacher cultures within schools. For example, teacher individualism is not considered to be the same as teacher individuality; the latter involving the voicing of disagreement, opportunity for teacher solitude and teachers' experiences of personal meaning (Fullan \& Hargreaves, 1996; Little, 2001). Fullan and Hargreaves (ibid) argue that a respect for teacher individuality is needed because it is the key to personal renewal and personal renewal is needed for collective renewal in schools. One of the most important tensions, according to Fullan and Hargreaves, is creating a collaborative school culture that respects teacher individuality (1996, p. 49).

Teacher individualism, however, can also come about because of "impossibly high expectations" (Fullan \& Hargreaves, 1996, p. 42). It has been argued that the work of teachers is becoming more complex (Stoll, Fink \& Earle, 2003) and teachers may drive themselves to meet "virtually unattainable standards of perfection which they have set themselves" (Fullan \& Hargreaves, 1996, p. 42). These authors (ibid) argue that there are consequences in setting unrealistically high expectations that reinforce teacher individualism and which create further barriers to change in schools. First, teachers have little time to collaborate because there are always pressing needs within their own classrooms and some teachers may prefer to work through their break times and plan alone. Secondly, teachers may fear the judgement of colleagues because of their own stringent expectations, and thus reinforce a system of growing individualism and isolationism:

If teachers are trapped in the pursuit of their own unending aspirations, if they cannot ever do enough in their own eyes, how could they possibly meet the expectations of others? (Fullan \& Hargreaves, 1996, p. 43)

Under such circumstances, it is likely that teachers will retreat to their classrooms and act defensively and suspiciously towards programmes designed to encourage collaborative action in schools (Fullan \& Hargreaves, 1996). 
It is clear that complex issues are raised within the literature, and I wondered whether practitioners themselves ever had the time and space within their busy teaching lives, to read about such phenomena.

\section{Contextual Influences on Teachers' Collaborative Behaviour}

Several authors have highlighted both the culture and structure of the school as contextual influences on teacher collaboration within the context of reform work (Lieberman \& Miller, 1999; Little, 2001; McLaughlin \& Zarrow, 2001; Rosenholtz, 1989; Senge, Cambron-McCabe, Lucas, Smith, Dutton, Kleiner, 2000; Stoll, Fink \& Earle, 2003; Fullan \& Stiegelbauer, 1991). Rosenholtz (1989) draws attention to two particular school cultures, stuck (or learning impoverished) and moving (or learning enriched). Student achievement is lower in stuck schools. In these schools, teachers are unlikely to ask for help or assistance and spend a great deal of time working alone. In moving schools, Rosenholtz argues that teachers work together more often, and see teaching as challenging and difficult within a context of trying to improve practice. Teachers in moving schools give and receive help more often than their colleagues in stuck schools. Giving and receiving assistance from colleagues does not imply incompetence, but rather is seen as an important mechanism for ongoing improvement in teaching in moving schools. Teachers in these schools have more confidence and certainty about what they are trying to achieve and a sense of how well they are achieving due to ongoing support, work and communication with colleagues. While it is clear that these descriptors identify some basic discernible differences between schools, they are also simplistic: it is not clear how assessment of "stuck" and "moving" cultures is made other than by reference to student achievement. It also seems that such measures may ignore cultural identity and issues of practice and improvement, particularly if they are one-dimensional and monocultural. Only one of these studies addresses issues of participants' cultural identity, diversity and/or culture as impacting factors.

I knew that a considerable literature base has developed around the importance of the notion of a school culture, its effect on teacher collaboration, and its implications for change and the work of reform (Fullan \& Stiegelbauer, 1991; Fullan, 1999; Fullan \& Hargreaves, 1996; McLaughlin \& Zarrow, 2001; Sarason, 1996; Senge, CambronMcCabe, Lucas, Smith, Dutton, Kleiner, 2000; Stoll \& Fink, 1996; Stoll, Fink \& Earle, 2003). It has been argued that a school's culture is its most enduring aspect (Senge, Cambron-McCabe, Lucas, Smith, Dutton, Kleiner, 2000; Stoll \& Fink, 1996). The heart 
of school culture has been described as the "deeper level of basic beliefs and values shared by those within the school" (Stoll, Fink \& Earle, 2003, p. 137), and any attempt to improve a school without attending to its culture may be doomed to tinkering because school culture influences readiness for change (Fullan, 1992; Stoll \& Fink, 1996; Stoll, Fink \& Earle, 2003). An individual school's culture can work to encourage or constrain teachers risk-taking and experimentation in class (Stoll \& Fink, 1996), and firmly entrenched traditions and practices can subvert new innovations because proposed changes in schools imply changes in attitudes, norms, beliefs and values associated with school culture:

School improvement efforts depend on the belief that curriculum, instruction, and social climate affect student learning. If the culture of a school is permeated with a belief that the causes of student learning lie largely outside the school, in the genes and social background of students, school improvement efforts may appear hopeless and even ridiculous. (Stoll \& Fink, 1996, p. 93)

It has been argued that the culture of each school creates a different reality and to a large extent determines the life of that school and the different concepts about how it should go about its core business of teaching and learning (Stoll, Fink \& Earle, 2003).

In my own study, I found that there were unexamined, hidden and unacknowledged values, beliefs, identities and existing practices that influenced the acceptance of teachers' collaborative partnership work, as well as its efficacy and place within each school's culture. I agree with Stoll, Fink and Earle (2003) that there is a deeper, less visible dimension to school culture that would need to be acknowledged and examined if teachers were truly to work together for change and transformation.

\section{The Impact of Reform - Is It Good For Teachers?}

It was not hard to find debates within the literature surrounding teacher collaboration and/or partnership as reform mechanisms. For example, Little (2001) states that school reform efforts typically attempt to make changes or improvements in teachers' classroom practice. This means such reforms have the potential to "enhance or threaten the intellectual, moral and emotional satisfactions" of teachers for classroom teaching (Little, 2001, p. 26). Sometimes, reform efforts result in increased teacher collaborative activities 
and interaction with colleagues, and sometimes in withdrawal, disruption and opting out. Little (2001) found that collaborative teacher activities had the potential to unite or divide colleagues; interrupt existing friendships or create new ones; and encourage new bonds of professional community or destroy traditional ones. Little has stated that reform activities have the potential to consume teachers' private lives and strain family relationships (2001, p. 27). Through her own study, she notes that teachers involved in reform efforts identify increased personal commitments of time, and emotional and intellectual energy as well as actual work-load commitments (some of these include new teacher activities such as attending particular meetings, developing new curricula and resources, and collecting unaccustomed student data). Little notes that in most instances this new teacher activity is an add-on to teachers' daily work and with "rare exceptions" teacher leaders are not granted a reduced teaching load (2001, p. 27).

Little states that when teachers experience a happy fit between reform initiatives and certain aspects of their teaching lives, they are more likely to be seen as reform enthusiasts within their schools (2001, p. 28). However, she also notes that a "happy fit" seems elusive, especially over long periods of sustained innovation. At issue here is how teachers interpret the significance of the reform within the context of ongoing obligations and opportunities for teaching (Little, 2001, p. 28). Regardless of how reform proposals are worded or defended by advocates inside or outside the school, they remain subject to teacher interpretations that are individual, collective and institutional (Little, 2001, p. 28). Such interpretations of reform are not static but are an ongoing interpretative act.

Restructuring activities within schools cause teachers to engage in collaborative work that is also more collective and public (Little, 2001). Such restructuring activities could prove complex and contentious as teachers engage in more public scrutiny of classroom practice, are involved in new conversations where widespread agreement is sought on teaching priorities and as they find themselves in new leadership roles. Restructuring activities may also engage teachers in new forms of governance and decision-making activities which alter existing traditional relationships and boundaries between school community members. Little notes that being involved actively in new restructuring activities is something of "an emotional, intellectual and professional roller coaster" for teachers within her study (2001, p. 32). Although teacher reform advocates were genuinely excited about the possibilities of new approaches to teaching and learning as well as new ways of working with colleagues, by the fourth year of restructuring 38 percent of middle school teachers and 43 percent of high school teachers said they would 
be likely to accept a job in a traditional school if one were offered (Little, 2001, p. 33). Little argues that the restructuring experience encourages personal renewal and burnout, with talk of teacher burnout increasing over time (2001, p. 33). Expectations of the rate of change, particularly visible or measurable outcomes, may exacerbate the difficulties surrounding teacher learning in a context of reform:

\begin{abstract}
At issue here is whether such intensity is conducive to deep questioning of assumptions and certainties, or whether it drains individuals of the energy and concentration needed to learn. Reform environments tend to be volatile, fast-paced and public, while learning may require sustained concentration, gradual development and opportunities for relatively private ('safe') disclosure of struggles and uncertainties. (Little, 2001, p.
\end{abstract}

Little adds that even in schools where a large proportion of teachers had ownership of the process, had taken part in deciding the overall restructuring plan and where support for the core principles of the reform effort ran high, teachers were often challenged by the learning demands that emerged over time (2001, p. 33). It appears from Little's research that reform environments that are "fast-paced and public" might not encourage teachers to question their assumptions deeply and inquire into their teaching practice. Issues of time and intensity of change, coupled with the environment of reform, could all impact on teachers' willingness and ability to engage in collaborative reform work within their school communities.

\title{
Collaboration and the Presence of Conflict
}

Much of the literature on teacher collaboration that I found readily available highlights issues of conflict (Fullan, 1999; Lieberman \& Miller, 1999; Little, 2001; Senge, Cambron-McCabe, Lucas, Smith, Dutton, Kleiner, 2000), and this resonated with my own personal experiences as an educator and as a researcher (Hynds, 2000). It has been argued that educators must learn how to deal with conflict, because it is a natural byproduct of collaboration, particularly when teachers' practice and teachers' beliefs become topics for public conversation (Lieberman \& Miller, 1999). However, teachers may view conflict as a 'communications killer' and something to be avoided or immediately resolved (Lieberman \& Miller, 1999). 
A number of authors have called for the need to recognise conflict as a 'friend' in the collaborative learning environment, because diversity of thinking is needed to solve complex problems which could emerge unanticipated within the context of reform (Fullan, 1999; Lieberman \& Miller, 1999; Stoll, Fink \& Earle, 2003). However, it can be difficult for people to cope with difference and diversity of thinking, particularly as we are most likely to gravitate to people who are "like-minded" (Fullan, 1999). Lieberman \& Miller (1999) have stressed that learning to collaborate and deal with conflict is a necessary skill that with practice and commitment can be learned (Lieberman \& Miller, 1999, p. 25). These authors, however, emphasise that a tolerance for conflict and disagreement is made possible only once teachers have reached broad agreement on fundamental values, directions and "non-negotiables" (Forest, 1998; Fullan, 1999; Fullan \& Hargreaves, 1996). The development from 'safe' technical inquiry to more challenging issues can have an effect on teachers' collaborative behaviour (Forest, 1998; Hynds, 2000). "Once the group tackles more symbolic, abstract, or complex academic or professional tasks, the community may encounter many internal resistances and obstacles" (Forest, 1998, p. 299). Staff groups tackling challenging and complex reform issues may lapse into chaos and recrimination, "fight or flight" (Forest, 1998, p. 299).

Interdependency amongst educators can create potential for conflict because we may hold varying beliefs about learning, reform intentions, goals, means and ideologies, which can remain unexamined and hidden from view (Lieberman \& Miller, 1999; Senge, Cambron-McCabe, Lucas, Smith, Dutton, Kleiner, 2000). Senge, Cambron-McCabe, Lucas, Smith, Dutton, Kleiner (2000) argue that people are creatures of interpretation and, as such, behaviour and attitudes "are shaped by the images, assumptions and stories that we carry in our minds of ourselves, other people, institutions and every aspect of the world" (p. 67). New insights fail to get into practice because they conflict with deeply held internal images or "mental models":

Since most mental models in education are 'undiscussable' and hidden from view, one of the most critical acts for a learning school is to develop the capability to talk safely and productively about dangerous and discomfiting subjects. (Senge, Cambron-McCabe, Lucas, Smith, Dutton, Kleiner, 2000, p. 70) 
It had been argued that mental models limit people's ability to change, and these authors stress that most change initiatives fail (Senge, Cambron-McCabe, Lucas, Smith, Dutton, Kleiner, 2000). They note that sources of change problems cannot be remedied by expert advice, better consultants or more committed managers, as the sources lie in our most basic ways of thinking. If these do not change, then any new 'input' will end up ordering the same fundamentally unproductive types of actions. Therefore, getting people to talk openly, honestly and constructively about 'undiscussable' topics in schools, as well as encouraging ongoing enquiry into thinking and evidence for personal assumptions, remain major challenges for school reformers (Senge, Cambron-McCabe, Lucas, Smith, Dutton, Kleiner, 2000).

Other authors have echoed this view and argue that strong and effective forms of collaboration are possible in schools only when conditions allow and support teachers to raise and "address critical, intrusive questions" about practice (Fullan and Hargreaves, 1996). A safe and effective learning environment is required whereby teachers are both challenged and supported to undertake the work of reform (Fullan, 1999; Lieberman \& Miller, 1999; Stoll, Fink \& Earle, 2003). Before I started eliciting stories from participants for this study, I knew, based on my own experience of collaboration, that there was a need for a 'delicate balance' in the context of collaborative reform work (Hynds, 2000). However, looking back at the end of my own learning journey I realise now that such learning conversations must be centered around racism, prejudice, deficit theorising and pathologising practices. Change and transformation can occur only through collaborative partnership work which is unashamedly political; a collective learning process which seeks to undercover the hidden dimensions which underpin our mainstream schooling practices. I could find no research studies within Aotearoa/New Zealand which described teachers' collaborative partnership work in such ways, and from the experiences and perspectives of culturally diverse teachers, students, parents/caregivers and principals.

\section{The Cultural Map: Opting In or Opting Out}

\section{The Function of Aroha in Teachers' Collaborative Partnership Work}

As explained earlier, at the start of my own inquiry I searched for studies of teachers' collaboration and partnership work that could speak directly to issues of participant culture and identity, and I found large gaps within the research literature. I could find none that specifically investigated teachers' collaborative partnership work from 
culturally diverse and multiple perspectives. However, I did find that B. L. McDonald (2001) had undertaken a PhD study in the Polynesian island state of the Cook Islands. The aim of this research was to investigate the influence of cultural factors upon teacher in-service transfer of training ${ }^{23}$ and to identify strategies and barriers that could impact on or impede the process.

As part of his study, McDonald interviewed 30 Rarotongan primary teachers from six different schools in the Cook Islands. A key finding from his study was the importance of teachers' social support and collaboration within the school community, as well as support from outside this context. A function of support could be the provision of a sense of aroha (concern about teachers' welfare) as teachers worked together to transfer skills and knowledge learned from in-service training into their classroom practice. However, social support was seen as problematic in some situations, as it could be interpreted as a personal weakness if assistance was sought by teachers to enact changes in their classrooms. Adverse responses and criticism from colleagues were common phenomena and could prevent a teacher from developing course ideas into classroom practice. Criticism from senior or older staff members made it difficult for individual teachers to sustain risk-taking and experimentation in their classrooms. Teachers then considered support from the principal of the school vital. McDonald notes that support was a complex phenomenon and subject to a number of influences. The potency of criticism from colleagues could be mediated by other factors such as age, gender, status of the individual (seniority in school, position in the community etc.) as well as issues involved in receiving/giving criticism, and the existence of familial affiliation bonds. McDonald draws attention to the significance of support, interdependence and collaboration for teachers as important mechanisms within a context of reform.

It was clear from this study that the beliefs and values of these Cook Islands teachers related to the phenomena of social support and aroha which emerged as impacting factors within the context of their collaboration (McDonald, B. L., 2001). Results from this study challenged my thinking related to other texts on teachers' collaborative work (Fullan, 1999; Lieberman \& Miller, 1999; Senge, Cambron-McCabe, Lucas, Smith, Dutton, Kleiner, 2000; Stoll, Fink \& Earle, 2003) as participants' cultural values related to age, gender and status appeared to impact on the development of

23 Transfer of training can be defined as something that "occur[s] when a training participant applies in the work setting the knowledge or skills he or she has learned in a training setting, usually a classroom" (Gradous, 1991, p. 12). 
collaborative reform (McDonald, B. L., 2001). None of the other texts I had read on teacher collaboration or partnership had described and/or outlined how culturally diverse teachers may navigate such differences as they work together for change over time. I wanted to find out more about teachers' collaborative partnership experiences within mainstream schools in Aotearoa/New Zealand, where participants' cultural identity was central to any discussion regarding improvement in teachers' pedagogy.

\section{Muddying the Waters: A Search for Evidence within Aotearoa/New Zealand on Culturally Diverse Teachers' Experiences of Collaboration and Partnership Work}

As explained earlier, I searched for literature on teacher collaboration and/or partnership within Aotearoa/New Zealand, and found that there was a lack of attention in the easily available texts related to the experiences of such work amongst culturally diverse participants. It was easy to find studies on teacher collaboration and partnership within the context of reform, but they appeared largely superficial and monocultural. For example, I found that Poskitt has analysed 44 individual school-based proposals aimed at enhancing teachers' professional development (2001). Analysis of the proposals was conducted using a weighted-attribute contract evaluation devised by Poskitt and in consultation with the Ministry of Education. Through this evaluation, she identified five critical factors or phases for successful school-based professional development. These appear as interrelated factors or phases and include:

- Selecting a relevant project. This includes selecting a project that is important for addressing issues of teacher ownership (in determining the topic), relevance and practical application in teachers' classrooms. Such issues are important for sustaining teacher enthusiasm and motivation, particularly through the risky business of experimentation in class.

- Planning the project. This includes the practical issues of availability of resources needed to ensure teachers are able to trial new ideas in their classes. This relates to the next point below.

- Creating supportive 'people' structures within individual schools. This is important for assisting teachers to trial new ideas or skills learned, as well as supporting teachers to overcome difficulties encountered, particularly in the early stages of change. Supportive people structures include availability of mentors, regular 
information given at staff meetings, frequent communication, and availability of release time to encourage teachers to trial and implement new ideas and/or observe colleagues. Provisions of time are necessary to discuss issues and problem-solve with colleagues, prepare necessary resources and reflect on the experience.

- Implementing sustainable systems. Poskitt notes that the challenge for any professional development is continuity and implementing sustainable systems which encourage change that needs to be institutionalised within individual schools.

- Translating development to professional practice. This includes the actual changes in teacher knowledge, skills and dispositions which are translated and/or are observable in teachers' professional 'day-to-day' practice (Poskitt, 2001).

I felt frustrated by this study. Although Poskitt notes that some of the most successful schools involved students in monitoring change, it did not appear from her description that teachers were necessarily working together to develop culturally responsive pedagogy, where culturally diverse groups of students were encouraged to take a critical stance towards knowledge creation (Ladson-Billings, 2001), or encouraged to share power within the classroom (Bishop \& Glynn, 1999). I was also interested in Poskitt's comments about schools only involving staff who are interested in participating in the professional development activities, "rather than battling with reluctant or antagonistic staff" (2001, p. 7). I wondered why teachers should be allowed to opt out of collaborative involvement, particularly when our national achievement rates for Māori students are so poor. There seemed to be a lack of recognition within the professional development and school reform literature on teachers working together to uncover deficit theorising related to culturally diverse student achievement. There were clearly large gaps within the research literature, and a lack of attention to issues of cultural identity and diversity and their impact on teacher collaboration and partnership work.

I had read that there are three critical problems facing US schools, all of which involve teacher learning (McDonald, P., 2001). McDonald identifies one of these problems as "teachers' reluctance or incapacity to work collaboratively and accountably across classrooms and grade levels to improve all student outcomes" (McDonald, P., 2001, pp. 229-230). I was interested in the argument that teachers may not wish to work collaboratively to improve all students' outcomes. Questions arose in my mind regarding the experiences of culturally diverse teachers within Aotearoa/New Zealand as they 
attempt to work together for improvement over time. I felt that since there was a lack of research evidence on this type of collaborative partnership work, it was an important area to research and explore. As noted earlier, the majority of research literature which I located on teacher collaboration, partnership and collegiality remained silent on issues of culture, diversity and identity. Bishop and Glynn have argued that due to the dominance of "deficit theorising", there have been few large-scale research studies that identify the importance of cultural identity and diversity for successful participation in education (1999, p. 149). I noted my concerns and questions within my research journal and dug deeper, narrowing my search in an attempt to address such gaps. Finally, I received some studies which helped to shed light on these issues.

\section{Māori Teachers' Experiences of Collaborative Partnership Work in Mainstream Schools}

Since I found it so difficult to locate research studies in Aotearoa/New Zealand which would speak to such partnership work, I decided to search for literature which would directly address the experiences of Māori teachers within mainstream schooling settings.

Cram, Smith, Smith \& Tunks (1999) conducted a study into Māori secondary teachers' workloads for Gardiner and Parata $\mathrm{Ltd},{ }^{24}$ which included an extensive literature review into indigenous teachers' workloads and a questionnaire that could identify and measure some key factors. The study built on issues already identified in the research literature by Māori teachers. Cram, Smith, Smith \& Tunks (1999) note that there is very little research published that tells us about Māori secondary teachers' experiences, their contribution to education, to te reo Māori me ona tikanga or to society in Aotearoa/New Zealand. A finding from this study emphasises that Māori teachers describe their work in particular ways and that it is necessary to understand the nature of their work historically when trying to analyse current workload issues in secondary schools. This study suggests that Māori teachers see their work in schools as being important and define it as including:

- teaching te reo Māori;

- being an advocate for Māori students;

24 This work was carried out for Gardiner and Parata by researchers from the International Research Institute for Māori and Indigenous Education at the University of Auckland. 
- looking after victims of the system;

- liaising with the Māori community;

- taking the culture group;

- managing a school-based marae;

- providing powhiri at short notice; and

- $\quad$ educating their non-Māori colleagues (Cram, Smith, Smith \& Tunks, 1999, p. 5).

A similar study was conducted by Bloor (1996) to identify the workload characteristics and perceptions of Māori secondary school teachers through a survey. Bloor's research was based on a random sample of 176 Māori secondary teachers drawn from the Post-Primary Teachers' Association national data base. The research found that Māori teachers spent a further 28 hours beyond their normal classroom duties, on average, engaged in activities directly related to being a Māori in the profession. Overall, the demands of being Māori in the profession meant that Māori secondary school teachers were required to work on average 76.89 hours per week, a figure which represents around 22 hours more than the workload found in the general secondary teaching community (Bloor, 1996, p. iv). Bloor reports that Māori secondary school teachers were highly motivated to do well for their pupils, schools and communities, but long hours in the classroom and community work were linked to personal stress. Māori teachers were expected to spend anywhere from an hour for assistant teachers to over five hours for those in management in activities designed to educate their non-Māori colleagues on issues to do with Māori (Bloor, 1996). "The picture that emerges is of a physically, emotionally, spiritually and socially strained group within the teaching profession” (Bloor, 1996, p. 48).

In an even earlier study, Mitchell and Mitchell (1993) interviewed 74 Māori teachers who had resigned from classroom and school environments and 23 others with past or current interests in Māori education policy and practice. Interviewees described the difficulties faced by many Māori teachers in being Māori in an otherwise non-Māori school environment, including:

- working with non-Māori colleagues who held deficit views about Māori students, their learning and behaviour; and

- working with non-Māori colleagues who held deficit views about Māori teachers, and parents/caregivers. 
I was interested that the authors of this report noted,

A number of interviewees do not see any hope of real progress unless there is structural change - a shifting of the whole basis of education in this country, especially in areas of power structures, decision-making and underlying philosophy. The incorporation of Māori values, Māori knowledge and Māori methods of transmitting knowledge would be necessary to bring about change. Recognition of the gifts, knowledge and talents brought to school by Māori pupils would be essential for Māori achievement. (Mitchell \& Mitchell, 1993, p. 121)

The findings of these three separate studies highlight important contextual issues, ignored by other researchers, which link to Māori teachers' experience of working and teaching in mainstream schools. It appeared to me after reading these studies that much of the previous discussion on teacher collaboration and partnership had neglected important issues. For example, a number of authors stressed the importance of respect as a 'non-negotiable' within the context of teachers' engagement in collaborative reform activities (Fullan, 1999; Senge, Cambron-McCabe, Lucas, Smith, Dutton, Kleiner, 2000; Timperley \& Wiseman, 2003). Mutual respect is considered important within a wider spirit of inquiry where participants challenge one another appropriately about their viewpoints and are required to provide evidence to support their assumptions (Fullan, 1999; Senge, Cambron-McCabe, Lucas, Smith, Dutton, Kleiner, 2000; Timperley \& Wiseman, 2003). However, the research regarding Māori teachers' experiences in mainstream schools indicates that the clear majority did not feel respected by their nonMāori colleagues for the work that they undertook in schools (Bloor, 1996; Cram, Smith, Smith \& Tunks, 1999; Mitchell \& Mitchell, 1993).

It appears from the studies above that:

- Māori teachers in mainstream schools are dramatically under-represented in numbers of teachers when compared with non-Māori teachers;

- Māori teachers define their workloads differently from non-Māori teachers;

- Māori teachers respond to different responsibilities, particularly when dealing with issues of practice for Māori students, such as being an advocate for Māori students 
within mainstream schooling contexts which are often also described as unsupportive (Bloor, 1996; Cram, Smith, Smith \& Tunks, 1999; Mitchell \& Mitchell, 1993).

It appeared to me that trust and respect were culturally defined concepts, open to different and competing interpretations. The incorporation of Māori values into the context of collaborative partnerships would appear to be an important factor that would influence Māori teachers' engagement. Given that Fielding (1999) argues that forms of teacher collaboration and collegiality are saturated with values, I wondered how culturally diverse teachers (particularly indigenous and non-indigenous) would work together to navigate their differences as they attempted to transform teaching practice for culturally diverse children and young people. Large uncharted areas were noticeable within the literature related to teachers' partnership work, as I had not been able to find research studies within the context of Aotearoa/New Zealand which detailed the experiences and challenges culturally diverse teachers face as they attempt to work together for equally diverse groups of students. Questions arose as I read through the literature: Under what conditions, and with what supports and for what purposes would Māori and non-Māori teachers view themselves as partners?

\section{Conflicting and Incomplete Navigational Charts}

There were clearly competing voices within the research texts I had read, and large gaps and periods of silence related to particular dynamics underlying the practice and acceptance of teachers' collaborative partnership work as well as its efficacy and place within a school's culture. I found a lack of published research studies which detailed the experiences of culturally diverse participants' experiences (students, their parents/caregivers, teachers, in-school facilitators, principals and specialists) of teachers' collaborative partnership work as a reform mechanism. Although the educational literature on teacher collaboration (as a mechanism for improving classroom practice and student outcomes) was extensive, I found the majority of readily available texts were superficial, largely ignoring issues of cultural identity and diversity, and would not be helpful for navigating 'uncharted territory'. I also discovered a confusing array of terms which had been used to define teachers' collaborative and/or partnership work, and a lack of consensus regarding definitions and/or the purposes of such work. Although I was mindful of terms such as 'teacher individuality', 'balkanisation' and 'joint work', it also concerned me that the majority of the literature remained silent on issues related to 
teachers' culture, their identities, values and beliefs, and their prior experiences in diverse social environments which had helped shape such constructions. Looking back, I can see that these available navigational charts were largely unhelpful for preparing participants (particularly teachers) to engage in a collaborative reform journey where changing the status quo for Māori students in mainstream schooling contexts was the ultimate aim. As I reflect back on my own learning as a result of this study, I realise that there is a lack of acknowledgement of the visible and less visible dimensions which I found to be powerful but largely unacknowledged and hidden influencing factors.

The following chapters give an account of my own slow learning journey; a process which required careful navigation of teachers' collaborative partnership work. Over time, several tohu (blessings and warnings) emerged which enabled me to see the visible and less visible dimensions which influenced the practice of such work; and to begin to identify an internal and external dynamic that influenced the acceptance of teachers' collaborative partnership work, and well as its efficacy and place within each school's culture. 


\section{Chapter 3. Interpreting Signs and Messages}

In this chapter, I begin my own journey of interpreting teachers' collaborative partnership work, something which required a slow and careful navigation of my own and others' thinking. As I engaged in this process, I became aware first of an account of teachers' collaborative work that appeared initially to be reflective and accepting of difference, and which looked as if it would simply and descriptively fill out a map of what this dynamic involves, the participants, the currents and eddies, the efficacy and innate goodness of it. Over time, though, I noticed significant navigational signals or messages which emerged from participant stories, and I started to view these as different tohu, signs that tohunga ${ }^{25}$ interpret as blessings or warnings from ancestral guardians and spirits (Metge, 1976, p. 93). Some of these tohu I initially interpreted as blessings, yet these signs appeared to go largely unnoticed and ignored within the context of teachers' collective reform work. Over time I came to view this too as a message about the efficacy of such partnership work, and eventually the signs re-emerged as warnings.

My analysis of the first set of teacher interviews conducted in 2003 appeared to me to indicate a way of moving forward, signalling important partnership processes on a journey of collective learning. However, after listening to participants describe their own experiences a year later (in 2004) I started to see teachers' collaborative partnership work in a different light. Although several signs helped guide my own slow journey of navigation and analysis, it eventually became clear to me that they were largely unacknowledged or ignored by the participants themselves. And then I began to see that there was a different, much more complex, largely hidden dynamic involved.

Instead of teachers' collaborative partnership work being an entity, a set of behaviours rejecting the status quo, I began to see it as superficially understood and even more superficially practised, a set of responses and behaviours that was more likely to retain and solidify the status quo of previous opinions, prejudices and power structures than forming and creating a new way of interacting, building, sharing and learning. I also noticed how the notions and practice of collaborative partnership work were not genuinely owned by the teachers themselves.

25 Metge (1976) argues that the word tohunga can be used to describe an "expert" (p. 11). A tohunga may be "an expert in esoteric knowledge" and a "specialist in communication with the spiritual world" (p. 93). 
Eventually, then, I interpreted some of my initial findings not as blessings but as warnings, and then began to see the potential hazards which lurked unseen, revealing hidden depths and dangers beneath the surface of teachers' collaborative partnership work. My analysis of participant stories revealed the influence of existing (but largely unacknowledged and hidden) power relationships which resulted in dominant, unexamined discourses. It was these discourses which I felt ultimately influenced the practice, acceptance and efficacy of teachers' collaborative partnership work, within and across both school communities.

However, I am forging ahead of myself on this journey. To tell the story properly, I need to explain why I had initially felt so much hope, and why first of all the signs looked good, like blessings rather than warnings.

\section{The Blessings: Exploring Mindsets, Beliefs and Values}

When I first conducted interviews and analysed participants' stories, I noticed responses which seemed to signal a way forward. A particular sign which appeared to me to have supported initial change was the way various teachers described how they collectively explored their values and beliefs honestly, openly and respectfully whilst examining the nature of existing teaching practice for Māori children. Twelve/17 teachers (6 Māori and 6 non-Māori) stressed that it had been important to establish the right environments for them to be able to reflect on their practice, particularly since these were not usual ways of approaching teaching within their schools. These teachers explained that an important part of developing an initial commitment to collaborative partnership work started when they felt safe to explore their "mindsets", their own beliefs and values as well as their teaching visions for Māori children within their schools:

... firstly with Te Kauhua, we had to do a lot of reculturing at our school, and that started with a vision, and that vision had to be a collective vision, so I think for us at our school, collaboration started with us changing our mindsets and changing the way that we teach and the way that we learn, and being aware of how we can do it more effectively, ... so again it was about getting everybody talking openly to see that this is how it would be able to benefit the school, and Māori children particularly ... we started collaboratively planning across the school, but I think the shared vision 
had to come through first. ... It was about accommodating each other's values, talking through our own ideas, understanding each other, having an open mind, and then developing our vision and our philosophy - and thinking, 'Well, where are we going to head to?' So that process got us on to the right path I think, and without the shared vision and a collective vision, then I don't think we would have got anywhere. (Saul, Māori teacher, 2003)

First of all, coming in here what we realised through working together and the professional development of Te Kauhua, it was about raising the achievement of Māori children but that could only [happen] through raising our own teaching standards ... well, for instance, it wasn't until now that you can see that we were actually trying to raise teaching standards by raising our own standards, our expectations of the children and what they could do. ... Because we'd been so relaxed before that, yeah, we didn't have any accountability measures, our school wasn't aligned to anything, everyone was pretty much in their own classrooms and little niches and did what they wanted to, yeah. So now it's kinda like a huge turnaround where everyone was accountable and there had to be that mindshift ... . (Herewini, Māori teacher, 2003)

Other teachers talked about the importance of examining their teaching beliefs, as well as thinking about Māori students' experiences at school:

A key part of those hui was the need for us to examine our own teaching beliefs, and to ask ourselves some key questions: 'What's it like to be Māori kid in my classroom? At our school?' And 'How do I know?' (James, non-Māori teacher, 2004)

Establishing a shared vision amongst teachers was another important factor that helped teachers commit to change:

This was an organised thing. There would have been circumstances where people got together and did things before, particularly as syndicates, but 
as a school, to focus on agreed goals for the whole school, that was a new thing ... a good thing, yes it was. It certainly helps to focus the mind and it's a good feeling to know that everybody's working towards the same thing - agreed things between everybody. It took a while to work out what our goals were, quite often, and everybody had input and felt like they contributed to [it] and in the end we had things that we all agreed to. (Elaine, non-Māori teacher, 2003)

Everyone had to make changes because people had agreed to the vision and if they didn't make changes then everyone could see that, and I don't think anyone wanted to be seen as being the weakest link or anything. (Maree, Māori teacher, 2003)

I think because we, the teachers from the science department, all went through the training together, with the Te Kauhua project either in the first or second year, we also had that vision of seeing Māori achievement being improved, particularly in science. (Julie, Māori teacher, 2003)

Herewini described the process of teachers collectively creating an ambitious goal and vision while at the same time holding a deep respect for resources within the school community:

... the vision for this school was we were going to be the leading school in New Zealand and the world in terms of the way we deliver education and in terms of Màori kaupapa, that we use the resources that are around us and are abundant in our community, that we set our plans and goals out together and then achieve them in a systematic way. (Herewini, Māori teacher, 2003)

Some participants stressed that the process of examining their personal values and beliefs in relation to their teaching practice for Māori students could be a deeply emotional, intellectual and spiritual experience. Robyn described how the difficult process of re-examining her teaching beliefs and values openly with colleagues enabled her to reconnect to cultural and spiritual beliefs that were important to her identity as a 
Māori person. She said this had led to "personal healing", as it encouraged her to examine her values in line with evidence related to existing teaching practice, developed through collective inquiry:

... within the Te Kauhua programme we [teachers] had to think ... and talk honestly together and put together our values about our teaching ... . For me it was going into myself, to look at my values and feelings about why I am here as a teacher. And what I needed to clean up for myself in order to start this, in order to start these wonderful new things and change my ways in teaching, and that wasn't an easy thing to do and I don't think it was easy for anyone to do. Because you had to admit to yourself, 'Yes, maybe I shouldn't be doing that, I could be doing it in another way, in a better way'. So for me it was a healing process, a personal healing process. (Robyn, Māori teacher, 2003)

This process of rediscovery and personal change was described as uneasy and unsettling, but Robyn believed that she had been able to "cleanse" her teaching. She described this as a deeply spiritual process, which enabled her to reconnect with her wairua:

There have been changes since our mahi on our vision ... . I think every teacher had to go through that. As I said before, it was like a healing process to come out the other side, and it's made big changes for some teachers and I talked about myself before. I've noticed we're more considerate, we respect one another a lot more, we share a lot more and we're not afraid to challenge each other. Because the way we look at things now is different to what it was before. And it was like cleansing, it's getting rid of the staleness, and for me reconnecting to my wairua, like that's how I felt. I had got to this point in my teaching which was like just, 'Do it, turn it over, turn it over', but I wasn't really doing anything for my own growth and I certainly wasn't doing anything for my children's growth. (Robyn, Māori teacher, 2003) 


\section{The Blessings: Establishing the Right Environment}

These teachers talked optimistically about their 're-visioning', their reconnection with spirituality, and with the finer purposes and aims of teaching. It seemed as if we would move together through the interview process gaining a fuller understanding of their personal and professional growth in the context of collaborative partnership work. For example, 15/17 teachers (6/7 Māori and 9/10 non-Māori) who were interviewed from across the two mainstream school sites talked about their shared experiences in the Te Kauhua professional development programme which had influenced their initial decisions to work with colleagues. Bishop and O'Sullivan (2005) note that the focus of providing professional development which results in improved practice and outcomes for Māori students must involve the entire school staff, because reform initiatives must involve a "cultural change" within the school and all teachers should feel supported and knowledgeable about new approaches (p. 6).

Many participants whom I interviewed talked about the impact of being together with colleagues from across their school in new and different learning environments, usually hui conducted on their local marae. It appeared to me that these very new and different experiences for teachers, where they had time to engage in collective discussions and inquiry regarding existing practice for Māori students, were enervating and encouraging. In these different settings, power structures were changed and unravelled, and teachers were able to relate in new ways outside of the constraints of the school and all its entrenched hierarchies and expectations:

It was incredibly important sharing those experiences together as teachers and then coming back to school and trialling activities in class ... certainly in terms of learning from my colleagues, Māori and non-Māori at the hui, ... and being in a environment where that kind of discussion was not only encouraged, it was heavily encouraged, because that is why we were there, and it was a chance to sit down and look at learning strategies for Māori students in a way that we have never really done much of before. (Andrew, non-Māori teacher, 2003)

We did things ... like we went up to the local marae, we spent two days up there and we looked at what had worked successfully, culturally for our 
Māori children. We looked at what was best practice and we shared our own ideas. (Principal 1, 2003)

... you were in the same place, umm, with the same goal for four days, umm, and it was new, it was exciting, we were being introduced to new learning and teaching strategies, and being challenged to think about how we catered for Māori kids ... we talked over drinks and stuff, we shared ideas and got to know people. (Leanne, non-Māori teacher, 2003)

I think the best experience was working with teachers, Māori and nonMàori from the same school, as part of two in-service huis, part of Te Kauhua. And it was the interaction with my colleagues that was so good. It was a new experience for me here at this school. The quality of the interactions, discussing ideas, sharing our own thoughts and ideas, having a look at what was presented to us on the course, and the fact that we shared that experience together, a group of us. (John, non-Māori teacher, 2003)

Sharing thoughts about what was happening at the hui was really incredible ... we had time to meet and talk as colleagues and just sharing that experience with staff back at the school was really powerful ... so a group of us came back from that professional development really inspired and wanting to make a difference ... and that's important too, having a group of committed teachers who came back wanting to try and do things differently ... . (James, non-Māori teacher, 2003)

Just the informal sitting down with other teachers [Māori and nonMāori], whether at the meal table or between sessions and we're discussing what points of view we have on what has been put before you ... it was interesting hearing other people's points of view and we talked with people across departments, which we don't usually do at school. (Max, non-Māori teacher, 2003) 
These accounts of meetings, of barriers dropping, of sharing and visioning, seemed to be indicative of a 'cultural change', of an environment which could nurture new collaborative attitudes and behaviours. The signs looked good.

\section{The Blessings: Awakening, Understanding and Listening}

Teachers told me about engaging in collaborative inquiry and responding to challenges to their personal beliefs and prejudices that came from taking part in creating a shared vision and in action research. Different social activities within the context of the Te Kauhua professional development hui had affected some of them in very individual, deeply personal and emotional ways. By being outside of the normal school environment and culture, the Te Kauhua professional development programme created spaces for culturally diverse participants to speak about their experiences and interpretations of mainstream schooling. In this setting, they told and listened to stories about their classroom, teaching and school experiences; but it was not only the telling of stories and the face-to-face honesty that was crucial, it was also the reception of and openness to the stories of others. While 15/17 teachers from across two very different school contexts were aware of the importance of sharing in the Te Kauhua professional development programme, 10/15 teachers (5 Māori and 5 non-Māori) from both school communities described how their thinking was transformed when they listened to the experiences of others involved in the whole school setting.

It was clear at this stage of the research that a change in teacher thinking had occurred, not through familiarisation with the results of achievement scores, examining test results or reading the latest research on best practice for culturally diverse groups (although any of these may have had an impact), but through teachers' engagement in a different form of collaborative partnership work. What was crucial was the impact of teachers listening to culturally diverse voices (not typically heard in discussions of effectiveness of classroom and school reform) speaking about their own experiences of mainstream schooling practices:

... it was listening to the stories of kaumatua and of Māori students at the hui and hearing their experiences of being in mainstream classrooms ... so those huis were really powerful and I could see how classes were for Māori kids ... it made me see my teaching quite differently ... . (James, non-Māori teacher, 2003) 
But having listened to the commentaries, the voices of Mãori students and realising now that my whole teaching delivery was uncomfortable, suddenly the problem was there for me, and I haven't got solutions I know, but at least I see it. I couldn't see the problem before. My eyes have been opened to that, I don't think I am alone, and we haven't solved it yet, it is huge. But let's start identifying what the problem is, and the problem doesn't necessarily sit out there ... , it sits here within us as teachers. (Andrew, non-Māori teacher, 2003)

I was interested in the descriptions that these teachers used, as if they had existed in a state of unconsciousness which some described as a kind of blindness, and had then experienced an uncomfortable awakening from a deep sleep. It seemed that the experience of 'seeing' their classroom practice through another pair of eyes was very empowering and was not something that they would easily forget:

... it was listening at the hui, and seeing how classes were for many Māori students, and from their grandparents' perspectives and becoming more aware, more of what the cultural differences are ... . It was somebody from outside in the local Mãori community, a kaumatua who spoke and some of the Māori staff spoke, it made me aware of what my downfall had been, my lack of cultural knowledge. I picked up so much more, and it made me rethink about why I was at the hui, it made me realise what does go on in my classes and rethink how I approach teaching ... and the way I had been treating students prior to this. (Max, non-Māori teacher, 2003)

I started to realise that something significant had happened to these teachers, something that had clearly touched them and stirred a new level of consciousness in them. It interested me that many of them referred to their personal transformations in the language of metaphor. They used such descriptions as "my eyes opened", "[it] woke us up", "[I] saw for the first time", and I wondered about collaborative processes which might fail to awaken teachers. Other participants who were interviewed also noted that it had been an 'eye-opening' experience for some teachers: 
I have been to a couple of their huis, down at the wharenui, where ... some of the teachers talked ... and basically I think it's been an eye-opener for the teachers from their point of view, learning about the needs of Mãori students. (Mr Huia, parent/caregiver of Māori children, 2004)

Seeing their classroom practice from culturally diverse perspectives enabled these teachers to re-examine and think about their teaching differently. It gave them a different perspective, a better sense of empathy, while at the same time it was also an unsettling experience. The openness these teachers expressed towards their involvement in these professional development programmes also looked like a good sign.

\section{The Blessings: Real/Honest Heart-felt Stories}

Participants described listening to the heart-felt stories of others, to stories told by elders, young people, children and colleagues. These stories had a huge impact and evoked emotional responses in those who listened to them. Being opened in this way, participants were able to listen better and to hear and accept the reality of others' experiences:

I had had some difficulty with a particular teacher from the very first day when I came here to this school ... . I had got a sarcastic comment from this person and I felt that I couldn't warm to this person, but at the hui she did something that ... really moved, touched and inspired me, and my relationship with her has been different ever since ... . Something happened at the hui for her and she spoke from the heart about how she'd realised that her teaching needed to change for Māori kids, that she'd had this revelation and she was very open and honest in sharing that with us. I mean, she's not the sort of person I'd choose to hang out with or anything but, umm, I was blown away by that and I thought she's got some skills that would be useful to me and she's been helpful to me ... . (Heria, Māori teacher, 2003)

... one of the most powerful moments we had as teachers was on the professional development hui which was the beginning session ... and we listened to kaumatua talk about their experiences of school but more 
importantly their grandchildren's experiences and what they had seen and how there was this degree of alienation and what they had experienced of mainstream schools, teachers and classrooms, and it was heartfelt ... . I don't think I've ever quite heard it that way, I mean I've read it, but it was powerful just listening because it was coming from very real people in your own community speaking ... about their experiences of trying to fit in with a system which can be quite harsh on people ... . I guess it's just hearing it from their point of view in quite a natural situation, you know, where people were being honest. So that moment was quite defining for me. (Max, non-Māori teacher, 2003)

I was struck by the similarities of these teachers' accounts. It was clear that teachers from two very different mainstream schooling sites had experienced similar transformations in thinking. These teachers told me in separate interviews that they had been able to re-think and re-examine the effectiveness of their practice for culturally diverse groups of learners through a simple act of listening, a process which involved seeing their classroom practice from diverse perspectives:

... one of the things that the professional development has forced me to do is to re-evaluate where I am, about my own competence for the rest of my career, about what I'm doing as a teacher for those kids who aren't really achieving, and for whom the techniques that I have used so far don't match their learning style ... . Now I am beginning to understand the surface of this thing called non-achievement, not just for Māori students, for other students who I haven't thought of before ... now that I have come to understand that they want to learn, all those excuses that we bandied around before, 'I have done all I can, now it is up to them'. ... I guess that I would have been classed in the mould of the traditional teacher ... . I have always been fairly good at standing up there at the front of the class, telling the stories, illustrating the point and so on. And in many ways, that was the thing that attracted me into the profession. I had a captive audience and there I was at the front of the class, but now I am refocusing my position in the classroom away from me being the fountain of knowledge, and using the pre-knowledge of the children and co- 
constructing things with the kids, and finding out what is out there for a start, and understanding that children can communicate ideas to each other better than I can. That was a bit humbling, but it is working. The kids learn from each other a lot better than from me. (Andrew, non-Māori teacher, 2004)

A number of participants (facilitators, principals, Māori students and parents and caregivers of Māori children, as well as teachers) from across both schools acknowledged the impact of narratives and stories on teachers' thinking:

... the teachers are more on board and committed to working together and it's been through that process of hearing kaumatua talk on the marae, and the stories from Māori students, seeing how school was for them. One colleague in particular came back really inspired, more than I have ever seen anybody else ... And they have trialled new ideas into their classes and are amazed at how their class dynamics have turned around, which is great ... . (Max, non-Māori teacher, 2003)

\section{The Blessings: Examining Contradictions of Practice in a Context of Collaborative Inquiry}

Some teachers described what it meant to engage in action research and/or collaborative inquiry with others. These activities appeared to focus them on examining evidence of practice and listening to culturally diverse voices, whilst also identifying and talking through their beliefs about effective teaching. Description, discussion and analysis in this wider setting appeared to allow them to weigh up and hold a sense of contradiction between belief and practice, and between practice and needs; and between what they thought they were doing as they taught compared to their teaching beliefs (what had gone before) and their teaching outcomes (what their teaching led to):

Some of that was really tough data ... data coming from teachers and particularly from their Māori students. Teachers confessing that it was all on top of them and they couldn't do it, teachers believing one thing about their teaching and then having students giving data that absolutely 
opposed their beliefs, and teachers having to confront that gap. (In-school Facilitator 2, 2003)

One of the facilitators explained the process:

We used action research as a tool to ensure that it was going to happen ... . So I worked really hard and I did a lot of data gathering, particularly with the students in the senior classrooms and feeding their views and perspectives back to the teachers in that syndicate ... . I interviewed three groups of Māori students from the three classes involved in the senior syndicate, to find out what they liked and disliked about school, what they liked or disliked about their teacher, and just generally what they thought about what was happening in the classroom and in the school. This information was then structured in a way to protect the children's identity. (In-school Facilitator 2, 2003)

Reading the perspectives of children from his classroom had a profound effect on Saul, a young Māori teacher. When I interviewed him, his use of language revealed a lot about the revisioning that occurred in the juxtaposition between expectations and outcomes, and beliefs and practice. He talked about "waking up" to the needs of learners in his classroom, of "realising" and "seeing". He believed that this experience enabled teachers within the syndicate to re-think their classroom practice and work to "hook" children into learning:

We undertook an action research through Te Kauhua, with the help of the facilitator. She took notes, anecdotal notes, of all of our meetings for three months, and she interviewed the children in our classrooms and then she gave us back the information, and we read it and we, the teachers, were really amazed and dumbfounded, we actually were blown away. ...

Looking [at], reading what the children had said, woke us up, the teachers, and made us realise that, yes, we had to do a better job, so that got us into the thinking that, yeah, we need to provide the children with more powerful learning experiences so that we can hook everybody in our classes ... . So I think viewing the information provided by the children 
from the action research and by seeing the results, seeing the results in the children, seeing that they were interested in learning, but it was reading the language from the children that made a difference to teachers. (Saul, Māori teacher, 2003)

Just as his own language indicated the multi-layered nature of his reflective practice, Saul believed that it was the language of the children which had enabled teachers in his syndicate to confront some of their assumptions about the effectiveness of their classroom practice and how well they were responding to the needs of culturally diverse groups of children:

... the action research approach allowed us to reflect on what we were doing, and allowed us to be very critical of what we do. However, the $x$ factor was the language from the children .... So I think viewing the information provided by the children from the action research ... and reading the language from the children made a powerful difference. (Saul, Māori teacher, 2003)

Another Māori teacher from the same syndicate described his experience of engaging in this action research project. He felt the perspectives of the children enabled him to "own up to the truth", and to look at his behaviour in the classroom, his preparedness and also his presentness:

I loved the action research because it made me look at myself as a teacher. And, umm, the facilitator was implementing the stuff at the time and told me about it and I thought, 'Oh yeah! That's cool. That's cool'. But when it came to implementing it in your classroom, it was hard because you had to own up to yourself as a teacher, you know, own up to the truth of it's not the kids being naughty, it's you not being prepared. Or you not turning up to class being onto it and all organised. So it's looking at yourself first before you look at other issues within the class, making sure you can eliminate anything you may be contributing to in terms of your own teaching, before you start pointing the finger, and that's the 
biggest learning curve for me, coming from the action research that I found. (Herewini, Māori teacher, 2003)

Other teachers who were interviewed explained that they were aware of trying to work with colleagues in a spirit of inquiry, and that this openness challenged them to rethink their teaching assumptions, particularly as they related to the teaching of Māori students and their ability to engage in learning activities within the classroom. Andrew described his sense of shock following an in-class observation template as he observed a colleague teach. He explained that he was amazed as he watched a particular student become engaged in his colleague's class, something which, because of his own experience with this student, he would never have expected:

I got totally engaged myself in observing things which weren't necessarily on the observation template because my mind was just focused on other things ... . I was just fascinated by something that was happening in front of me, seeing this one particular kid who hasn't achieved much for me ... doing so well in another subject ... it was absolutely fascinating for me. I didn't suspect he would achieve in Max's class but he did! ... I found it was a bit of a shock. (Andrew, non-Māori teacher, 2003)

These teachers, by entering into the collaborative environment, were opened up to surprises, unexpected juxtapositions and challenges. They were mostly prepared to reel in the face of these surprises, and to accept the contradictions as possible signs of change and growth.

It appeared from my analysis that particular collaborative partnership processes developed through the Te Kauhua professional development programme, and particularly the hui, had created the space for culturally diverse participants (Māori children and young people, kaumatua and kuia, from primary and secondary settings) to talk about their own lived experience of mainstream schooling/classroom practice; and, in turn, that this talking had had a profound effect on the thinking and actions of a particular group of teachers even though they worked in very different schooling and practice contexts (primary and secondary). 
Hemi was one Māori student who was able to identify student contributions to developments in teachers' practice, and to express some of the reformative changes that could be brought about through such processes:

... we made suggestions to teachers on a survey, like not to have such a boring period, ... [and later] ... and so we'd just tell them [the teachers] about those things which helped us ... what we wanted, and ... we'd just give them ideas, like ... talking to us instead of just telling us without explaining it, and like helping us try and understand why we're doing this, what this is helping us for, 'cause usually if people don't want to do stuff in class or if they play up, there's a reason. (Hemi, Yr 11 Māori student, 2004)

Other participants who were interviewed also stressed the importance and impact of different Māori participants' engagement in the development of teachers' collaborative partnership work:

... there's a couple of kaumatua that are involved, ... and one has a lot to do with helping teachers ... and he's been strongly involved with the Te Kauhua project and actually working with the teachers on the marae. He's established a very strong rapport, and I think that helps. (Mr Huia, parent/caregiver of Māori child, 2004)

I searched for literature which would help me make sense of these experiences, and I found a number of competing theories. Firstly, I found a number of authors who had argued that existing teacher beliefs can be changed through evidence-based processes (Goodman, Baron \& Myers, 2005; Timperley, 2003; Timperley \& Parr, 2004). The importance of cognitive dissonance in professional learning has been highlighted (AltonLee, 2005). According to Henderson \& Hawthorne (1995), cognitive dissonance can be described as a discomforting feeling when a person experiences information that they perceive to be in conflict with their fundamental beliefs. McInerney and McInerney have called it an "unpleasant tension" in thinking which can occur when individuals confront incompatible thoughts (2002, p. 311). Many of the research participants were in fact 
describing feelings that can be interpreted as cognitive dissonance in the light of this scholarship.

Certainly some of the teachers themselves used descriptions that related to "uncomfortable" feelings as they confronted old assumptions during the professional development programme. I was interested to read about "persuasive communication", which involves "an expert source of knowledge, honesty, sincerity and relevance" in the development of cognitive dissonance (McInerney \& McInerney, 2002, p. 311). In discussing qualities of communities of practice, Wenger (2005) has argued that we need "dislocations" in thinking in order to learn and relearn. He makes the point that there is great potential for learning when the practices of different cultural groups collide. He maintains strongly that during such collisions there is often conflict, misunderstanding and emotional upheaval but there are also extensive learning opportunities. Wenger argues that this upheaval is due to our assumptions being dislocated through different interpretations of competence and that it is only through this uncomfortable process that these assumptions can be rethought. Johnson and Bush have also stated that schools can develop culturally responsive practice only through a process of listening to the voices of culturally diverse participants (students, parents and teachers), because their voices "contain essential data for shaping reform strategies" (2005, p. 292). Listening can be more powerful than examining "mounds of quantitative data", according to Johnson and Bush (2005, p. 292).

It interested me that while I had been asking teachers to describe their experiences of working collaboratively with peers in improving classroom practice, focusing perhaps on the pedagogy of such experiences, evidence suggested that it was other expressions of partnership that had made an impact on many teachers' thinking and on the development of their collaborative partnership work within and across both school communities. By other forms of partnership, I am referring to the participation of culturally diverse participants in school and non-school settings (Māori students, their parents/caregivers, kaumatua and kuia, as well as teaching peers) in a spirit of openness that allows these voices to impact on the thinking of many teachers within and across both school communities.

I discovered that the act of listening can be interpreted as a political act (Bishop \& Glynn, 1999; Fine \& Weiss, 2005; Jones, 2001); and voice as an expression of 
knowledge and power (Smyth, 1999; Wenger, 2005). ${ }^{26}$ Jones (2001) has argued that "voice" is at the heart of dialogic pedagogy (p. 30). She stresses that the most significant act is not through the process of telling stories, but "the hearing of those stories" (emphasis of the author) (Jones, 2001, p. 30):

... the call for dialogue or border crossing is not a call for voices to speak. Instead it is really a call for the members of powerful groups to listen to the usually excluded, suppressed and marginalised voices. (2001, p. 30)

\section{The Blessings: Ownership, Voice and Choice}

Teacher ownership in collaborative partnership work was considered important for influencing engagement by many participants who were interviewed. Some explained that responsibility for improvement was required of all teachers within the school if progress was to be made, and that this involved a process of inquiry into teachers' own beliefs and values:

... we went through that whole process of, like, asking questions: What do we believe in terms of teaching and learning? What do we want for all of our kids? All of those kinds of things, and then there were surveys and things filled out by teachers and that was all collated and put together and it came out as a set of teaching beliefs which I think was a reasonable reflection of what they wanted ... . And the good thing about that was that we could say, 'Well, we all agreed', you know, it's not like the principal said you have to do this ... and I guess that was the first time the school had ever come to that point of 'We agree on this', or in this school we do this because we believe in it. (In-school Facilitator 2, 2003)

We have had a lot of professional development days previously, there had been teacher-only days, but the facilitator came and talked to us and

26 I would like to acknowledge concerns expressed by some authors that voice also co-exists with the notion of silence (Fine \& Weiss, 2005; Jones, 2001; Smith, G., 2002). Many participants who were interviewed (particularly Year 11 Māori students and parents and caregivers of Māori students in both schools) acknowledged that they knew of Māori families and/or students who had given up trying to be heard in discussions of mainstream schooling practice. 
presented the programme to us and some of us, we chose to come on board. (Leanne, non-Māori teacher, 2003)

... we're not now passing the buck onto one person that has to deal with all of it, you know, it's now, 'Let's all help, let's all deal with it, we're not leaving it to the senior management to find all the answers', you know. We're saying, 'Well, we don't have all the answers but let's all develop them together', 'cause the senior management don't have all the answers either, you know. So now we're moving, I think, to a time where we're more collective in our thinking, we're all balancing out, you know, we each have different roles, we're balancing that out, and we're not leaving it up to just that one person to deal with, we're dealing with it together. (Saul, Māori teacher, 2003)

... this is an issue for all of us as teachers, it's not just for non-Māori teachers and it's not just for Māori teachers and it's not just one department's responsibility in the school. If you don't get all of the departments, then everyone thinks that it's only the role of one department or seven people, it's not our problem, but, yeah, it's more about the direction that our school is heading in, and all of us owning the work. (Inschool Facilitator 1, 2003)

All of the teachers (17/17) who were interviewed believed it was important for them to have ownership, to have a voice and share in decision-making processes if the goal was to improve the quality of teaching practice and outcomes for Māori students. Participating in decision-making processes as part of the Te Kauhua professional development was important for influencing teachers' engagement in such reform work, according to this participant:

I know there were lots of consultations during staff meetings, where both Māori and non-Māori teachers could express their feelings and talk about what they wanted and what they thought and what they wanted for the school, and where it would take the school. (Mrs Gay, parent/caregiver of non-Māori child, 2004) 
Drawing on teachers' own strengths and on different forms of teacher knowledge was seen to be pivotal to give teachers the sort of reciprocal support necessary to improve aspects of practice, according to the participants who were interviewed. This required teachers to share their own ideas and make decisions collaboratively:

... collaboratively planning together Māori and non-Māori teachers was the best thing and that worked well because we targeted the strengths of each teacher. That made the teacher develop their ideas the way they wanted to, and it helped the children be with that teacher on a learning rotation. ... One topic that we did was 'Bridges' ... and we drew on Māori and non-Màori local knowledge about different bridges and the names and how the names were given, ... so we targeted different strengths of teachers, ... and we had the students broken up into teams, not classrooms, so you had children working with peers in mixed levels. Now that process worked a treat. When we reflected on it, and asked the children, they enjoyed the experience. They had four different teachers for four different activities. The children said that their learning was in context with our local township because we ... didn't talk about any other bridges except these ones here in the town. (Saul, Māori teacher, 2003)

One unit we did really well, it was the unit on 'The Bridges'. And we all had our say, the teachers, and we all talked and shared our ideas, and we met and decided how we'd do it and we all managed the activities and it was great. And the kids were really into it, ... and we incorporated Māori and non-Màori local knowledge into that unit and the kids were really interested. (Herewini, Māori teacher, 2003)

One of the principals believed at the time of his initial interview that there was more of a focus on shared teacher ownership of collaborative reform activities within the school:

I have made probably the last authoritarian decision of my life ... [and later] and that's part of our school culture now, we're working together ... . For example, we have one teacher who is responsible for reading and 
who is released on a regular basis to work with teachers on reading programmes. We are trying to get a reading programme that is consistent throughout the school. ... He has put together a reading programme and he is working alongside teachers in their classrooms, observing and giving feedback and modelling different approaches ... . Now, the beauty of this is that I'm not taking ownership of it, ... I support him and he comes in and he talks to me about what he sees but I don't have to take ownership of it ... . Now, what a wonderful learning experience for him and what a marvellous thing for me to be able to listen to the growth that this teacher is showing and know that I'm not dictating and it's just great, I find this really exciting. (Principal 2, non-Māori, 2003)

These participant stories highlighted themes related to teachers' ownership and seemed to stress the importance of teachers' voices as impacting on their engagement in new, collaborative partnership work within and across both school communities. Being able to exercise power and to have a voice within collaborative partnership activities appeared to be an important framework for encouraging teachers' engagement, according to those teachers who were interviewed. And the signs suggested that this ownership was real and efficacious.

\section{The Blessings: Valuing Voices Not Usually Heard}

While all teachers who were interviewed (17/17) believed it was important for them to have a voice in the structuring of collaborative partnership reform work, Māori teachers who were interviewed explained that it was very unusual practice for them to have a voice and to be listened to within their school communities:

This was a very new situation for us as Mãori teachers at this school ... for us to feel our voices are valued and to be consulted, to be asked our views. (Herewini, Māori teacher, 2003)

Heria explained that it was unusual for senior management to trust Māori staff members and Māori whānau to make decisions within a context of professional development: 
It is very rare to have the senior management of a school trusting the Māori staff and the Māori whānau to make decisions, which best fit their needs ... usually it's got to be balanced up against what can fit in the school organisation, you know ... . (Heria, Māori teacher, 2003)

The recent appointment of a new Māori teacher to one of the school's senior management teams was important for ensuring a Māori voice was represented in the work of reform, according to Herewini:

Because he is a member of the senior management team, we now have that voice there ... that's awesome, he can bring up issues for us ... . One thing that has really changed had been the accountability of assessments in terms of where the children are in reading that's improved, the writing continuum, the maths results in terms of the numeracy project that we've got. We have got te reo Māori, that's one of things that we have got built into our appraisal now, and we were having to show that we are making changes because there has been an attitude of apathy here towards those sorts of things. But now it's like, well, you have to step up to the mark and do them. (Herewini, Māori teacher, 2003)

It appeared from my analysis of participant stories that issues of representation and voice were particularly important factors that impacted on the way teachers viewed and/or engaged in collaborative work over time. Within the discourse on educational reform, I knew that voice is related to politics: "who gets to speak ... and who gets listened to is an artefact of power" (Smyth, 1999, p. 74). I learned that voice is a political and complex issue within communities of practice, because voice makes claims to knowledge (Fine \& Weiss, 2005; Freire, 1998; Wenger, 2005). Freire's notion of dialogical communication (1998) highlights voice because the development of democratic life requires participants' critical engagement with ideas through dialogue. Such dialogue demands participant engagement, and does not occur if different parties choose silence, or when those in positions of power impose their views. The concepts of voice and dialogue can act as pedagogical tools for democratic purposes, uncovering whose ideas are represented, and whose are left out, submerged and/or marginalised 
(Freire, 1998; Sleeter \& Delgado-Bernal, 2004). Some theorists have argued strongly that students must be invited to speak as cultural interpreters of mainstream schooling and classroom practice (Bishop, Berryman, Tiakiwai \& Richards, 2003; Fine \& Weiss, 2005; Shields, 1999).

I learned that many Māori teachers had not felt listened to and/or respected by their non-Māori colleagues prior to their schools becoming engaged in the Te Kauhua professional development. These teachers' experiences appeared identical to the study results which had previously described Māori teachers' experiences in mainstream schools (Bloor, 1996; Cram, Smith, Smith, \& Tunks, 1999; Mitchell \& Mitchell, $1993^{27}$ ). Robyn believed that the Te Kauhua professional development process had been a very different form of professional learning which had encouraged Māori teachers to have a voice within the context of reform:

We met, the Māori staff as a collective, and our Deputy Principal put it to staff and we had a talk about it in the staffroom ... . Māori students have Māori names that might go back to their tipuna and they have meaning. Pronunciation of children's names, learning and acknowledging their cultural side is very important as well as learning about the holistic way we learn. ... with my colleagues to look at that as a value aspect, they would most probably gain respect and build a relationship with that child a lot quicker if they realise how important understanding the child's culture is. ... I suppose because as a Màori collective of the school we are not going to sit back anymore and see our Pakeha colleagues tell us what's best for Māori. That's where it lies for me. (Robyn, Māori teacher, 2003)

I saw many messages embedded within participant stories which emphasised particular partnership mechanisms and processes which had influenced the practice of teachers' collaborative partnership work and its acceptance within each school community. Bishop and Glynn have highlighted the power of stories of culturally diverse participants in educators' research and professional learning as a "culturally located and culturally legitimated process", which connects participants in a collaborative learning

27 For further information on these studies, refer back to Chapter 2. 
process $(1999$, p. 123). I felt that this was very new and uncharted territory as teachers were not used to working with culturally diverse colleagues from across their schools to improve practice and outcomes for equally diverse students. It interested me that the established school social practices had ensured that some teachers and other participants had historically experienced less 'voice' and less power within their school communities. Participant stories indicated that such practices and the beliefs and values which underpinned them remained unacknowledged and unexamined over time. I became gradually aware of what I felt were less visible currents and tensions fuelled by unexamined and largely deficit and dominant beliefs, values and activities which made up each of the school's existing cultures.

Suggestions from my data about the importance of the role of all participants were corroborated in my reading as well. Whereas teachers have a clearly pivotal role in the delivery of school programmes, whether in a context of reform or not, the significance of what students, parents/caregivers and other community members said during my interviews with them was such that I was alert to their inclusion as change agents and stakeholders in the literature also. A number of educational researchers in Aotearoa/New Zealand and overseas have stated that teachers in schools can connect with students in conversations about their learning, their motivations and their difficulties, and their ideas for improvement of practice (Bishop, Berryman, Tiakiwai \& Richards, 2003; Bishop \& Glynn, 1999; Fullan; 2005; Fullan \& Hargreaves, 1998; Johnson \& Bush, 2005; Ladson-Billings, 2001; McFarlane, 2004; Senge, Cambron-McCabe, Lucas, Smith, Dutton, \& Kleiner, 2000; Shields, 1999; Shields, Bishop \& Mazawi, 2005; Shultz \& Cook-Satler, 2001). Students have valuable pedagogical insights into teaching and learning activities, yet their voices are often silenced in discussions about classroom and school reform (Fine \& Weiss, 2005; Shields, 1999; Shields, Bishop \& Mazawi, 2005). Bishop, Berryman, Tiakiwai \& Richards state that Māori students can provide solutions in our quest to improve existing teaching practices that would enable them to engage in learning more effectively (2003, p. 95). Different models of culturally relevant or responsive teaching, Ladson-Billings (1995) has argued, start with the premise that culturally diverse students pose opportunities instead of problems for teachers. And indeed, interviews with students from across both school communities emphasised that they had unique perspectives about the work of reform over time.

On the other hand, Penetito (2001) has argued that local whānau/hapū/iwi must decide the knowledge that should be made available for teaching and evaluation purposes 
in the classroom as well as how such knowledge should be made accessible for teachers. He warns that while Māori have prioritised the survival of te reo as a main focus for the future, a "holistic approach" to education would require participants to consider questions such as:

- "what counts as knowledge" (matauranga);

- "what counts as pedagogy" (whakakoranga); and

- “what it means to be Māori” (Mana Māori) (Penetito, 2001, p. 299).

As Penetito has warned, improvement in outcomes for Māori students can come about only through collaborative work and participatory learning between teachers/schools and local whānau/hapū/iwi. At this point, I felt there was a lot of hope for the future, as teachers' collaborative partnership work appeared to have extended to include the voices and diverse perspectives of Māori teachers, Māori students and their parents/caregivers, elders and local community members.

Thus, in their first discussions of their immersion in collaborative partnership work, teachers talked excitedly about becoming aware of their mindsets, beliefs and values, the things they unconsciously brought into their teaching practice. As they engaged in developing a shared vision in what was apparently a new, safe and expansive environment, they were awakened to other ways of seeing and were confronted with contradictions that appeared to provide vehicles for reform and growth. They became aware of the importance of the language of their peers as well as their students and the elders from their communities, and how words often provide wise and diverse metaphors, signs and signals. They were awed to find themselves not only hearing (a uni-directional process) but also listening (a bi-directional dynamic). They optimistically felt involved because of the stirrings of their heartstrings, and believed themselves in full ownership of the collaborative partnership work.

\section{The Gathering of the Blessings}

When I first interviewed teachers from across both school communities in 2003, there appeared to be much potential for change. My own observations were supported by many parents/caregivers of Māori students who talked during the interviews about seeing teachers excited and enthusiastic in their collective reform efforts. Twelve/15 
parents/caregivers of Māori children who were interviewed from both schools believed that teachers had engaged together in a very different form of professional development. It was unusual for these whānau members to see this level of excitement and enthusiasm when teachers talked about their expectations and aspirations for Māori children:

I actually have observed the teachers working together, ... oh, it was good to see actually, and it wasn't normal to see that, for non-Māori and Māori teachers working together the way they were, to see that was really good ... and they'd been wanting to have good korero, and there was a good interaction of ideas, and it flowed. I thought it was good to see Māori and non-Māori teachers talking together with us and sharing their ideas about what they were trying to do to improve their teaching for our tamariki. ... when I was at school which was some years ago, we didn't see that ... type of teacher interaction, so it was quite, you know, new to me to see nonMāori teachers wanting to work with Māori teachers and whānau, that they were interacting for the good of the children, like the way they were and just trying different things out, that they were willing to do that, to try new things out in their classrooms to help the children, so that was a good thing, really positive, and it made me think that the teachers were quite serious about this. (Mrs Pio, parent/caregiver of Māori child, 2004)

... well, the Te Kauhua teacher presentations was very new for me to see, and I don't think we've ever had Pakeha teachers talk to us in this way before, who had this sort of professional development hui, this sort of new experience, because it sounded as if this was quite a different professional learning for them ... and they were quite excited and enthusiastic about the mahi. (Mr Tui, parent/caregiver of Māori child, 2004)

Well, it was good to see the teachers really excited, especially since this was a programme for Māori and non-Māori teachers, and just encouraging that bicultural perspective. ... The teachers were excited about the programme, and bringing in our young Māori children through the system and trying to get them to achieve higher results and just to really help them up and succeed ... . From my point of view, it's something 
that's been quite important for a long time, the fact that most of us know that if you're expected to be successful, and pushed to succeed - then you've got more of a chance ... so it's about creating positive learning environments for our Māori students. (Mr Tumu, parent/caregiver of Māori child, 2004)

Fourteen teachers (7 Māori and 7 non-Māori) explained that the incorporation of Māori cultural values, language and/or practices had been an important element of teachers' collaborative partnership work. For example, 7/10 non-Māori teachers explained that they were now talking more openly with Māori staff members and seeking their support to improve aspects of their pedagogy. Participants identified improvements in practice as:

- demonstrating a respect for Māori culture by incorporating a cultural dimension within teaching practice;

- pronouncing Māori students' names correctly;

- a focus on improving relationships, including teacher-student, student-student, teacher-parents/caregivers;

- valuing Māori children's prior knowledge and drawing on this knowledge in learning contexts;

- co-construction and/or power-sharing strategies with students;

- cooperative learning / collaborative teaching methods; and

- raising teacher expectations.

At the time of my first interviews, it seemed that teachers had been working together in new and very different ways with a focus on improving classroom practice and outcomes for Māori students. Participants told me that teachers had been seeking support from their colleagues and that there had been an attempt to develop a more open and inclusive school environment where teachers felt comfortable and confident to ask questions, take risks and experiment with new teaching approaches:

Well, one of the really good things is it's given me the confidence or permission to ask questions and to seek out support of my Māori 
colleagues. So I've asked some of the Māori staff here about my pronunciation of words and students' names and also just talking to them about cultural differences in relation to students' needs ... So that's been really useful for me. (Leanne, non-Māori teacher, 2003)

... I do often talk to the Māori staff, particularly with the pronunciation of students' names, also some of the information that we get about Te Kauhua is in Màori and I have a basic understanding of some of the words, but I do need clarification of the understanding, and I talk to them about that. It is difficult in my subject area to use a lot of Māori terminology, because it is so much closer to the European. It is mainly in the greetings and the students' names, showing the respect for the culture, and the way to talk to the students in class, that has been the biggest factor that I have faced, and it has been a big challenge for me ... and my Māori colleagues have supported me with this. (Max, non-Māori teacher, 2003)

I've talked to Māori staff about Māori students in my classroom, about my pronunciation of Mäori students' names and about how I can incorporate cultural elements more successfully into my teaching ... it's a reciprocal thing too, though, learning - I've been asked by some Māori teachers if they can come in and watch me teach. I think we are taking more responsibility for Māori students as teachers, their success or lack of it in some cases ... . I am working on my pronunciation, the kids are good, they tell me when I am saying things wrong ... . I mean, I've told them to and that's good. That's part of the feedback from them and the friendliness and the openness ... learning the Māori language pushes the comfort zone when I have to publicly repeat it back at times. It's just fear of failure, I guess, the fear of embarrassment ... . I'm also pushing them more and raising my expectations, and encouraging kids: 'I know you can get to here’. (James, non-Māori teacher, 2003)

When I had first listened to participant stories, I felt that there was increased teacher collaboration in both schools, reflected in a close examination of teachers' planning and classroom practice for Māori students: 
... there was a feeling amongst our Māori teachers that the teachers' understanding of te reo me ona tikanga Māori wasn't really there. And although some people could say their mihi and although there are benchmarks for Māori in the school, they weren't necessarily being followed in an effective way. And although there has to be an input of Māori into any planning, unit planning, it was kind of not receiving lipservice but it was certainly secondary to anything else that occurred. (Principal 2, 2003)

Well, we were meeting together as a group of teachers to plan an integrated approach, English, social studies, maths and science, and ... we're trying to incorporate culture into the classroom programme, the Māori deities, so they [teachers] looked up a legend in English and then they looked at them in social studies as modern day characters affecting the modern day running of Mãori society at the moment, ... that was the planning focus ... the teachers were trying to plan that together. And then also getting the students to take part, and be involved in the decisionmaking, to co-construct what they would learn. ... For science they did the science of the wind and the fire and those things ... so it's more of a themed approach, holistic learning experience, and then the idea was that they would do it outside the classroom ... so teachers were really planning together across their curriculum areas, seeing how they could involve more of the children's culture and knowledge into the learning activities. (Resource Teacher of Learning \& Behaviour 1, 2004)

Twelve/15 Māori students who were interviewed from both schools told me that they had noticed that non-Māori teachers had been working with Māori teachers to improve their pronunciation of Māori students' names and/or increase their knowledge and use of te reo me ona tikanga:

I did hear one of my Pakeha teachers asking Whaea about pronunciation, ... and we heard him asking questions to her about karakia and stuff. (Hemi, Yr 11 Māori student, 2004) 
Pakeha teachers are learning from Māori teachers, how to do karakias and te reo and that sort of stuff. Oh, it's quite good, because the Māori teachers are teaching the other teachers to do all sorts of stuff in their classrooms with their kids. ... It's quite cool because then teachers can teach the same things in their classrooms as the Māori teachers taught them. So kids learn te reo and how to pronounce words properly. (Aroha, Yr 5 Māori student, 2004)

Many Māori students who were interviewed talked to me about the impact of nonMāori teachers learning to pronounce their names correctly. These students explained some of the personal consequences of teachers mispronouncing their names in class, such as the fact that they could be distracted from learning:

Some Pakeha teachers have been really trying how to pronounce my name correctly, that's a big one, especially with my name, 'cause, you know, it is pretty hard to pronounce, but if you think about it, if you want students to take the time out and try and pronounce your name right, you'd want the same back, like, yeah, you'd like to know that they're [teachers] taking the time to learn your name and you're learning their name as well. I mean, I know it would be hard in a Màori class because there would be heaps of Māori people with Māori names that would be hard to pronounce, but even just to take the effort to try, just to try, not just to say anything without even trying, just trying, that's pretty good - and then it shows that they respect you more, that they're taking the effort to actually help you and stuff. And make you feel comfortable in class ... Because if someone pronounced my name wrong, I'd probably get off task and be all worried about it for the whole period and saying, 'Oh, she doesn't even know how to say my name'. ... you'd just think about it for the whole period but when you see that they're trying to make an effort, it's like, 'Oh, may as well carry on working then, there's nothing to think about'... . You don't worry, but when the teacher says your name wrong, 'Oh, OK', and then people are like laughing and everything and so you're kind of off task, but if they know it and if they're trying to say it, or even if they ask you, actually ask you how to say it, then you're thinking, 'Oh, you know, 
they're here to do the business, not here to muck around' - so it's really good. (Ngawai, Yr 11 Māori student, 2004)

Māori teachers have been teaching Pakeha teachers Māori words. They've been learning how to speak Māori names right. If the teacher says your name wrong then the other children get smart, so it's better if the teacher knows how to say your name right. (Tama Yr 5 Māori student, 2004)

Some students identified changes in teachers' practice which they put down to teachers' collaborative reform efforts:

... with one of my teachers, he was non-Mäori, he was really cool, like he did try things, he'd involve our culture as well, he'd try and say Māori words and it would just make us laugh and that and he was like really hip, he was cool, and he'd involve everyone, and he was just fun too ... . The way that he taught things, well, with one example he was telling us about diffusion and stuff and he'd say, 'Oh, yes, if somebody farted down this part of the room and it went all the way down there', ... he'd like put it in a way we'd want to listen to it, so we'd enjoy it but we'd get it, we'd understand it, he explained it in a way which made sense. Yeah, that was really cool. (Marama, Yr 11 Māori student, 2004)

Five $^{28} / 15$ non-Māori students talked about some of the changes that they noticed:

... some of the English teachers I've noticed have been pronouncing all their Māori words right ... . (Ted, Yr 11 non-Māori student, 2004)

Our teachers have been learning about Māori and teaching us about Māori and so we can understand people that just talk Māori. And we've been learning about Màori places around here and about our history. (Sean, Yr 5 non-Māori student, 2004)

28 Four/6 non-Māori students from Rata Primary and 1/9 non-Māori students from Kowhai College. 
... it's good [Māori and non-Māori teachers working together] because we learn how to speak Māori and we always go up to maraes. (Sheldon, Yr 5 non-Māori student, 2004)

It appeared that teachers were attempting to build better relationships with Māori children and their whānau:

... our non-Māori colleagues are getting out there into the community now and into homes and it's really awesome to see. I don't think, when I first started here, I don't think any of my non-Māori teachers got out there, and visited homes or anything like that. To understand our Māori families within our community, you have to get out there in the community. And there's a saying about Māori, face-to-face, kanohi te kanohi, and that works for our people. So there's been good moves, good moves ... . (Robyn, Māori teacher, 2003)

There is more discussion now in the staffroom about the importance of building better relationships with Māori kids, ... and much of what we've been talking about is developing that cooperative approach within our classrooms. (James, non-Māori teacher, 2003)

Nine/17 teachers (7 non-Māori teachers and 2 Māori teachers) whom I interviewed in 2003 explained that they had talked to colleagues and/or sought support from other teachers in order to develop more cooperative and inclusive classroom environments. Some of these teachers talked about the importance of developing a collective approach to teaching and learning activities, which better reflected Māori cultural values:

There have been a lot of discussions about cooperative learning strategies in the staffroom and also to have members of your own department that were on the course as well, to share viewpoints. I was able to get other teachers' ideas on how they saw the benefits of cooperative learning from different points of view, working across the curriculum so from a maths 
point of view or an English point of view. The sharing of ideas about that was really good. (Leanne, non-Māori teacher, 2003)

I'm talking about cooperative learning [with colleagues] and it works for kids. ... We've been talking about and using various kinds of jigsaw approaches which I quite like using like expert sharing ... . (Andrew, nonMāori teacher, 2003)

My initial analysis suggested that a group of teachers within both schools had emerged from shared experiences in the Te Kauhua programme, committed to engaging in collaborative partnership work focused on improving classroom practice and outcomes for Māori students:

Using the group work techniques has been an important part of our own cooperative work as teachers ... . At the huis we've been talking about how important positive relationships are for engaging kids ... and I think that it fits more with the collaborative ways of doing things ... on the marae that's the way we worked more as a collective. (Max, non-Māori teacher, 2003)

Well, one of the highlights for me professionally was the last two days [of the hui] .... when we saw teachers from our school actually demonstrate some of those teaching strategies and cooperative learning groups ... I just got so much out of that. I so enjoyed participating with others in my group and because there was a range of teachers working together across departments, the teachers that did the demonstrations were from a range of curriculum areas. Umm, at any given time there would have been a number of teachers working in a strange curriculum area ... and so we were like the students, out of our depth, and we got to see ... well, for me anyway ... I got to see how those activities can help students who are lost with the content and how they can still work with their peers to work it out. (Heria, Māori teacher, 2003) 
When I came back from the initial hui, the first thing I did was to rearrange the class into groups, and they are fluid groups, they are not static groups. As a result, my furniture is a mess at the end of the day. I don't think the cleaners liked it. It does help the students' learning, though, if they can be involved in group dynamics, of cooperative learning, all learning from each other. (Andrew, non-Māori teacher, 2003)

... some teachers have been trying different things out in class, like $\mathrm{Mr}$ Roberts did group work, so learning about that and, I mean, it was easier to learn in groups because you're talking to people that talk your language, like your slang, your phrases, and they get what you're saying, like some teachers they talk too brainy so you're like thinking - what? What does that mean? And you don't know what they're saying, but if you've got someone who's teaching you who talks like you and you understand what they're saying, it's easier, and it helps ... . (Ngawai, Yr 11 Māori student)

Mr Roberts did a lot of that, trying new ways of teaching in his classes with us ... . He used to just put us into our own work groups, and each of us would all learn one specific equation, kind of thing, then we'd number off and stood back up into our old groups ... so there's like four people would all know different equation things, and we'd all just teach it to each other, in groups. Yeah, we did a lot of group work in maths, it was cool, working with all the other students ... . We taught it to other people, so it really helped, it just made it easier to understand ... easier to understand from our friends too, because they would be teaching us as well, like because they put it in a way you understand ... we weren't like afraid to ask them questions, 'Oh, how do you do this?' and 'How do you do that?' (Hemi, Yr 11 Māori student, 2004)

Improving practice for Māori students required teachers to re-examine their teaching beliefs as well as their established programme approaches, according to Saul. He 
believed that teachers needed to value Māori students' cultural capital, their language, knowledge and experiences, as well as raising their expectations of local children: ${ }^{29}$

... some people think there's only one way that we can raise Mãori children's achievements levels, so they see that literacy is the way, through the reading rather than through the Māori language programme that would allow you to speak the children's language and would allow you to know and bring Māori children's experiences into class. For example, being on a marae, for teachers to understand that, what that means and really value our children's experiences, and start slowly breaking down your barriers, it's important that teachers see our children as bringing knowledge and experiences that we can use in our teaching, we can understand and value our children's experiences into our classrooms. It's understanding how to use that ... . (Saul, Māori teacher, 2004)

Some participants within both school communities explained that Māori staff members were giving up hours after school to support non-Māori teachers to learn te reo me ona tikanga in order to develop a cultural dimension within their teaching programme:

... teachers are doing the Te Ara Reo courses, and Mäori teachers have been supporting them after school in their own time. (Mrs Thompson, parent/caregiver of a Māori child 2004)

Other participants had noticed teachers being supported by colleagues to develop new approaches within their teaching practice:

I've noticed changes [due to Māori and non-Māori teachers working together], like the teachers have been learning about harakeke, how we

29 It is important to note that evidence emerged from a few participants from Rata Primary School which indicated that a cultural dimension was incorporated with literacy practices. This included some parents/caregivers and teachers who were working together to implement 'Hei Awhiawhi Tamariki ki te Panui Pukupuka' (HPP). This evidence emerged from interviews with two Māori parents/caregivers and one non-Māori parent/caregiver. 
use the natural resources in our local community, like kai. When they go for walks down to the beach, one child mentioned, 'Oh, that's a kina'. 'No, that's a sea egg.' 'No, it's a kina!' And then other children understand, 'Oh, OK, that's its name'. So they understood the difference in what we say to what they know it as. And how we know it as what they say, so they know, 'Yes, it is a sea egg but it's also a kina, in Māori'. So they understood. And also about harakeke as well, like they're allowing children to experience it and they don't just go over and go, 'Oh yeah, a piece of flax', and cut it off. They've asked someone, 'How do you cut a flax?' Because they know there's a kaupapa that comes with it. And they've understood the kaupapa that does go with the flax, and then other things too like, 'What's the pohutakawa tree?' 'That's our Christmas tree.' Wow, like they've never known things like this, they've just thought, 'Oh, it's just a tree, it's just a tree with a name like pohutakawa'. But they now know that's our Christmas tree and when that flourishes, that's Christmas to us. And that's been in our culture for as long as we can remember. (Ms Lynn, parent/caregiver of Māori child, 2004)

I think there's a lot more consultation amongst Māori and non-Māori teachers here at school, in terms of what they're adapting in mainstream classes and what they're doing in the whànau, bilingual classes. They're adapting the programme content, where they can, like when they do the environment, they bring in more of the cultural names of the trees, like the translation from Māori to English and learning about protocols, like how important it is not to take branches of trees and things like that. And I think the teachers, the non-Māori teachers, are asking for more help. They're not just going in and saying how they think the words should be said, they will consult with Māori teachers and say, 'How do you think this should be said?' 'Am I saying this right?' 'Could someone come in and give me some help?' I'm noticing that particularly this year, where people are asking for more help. (Mrs Thompson, parent/caregiver of Māori child, 2004) 
What I thought I saw both during the process of first interviewing the research participants and also during my analysis of the data was a gathering of blessings, signs of real collaboration that indicated the growth of actual change, as teachers appeared to row together towards the vast richness and diversity of te ao Māori; the start of a much longer learning journey which could promise real potential and better outcomes for culturally diverse students. Teachers, students and parents/caregivers described the sharing of ideas, and the expression of this sharing in classroom planning and practice. It implied mutual respect between Māori and non-Māori teachers, teachers and Māori students, and teachers and Māori parents/caregivers. A concrete indication of this respect was the effort of many non-Māori staff to learn te reo or at least to attempt to pronounce Māori names correctly, and the willingness of Māori staff to help their non-Māori colleagues.

I initially felt very optimistic about the potential of teachers' collaborative reform work, particularly as many participants identified changes or transformations as a result of new partnership processes. This was the stage in my own journey which promised calm sailing and plentiful catches and I was very hopeful for the future.

\section{Mixed Messages: Different, Contradictory Signs within the Context of Teachers' Collaborative Partnership Work}

Some of the navigational signs I first noticed implied particular collaborative partnership activities and processes which encouraged initial change and a collective commitment amongst many teachers towards reform. It also implied teacher ownership of the process.

However, as I proceeded on my research journey, I became aware that teachers' engagement in collaborative partnership work changed and declined over time in both schools. This became more evident when I interviewed participants in 2004, a year after my first set of interviews. Some of the students I interviewed explained why they were unsure of teachers' collaborative partnership work within their school: while they had noticed a burst of teacher experimentation with new strategies, these appeared in many cases to be short-lived:

... I know my science teacher tried some different things in class ..., she said something like, 'I'm going to try this new teaching technique', and she put us into groups and stuff ... but then she gave up on it ... . Yeah ... She didn't do it again anyway. 
Q. Why do you think she stopped?

I don't know ... (Louise, Yr 11 non-Māori student, 2004)

Mr Roberts's class was really good last year, he would teach in different ways, like sometimes when he had us working in groups, that was really good. ... We tried it in English this year and it helped, but then we stopped doing it for some reason.

Q. Why do you think the teacher stopped doing it?

Probably because our class is really loud, like if we would get together we're all talkative, but then we get down to doing the work but, I don't know, she doesn't like loud noises, so yeah ... . Oh, the not so good things are - you laugh and talk a lot, but the good things are you feed off the ideas of people in your group, and you end up doing a lot of work, and it helps you to understand more, so like, I might not know about something, but they would, so they'll help me to understand it, whereas I help them to understand something else, you know. That's one of the really good things about group work. (Kowhai, Yr 11 Māori student, 2004)

... like last year, it was the bomb... some of the teachers were the best, like with my science teacher ... like it was as if I was a normal being in his class, but this year it's way different. (Hemi, Year 11 Māori student, 2004)

This RTLB observed that while teachers' collaborative work seemed to have taken off very well, there were aspects of teachers' collective reform that had not been sustained:

Well, we were meeting together as a group of teachers ... . I haven't had time to catch up with that yet to see how it was going, but I knew Sue was quite keen at the start, and I don't know whether it just happened for one unit, I haven't had time to find out. ... I'm not sure how far they've got. It started off with a hiss and a roar but I'm not sure if it's fallen apart. (Resource Teacher Learning and Behaviour 1, 2004) 
During my first interviews, 15/17 teachers (6 Māori and 9 non-Māori) told me that a commitment to work together was developed out of their shared engagement in particular collaborative events or activities facilitated as part of the Te Kauhua professional development work. However, by the time of my second interviews with teachers, 11/17 (4 Māori and 7 non-Māori) explained that their own and other teachers' engagement in collaborative partnership work had diminished. My analysis of participant stories indicated that over the course of a year, the majority of teachers who had been interviewed had faced particular challenges and/or dilemmas as they attempted to work with colleagues over time. During my second interviews in 2004, 12/17 (4 Māori and 8 non-Māori) teachers told me that they had chosen not to share particular ideas, questions or concerns openly or honestly with colleagues. I was interested to note that by their second interviews, only $4 / 17$ teachers (2 Māori and 2 non-Māori) who were interviewed actually talked about collecting or examining Māori student achievement data within the context of their collaborative partnership work.

Over time, I realised that particular contradictions which emerged from my analysis related to the development of a 'shared vision' of reform, something which many teachers had initially told me was an important part of creating a collective commitment. For example, participant stories suggested that teachers from Rata Primary had been involved in a collaborative process of establishing a shared set of teaching beliefs which they called their koru. Many participants explained that these koru had been established to guide collective reform practices within classrooms and across the school. The six koru consisted of:

- powerful learning experiences;

- clear classroom management and exciting environments;

- students as strategic learners;

- teachers as coaches;

- expecting personal best from all;

- having foundation skills in place.

It surprised me that these koru did not mention the recognition of Māori as tangata whenua or valuing the rich diversity of te ao Māori; the importance of ongoing values exploration within a context of respect; the need to value and acknowledge cultural diversity and that it 'counted' in learning activities; and, more importantly, acknowledging the essential process of teachers working in partnership with culturally 
diverse students, their parents/caregivers and local community elders to enable an ongoing examination of contradictions of practice and to create a shared pathway of learning. I wondered why teachers had not acknowledged important collaborative partnership processes introduced as part of the Te Kauhua professional development, such as the need for ongoing collaborative inquiry and listening devices which had engaged school community participants speaking about their visions of reform.

Over time, I interpreted this too as a sign, a warning as I navigated participant stories and my own thinking. It appeared to me that teachers had not recognised (and were not encouraged ${ }^{30}$ to do so) important messages within the context of their own collaborative reform work. As I reinterpreted this data I also went back to the literature. I found that Fullan and Stiegelbauer (1991) had emphasised that educational change is a "socio-political process" and that "we need to comprehend the dynamics of educational change .... involving all kinds of individual, classroom, school, local, regional, and national factors at work in interactive ways" (pp 4-5). Bascia and Hargreaves held similar views as they argued that teachers are "political actors" individually and collectively, who work in contexts "that are inescapably political" (p. 13). A socio-political dimension of teaching should emphasise the micro and macro power relationships which affect and influence school reform efforts through different, competing political agendas (Bascia \& Hargreaves, 2000; Fullan \& Stiegelbauer, 1991). Over the course of analysis, I became more aware of the power and influence of hidden and unexamined values, beliefs and assumptions which appeared to me to undermine the practice of teachers' collaborative partnership work as well as its acceptance and place within each school's culture. Warning signs emerged as I navigated the less visible, hidden and menacing messages contained within participants' stories. Over time, I developed a slow awareness of established school practices which I interpreted as the underlying school culture or 'the way we do things around here' (Stoll \& Fink, 1996; Stoll, Fink \& Earle, 2003), and which I felt were related to dominant but unacknowledged discourses and power relationships within and across both school communities.

30 In relation to encouragement, I am referring to several issues. Over time I realised that teachers did not have the time and space within their busy school lives to sustain this type of work. It appeared that during the Te Kauhua professional development initiative that teachers had planned release from everyday teaching. However, planned release for all teachers did not appear to be sustained. I also believed that teachers' experiences of previous 'training' and/or 'professional development' experiences may have dulled teachers' abilities to engage in and sustain what is essentially intellectual, moral, political, spiritual and emotional work. These arguments are explored in more detail in the following chapters. 


\section{Chapter 4. The Tip of the Iceberg and What Lies Beneath}

This chapter charts a new direction in my analysis that occurred as I examined participant stories over time. It explores the less visible, submerged and hidden influences on the practice and acceptance of teachers' collaborative partnership work, within and across both school communities.

\section{The Second Interviews}

I looked forward to my second interviews with teachers, because the initial ones had led me to believe there was hope for teachers' collaborative partnership work. As I listened to participants tell their stories of collective reform work a second time in 2004, I learned that since our last interviews (over a year) the majority of teachers had been involved in new and very different forms of collaborative work. Some of these included:

- engaging in new meeting structures where teachers examined issues of practice and/or the achievement of Māori students;

- planning together in an attempt to improve classroom practice;

- engaging in reciprocal in-class observation and feedback with colleagues.

As I analysed participant stories, however, signs and messages appeared to me to highlight less visible aspects of the practice of teachers' collaborative partnership work and its acceptance into each school's culture. Initially, I found it difficult to interpret these messages because of the contradictions between what teachers had first expressed optimistically about their collaborative work, what they described less optimistically in the second interviews, and what others in the school community experienced and observed. In addition, I was aware that together we were entering uncharted waters and that there was little by which we could navigate teachers' collective reform work. As I have explained previously, when I first interviewed teachers in 2003, the majority (15/17) were largely enthusiastic and optimistic about the possibilities of change and improvement through their collective efforts. Because of this, I expected to see teachers' collaborative partnership resulting in transformation in each of the mainstream schools.

The following section tracks my journey of analysis as I began to see that such transformation was not actually occurring, which led me to interpret different messages 
and signs as revealing 'the less visible' influences which impacted on the way teachers chose to view and/or engage in new partnership work over time. As qualitative researcher, I became conscious of currents, ripples and submerged tensions which my analysis brought to the surface. These included the hidden and submerged values, beliefs, personal identities and practices that teachers bring into their work and, in this context, their collaborative partnership work. From my own analysis, I felt that particular signs highlighted these influencing factors on the practice of teachers' collaborative partnership work, yet they appeared to remain hidden, unexamined, unacknowledged and primarily outside of teachers' awareness. These signs revealed to me:

- underlying issues of trust and a lack of respect underpinning teachers' collaborative partnership work;

- established power relationships and hierarchies which resulted in privileged and silenced voices;

- deficit thinking, stereotypes, racism and prejudice;

- a lack of acknowledgement and valuing of cultural difference, identity and diversity; and

- a lack of participant knowledge, skills and dispositions which would enable teachers to work in partnership to develop culturally responsive practice, which would help all students to achieve, as described by different theorists (Banks, 2004; Bishop \& Glynn, 1999; Johnston \& Bush, 2005; Penetito, 2004; Shields, Bishop \& Mazawi, 2005).

I found that teachers' personal values and beliefs influenced the way they chose to view their collaborative partnership work, which then also impacted on the quality and quantity of their engagement. Although many participants (particularly teachers) had initially talked about the importance of challenging teacher mindsets, as well as the impact of teachers actively and openly exploring personal beliefs and values within collective settings, these were not practices which were sustained in either school community. I became aware of warning signs, of more 'submerged' teacher beliefs, which emphasised to me that a shared vision of reform had not been achieved. Participant narratives revealed to me that teachers held different beliefs about what counted as improved practice for Māori students within the context of their collective reform work. 
Warning signs prompted my awareness of the less visible beliefs and values alongside hidden, unacknowledged and unexamined practices which threatened to wreak havoc and destroy the sustainability of teachers' collective reform journeys.

\section{Signs and Messages: Emotionally-charged Discussions}

Participant emotions appeared to me to be one of the indicators or signs of deeper tensions and unacknowledged or unexamined values and beliefs that those involved bring into the collaborative dynamic. When a situation of potential conflict or disagreement arose, the presence of tensions would be indicated by a range of emotions. I found that there was a lack of skills, knowledge and dispositions which would enable culturally diverse participants to navigate ${ }^{31}$ these tensions and currents. For example, different participants talked about their experiences of engaging in what they described as "emotionally charged" conversations and that such tensions appeared to develop between participants over time. During my second interview with Heria, she described some of the challenges she had experienced over the year as she attempted to work with different colleagues from across her school. She told me that while she had no problem "talking straight" about her own beliefs about improved practice for culturally diverse groups of students, she believed some of her colleagues felt uncomfortable with her comments. She described a particular staff meeting where teachers had been encouraged to talk about their beliefs related to teaching practice and issues of discipline:

One particular staff meeting ... we were talking about discipline and we were working in groups where we were given scenarios to discuss - you know, what we would do in a particular situation - and a couple of people said to me, 'Well, you manage the students' behaviour really well, what would you do in this scenario?', and I said, 'Well, the very first thing I would do is take out any judgement I've had about what's happened'. Say it was an incident of smoking, maybe I catch a kid smoking, and I don't personally believe in detentions and stand-downs because I don't believe it achieves anything. I don't give kids detention if I catch them smoking, I just say to them, 'Put it out, this is really dumb. Either stop smoking at

31 By navigate, I do not mean to avoid, ignore or resolve immediately, but rather to explore and inquire into, to chart these tensions and currents and the underlying reasons for them. 
school or don't get caught. Sharpen up. You know, if you really can't go without the nicotine then sharpen up. Don't be so thick otherwise you're going to get caught', because I know what it's like to have a nicotine addiction, I used to be a smoker, but I don't smoke now ... . Well, one of the teachers in my group, he got real upset, ... banged the table and shouted, 'But they need to do as they're told, you know, there are rules here and the rules are to be obeyed and if you let one off then you set a precedent!' ... Okay, I don't mind ... so I stopped talking. (Heria, Māori teacher, 2004)

Heria realised that even though she had been invited to speak about her beliefs in a collaborative context, her colleague became visibly upset when she did so and as a result of his reactions the conversation stopped. It appeared to me that teachers lacked appropriate skills, knowledge and/or dispositions for debating differences in beliefs and values related to school and/or classroom practices in honest, open and constructive ways. Stoll, Fink and Earle have drawn attention to the impact of teacher emotions on change and reform programmes. These authors state that teachers' "readiness to engage in learning is influenced by their psychological state" (2003, p. 85). They note that teachers may behave "defensively" to protect themselves from reform programmes which may "expose their inadequacies" (Stoll, Fink and Earle, 2003, p. 85). Timperley, Fung, Wilson and Barrar reiterate such a view; they add that change programmes "may touch" the raw nerves of teachers 'because they are likely to impinge on teachers' feelings of professional identity and competence" (2006, p. 9). Heifetz highlights the emotional discomfort and turbulence of engaging with people with different ideas, stating that “one's emotional impulse ... is to squash those in the community who raise disturbing questions" (1994, p. 271).

At the same time that heightened emotions could indicate that there were few if any structures present in the meetings of those involved in collaborative partnership work to help them in fact to work collaboratively, it also became apparent that any deeply held belief or value could bind individuals into a trenchant position and thus prevent them from moving into the fluidity required by collaboration. For example, it was clear from my analysis that not all teachers who were interviewed were enthusiastic about new roles and responsibilities within the context of teachers' collaborative partnership work. Barbara explained that while she felt passionate about Māori education, and that this 
passion was tied to her own important cultural values, she did not believe it was her job to "teach other teachers":

Màori education is my passion. I am not out there to teach other teachers, I am here to teach kids and it is not just te reo that I want to teach them, I want to teach them their values, I want to teach them where they come from, because there is a whole world out there that if they can grasp up just a little piece of it, it's going to help them when they grow when they get out, that's what I tell them. (Barbara, Māori teacher, 2004)

I found that new roles and responsibilities within the context of teachers' collaborative partnership work could provoke participant feelings, passions and emotions because such roles clashed with their own deeply held beliefs and values. I searched for literature which would help me make sense of the data. I knew that Lieberman and Miller (1999) had argued that teachers needed to rethink their roles and responsibilities within the context of new collaborative reform work. Collegiality, according to these authors, means teachers assuming shared responsibility for change across classrooms. I found myself realising that teachers lacked the knowledge about such issues related to their reform work that would have allowed them to carry their passions about their beliefs and values with them into the new dynamic and then to examine them in that context.

Participants' emotional reactions indicated to me that something was stirring far deeper, at a less conscious level. I felt that these reactions were related to new partnership processes 'rubbing up against' participants' personal identities and their deeply held values and beliefs about teaching and learning, especially in a context of cultural diversity. My analysis indicated that a person's beliefs about identity could influence the way they chose to engage in and/or define teachers' collaborative partnership work. For example, one participant became visibly upset and angry during her interview and it appeared to me that she viewed teachers' reform work as threatening to a collective identity of 'New Zealanders', which she appeared to believe we should all hold. She acknowledged that she did not know anything about teachers' collaborative partnership work, but her strong views about the importance of a collective national identity precluded an acknowledgement of cultural diversity, an identity that was in her view being threatened by teachers' partnership work: 
No, I don't want any information on how Māori and non-Māori teachers are working together! ... like I said to my daughter early on today, I think it's time we stopped looking at the colour of people's skin and started treating everyone like New Zealanders, and we started treating people equally ... . (Mrs Jones, non-Māori parent/caregiver, 2004)

Some participants believed it was hard to engage in open, honest and constructive conversations related to new collaborative partnership work because such discussions could become "emotionally charged". One principal confided that it had been difficult to engage in conversations within his school community because of the emotional responses he had encountered:

It's hard to have these sort of discussions in schools, because they are often emotionally charged. (Principal 2, 2004)

Thus, it became apparent as I read these signs that emotions flagged entrenchment, a sense of threat, a defence against alterations to the status quo, and the difficulty people have in repositioning themselves as their beliefs and values are challenged by reform, assertion or change. It also appeared to me that emotions arose in a situation of distrust, and that ironically the entire basis of collaborative partnership work - trust and collaboration - was non-existent at worst and flimsy at best.

\section{Trust and Respect: Less Visible and/or Examined Beliefs and Practices}

Thirteen/17 (5 Māori and 8 non-Māori) teachers who were interviewed explained that over time teachers started to trial the process of observing colleagues teaching in their classrooms. Opening up classrooms to teaching peers was considered an important aspect of improving classroom practice by many of the teachers who were interviewed. Ten/13 (4 Māori and 6 non-Māori) teachers who talked about the process of conducting reciprocal in-class observation with peers indicated that their engagement was influenced by feelings of trust and professional respect for their colleague. These participants gave every indication that such attitudes were straightforward and visible, expressing a commonsense approach which strongly emphasised the importance of trust, respect and collective safety as teachers engaged in new and potentially 'risky' activities: 
There has got to be trust when you work with colleagues really closely ... and there has to be trust that we can freely talk about my shortcomings or the shortcomings of the method that I had chosen that day and why it didn't work for certain students and there has to be quite a bit of trust between two people to broach that. (Andrew, non-Māori teacher, 2004)

So to be critically supportive involves a colleague looking at what I do and examining ways in which it can be done better, but at the same time it doesn't belittle my whole methodology and that's why that trust thing comes in. If I am working with somebody that I can trust, that is generally supportive of the thrust of what I am trying to do, then we can happily criticise or tweak the bits that need to be tweaked. So I think it actually again comes down to trust. I always come back to that. (James, non-Māori teacher, 2004)

These participants explained that feelings of respect and trust influenced their decisions to work with peers. I was interested to note that these teachers believed it was important to work with someone whom they believed was a good role model and had credible ideas and judgements about teaching practice:

... in our department there's a couple of teachers who are really strong teachers and who I think are good role models in terms of what I would like to have in my classroom or how I would like to be as a teacher so I'd really value their contributions, and there are teachers who aren't as strong or who might do certain things that I might not necessarily want to model my teaching on and so you'd put less value on their contributions ... so that's important in terms of choosing your peer ... . (Julie, Māori teacher, 2004)

The facilitator had approached me and asked would I be interested in helping this teacher, and that he had asked for my help and I said, 'Yes, that's fine' ... . He wanted to set up a reading rotation or a reading system, a reading programme that was manageable for him and so that he could have a system of teaching reading ... . So that's what we did, we 
started out with just that goal, to get a system up that he could manage, and I worked in his room and he watched me teach. (Verna, non-Māori teacher, 2004)

Having professional respect for a colleague was important for teachers' engagement in collaborative work, according to different participants who were interviewed:

Well, we sat in here after the lesson. I think we are two colleagues who have quite a lot of professional respect for each other so we could actually push the boundaries a wee bit in terms of questioning each other, like 'Why did you do that?', which you wouldn't necessarily do with someone that you might not value their opinion. We were able to do that and it forced us to think, it forced me anyway, and hopefully I did the same for him, forced him to think about techniques that worked and didn't work, and he was focusing on the non-engaged kids in my class which was quite interesting, why they weren't turned on to that particular activity, so that came out of that feedback process, but we are comfortable enough with each other that we can do that and I think the pairing worked well ... but we are quite happy so the feedback session which should have only taken about half an hour ended up taking the whole hour and it was really interesting to see Max's perspective from where he was and for him to hear mine. (Andrew, non-Māori teacher, 2004)

Differences in teachers' beliefs and values appeared to me to influence the decisions they made within the context of their collaborative partnership work, and over time I became conscious of cultural differences that influenced their interpretations of collaborative partnership work. I discovered that teachers did not in fact continue with their focus on values exploration, critical collective inquiry and/or listening practices with culturally diverse peers, students and/or parents/caregivers over time, but instead chose safety instead of expansiveness, the known rather than the unknown. As a result, aspects of teachers' discussions and collective activities, such as observing peers in class, now appeared to me to be largely superficial and contrived. As I analysed teachers' second 
interviews, it appeared to me that the majority chose to work with colleagues whom they believed:

- were good role models of 'effective' teaching;

- shared similar beliefs and values related to effective teaching;

- were trustworthy (or made judgements they felt were trustworthy);

- were comfortable to be around; and

- were respectful of individual teachers' needs within the context of new collaborative partnership work.

One of the facilitators described how teachers were requesting to work with a specific colleague whom they perceived to be an expert in a particular teaching area:

Some staff are now asking after their in-class observation sessions, asking if they can observe someone, another teacher, that they perceive to be an expert in an area that they want to know or learn more about. (Resource Teacher Learning Behaviour 1, 2004)

I started to see teachers' reasons for choosing a peer as indicative of perhaps less visible and 'taken-for-granted' beliefs and of a conservatism that could not sit well in a context of reform. These reasons remained unexamined by teachers themselves. For example, 10/13 teachers who had taken part in reciprocal in-class observation and feedback with peers indicated that it was important for them to exercise choice. They felt that being able to choose their own peer observer was important for developing their commitment to and engagement in collaborative reform work:

... so the idea is actually to have a teacher selecting another teacher who he or she feels confident and comfortable with and then they observe each other, so it's like peer coaching because some teachers felt a bit threatened having someone ... they are not familiar with barging in and observing and then giving lessons afterwards. ... it's important for teachers to have a say in who will be their observer. (Richard, non-Māori teacher, 2004) 
You've got to be able to choose your own peer ... because you know what you want to improve ... within your own teaching practice. (Julie, Māori teacher, 2004)

However, from my analysis I felt that many teachers chose to work with colleagues whom they believed held similar values and beliefs, and could provide appropriate role models. I found that Fullan $(1999,2005)$ has argued that collaborative school cultures should avoid "like-minded consensus" and value diversity of perspective. It was apparent from participants' stories that they had no understanding or knowledge of such theories. Warning signs were starting to appear in my analysis, which threw up questions about issues of trust and respect within the context of teachers' collaborative partnership work. In fact, it started to seem that trust could simply be another way of holding on to the status quo, or keeping within known waters, whereas trust could, in a situation of true collegiality and collaboration, instead be the guiding principle for leaving safety behind.

\section{Warning Signs: Submerged Beliefs, Revealed Prejudice}

It appeared to me, as qualitative researcher, that the degree to which values and beliefs were shared and understood, as well as acknowledged and examined (over time), influenced the practice of teachers' collaborative partnership work as well as the efficacy of such work and its place within each school culture.

I also became aware of a range of 'less visible' submerged and hidden beliefs and values embedded within the narratives of teachers as they described their experiences of working with colleagues. These 'less visible' beliefs also influenced the practice of teachers' collaborative partnership work within and across both school communities.

It is important to note that these themes did not surface and reveal themselves to me, as qualitative researcher, until I closely examined the second teacher interviews conducted in 2004. It took me some time to become aware of the presence and influence of these identity themes, which appeared to be socially constructed.

For example, Max described the ways he had attempted to work with colleagues in order to improve students' ownership, motivation and/or engagement in classroom learning activities. Max appeared very motivated through his own personal experience of the Te Kauhua professional development, and in particular the importance of allowing 
Māori students more ownership and choice in learning activities. During the course of analysing his story, I found what appeared to me to be 'submerged beliefs' (not yet examined or unacknowledged) about 'workshop' students and Max's expectations of their lives once they left school:

One of the things I've been trying to talk to my colleagues about is letting Māori students have more ownership and giving all students more responsibility for what happens in class. Like in the workshop, and relating things back to real situations and what happens in the workplace. Like when they leave school they are going to be going into workshops with tools and they have got to learn to respect that they are the property of the workshop, and they'll need to be responsible for issues of safety when they are working. So giving them that ethos of a work environment is working very well and some of the students have really realised and changed the way they've behaved, they've taken a vast amount of ownership. They've taken more ownership than anybody else which is really good. ... But when I've talked to some of my colleagues, they are very resistant to these ideas ... they aren't interested and it just reminds me how blindfolded some staff are to students and their needs. (Max, nonMāori teacher, 2004)

I was interested in Max's description of his colleagues being "blindfolded" to the needs of Māori students and I found myself wondering about Max's own ability to see clearly what I felt were his lower expectations and submerged beliefs that Māori students were destined for workshop life after school.

Other submerged and less visible beliefs surfaced as I analysed the research data. During my second interview with another teacher, Ian, he explained how he had chosen to work with one of his colleagues, making the point that in his view female teachers were typically not strong in maths. I found myself wondering about Ian's expectations towards female students in his classes:

... as is typical with a few female teachers, maths doesn't tend to be a hell of a strong point with her. She [my colleague] watched me teaching a maths lesson and setting the lesson up with a game, a starter, at the 
beginning of the game, at the end and having a break in the middle so they can change activity or a distracter, seeing me setting things up and chunking the period through so the kids don't have this image of maths being a long-drawn-out procedure. (Ian, non-Māori teacher, 2004)

As well as having unexamined beliefs about "female teachers", his beliefs and assumptions influenced the way he had behaved with his colleague:

... there are sometimes difficulties in working with other teachers closely. With my colleague, for example, she was very fragile coming into this observation process so what I could say to her had to be very carefully said and I can be extremely blunt and forthright but I had to guard my words and make sure she didn't feel they were an attack, they were suggestions ... . I came into the room after the class had started and slipped into the back and then tried to fill in the [observation] sheets as best I could ... it still gave some interesting patterns for her to look at, like where she stood in the classroom and how she interacted with students, but the type of lesson was very much an individual lesson rather than a group lesson so there was no opportunity for co-construction, there was no opportunity for expert learners or group work or anything like that ... so it wasn't the ideal situation and it wasn't the right time for the teacher ... . All I simply looked at was where she stood in the room, who she interacted with and I would have made that comment anyway, but she was mainly based at her desk, for example. (Ian, non-Māori teacher, 2004)

Barbara described to me how she had reached her decision to work with a suitable peer to investigate issues of current practice for Māori students in her classes. She explained that she had deliberately chosen not to work with one of her colleagues within the same syndicate/department. Her decision not to work with this colleague appeared to me to be based on her beliefs about 'trained' teachers. During her interview, Barbara told me that part of establishing an identity as an effective teacher was dependent on where teachers had received their training: 
... there is another teacher here, she takes the [Mäori] immersion class, and I would not be able to have a challenging discussion with her, if you know what I mean. ... Because she is not my idea of a trained teacher. She hasn't, well, been to Teachers' College, maybe that's why I like Susy, because Susy and I went to Teachers' College together and teachers who came out of there were always very well equipped, they were good teachers, they just had that sort of reputation and when Susan mentioned it, I said, 'Yeah, I trained there too', and so, 'What year?', and we talked about that. Whereas the other teacher, I think she hasn't been given that type of training. (Barbara, Māori teacher, 2004)

It appeared to me that Barbara's beliefs about 'trained' and 'effective' teachers were related to other beliefs associated with status and the reputation of her teachers' training college. Barbara appeared to believe that her colleague, Susy, was "very well equipped" and suitably "trained", whereas her other peer (who had not gone to the same type of training institution) was less trustworthy. I wondered about the influence of these 'hidden' or 'submerged' beliefs and values as well as personal identities which I felt teachers had brought into the context of their collaborative partnership work, but which were unexamined and unacknowledged. These submerged beliefs appeared to me to impact on the way teachers chose to view and/or engage in collaborative partnership work over time.

I searched for literature which would help me make sense of this and I found that Welmond (2002) had studied teachers in Benin, within a context of change. He argues that diverse teacher identities emerged from analysis as teachers brought their own unexamined preferences and ambitions to the process of reform. Welmond found that teachers' beliefs about their roles and responsibilities influenced their identities as educators, and their social visions within the context of reform. I also found other emerging literature which argued that teachers' constructed identities of effectiveness have serious implications for change programmes (Timperley, Fung, Wilson \& Barrar, 2006; Welmond, 2002). Timperley, Fung, Wilson \& Barrar, 2006; Welmond warn that teachers' beliefs about the purposes of education, coupled with their professional identities as teachers, need to be openly, actively and critically examined if effective changes are to be made and sustained within reform contexts (2006). I found a number of other authors who argue that identity formation is not a process that any individual 
constructs by themselves (Alejandra Elenes, 2003; Fine \& Weiss, 2005; Hooks, 2003; McCreanor, 2005; McIntosh, 2005; Shields \& Sayani, 2005): "Identities are coconstructed between individuals and society at large" (Alejandra Elenes, 2003, p. 191).

As I interviewed teachers and listened to their stories, it became clearer to me that trust was a major influencing factor on the practice of teachers' collaborative partnership work, as well as its acceptance and place within each school's culture. I was also interested to find that teachers held different beliefs about the competency and judgements of their colleagues, which revealed to me a lack of respect, but also the need for ongoing critical, collective inquiry, such as the action research process. It also became apparent that there was a lack of acknowledgement, respect for and valuing of cultural diversity and Māori participants' indigeneity, their unique position as tangata whenua. Some theorists have argued that teachers must identify, accept and value cultural diversity if they are to work together to develop culturally responsive practice in their schools (Johnston \& Bush, 2005; Shields, Bishop \& Mazawi, 2005). Although I became aware of these underlying trust and respect issues, they appeared to remain unexamined and unacknowledged by teachers themselves within the context of their new collaborative partnership work.

\section{Differences in Teachers' Beliefs: Trust, Respect, Status, Leadership and Mana}

Over time I became more aware of the differences in teachers' cultural beliefs and values. These differences revealed inter-cultural differences (across groups) as well as intracultural differences (within groups). For example, I was interested to find that 3/7 of the Māori teachers who were interviewed talked about the importance of status as a factor that influenced the way they chose to engage in collaborative partnership work over time. Maree described during her second interview how she had concerns about fading teacher engagement in collaborative work within her school:

... we used to walk around the classrooms once a term or maybe twice and we used to go in and see each other and observe one another teaching. We used to go in and have a look and we all used to share something that's gone well for us in our classrooms related to our koru (teaching beliefs), and just by doing that ... all the classrooms were up around the same 
level, right when you looked around the classrooms and you'd see huge improvements ... . But the in-class observations have dropped off, we're not doing that as much now as we did ... . (Maree, Māori teacher, 2004)

I asked Maree whether she had talked to anyone about her observations and concerns. She told me that, as a new teacher, she did not feel that it was her place to raise such issues within the staffroom. Maree explained that her decision had been influenced by her own cultural beliefs, related to her status as a young Māori teacher, which had also been shaped through her family experiences:

I feel uneasy with myself about it because of the way that I have been bought up ... we don't talk back to our elders ... it would be a bit like back-chatting to my Nan or something ... . I'm the junior of this place and I already have enough to say and I have to be careful of the way I say things and I think maybe I might say too much ... . I've done a lot of things already in this school that I think I'm very lucky to have been able to do ... And the other thing is ... that's the role of senior staff and I respect the other people that are already here and I don't like to ... . I'm young and they're more experienced and have been here for longer. I don't feel it's my place to intrude, ... it sort of goes against my upbringing. It's like talking back to your elders, it's the whole sort of values and morals that you're used to. (Maree, Māori teacher, 2004)

Herewini explained that his decision to work under a mentor was influenced by his beliefs related to mana and leadership:

... I came under Saul ... and he mentored me just in the basics, yeah, which I hadn't had before. Organising your day, time management skills, your planning, making sure it's all there and is systematic, and that you're following it, making sure that you deliver, and that you're organised. And Saul, he's been one of the key people who has been instrumental in changing this school around because of his professionalism, his mana. He came here wanting to improve himself as a teacher, he had a goal and he knew where he was going and how he could help the school. A lot of us 
were just here and bumbling on but he came with purpose and, yeah, he's pretty much kept to that, and he's done a tremendous job in lifting the standards of teaching and maintaining that professional integrity. (Herewini, Māori teacher, 2004).

In my interview with Herewini, he explained that Saul had been instrumental in bringing about change within teachers' thinking and practices:

The other thing is he's challenged us, coming from thinking that the Māori kids here, ... that it's the home environment is the reason they're not improving in your class or thinking that we don't expect much from them with their reading and writing ... and it's about ensuring you're delivering the best quality education and you've got to be looking at the results of their learning and thinking, Well, how can we improve this and doing that collectively, as a staff? ... Like Saul, he's looking at the hard facts, the hard data, and that idea to improve education for Māori children, you've got to be looking at the outcomes, the statistics, the maths results of our children, the reading results, and it's much more purposeful now, it's not like we're doing it for it's own sake, but really looking at how well our Màori children are doing here and progressing at the school in all spheres. (Herewini, Māori teacher, 2003)

It seemed that Herewini trusted Saul's judgement within the context of new collaborative partnership work as he felt Saul had mana and had demonstrated a particular type of leadership. According to Metge (1976), the concept of mana is tied to notions of "power", "prestige" or "standing" (p. 64). Metge acknowledges that the meaning of the word mana has changed and is subject to interpretation (1976). She argues that for "elders steeped in Māoritanga, mana still retains its full force, signifying power beyond the ordinary possessing and possessed by extra-ordinary individuals" (Metge, 1976, p. 64). Herewini's beliefs about his colleague's mana appeared to me to be linked to other beliefs about leadership.

Herewini told me that Saul had taken a leadership role within his school by examining student achievement data as a basis for improvement and informing judgements. Timperley and Parr (2004) have argued that a key feature of professional 
learning communities is the type of conversation that emerges within the community, with the most "powerful" being learning conversations centred around data or evidence of student outcomes (p. 115). Data must become the basis for teacher conversations, in order to improve the quality of judgements needed for further planning and on-going action, according to Timperley and Parr (2004). These authors argue that teachers need opportunities to work together to describe or demonstrate how they teach; to analyse their students' work; and to use that evidence continually to improve practice and increase their students' achievement (Timperley \& Parr, 2004). Rubin, on the other hand, highlights the role of individuals or change agents who take responsibility for changing practice in schools, and who lead different partners collectively towards shared goals (2002, p. 106). It was clear that Herewini believed that Saul had taken a leadership role within the context of reform, and that for Herewini Saul's leadership was related to his mana as a leader of change. This caused me to reflect: perhaps Herewini viewed Saul as an institutional warrior, someone ready to pick up the challenge of reform.

Barbara, an older Māori teacher, stressed her age when I initially interviewed her. She explained to me that she was older than some of her teaching colleagues and during her interview she shared some of her concerns about the use of new, introduced teaching strategies within the context of teachers' collaborative partnership work. She explained that while she supported this work, she felt that some "power-sharing" strategies, introduced as part of the Te Kauhua professional development programme, did not fit with her values and beliefs:

... you know, there are some strategies that are in there that are not quite Māori, to my way of saying ... . I didn't say anything to my colleagues at the time because it was on reflection ... I mean, you hear all these things, and you think to yourself, 'Oh yes, yes', and then when you go to think about it then that's when you start to question, maybe I should have brought those questions in before. But you know, I still think about it ... the work goes on, but I still have it at the back of my head. (Barbara, Māori teacher, 2003)

I initially glossed over the comments Barbara made in the course of this first interview. Later as I analysed her story over time, I came to understand her personal identity as an 'older' Māori teacher, linked to her age. During my second interview with 
her, I asked her about the comments she had made in this first interview. She told me that she felt that children were now being pushed to take on roles without proper understanding of appropriate responsibilities. Barbara told me that cultural practices had changed over time, and she was particularly concerned about important traditional values being lost within the programme of teachers' collaborative partnership work:

... we're making our little tiny children stand up and do haka that they know nothing about, and when you look at what is happening now, in my day you had to be white haired, just about bald before you could stand up and speak on a marae. Now they've got systems where anybody can go and stand up on the marae and korero because this is how they're being taught - 'You go to the front'- and yet there's an old Màori saying that, 'If it's all right at the back then it's right in the front; if there's no workers at the back then the front will fall down', and a lot of our Màori people are forgetting to learn how to work before they make their way up, because there is a step and our kids aren't going through those steps, ... you've got to go back to values... . I'd love the older people to be more involved in this, because I'm sure I'm not the only person who has got these same points of view, and I am sure that there will be some old people out there, and I'm going past the parents, I'm going to the older lot who have exactly the same concerns as I have got. (Barbara, Māori teacher, 2004)

It appeared to me that teachers held different beliefs about the goal of collaborative partnership work, and that these beliefs were intersected by factors of ethnicity, age, gender and status which all impacted on the way an individual teacher may choose to view and/or engage in collaborative partnership work over time.

\section{Diversity of Teachers' Identities, Beliefs and Values}

Heria seemed to me to have a particular identity within her school community which influenced the way colleagues chose to view and/or engage with her. Although she described herself as a "staunch Māori teacher", committed to working with colleagues to improve practice for Māori pupils, she said that some of her colleagues saw her as a 
"radical". She explained that her training had been through Māori immersion and that she had taught previously at kura kaupapa. She described how her outspoken beliefs had caused some problems at her school. A few of her colleagues (Māori and non-Māori) had written a letter of complaint to the principal about her behaviour and her conduct with students, in particular her behaviour towards Māori students.

During 2003, when I first interviewed her, she had seemed very enthusiastic about the possibilities of working collaboratively with colleagues across her school to improve aspects of her classroom practice for Māori students. She had told me that she was particularly interested in improving practice for those Māori pupils "who fell through the cracks", and by her own accounts described herself as a "straight talker", someone who was not afraid to raise the "hard issues" within her school. During my second interview with her, she explained that recent experiences had put her off engaging in collaborative partnership work:

I've been described as a radical and accused of deficit theorising by my some of my colleagues, which is actually bull-shit ... . I'm interested in our kids who struggle to get to school ... . I'll give you an example ... . I am monitoring the 30 worst [student] attendees in Year 9 ... . One of those students is in my house group ... this boy ... , he'd been away for a long time from school and then he turned up on the day we were going on a trip and I said, 'Where have you been?' and he said 'I've been at home'. And I said, 'Why, what's up? Where were you yesterday?' 'Oh, nowhere.' So I said, 'Hey, I've got your report, you haven't been here to give them to you. How about I take you home and meet Mum and show her your report?' And he said, 'Oh, she's not home, Miss'. 'Oh, where is she?' 'Oh, she's taking Dad back to prison.' So I said, 'Oh sweet, how long is she away for?' I didn't make any judgement about that's where she was. And I just left it at that. Then later on in the day I said to him quietly, 'What's Dad gone away for? Are you all right? Is Mum all right? Who is at home then?' He never, he didn't tell me but I said, 'When Mum comes back and things have settled down a bit, I'd like to meet Mum' ... . I said to him, 'If you don't come to school, the cops will come, you'd better come to school'. Anyway, he has been coming, but he's been getting here late, half past nine, quarter past nine, missing house group but at least he's been 
getting here to school like fairly regularly. Like this morning he was here at house group. I'm like, 'Chad bro, you made house group, you're the bomb!'. Because yesterday I said to him, 'I've still got your reports, what do you want me to do, do you want to take them, shall I come down and meet Mum?' I said, 'Well, think about it and let me know', and I ... said to him after school, 'Hey, do you want your reports, shall I give you your reports?', and he said, 'No, hang on to them and come and meet my Mum'. You know, to me that was huge, that was a huge change. And he has always got on a hoodie, he has got a gang scarf and got caught smoking yesterday after assembly. To me, he is one of my success stories because now he comes to school, he's coming and he's late because he drops his younger siblings off and you know what I feel with these other teachers who are going on about things, about getting tough on uniform and getting tough on rules, just get off this guy's back. Like that other staff member that I mentioned before, would say, 'No, it's not his responsibility to take his younger siblings and drop them off'. I know that but the reality is that he does. 'No, the mother should be doing that and he should be here on time and he should be in correct uniform', and it's like, 'Back off'. You know what I mean. (Heria, Māori teacher, 2004)

Heria's disillusionment with collaborative partnership work was a reflection of the way she was typecast and shunned for her professional expression of her beliefs and values, and the fact that her application of these beliefs and vales was fluid and inclusive and did not allow external limitations to circumscribe success. She as an individual was able to relate to students whom other teachers probably labelled as difficult, and she was able to realign their non-conformist behaviour (such as arriving late) with success (since they arrived at school at all). Criticism and rejection of her practices implied a negative view of her and her values; it did not imply expansiveness, acceptance and flexibility. Thus her very being was subject to exile, the absolute opposite of any collaborative dynamic.

I started to wonder whether teachers who could not acknowledge and allow personal diversity would in any way be able to identify, acknowledge, accept and value cultural diversity across groups and within groups. If they were not only unable to allow 
personal diversity but also to attribute this negatively to cultural difference, what hope was there for a culture of collaboration to be established?

It became important to examine the idea of identity within the context of this research. I turned first to the notion of Māori identity. I found different writers talking about the significance of diversity within Māori identities (Bishop, Berryman, Tiakiwai and Richardson, 2003; McIntosh, 2005; Penetito, 2001; Waitere-Ang, 1999). I became more aware of the danger of using 'homogenising titles' in educational research and that many Māori are “... strongly resistant to the fact that they may be cast as holding 'the' Māori voice" (Waitere-Ang, 1999, p. 242). Bishop, Berryman, Tiakiwai and Richardson (2003) note there is danger in stereotyping Māori students and that Māori students' individual identities are multi-facted and not monocultural. Penetito (2001) warns that there "are many ways to be Māori ... there is no such thing as 'the' Māori identity, there are only Māori identities" (p. 19). Many argue that there is marked heterogeneity within broad ethnic group descriptions within Aotearoa/New Zealand including Pakeha, Māori, European, Asian and Pasifika students (Alton-Lee, 2005; Bishop, Berryman, Tiakiwai and Richardson, 2003; McCreanor, 2005; McIntosh, 2005; Waitere-Ang, 1999). I found that there was marked heterogeneity within participant groups who were interviewed for this study and some reminded me of this during their interviews:

I just want to add that there's no such thing as an expert Māori. So I'm going to give you my view, but it's my view and I'm not speaking for other Māori people. (Ms Wilson, parent/caregiver of Māori child, 2004)

The importance of teachers recognising the diverse identities of Māori children and young people as teachers worked together for change was also stressed:

When my son was doing his speech for this manu korero competitions, it's about what his whakapapa means to him, and he was very strong on what he wrote, and it'll be interesting to see how it goes across when he gives his speech, but he was very strong, because he comes from two different family backgrounds, two different races, both of them are as strong as the other, and that comes across in his speech, which I think is really important. (Mrs Tumu, parent/caregiver of Māori child, 2004) 
Some theorists writing in the area of culturally responsive practice emphasise the importance of educators taking account of youth identities:

We cannot assume that because we are educators we understand how students construct their identity. Neither can we assume that we see them as they do themselves or that we know, without consultation or dialogue, what they need to be successful or fulfilled. (Shields, 1999, pp. 106-108)

Alton-Lee (2005) also notes the fluidity of student identities and warns that such identities are complex and influenced by "intersections" of ethnicity, gender, sexuality, dis/ability and the socio-economic status of family. She states that a new agenda for quality teaching in Aotearoa/New Zealand would need to be responsive to such diversity:

The use of the term 'diversity' rejects the notion of a 'normal' group and 'other' or minority groups of children and constitutes diversity and difference as central to educational practice. That means all learners, including students who are Pakeha or of European heritage, Māori, Pasifika, Asian and learners of many ethnicities and heritages, including high and low achievers, including boys and girls, and so on. This point is important because the word 'diversity' can be inappropriately co-opted as a way of constructing an 'us' and 'other' distinction around an assumed 'norm'. (Alton-Lee, 2005, p. 9)

Fatiu and Rodgers (1984) have suggested that teachers and students need to recognise culture as having visible and less visible features, something akin to an iceberg. They argue that the tip of the iceberg can be viewed as containing visible aspects of culture (primarily in awareness) such as forms of language, expressions of art, music and dancing rituals, whereas many aspects of culture lie beneath the surface (primarily out of awareness) and include notions of beauty, sexuality, ideas governing child-raising practices, patterns of superior and subordinate relations, and so forth (Fatiu \& Rodgers, 1984).

I found other writers who put forward compelling arguments. McIntosh's writings on Māori identities note that one of the dominant, recognised identities for Māori is "traditional" and that, while this identity has been "vital to the Māori struggle" within 
Aotearoa/New Zealand, groups working for reform must encompass diversity within Māori society (McIntosh, 2005, p. 46). McIntosh argues that traditional Māori identity is closely linked with the struggle to reclaim what has been lost as a result of colonisation: land, language, culture, identity. However, she emphasises that there are several Māori identities, with the most "fluid" relating to young Māori. Durie (2005), a noted Māori academic, cautions that:

... being Māori will not necessarily hinge on conformity to a preconceived or classical notion of Māori-ness or on stereotypes derived from socioeconomic indicators, but on access to te ao Māori and opportunities to participate in the richness of that world ... . [and later] Te ao Māori, the Māori world, is not static nor is it a pristine memorial to the past. While some of its features, such as the land, rivers, and even the sea, have survived the threats of time, their significance and their relationship to whānau has been shaped by modern understandings and experience of environment. Similarly, although a 'corpus of basic convictions about reality and life' has remained relatively constant, the manifestations of culture are subject to flux, so that change becomes the norm (p. 3). ... Being Māori in the third millennium will not be the same as it was a thousand years earlier, but nor will it be the same as not being Māori. (p. 4)

It appeared from analysis of interview evidence that there were gaps in teachers' knowledge about the importance of ensuring students' access to the rich diversity of te ao Māori. Durie has argued that while recognising and celebrating diversity within contemporary Māori society, education for Māori must also recognise the notion of culture as a "foundation for identity and a building block for learning" (2005, p. 43). He states "that schools where a strong Māori cultural identity is positively reinforced are more likely to lead to success" and reiterates the importance of access to te ao Māori (2005, p. 43). I felt that there were complex yet essential arguments put forth within the texts that I was reading which were not examined and acknowledged within the context of teachers' collaborative, partnership work.

It has been argued that teachers must work to identify, accept, respect and value their own cultural identity and diversity if they are to create culturally responsive practice 
(Bishop \& Glynn, 1999; Johnston \& Bush, 2005; Shields, Bishop \& Mazawi, 2005). It could equally be argued that they must become aware of their responses to the identities, values, world-views and cultures of others if they are to be able to work in an environment of collaboration and trust.

It seemed to me that teachers were not investigating issues of culture (personal identity, collective and/or institutional culture) in their reflective practice. Instead, they seemed to be falling back on a set of beliefs and prejudices that bound them rather than opened them up, that allowed them to reject identities and values different from their own, and that therefore encouraged them to stay safe and unexamined in a backwater of stasis and conservatism. The interview evidence indicated that teachers were unaware of theories that challenged received opinion about te ao Māori, culture and identity and that overturned the prescriptive notions of acceptability and unacceptability, success and failure within schools.

\section{Power-sharing Strategies in the Work of Reform}

It appeared from my analysis of participant stories that teachers held different beliefs about the goals of their collaborative partnership work. It took some time for me to become aware of these differences, as they emerged and became visible to me only gradually. A particular point of disagreement and/or resistance seemed to centre around teachers' beliefs about their use of power-sharing and/or co-construction, particularly with students, as a means of improving classroom practice. Interview evidence highlighted a group of seven teachers (3/7 Māori teachers and 4/8 non-Māori teachers) from across both school communities who explained that they had been talking to and/or working with colleagues to help improve their classroom practice through the use of coconstruction or power-sharing strategies ${ }^{32}$ with students:

\footnotetext{
... we learned from the [Te Kauhua] facilitator that co-construction is about giving the students a voice in the classroom programme and allowing them to have more of a say in the decision-making in the class ... (Julie, Māori teacher, 2003)
}

32 Data analysis indicated that this appeared to be a particular point of difference between the high school programme and the primary programme. Six/7 teachers who talked about power-sharing and/or coconstruction activities came from the high school, whereas only one teacher from the primary school mentioned this as an important part of improving classroom practice. 
These teachers told me that they believed an important part of their collaborative work with colleagues was allowing students greater ownership, voice and/or choice in classroom learning activities:

Co-construction for me is planning the whole learning process with the kids, that's all it is and I sometimes give them a limited menu to choose from of ways of doing this job, but sometimes I don't because sometimes I haven't got a particularly good menu in my own mind and I just think of the planning process: this is what we need to get through, these are the learning objectives, what's a good way of doing this? They love me asking that question and even if they come up with methods which I would have come up with myself or sometimes they come up with methods which I actually find quite dry, I find I get better engagement from students in the lesson purely because they owned the process, and when they say, 'We want you to stand in front of the class and tell us about this because it is too complicated for us to read ourselves or do ourselves', I get far better attention from the class rather than me saying, 'I'm going to read this out for you'. That's co-construction, it's power-sharing, it's about empowerment, empowering their learning. (Andrew, non-Māori teacher, 2003)

Some teachers explained that allowing students to make choices enabled them to become more responsible and to take ownership for their actions:

There is much less talk and chalk in my teaching, and I have much more of a range of activities for students now, like them working in groups, and with power-sharing you now discuss the lessons with the kids, and how they would like the lessons to run, you are not making all the decisions for them. I am letting them choose. (Leanne, non-Māori teacher, 2003)

Getting into the worlds of culturally diverse groups of students was an important part of improving classroom practice, according to Heria. She believed teachers needed to let go of power and build a different type of relationship with students: 
Teachers need to get off their pedestal, you know, and get into the role of their students more ... . Does it really matter what language the kids use if they're turning up to class and getting their work done? I mean, for me, it's about working with them, the students first and stepping into their world and then when you have their trust and some credibility with them, because for a lot of our young people their experience of adults is that they shit on them and just want to disempower them all the time, so if teachers, we get off our pedestals and work alongside our students and really build that relationship and our understanding of them as people ... but that means letting go of the power ... and teachers like power ... . I'm not really fond of teaching as a profession. (Heria, Māori teacher, 2003)

Sharing power and reciprocal learning between teachers, students and their families was an important part of improving practice for another teacher:

We think that it's easy to know what's best at this school as teachers, 'cause we're seen as experts, and maybe others aren't seen that way, you know, but we can learn off everybody and you should never ever say that you know lots and never ever assume and judge, 'cause our parents here have got knowledge that they can hand on, kids have too, kids have got knowledge that they can hand on that they know something about, so you should never cut those links or cut off that line of communication. There should always be a reciprocal sharing of knowledge, so as teachers Māori and non-Māori - we don't hold the power, it's a shared thing, you know, and I think maybe teachers do think that they have all the power, and that knowledge is power, but it can also be ignorance. (Saul, Māori teacher, 2003)

These ideas about power-sharing were supported by descriptions that students gave about changed classroom practice. Some Māori students who were interviewed talked about their experiences of teachers allowing them more choice and/or increased participation in decision-making processes within learning activities. I was interested to note that 4/9 Māori students who were interviewed from Kowhai College talked enthusiastically about such improvement to their teachers' practice. This Year 11 Māori 
student told me that the previous year she believed she had experienced some excellent teaching ${ }^{33}$ because of her teachers' use of power-sharing and problem-solving strategies:

... last year some of the teachers' teaching was the best, the best thing ... like one teacher was asking us how to find answers to things and we had to work in groups to find the answers ... as if we were in charge, and that teacher said he wasn't sure how to go about finding out the answer ... and he'd get everyone making suggestions, and he did that really well, he'd say, 'Well, I'm not sure how to go about this. Does anyone have any ideas?' And it got everyone just onto it, everyone's talking about their ideas on how to do it ... . (Lucy, Yr 11 Māori student, 2004)

Taking over the teaching role enabled another student to have a greater appreciation and respect for her teacher:

Like last year ..., we had to do the ten questions first, because Mr Roberts left it up to us how we would do this, so it was just anyone get up, get a pen and do the questions, and it meant that it made us feel good. I mean, when you're up there in front of the whole class in charge, it makes you feel better, so you're like teaching and if they're not respecting you, you know how it feels to be a teacher when someone's not listening, so ... When you're the student, you'll know to respect the teacher 'cause you know how it feels, so that's another way of, like, making the student be more on task, things like, by letting them feel how it, the teaching, letting them know how it feels to be in the teaching situation. (Marama, Yr 11 Māori student, 2004)

Max described the ways he had attempted to work with colleagues over the course of the year in order to improve students' ownership, motivation and/or engagement in classroom learning activities:

33 This student was one of the Māori students who was involved in the Te Kauhua class as a Year 9 and 10 student. 
One of the things I've been trying to talk to my colleagues about is letting Māori students have more ownership and giving all students more responsibility for what happens in class. ... So giving them that ethos of a work environment is working very well and some of the students have really realised and changed the way they've behaved, they've taken a vast amount of ownership. They've taken more ownership than anybody else which is really good. ... But when I've talked to some of my colleagues, they are very resistant to these ideas ... they aren't interested and it just reminds me how blindfolded some staff are to students and their needs. (Max, non-Māori teacher, 2004)

Data indicated that teachers could hold very different beliefs about what counted as 'improved practice' for students within their schools. This was evident in teachers' second interviews as participants explained how they sought peers to observe and how they explained the basis of their choices: in other words, which peer provided the most appropriate role model for 'effective teaching'. It was also evident in some teacher descriptions of staffroom discussions, as they found themselves talking with peers from across their school about 'what counted' as effective discipline. I discovered that the notion of power-sharing or co-construction with students was contested, particularly within Kowhai College. However, teacher discussions about the appropriateness of coconstruction and/or power-sharing strategies in the classroom appeared to be limited to particular teacher groupings within this school. Evidence suggested that this was not an issue which teachers debated openly and/or constructively across their school communities, which inevitably had an effect on students' experiences of teaching efficacy:

I don't think all the teachers see it like I do. Actually, in our [department] discussions, I think some people see co-construction completely differently to me, and I know that this is not necessarily out there with everybody else, we've got completely different views about co-construction which is interesting, but I've never really come across the term and I just took it to mean that, let's build this thing together with the kids, let's not have the whole thing controlled by the teacher from the front of the room. (Andrew, non-Māori teacher, 2004) 
... there's teachers, Māori and non-Māori, here that are really enthusiastic and really trying to run with it - the project, and think they're really working really well with it, but sometimes I find the kids don't feel like they're still getting heard when they say, well, they're not actually understanding what's happening in the class, even though ... the teachers are trying all these new things, but it's not actually being clarified, and when I actually approached one of the teachers ... she didn't think that listening to the kids was actually the idea of the whole thing. (Mrs Tito, parent/caregiver of Māori child, 2004)

It was clear to me that teachers held different beliefs about the importance of using power-sharing strategies with students and/or the status of culturally diverse voices within the context of their reform work. As emphasised in earlier chapters, teachers' beliefs about what counted as improved practice and outcomes for Māori students appeared to me to remain unexamined and/or unacknowledged over time:

Power-sharing and co-construction strategies are all very well ... for the mainstream, but they're not appropriate for the children I work with ... I have quite set views on discipline and I didn't feel the material covered was as relevant for me. (Ian, non-Māori teacher, 2004)

I found a range of competing theories within the literature related to teacher beliefs and issues of power within school communities. It has been argued that teachers often want increased power and status for themselves as a professional group, yet this can be the very thing that they deny students and their parents/caregivers (Bascia \& Hargreaves, 2000). Certainly all of the teachers I interviewed (17/17) believed it was important for them to exercise "ownership" within the context of teachers" collaborative partnership work. Having ownership enabled teacher engagement in new, collective learning activities, according to many participants who were interviewed:

We were given the option of whether we wanted to pair up or not. We didn't have to pair up with certain people ... so we could make our own choices, which I think was important for encouraging that ownership ... . Since Andrew and I share the same class, even though we teach different 
subjects and in different environments, we thought we would see how it would work observing each other teaching that same class and see whether we used similar tactics in getting the students to perform. (Max, non-Māori teacher, 2004)

... a teacher will usually identify their goal, and then we'll have a chat ... as to what their goals are, how do they want to get there? What do they want from their ... coaching sessions? Can I help them with something they want to improve? So it's something we're planning together ... the ownership of the process is important, because it's starting from the teacher's level, you're not going in and imposing it on them ... . For some teachers, they've wanted to get some ideas of how to use cooperative activities ... so it might be modelling something for them in class and then they'll give it a go, and I'll be in class just supporting them ... . They [the teachers] also had complete confidentiality and control. In meetings, if they brought their in-class observations to share, they could bring out this stuff, but I couldn't bring up the fact that half the kids were off task in their classroom. They could bring it up, but I couldn't. So the control rested with the teachers ... . (Resource Teacher of Learning and Behaviour 1, 2003)

As mentioned in the previous chapters, I knew that school reform programmes were increasingly promoting 'power-with' processes which included teachers' involvement in joint decision-making (Frost, Durrant, Head \& Holden, 2000; Fullan, 1999; Goddard, 2001; Lieberman \& Miller, 1999). Such processes are necessary in order to develop teacher capacity to improve classroom practice and student outcomes provided there are appropriate levels of support and accountability (Fullan, 2005). Frost, Durrant, Head \& Holden (2000) have argued that if successful change is to occur in schools, related to improved classroom practice and outcomes for students, then teachers need to be supported in developing their agency. According to social cognitive theory, individuals exercise agency through choice (Goddard, 2001). The development of teacher agency in schools can transform institutional structures which constrain the development and improvement of practice (Frost, Durrant, Head \& Holden, 2000). The agency of the teacher is central to the discourse on instructional practice, because it enables teachers (as 
individuals) to initiate and sustain change, to be active agents rather than objects of change strategies (Frost, Durrant, Head \& Holden, 2000).

However, I felt the arguments put forth by Bascia and Hargreaves (2000) which stress that teachers often want power, "the very thing that teachers deny their students", ignore the complex cultural hierarchies related to status within collective settings that are illustrated by interviews with some Māori participants. It seemed to me that teachers needed to engage in dialogue with Māori students, their parents/caregivers and community elders to determine 'what counted' as improved classroom practice and outcomes. I felt this illustrated a lack of trust and respect. However, as explained previously, there appeared to be no acknowledgement of the need for such collaborative partnership mechanisms within the context of teachers' collaborative partnership work, and the collective inquiry practices and listening mechanisms which I felt had such an impact were not developed into either of the schools' systems.

I started to see my initial analysis of teachers' stories, of the need for a 'shared vision', as being very superficial. I discovered that there was some debate within educational research literature about the importance of teachers' shared vision of reform within school communities. Some authors highlight the importance of teachers establishing shared values and a school vision by their involvement in conversations about the purposes of schooling over time (Senge, Cambron-McCabe, Lucas, Smith, Dutton \& Kleiner, 2000). However, Fullan (1999) argues that a shared vision can develop only after a process of shared inquiry because participant beliefs and values can remain unexamined and interrupt the process of collective learning over time. Timperley, Fung, Wilson and Barrar (2006), citing the work of Nonaka and Takeuchi (1995), note that there may be difficulties in challenging teachers' current values, beliefs and knowledge associated with existing teaching practices, as these are usually tacit rather than explicit. These authors note that tacit knowledge may remain unexamined because it has been developed over time and constructed through participants' experiences in diverse social environments:

While explicit knowledge is typically articulated in formal language, and therefore, is more easily expressed, tacit knowledge is often intuitive and involves more intangible factors such as personal beliefs, perspectives and values systems which may never have been articulated. Because tacit knowledge has been built up over time and is embedded in personal 
experiences, it can be a deterrent to change, because it is often unexamined, unquestioned and is accepted because it is known to work. (Timperley, Fung, Wilson and Barrar, 2006, p. 10)

It appeared to me that teachers' beliefs about new partnership work could remain unexamined and unacknowledged over time, along with unacknowledged, submerged and hidden (subversive) practices which influenced the acceptance, practice and adoption of teachers' partnership work as well as its place within each school's culture.

\section{Messages about Established Listening and Partnership Practices with Culturally Diverse Stakeholder Groups}

I found myself wondering why teachers had stopped listening to and inquiring into the perspectives of Māori students and their parents/caregivers/whānau, particularly since stories had suggested to me that these had been powerful mechanisms for encouraging a change in teacher thinking and increased understanding. As cited in earlier chapters, I found that in Aotearoa/New Zealand, Penetito $(2001,2004)$ has argued strongly that improvements in mainstream teaching practice that result in enhanced outcomes for Māori students can only be achieved through inquiry and dialogue with whānau, hapū and iwi. A number of authors writing in the area of multicultural education, culturally responsive practice and critical race theory have argued that in order to make a difference to the achievement and outcomes of marginalised and oppressed groups of learners, teachers and schools must continually seek out and actively listen and respond to culturally diverse stakeholder voices (Johnston \& Bush, 2005; Shields \& Sayani, 2005; Sleeter \& Delgado-Bernal, 2004). This would include the voices of elders, community members, parents/caregivers, young people and children as well as teachers within the work of reform (Johnston \& Bush, 2005; Shields and Sayani, 2005).

It appeared to me that there was a lack of acknowledgement and awareness of the need to establish and strengthen listening and partnership practices within each of the school's communities. My analysis of participant stories indicated that there were differences in opinion between teachers about who should be consulted and participate within the work of collaborative reform across both schools, but these opinions were never examined or debated openly. It has been argued that if culturally diverse teachers are to work together and improve practice for equally diverse learners, then they must 
engage different stakeholder groups in socio-cultural inquiry - a process which examines the values and beliefs underpinning existing practices - and that such inquiry continues over time (Johnston \& Bush, 2005; Shields \& Sayani, 2005).

It interested me that the clear majority (13/15) of parents and caregivers of Māori children who were interviewed, although supporting the collaborative work of teachers, believed that the goal of reform (improving Māori student outcomes) could not be undertaken without including whānau members:

I still think the partnership idea is good, Māori and Pakeha teachers working together to make it work, but what about involving whannau and community more? I don't think the school or the teachers can do it by themselves. (Mr Tumu, parent/caregiver of Māori child, 2004)

We've also had a number of projects designed to help change things for our tamariki which don't seem to last so people think this is just another project. How many times have we been involved in projects? About 15 years now at that school, and I've gone to different hui over those 15 years ... the school needs to be serious about the kaupapa and that means partnership with whānau, and that's more than having a token Māori voice here and there. (Mrs Huia, parent/caregiver of Māori child, 2004)

Nine/15 parents and caregivers of Māori students who were interviewed at both schools believed their children also needed to be consulted about the effectiveness of teachers' collaborative reform efforts over time:

... if they [the teachers] could do like an anonymous survey of the kids every now and then, of how the kids are feeling about that class and about that teacher - kids are blatantly honest and they'll write that either, 'I'm not learning anything in that class', or 'Yeah, that's really great and I've learnt heaps this year'. But I think if the teachers don't get that feedback, they can't improve. Like an appraisal. I know when I was doing my degree and we had to do teaching sessions, you had to be evaluating, you had to give all the students these forms and they had to put in what they thought of you, and it was really hard sometimes because people are really honest, 
but you can really learn a lot from what other people pick up, and I think that would be a very good thing. (Ms Wilson, parent/caregiver of Māori child, 2004)

The kids seem to be able to judge who's good and who isn't good and why they're not good, and why they didn't think that they were going to learn off them ... and this wasn't just the European teachers either, this was Māori teachers as well. At times they were just as critical of their Mãori teachers. (Ms Walker, parent/caregiver of Māori child, 2004)

I still think there's work to be done from the kids - from the feedback I've had from the children about how the teachers think they're coming across and how the children think they're coming across ... sometimes the two perspectives are quite different. (Mrs Grace, parent/caregiver of Māori child, 2004)

Kids know what's happening at school, even young kids ... we need to be asking them what they think ... . I know if my boy is happy at school, and if he's happy with his teacher ... so I think we need to be asking the kids more. (Mrs Tito, parent/caregiver of Māori child, 2004)

It appeared to me that there would have been experts within each of the school's communities who could have participated within collective discussions on 'what counted' as improved classroom practice and outcomes for Māori children and young people. I had learned from previous interviews that spaces had been created within the Te Kauhua professional development which had enabled these collective discussions to take place. It appeared to me, however, that there was no recognition of these partnerships and they were not developed or sustained into either of the school's cultures or structures:

... a kaumatua from the local community had done a session with teachers in terms of values, exploration etc. at our previous training conference ... and so he ended up teaching a lesson with one of these teachers, to her students ... he was working with the teacher to enable students to examine images and their beliefs through more critical eyes ... . What we're saying 
to teachers is that we're not asking you to be the expert, we're saying there are experts out there in the community. Make yourself safe, bring them in and give them the space to work with their own people ... because they can provide something that you can't ... so yeah ... it's about making space for kaumatua or kuia to come in ... we're just sort of touching on this and we've got a long way to go ... but it has been a powerful learning experience for teachers and for students. (In-school Facilitator 1, 2003)

I'd like to see them [Māori and non-Māori teachers] ask our kaumatua and get them more involved. Why I say the kaumatua is they have been here in this community a lot longer than, say, some of our Māori teachers. (Ms Lynn, parent/caregiver of Māori child, 2004)

I started to question the unexamined and unacknowledged practices of each school which appeared to me, as qualitative researcher, to make up the culture and structure of each school. These less visible practices began to act as warnings which highlighted the lack of inclusiveness and partnership practices in the schools. I began to realise that in order for culturally diverse teachers to work together for change and transformation, they would have to identify such practices, as well as the values and beliefs that underpinned them. 


\section{Chapter 5. Warning Signs About Resistance to Collaborative Partnership Approaches: The Internal Dynamic}

The process of navigating my way through participants' stories about teachers' collaborative partnership work continued to be a long and arduous journey, interrupted by what I came to see as different messages, signs and warnings. This chapter further explores the factors which influenced the practice of teachers' collaborative partnership work, as well as its acceptance and place within each school's culture. I found that the following proverb, used by Penetito, ${ }^{34}$ is particularly relevant to my own analysis as it emphasises how first impressions can be deceiving:

Although they share meals, within them is jealousy -

True unity is more difficult to achieve than its appearance.

As I listened, I became aware of largely hidden values, beliefs and practices that contributed to each of the school's cultures and fed resistance to collaborative partnership work. This resistance focused on a breakdown of any single-mindedness of vision the schools may have tried to achieve, and on interpretations of identity and equity. It included (internally) the presence of deficit thinking, prejudice, racism, forced identities and learnt behaviours, within an environment (externally) of established micro-politics, staff divisions and disputes, bullying and subversive practices, and hierarchies and power relationships within each school community, which also extended beyond the school gates (see Chapter 6).

As I navigated the messages contained within the stories of culturally diverse participants, I searched out literature which would help guide my analysis. I found some authors had argued that understanding the causes of resistance in collaborative reform work is important because, while there is a tendency to label dissenters as simply bad and/or outside of the 'in-group', it is necessary to identify the factors that impact on the learning capacity of the whole school and the organisation's ability to solve problems and create new ways of doing things (Fullan, 1999; Fullan, 2005; Fullan \& Hargreaves, 1996; Senge, Cambron-McCabe, Lucas, Smith, Dutton, Kleiner, 2000; Stoll \& Fink, 1996;

34 Penetito (2004, p. 2) explains that the proverb is from Tuwhenuakura and is cited Mead \& Grove (2001, p. 13). 
Stoll, Fink \& Earle, 2003). It was clear from my own analysis that teachers' collaborative partnership work had created emotional turbulence within both school communities, with some participants describing their feelings of shock, anxiety and/or anger over time.

Shields and Sayani (2005) have argued that learning communities that encourage an examination of classroom practice from culturally diverse perspectives inevitably allow conflict and tensions to arise. These authors maintain that the treatment of tension in much of the school reform literature suggests that it should be avoided or resolved rather than understood. They argue that since diversity is "a fact of life", it is "dangerous and damaging to equate it with difficulties; rather we would propose embedding discussions of diversity in concepts of possibility and opportunity" (Shields \& Sayani, 2005, p. 384).

When I interviewed teachers for a second time, it became gradually apparent that it was necessary to acknowledge and understand the causes of participant resistance because such factors must inevitably influence the practice and acceptance of teachers' collaborative partnership work and also its efficacy. I came to understand why many of the teachers had experienced considerable difficulty sustaining their engagement in this work.

This chapter explores the internal influences that would need to be acknowledged and critically examined if real reform and transformation were to take place through collaborative partnership work. The themes that emerge in this chapter call for a new type of leadership that works to identify the hidden and less visible factors that fuel resistance, and which allows, encourages and sustains partnership work through a recognition and valuing of cultural diversity, that engages in open dialogue, that is inclusive and respectful, but that is also unashamedly political in its approach. It appeared from data analysis that not all staff members 'owned' the collaborative partnership work: this may be one reason why there was a lack of unity and shared purpose amongst the teachers. Over time, I came to see that teachers' collaborative partnership work can flourish and take hold only through genuinely collaborative school cultures, which would be able to form and survive only if new forms of consciousness were encouraged through critical, collective inquiry and political activity. Such processes would be predicated on participants learning how knowledge is socially constructed and benefits certain groups within society. 


\section{Resistance to Teachers' Collaborative Partnership Work}

Different participants who were interviewed across both school communities believed that various groups emerged over time in response to teachers' collaborative partnership reform work. Some actively worked together for change and others were resistant to partnership work:

I guess we then had three different groups of teachers at that stage: one group who realised there was a real need for change and were right in there with it, there were those who disagreed but agreed to keep the peace and some of them were sort of simmering underneath, and there was the group who really thought it would all go away. (In-school Facilitator 2, 2004)

We now have our koru, our teaching beliefs that we have all agreed to, but the challenge lies in us making this a living document, in turning our beliefs into action and us continually examining data from different sources which let us know what our strengths and weaknesses are ... but even after doing our vision, we still don't have everyone in our waka, so there are still people that are fluttering around, wondering whether they wanted to be on the waka or not. (Saul, Māori teacher, 2004)

There were three camps really, the 'Let's go for it' camp, and then the middle camp saying, 'Oh, yeah, I suppose', and then the fringe one saying, 'No, you're not coming in here [into my classroom]'. (Resource Teacher of Learning \& Behaviour 2, 2004)

An in-school facilitator explained how he became "tipped off" that a group of teachers was pulling out of collaborative reform work:

Basically we send forms around first of all to see which teachers were participating ... and there'd been no response from a particular department, so that was your first tip-off that it wasn't happening because, particularly with these individual teachers, they're very well planned, 
they're good at doing the paperwork, so if they've missed that it wasn't by accident, if you know what I mean? So that was the first part, and then we do the face-to-face meetings as we've always done, and it wasn't so much a blatant, 'No, I'm never going to do this again'; it was more like, 'This is not a good time for me, I'd like to choose to do it when I'm less busy'. But in terms of the nature of this work, we were coming from the point of view that if you were a professional teacher then you had professional responsibilities, which was to participate in professional development experiences such as this, and to critically reflect on your teaching practice, for all of your students, not just some. So that's basically how I found out that some teachers from a particular department were pulling out. (In-school Facilitator 1, 2004)

A number of participants (teachers, students, parents/caregivers, in-school facilitators) noticed that particular groups were resistant to the work of reform over time, and there were clear differences in teacher beliefs about what counted as improved practice for Māori students within and across both school communities which indicated a lack of unity of purpose or vision:

The most challenging thing about working together is the comments of, 'What about the other children?', 'Why are we always doing this stuff for Māori children?' I never thought that teachers would say that sort of thing, but they really do. I also think that to raise the achievement of Māori children, we have to know and learn about teaching strategies that reach our children. I think if you know a culture, then you'll have a better understanding about how to teach those children and if we're not willing to go there, if you're not willing to talk about it ... . Sometimes people get a bit anti and that's a challenge ... if they are not willing to get involved in the mahi and do those strategies or try all those things, then nothing happens ... . How do you make someone do something that they don't want to do? You can talk until the cows come home, but at the end of the day, it's up to them. (Maree, Māori teacher, 2004) 
... there is a real strong core group of teachers who truly believe in the kaupapa, and who felt what we were doing was working ... but there have been other teachers who have pulled out ... we understood that it was going to be hard for some teachers so we have deliberately tried to be supportive and encourage teachers to take ownership, but really the hardest thing was your mindset change, you know, no additional money, no strategy. There wasn't anything else that was going to change that - it was the mindset, and so the reasons for teachers opting out were confusing to me and to other teachers on staff who have been involved in this from the start, and I tended to think maybe it's because this is about Māori student achievement, maybe that's the reason they've pulled out? Whether that was or wasn't the point at issue, I'm unclear ... and yet the data for our school and nationally is that we need to do better for our Māori students. This is a national issue and it's like burying your head in the sand if we don't talk about it, and with people opting out it's hard to sort of push the idea that we're all supporting each other on the staff, that we're all on the waka together, because obviously we're not when people do that [pull out]. (In-school Facilitator 1, 2004)

Some parents and caregivers of Māori children who were interviewed appeared to be sensitive to issues of teacher resistance to collaborative partnership work within their child's school. One participant described her own observations related to teachers' engagement in partnership work, suggesting that existing school power structures precluded the possibility of any real collaboration in settings such as hui which intrinsically embody a collaborative mode of operation, and where the failure of the group to act cohesively may be even more apparent than in another setting:

... and a lot of school sort of hui where they invite parents, they've got the teachers up the front, staff up the front, and you're [whānau] all up the back, and normally there's a lead speaker in the teachers' group, and they tend to take it over, so all the rest who are there don't speak, who want to but can't or don't - so the true reason about why others have gone isn't aired, or why other teachers aren't there. (Mrs Tui, Māori parent/caregiver, 2004) 
Some students appeared highly negative towards the idea of teachers' collaborative partnership work, and of the changes they had observed in class. This suggested that these students did not feel as if they were 'inside' the process, and their position outside it allowed them to denigrate it, as foreign, insincere or phony:

Nah, haven't heard anything about Māori and non-Māori teachers working together ... or anything ... but some of our teachers have been speaking PC language and talking gay, like you know they're trying to speak Māori proper with the way they speak like they're Màori or something, trying to be something they're not. (Andrew, Yr 12 non-Māori student, 2004)

One of our science teachers is all politically correct ... she's pronouncing the Māori words right and not using homophobic phrases - you know, that sort of stuff ... not being racist and stuff like that. (Ted, Yr 11 non-Māori student, 2004 )

Interview evidence highlighted the presence of a group of parents/caregivers who voiced their concerns about the direction and impact of new reform work. It was clear that this group viewed teachers' partnerships as threatening to their own children's education and academic success. Some participants from Rata Primary described the resistance that emerged when a group of parents/caregivers threatened to withdraw their children from the school because of the observable changes that teachers' collaborative partnership work were bringing about:

Well, the school held a parent meeting to talk about the project, but only a few turned up and the wrong ones I think. We had some bloody terrible racist views expressed as well in front of Saul and I could almost feel him get ready to throttle this red-necked guy across the room. It was all over teaching te reo in class and I just said to him quietly, 'No, not now Saul'. And thank goodness that he was strong enough to sit in his chair because that other guy was so out of order. But the truth is, he's a parent. Well, we got through the conversation and we explained that he had the wrong end of the stick and that the children weren't doing te reo all day long, they 
were doing a little bit of it. A little bit would be good in the world. We just calmed him down. But it was tricky for Saul who was ... doing his bit and in actual fact it was his class that they, the parents, were criticising most. (Consultant, non-Māori, 2002) ${ }^{35}$

A particular challenge to Māori and non-Māori teachers working together that we faced was really negative reactions from a few non-Māori parents to the amount of te reo being used in school and especially spoken in classrooms. They have expressed their concerns about their children learning te reo and have seen this as detrimental to their children's learning. A few parents have reacted quite negatively and said that they would pull their children from the school, particularly when we appointed our Deputy Principal who is Mãori, and there have been some families who have withdrawn their children. I've had to describe Te Kauhua as a programme which is based around good teaching and good teaching benefits all children, but there has been some negative reaction to the amount of te reo or a focus on tikanga Māori and that's been hard to deal with. I think as a principal you're always sensitive to parents who threaten this, with schools competing for numbers and we're struggling to keep our numbers up. There are families here who chose to send their children out of the town for their schooling so it's hard when you're trying to make positive change and you also are faced with dealing with the deficit thinking of the wider non-Māori parents towards anything to do with Māori. (Principal 2, 2004)

It seemed to me that some teachers had experienced considerable pressure to reduce the amount of te reo and/or tikanga practices within their teaching. I found that particular incidents occurred over time within the context of teachers' collaborative reform work which emphasised how little real respect there was for Māori as tangata whenua and also exposed racism, stereotypes and a real lack of respect for cultural difference and diversity. During final member checks in 2005, Barbara expressed her

35 This quotation was part of an interview with this consultant, gathered as part of the Te Kauhua Evaluation. The participant gave me permission to use this interview for the purposes of this study. 
anger that there had been recent pressure placed on one of her colleagues to reduce the amount of te reo or adherence to tikanga Māori within her classes:

I felt really angry that my colleague was told she was using too much te reo in class, after all that talk ... my feeling is we haven't really progressed ... . It's really come down to the nitty-gritty and it's a question of our values, and those values are inherited... I also feel if we took away the Māori words, such as Te Kauhua, there would be more acceptance of what teachers are doing, but I feel that is a cop-out, and really a lack of respect for us as Māori. (Barbara, Māori teacher, 2005)

Some parents and caregivers admitted to me that they resisted teachers' collaborative partnership work once they started to see changes in practice within their child's school. It seemed to me that their voices within the school community may have been privileged and heard well above the voices of others:

When I had my concerns, it was towards the end of last year when they were talking about increasing the Māori content. There were a few of us parents that spoke up and discussed, you know, other options if we didn't like how much was being introduced. Then we would remove our children, and I was one of those ... we would remove our children and take them to a school which didn't do so much, I suppose. (Mrs Kruger, parent/caregiver of non-Māori child, 2004)

I've noticed that the Māori influence has got stronger at the school ... the school has sent out information about what the teachers are doing, and what they are learning, like with the children's goal-setting and the literacy and what they are trying to change, and how they are bringing the Māori side into it. Well, they told us how much Māori was going to be taught in school, like the percentage of Māori being spoken. I wasn't sure that it was all that good, and there was a little resistance around the parents to that at the time, because most of us didn't want that much coming through. (Mrs Logen, parent/caregiver of non-Māori child, 2004) 
As I listened to the perspectives of individuals located within diverse participant groups, I wondered about the readiness of teachers and principals to cope with the wider political ramifications of their collaborative reform work. I started to realise that change and transformation are possible only if teachers work together as political activists, exposing the hidden curriculum and practices of schooling which privilege some over others. Critical approaches to education begin with the view that schools are not closed systems and are not cut off from wider influences (Corson, 1998). It has been argued that schooling and education are contested sites and places of struggle and resistance (Fine \& Weiss, 2005). As I could not locate research studies conducted in mainstream schools within Aotearoa/New Zealand which addressed these issues, I looked for research that had been done overseas and found an American report on 10 case studies of school reform efforts that were committed to issues of equity and social justice (Oakes, Wells, Yoneawa \& Ray, 2000). Oakes, Wells, Yoneawa and Ray (2000) explain how these reform programmes met with considerable parental resistance from white, middle-income parent groups; and how change agents working within these schools were ill-prepared to respond to considerable political pressure from powerful parent groups, who interpreted such activities as threatening to their own children's education and academic achievement. These authors note that principals eventually responded to political pressure and cut back on reform activities in their schools, particularly after groups made threats to pull their children out of the school. I could connect with the arguments put forward by Oakes, Wells, Yoneawa and Ray that the change agents generally neglected such sociopolitical issues, particularly if reform efforts are aimed at improving the responsiveness of existing classroom and school programmes in order better to meet the needs of culturally diverse groups:

Most of the change agents that we observed were caught unprepared when the process and shape of their equity-minded reforms were profoundly affected by norms and politics concerning race, gender, sexual orientation, language and socio-economic status. (Oakes, Wells, Yoneawa and Ray, 2000, p. 88)

It appeared to me that some participants' voices and concerns were clearly heard above others within the context of teachers' collaborative partnership work. I felt that at least one of the school principals interviewed was sensitive to the pressure applied by a 
group of parents/caregivers who actively resisted teachers' collaborative partnership work. He explained to me that his school had a falling roll and was susceptible to the 'white flight' of some family groups as a result of teachers' collaborative reform work. Hargreaves and Fink (2004) have highlighted the issue of sustainability within school reform programmes, and argue that ongoing improvement within individual school contexts can occur only in a national context where schools 'do not harm' one another. Competition can be viewed as a harm, as parents may initially resist innovation, particularly related to issues of equity and social justice (Bascia \& Hargreaves, 2000; Thrupp, 1999). Thrupp (1999) has argued strongly that the development of market competition (devolution and parental choice), coupled with tougher forms of school accountability within Aotearoa/New Zealand, has meant that current market-led reforms appear to be largely inadequate for addressing the problems of equity and excellence in mainstream classrooms. Clearly, a group of participants who were interviewed believed they could 'vote with their feet' if their concerns about "the growing Māori influence" within their children's schools were not addressed.

It seemed to me that one school was particularly vulnerable to the political pressure of parents/caregivers who threatened to withdraw their children, especially since this school had a falling roll and existing race relations within the town community were characterised by negative stereotypes and assumptions. According to Achinstein (2002), participants working towards collaborative reform must develop an understanding of participants' ideologies because such issues are important for understanding the nature of community within and beyond the school gates:

Ideologies are not solely framed within the teacher community. Both within and beyond the school house walls, people hold conceptions about the ways that schools should be (Cuban, 1984; Meyer \& Rowan, 1977). Schools cannot be understood without understanding the environment or larger social contexts in which they operate (Anderson, 1991; Ball, 1987). Micropolitical theorists often find that macro- (ideologies found in the larger environment) and micropolitical (ideologies within a community or organisation) factors frequently interact .... (Achinstein, 2002, p. 427)

I came to see that teachers could work together for change and transformation only if they became political activists. I found a series of authors who call for critical, 
collective enquiry; a process which engages culturally diverse stakeholder groups in dialogue and collective inquiry, raising participant consciousness into their own thought processes so that they discover that knowledge is socially constructed and that truth is relative not only to time and place but also to positions of race, class, gender, sexuality and dis/ability (Bigelow, 2001; Fine \& Weiss, 2005; Freire, 2000; Giroux, 1985; hooks, 2003; Kincheloe, 2003; McLaren, 2003; Unks, 2003).

Most of the authors I found writing about the need for teachers, students and parents/caregivers to study power are critical theorists interested in intersections of race, social class, gender, sexuality and issues of social justice (Fine \& Weiss, 2005; hooks, 2003; Kincheloe, 2003; McLaren, 2003; Sleeter, 2005; Unks, 2003). It seemed to me that these authors argue that participants must understand knowledge as a social construction, deeply rooted in a nexus of power relationships, because it is only through such understanding that they can work for change (Fine \& Weiss, 2005; hooks, 2003; Kincheloe, 2003; McLaren, 2003; Sleeter, 2005; Unks, 2003).

\section{The Dominant Discourses of Resistance: Identity and Equity}

As I interviewed a range of participants across various stakeholder groups, participant resistance to teachers' collaborative partnership work emerged more and more clearly within and across both school communities. This resistance was closely related to individuals' own values and beliefs, and their own personal identities. For example, one non-Māori parent/caregiver explained that she had not wanted to find out anything about teachers' collaborative partnership work because she identified as a "European":

I don't know much about it, that Māori and non-Māori teachers were working together at the school or anything about raising Māori student achievement ... . There might have been something in the newsletter about it, but I probably didn't read it because it's about Māori education and I don't think it really has anything to do with us, we're European ... . (Mrs Andrews, parent/caregiver of non-Māori child, 2004)

Being European, for this participant, meant that she was not interested in anything to do with "Māori education" at her child's school. Other participants stressed that their 
identity influenced the way they defined and/or engaged with teachers' collaborative partnership work:

I'm not interested in asking any questions about non-Māori and Māori teachers working together. Why would I be? I'm not Māori ... . (Heath, Yr 11 non-Māori student, 2004)

... this Pakeha and Māori nonsense has got to stop. We are all New Zealanders ... like we're all offered the same opportunities in life and if you want to take those, then take them, and if you don't, then you suffer the consequences. (Mrs Hall, parent/caregiver of a non-Māori student, 2004)

Some parents/caregivers expressed concerns that teachers' collaborative work at their children's school was racist, even though they acknowledged that they did not know much about what teachers were attempting to do. These participants appeared to jump to the conclusion that by addressing the needs of Māori students, teachers would ignore the needs of Pakeha children. They also espoused the idea that teachers should ignore racial differences, claiming acknowledgement of these differences to be a type of racism:

There seems to be so much of an emphasis on Māori children in education and that sort of thing and it doesn't seem to be focused on the Pakeha children who are struggling in the classroom. Like, it should be even ... as far as I'm concerned and all these special treatment for the Māori kids, it's like, why just for them? (Mrs Smith, parent/caregiver of non-Māori child, 2004)

Yeah, it's like it's racist ... I mean, to me we've all got the same ability to learn and just to say that one person's going to get special treatment just on their race ... it's a bit unfair ... . I mean, if some kid, whether he's a Pakeha who's struggling in reading and writing ... he's been told, 'No, sorry, you're not a Māori so you're not going to get any special treatment', ... I don't get this race difference, like, to me everyone is even and we should be treated the same ... like, to me, let's get over this race 
thing and try and get all our kids achieving ... . (Mr Smith, parent/caregiver of non-Māori child, 2004)

Twelve/15 parents/caregivers of non-Māori children expressed concerns about teachers' collaborative partnership work. Some of these participants appeared to believe that teachers' partnership work could threaten their own and/or their children's identity. I searched for literature which would help me make sense of their fears and prejudices. Bishop and Glynn argue that contemporary educational policies and practices within Aotearoa/New Zealand have developed from within a framework of colonisation, and as a result, "the system continues to serve the interests of a monocultural elite" (1999, p. 12). L. T. Smith (1999) notes that past educational polices and practices have contributed to Māori political and economic marginalisation and that colonisation has created power imbalances within New Zealand society. Bishop and Glynn (1999) detail a number of power imbalances which contribute to deficit theorising and low expectations for Māori children within the mainstream education system. One of these is the -

... perpetuation of an ideology of 'we are all New Zealanders', therefore legitimating the belief that all children are the same and need the same treatment. Those who fail deserve to do so because of some inherent personal problem or cultural deficiency. (1999, p. 53)

McCreanor (2005) researched patterns of Pakeha talk, ${ }^{36}$ particularly identifiable and recurring themes in mainstream media discourse about Māori and Māori/Pakeha relations in Aotearoa/New Zealand. He maintains that a firmly entrenched and widely endorsed standard story has emerged related to "Māori privilege" where groups of Pakeha perceive Māori as having "special treatment" (p. 57). "Māori privilege" is viewed as "rights and resources unavailable to the rest of society", (and later) "a special treatment which is racist and akin to apartheid" (McCreanor, 2005, p. 57). McCreanor also identified another pattern in the discourse related to "One people" which "seeks to bury" diversity within society in an appeal to national unity $(2005$, p. 59). Proponents of the "One people" idea have argued that -

36 McCreanor undertook research on a series of Letters to the Editor within national media publications during a specific timeframe. 
'Unless we drop our sectarian interests in favour of national unity, as New Zealanders or Kiwis, racial tension will continue to grow ...'. This remains a powerful part of the standard story as the prescription by which harmony is to be achieved. (McCreanor, 2005, p. 59)

Similar arguments are made by those Pakeha who denigrate the concept of biculturalism in Aotearoa/New Zealand and uphold the concept of multiculturalism, while in fact using this position as a way to deny tangata whenua status to Māori and to protest that they acknowledge the differences implied by multiculturalism (Vasil, 1988). In fact, multiculturalism in these hands tends to be a leveller of difference, and to support the notion of "One people" identified by McCreanor.

Within the United States of America, Ladson-Billings (2001) has also argued that ignoring racial differences in classrooms is a process which masks "a dysconsious racism" through "colour blindness" (p. 320). According to Ladson-Billings, dysconsious racism is an "uncritical habit of mind that justifies inequity and exploitation by accepting the existing order of things as given" (2001, p. 320). Ladson-Billings argues that if participants (particularly teachers) fail to see the colour of their students and their cultural identity, then they are unable to really see the child. She notes that equity as sameness only makes sense when all children were exactly the same, and she cautions that even children from the same families do not share the same characteristics or learning needs.

Shields and Sayani (2005) note that when individuals or groups have been successful in school, they are "held up" as models and examples of the point of view that "hard work leads to success", while those who fail schooling, "whose reality is not congruent with fundamentally white, middle-class norms of education", are seen as simply not applying themselves (p. 392). Citing Shields, Bishop \& Mazawi (2005), these authors note that this type of deficit thinking or "pathologising" is a model of colonisation, "used to govern, regulate, manage, marginalise, or minoritise" those who are different from the dominant social group (Shields \& Sayani, 2005, p. 392). Shields, Bishop \& Mazawi (2005) extend this argument by stating that "deficit thinking is the product of long-term power imbalances that must be examined by educators in terms of their own cultural assumptions and a consideration of how they might themselves be participants in the systemic marginalisation of students in their schools and classrooms" (p. 6). I felt from my analysis of interview material that resistance is a complex political phenomenon, tied to historical 
contexts within Aotearoa/New Zealand and macro-power relationships of domination, subordination and pathologising practices (Shields, Bishop \& Mazawi, 2005).

\section{The Undercurrents of Resistance: Deficit Thinking, Prejudice, Racism and Identity}

I was particularly disturbed by a number of less visible, unexamined and hidden values and beliefs that emerged as different participants talked about their experiences of teachers' collaborative partnership work. Some of these stories revealed submerged messages indicating the presence of racism, arrogance and prejudice and a lack of genuine respect and trust between teachers. Participant stories revealed horrendous interactions between some teachers which seemed to contribute to the lack of success in sustaining change. Some stories highlighted the racist beliefs that some non-Māori teachers were expressing to their Māori colleagues. Over time, these messages were emphasised with other evidence of deficit thinking, prejudice and racism within and across both school communities, and of stereotypical or "forced identities" (McIntosh, 2005 , p. 48). Although teachers referred to the importance of establishing trusting environments where they could talk together openly, honestly and constructively in order to improve classroom practice and outcomes for Māori students, the 'hidden' beliefs and practices that began to emerge showed a lack of respect and trust for cultural differences and a lack of acceptance of teachers' partnership work within each of the school's communities. For example, some participants expressed concerns about teacher behaviour and prejudice within their children's schools. A particular belief or stereotype emerging from my analysis of participant interviews related to "lazy" and "greedy" Māori. These constructions of Māori were at odds with my observations, which showed that the majority of Māori teachers were giving up their own time after school to support non-Māori colleagues in te reo classes and/or attending extra and additional whānau hui to encourage their non-Māori colleagues:

I also believe that Māori and non-Māori teachers do need to work together ... however, I have seen teachers from both cultures being basically racist and that troubles me. I really have at that school ... there was a general consensus among some of the non-Mäori teachers that the Māori teachers didn't work as hard, like they were really laid back, and 
the consensus was that these teachers hoped the Màori teachers would come up to everyone else's standard, not the other way around. (Mrs Shelly, parent/caregiver of non-Māori child, 2004)

Maree described how she was shocked and upset by a colleague's comments in the staffroom, and while she wanted to confront her colleague, she had felt unable to do so:

We were talking in the staffroom, I can't exactly remember what the topic was, but we were talking about equal rights and the Treaty and bits and pieces and there was something in the paper about Màori, I can't really remember, but the comment she made was, 'Oh, that's just typical ... they want everything!', and I thought to myself, it just blew me away and I really wanted to say something but I just, for some reason, I was shy to ... I don't know why I never said anything. When you're put on the spot like that, you sort of don't know what to say, even though my gut told me I should have said something and I still think about it now ... . (Maree, Māori teacher, 2004)

Other participants who were interviewed described practices which revealed teachers' prejudice and racism. A Māori student told how she was particularly upset by an incident which she observed in class:

I was probably one of the only Māoris in this class, and I hated it, 'cause they'd all say things about Māori and I had no-one to like stick up for us and that ... one of the teachers ... one day she just went off! I was sitting with two Mãori boys in our class, and they said something and then she said, 'Oh, I get really offended'. And she made this big thing in front of the whole class ... and I was like really shocked ... . And then she actually said, 'And I'll also have you know you Māoris have had nothing to do with Lord of the Rings', ... she was staring at the two boys, the two Māori boys, and I looked at her. I was really shocked that she actually said that. (Ngawai, Yr 11 Māori student, 2004) 
Ngawai told me that she had tried to speak out about her concerns but was not properly heard by the teacher she approached:

I did talk to one of the teachers, one of the Mãori teachers. She was a friend. At some point we told her, and she said, 'Oh, you shouldn't really tell the principal 'cause I don 't think she would have meant it in that way', 'cause she was married to a Māori, the teacher who said it, so I didn't think anything of it, and I just left it at that, but when she did say that, it allowed all the other people in class to say, 'Oh yeah, Māori weren't involved' - that's what people said, the other students, and I was like, 'Oh, what am I doing in this class?' (Ngawai, Yr 11 Māori student, 2004)

Some participants had noticed subtle teacher interactions during staff meetings and hui where teachers had been asked to think about their attitudes towards Māori students. This parent/caregiver believed some teachers had tried to hide their true feelings about the causes of Māori student underachievement within the school community:

... I know that the teachers were really encouraged to think about their attitudes and how their attitudes could impact on kids, Māori kids particularly. And to look at the whole picture and to look at the perspective of the students and that they did have different cultural values ... but some staff were just blaming the kids and seeing them as the problem ... . I was sitting at a table with some teachers and we were predominantly Pakeha, and there was a blackboard and there was a chart with Pros and Cons and attitudes written on it and the teacher that I was sitting next to, when a question was asked, 'When a kid comes to school without their lunch, what do you think?', and her attitude was extremely negative, and she was blaming the kids and the family and being just really negative in the group, yet she didn't raise these issues when the facilitator asked for comment. (Mrs Thompson, parent/caregiver of Māori child, 2004) 
Other participants noticed a lack of respect amongst some for Māori teachers' views:

... Umm, just generally the way that some teachers come across, whether they sound like they are giving Màori teachers like Saul or Robyn the respect and listening to what they have to say ... at the end of the day, it's the attitude that just says it all, and you can see if they don't care. ... . Like sometimes I do come over and I just sit in the staffroom and have a general chit-chat with some of the teachers and I find who is interested and who is not interested in the conversations about what's going on, or if the topic is about things Māori, then some up and leave, and you're left with the feeling that they don't want to know ... . I feel some [teachers] don't feel comfortable voicing their opinion to people ... . They would rather wait and go around the corner and say, 'God, check them out. Da. Da. Da. Da.' But they're not there saying it to the person. (Ms Lynn, parent/caregiver of Māori child, 2004)

Different parents and caregivers who were interviewed talked about the body language and/or 'face pulling' amongst teachers when subjects related to te reo Māori were raised within the staffroom:

I know for a time ... certain teachers would sit in one part of the staffroom and other teachers would sit in another, and people would pull faces when some teachers talked about te reo and things like that. That seems to have dropped, but it does still happen with a few teachers. ... I'm a people watcher, I like to see what people are doing and what they're saying, the expressions and the body language, and sometimes you see a reaction, like a stiff back and stuff ... . I think some teachers were frightened of it, and some maybe still do. They maybe feel threatened, or out of their comfort zone. (Mrs Huia, parent/caregiver of Māori child, 2004)

In her analysis of Māori identities, McIntosh (2005) notes that Māori have "forced identities", "formed under conditions of deprivation, distorted by the realities of living on the margins". Such identities are largely stereotypes based on the perceptions of "outsider groups" (2005, p. 48). While identities are social constructions, these negative 
stereotypes are an identity formation forced on Māori with damaging results, because they lead to low expectations, racism, prejudice and alienation (McIntosh, 2005). It appeared to me in my own research that these identity constructions and stereotypes (beliefs) influenced the acceptance of teachers' collaborative partnership work and its place within each school's culture, and were indeed both an indication of deep-seated prejudice within the school and wider community, and a controlling device to maintain the (inequitable) status quo. Existing as they did, they remained unexamined and unacknowledged within the context of teachers' reform work:

If it gets them Māoris good marks then, yeah, then it's good [non-Māori and Māori teachers working together], better than having all these Māori people sitting on the dole ... sitting on the dole and taking up all our taxes ... instead of buying us new stuff ... and making our country all flash ... . (Sonia, Yr 11 non-Māori student, 2004)

... the teachers, the Māori teachers and the non-Māori teachers at the school have accepted more stuff than they should have and let more stuff go. I think it's not good if there's too much of a Mãori influence in the school ... I think there needs to be a stricter discipline in the school, and that's because the discipline has broken down at home and the teachers are expected to do more of that. I think the kids that come into school now are more needier than they were, there's more theft in the area, there's more direct disobedience towards their elders and a lot of that has to do with the kids and where they come from. The lives that their parents have had. I mean, you might have a Māori woman who has five or six kids from different fathers and they're all in or out of jail. And the kids are living with their grandparents and they're swapped around and they don't have good role models. (Ms Robins, parent/caregiver of non-Māori child, 2004)

I found that it was mostly parents/caregivers of Māori students (as well as Māori students themselves) who appeared alert to and concerned about the presence of such stereotypes and/or racist practices within the school as well as the impact of deficit thinking, particularly on Māori students' identities as academic achievers: 
Like hearing so much on the news, and with this whole thing about the underachievement of Māori and they've emphasised it so much it's like this huge thing. It's like, 'Oh, Māoris are underachievers, we need to work and work and work on this'. And like my father said, 'It's actually downgrading for Māori, to have this emphasised so much, it's a real negative stereotype'. Like my kids are average-to-above average in school. When we talk about Māori underachievement, what are we actually talking about? (Mrs Tumu, parent/caregiver of Māori child, 2004)

Well, most of the Māoris just say non-Māori, they're brainy, if you're Māori, you're dumb, and you're going to end up working in the bush kind of thing, yeah ... . 'Cause a lot of Màori students don't know where they're going and that's why they just drop out of school. (Marama, Yr 11 Māori student, 2004)

It has been argued that societal stereotypes about particular groups can influence intellectual functioning and identity development of individual group members (Steele, 2004). Some research studies conducted in America have indicated that sustained school success for diverse groups of learners requires pupils to identify positively with academic achievement and develop a sense of belonging at school (Steele, 2004). Negative stereotypes related to groups can frustrate and disrupt this sense of belonging and the development of personal identity as achiever (Steele, 2004). Research has indicated that negative images can promote dis-identification with school achievement which leads to self-fulfilling prophecies of underachievement, truancy and drop-out rates (Steele, 2004).

It interested me that particular identities, stereotypes, instances of racism and prejudices seemed to remain unacknowledged and unexamined by participants themselves, even though they had influenced the embeddedness of teachers' collaborative partnership work within each school community. I also found other identities which emerged from my analysis of participant stories, which signalled messages about the extent to which difference and diversity were accepted and valued within each school community:

[My hope] is that this work with Te Kauhua keeps going and teachers don't give up. My concern is about the younger ones in the Te Kauhua 
class. Some of them think it's gay to be in kapahaka, like it's dumb, special needs, touchy-feelings, like somehow you're a fag if you're in kapahaka. (Marama, Yr 12 Māori student, 2005) ${ }^{37}$

Some participants talked about practices which they had observed which suggested to me hidden teacher prejudices and unexamined attitudes towards certain student groups:

In another class with a Māori teacher, I felt she was quite rude about homosexuals and she actually said to the kids that homosexuals shouldn't be allowed to marry in New Zealand and that homosexuality was wrong. ... I think she felt quite comfortable saying that to the kids. I was quite shocked at what she said. (Mrs Shelley, parent/caregiver of non-Māori child, 2004)

I wondered about what it was like for Māori and non-Māori students who wore such labels as 'gay', 'fag' and 'special needs'. I started to see these as warning signs, raising questions about hidden prejudices within each school community and the inclusiveness of each school's culture. I found that Town had researched the "'lived' reality of ten young gay men" in Aotearoa/New Zealand, "their perceptions of their schooling and the impact these have on their construction of 'gay' male identities" (1996, p. 2). Town argues that "overt homophobic language and behaviour used in the classroom" and wider school environment serves "different purposes" (1996, p. 21). He states that the use of terms such as "fag" or "faggot" could convey "genuine malice", a harassment that combines physical and verbal abuse and results in "young gay men 'playing truant', affecting their academic attendance and achievement" (Town, 1996, p. 21). I started to see that the schools' cultures, which were ostensibly collaborative, and therefore inclusive of all sorts of groups and differences, were in fact beset with prejudices that could only erode any connectedness created by collaborative partnership work. It also became apparent that even if teachers' collaborative partnership work improved classroom practice for some groups of Māori students, there was still plenty of scope for excluding other groups. Difference was at most tolerable, possibly only when it

37 This was a quotation gathered through the process of final member checking with participant groups. 
was scarcely noticed or only superficially accepted: there was nothing in the collaborative process, even after a year or more, which made difference safe and acceptable.

Participant stories revealed to me that teachers' collective practices had helped to shape new and diverse identities for some Māori students, across both school communities. For example, some parents/caregivers who were interviewed from Rata Primary talked about new identities which had developed for some children, as a result of teachers' collaborative partnership work. This identity appeared to be linked to the notion of "school achiever":

... we've got a child here, and their family has said that they are just so happy, like it's the best thing that has ever happened for this little one since they've been at school. And that's just so good to see that change and that's been through Te Kauhua, with those teachers working together in the programme and it's the best thing ever for that child and their family. And he now looks forward to coming to school and that's made the child happy and there have been changes in him ... he's happy to come into school and he's changed in class. And, yeah, another boy, his family are just over the moon, they came down to school to watch him get a Principal's Award and he's a kid that never talked, you couldn't get anything out of him, and it was because those teachers were learning about ways to tap into him and I just had to say to his teacher, 'He's just made such a transformation. I can't stop him talking', and ... it's all those that have had hands on with him. And that's just huge, it's just huge ... he sees himself as an achiever now and so do his family and it feels great when you see those changes, ... and that's the best thing, seeing those changes. (Ms Pio, parent/caregiver of Māori child, 2004)

There have been real changes [as a result of teachers working together] ... with my daughter. She is now happy to go to school, her reading has improved and she's an achiever now. She comes home and is using the reo and we are so proud of her ... and that's been because of teachers learning this work together. (Mrs Thompson, parent/caregiver of Māori child, 2004) 
Another identity which revealed itself to me was related to the Te Kauhua class. All of the Māori students who were interviewed from Kowhai College (9/9) explained that they had had direct experience of teachers' collaborative partnership work. They were also quick to point out that their experiences of teachers' partnership work had occurred while they were members of a particular class within the college, the Te Kauhua class.

When I interviewed these students who had just finished Year 10 and had left the Te Kauhua class, they said they now spent time in mainstream classes within the school. Seven out of the 9 Māori students who were interviewed from Kowhai College told me that the Te Kauhua class had been part of a special programme or project within their school. These students explained that while they had had direct experience of teachers working and learning together to improve the responsiveness of classroom teaching for Māori learners in the Te Kauhua class, this had not been a whole school process:

I had noticed some of my teachers last year, Māori and non-Māori teachers were working together for us, ... for the Te Kauhua class. (Hemi, Yr 11 Māori student, 2004)

We had non-Māori and Mãori teachers working together for the Te Kauhua class. Those teachers were awesome and they'd been learning about how to teach us and they were really interested in what we thought and helping us learn. (Ngawai, Yr 11 Māori student, 2004)

... when we were in the Te Kauhua class, our teachers were working with us and were trying out different things and learning together going to courses and learning new ways of teaching us. (Eru, Yr 11 Māori student, 2004)

It interested me that some participants talked about the impact of these new student groupings and that some Māori students had new identities as a result of being included in the Te Kauhua class:

[My concern] is that the Te Kauhua programme is not as strong as when we were in it and that students are using the term 'Te Kauhua' in not such a good way. It's like just for them, a term to be called ... like they are better or cooler than the rest of their form. (Marama, Yr 11 Māori student, 2004) 
Oh, I think it was good like when teachers were working together with the Te Kauhua classes ... . It kind of made us feel kind of special. (Hemi, Yr 11 Māori student, 2004)

A few participants questioned the social grouping practices of students within Kowhai College which appeared to divide and separate students and helped to create particular labels. It also seemed that only some Māori students from Kowhai College had been given the opportunity to become involved in the Te Kauhua class, and because of gaps in the interview evidence it was unclear to me why this occurred:

I've heard this before but I don't totally agree with it, that Kowhai College looks after non-Māori, top scholars who are Māori and Asian students, and if you don't fit into any of those categories, well, just go play on the field or go down to the soup kitchen, so the question is, what's happening to all our other kids? They play sports or something? (Mrs Pio, parent/caregiver of Māori child, 2004)

It just felt like, like my Māori friends who were in other classes, who weren't in the class with me, ... it felt like as if they didn't matter anyway, 'cause they weren't in the accelerant class. We were treated specially, eh? (Ngawai, Yr 11 Māori student, 2004)

It appeared to me the aspects of teachers' collaborative partnership work helped construct new and diverse identities for some Māori students, within and across both school communities. It interested me, however, that this phenomenon remained unacknowledged and unexamined by teachers themselves, within the context of their partnership reform work. There appeared to be a lack of teacher awareness and knowledge of how grouping practices (past and present) could help shape and construct diverse student identities. However, I also came to understand that these teachers were busy 'teaching'. I wondered how they could reach such analysis in addition to their other responsibilities. I recognised that I was in a privileged position, having a sustained period of time to reflect and read which also enabled me to develop deeper understandings. 


\section{Resistant and Automatic Learnt Behaviour}

As I analysed participants' stories, I came to see that there was another layer, a layer of unconscious beliefs and values that fuelled resistance. I also became more conscious of how these hidden 'world-views' and 'mental models' underpinned the 'learnt behaviour' which participants carried with them into the context of teachers' collaborative work. These included a lack of openness, transparency and honesty, and the presence of subterfuge; a style of leadership that hampered the creation of high-trust environments; a fixation on teachers' 'niceness'; ideas about social class; alongside a lack of listening abilities which would have enabled participants (and particularly teachers/principals) to dig deeper into issues of practice as well as to interpret and interrupt the dominant discourses fuelling resistance and undermining teachers' collaborative partnership work across both school communities.

\section{A Lack of Openness, Transparency and Honesty and the Presence of Subterfuge}

Signs emerged from my analysis of participant stories which warned me of the fact that established practices within each school could influence the acceptance of teachers' collaborative partnership work as well as its efficacy. For example, there appeared to be a lack of openness in communication, transparency and honesty which was at odds with the notion of collaborative partnership work, which by definition should be open and inclusive, not hidden or left unexplained.

When I interviewed teachers for a second time during 2004, I felt that many had experienced particular challenges within the context of their collaborative partnership work, for example, the ability of teachers to talk honestly, openly and respectfully about their collective reform efforts. During our second interviews, 12/17 teachers (4 Māori and 8 non-Māori) described such challenging experiences as they attempted to work with colleagues over time. As teachers talked to me about their experiences, it seemed that the issues raised by them emphasised a lack of trust and respect but also a lack of acknowledgement of less visible values underpinning the existing school's culture.

Heria described some of her experiences and observations of teachers' practice within staff meetings. She used expressions such as "tongue-in-cheek", "light-hearted" and "sarcasm" in her descriptions which, while they could arguably be identified as neutral, implied that there was more underneath teachers' banter, revealing different beliefs and values about what counted as improved practice: 
Sometimes I will be in a meeting and I'll say something and it's just the way people will look at me, it's like, 'Oh my God, you can't do that and you can't say that!'. Or I'll say something and they'll think, 'No, no, that's not on, we really need to be tough here with these kids. That's why things are so slack around here!'. This morning, for instance, in our meeting apparently - I didn't know this and fortunately I wasn't the only one - but when you give a student a uniform pass, you are supposed to give them these rules about uniform to write out, and I said, 'Well, when do they do that, in house group?' 'Yeah, yeah, they could do it in house group or for homework and bring it back to you for the next day.' And I said, 'What's the objective behind them doing that?' It was a genuine question, and then somebody said sort of tongue-in-cheek, 'It's punishment'. And I said, 'Well, I'm right into spending my time on punishment' - you know, this is me tongue and cheek and this is the little back and forth exchange that happened. It was light-hearted but I think underneath what we were saying was, there's a bit more to it about our different perceptions on how students should be dealt to, because that particular staff member is what I would consider very inside the box and everything has got to be neat and tidy and the students should all have correct uniform and there should be no smoking at school and serious consequences if you get caught and so on and so on ... so that's a common occurrence at meetings, that we will have this sarcasm. (Heria, Māori teacher, 2004)

Individual teachers told me that there were specific challenges to and dilemmas in developing honest, specific and constructive communication practices between teachers:

I think you have to weigh it up [being honest] ... . I have got a student teacher at the moment, it's my first time having a student teacher ... so it's completely new to me, having to do observations of her teaching and, you know, there are things that I am seeing that I cringe at ... but you have to weigh it up and I guess if by being honest all you are going to do is flatten her ... she is not going to get anything out of it ... . Is there any point saying anything? ... I know myself when I have been teaching I have had really bad lessons and you can see for yourself where you have gone 
wrong, you don't necessarily have to have someone point that out to you.

... I think you just have to weigh it up and make that judgement at the time ... . (Julie, Māori teacher, 2004)

I became aware that teachers in both Rata Primary and Kowhai College were not used to examining practice critically, honestly and constructively for culturally diverse students, particularly Māori students. One of the facilitators stressed this during his interview. He believed there was a lack of open, honest questioning of teachers' practice at the time the Te Kauhua programme was operating within his school:

One teacher had got to a stage where he realised that he was performing really, really badly but he was basically between a rock and a hard place and I had to say to him ultimately, 'You know, you are being paid to teach these children. If these kids aren't learning and you are being paid to teach them, you need to decide whether this is where you should be or whether you should perhaps think about some other career'. I mean, it's not an easy thing to say to somebody who's the breadwinner in their family and who thinks previously what they were doing was an OK job. That was probably one of the most difficult things I had to say because I knew that it was almost an ultimatum, that you either shape up or ship out because we can't afford to have people like you in front of our kids. That teacher thanked me subsequently. He said, 'You really gave me a shake up and made me think twice about what I was doing and I knew I had to make a decision'. That was lucky for me, I guess, but I didn't say it off the cuff or anything. I got to know him really well and we had quite a reasonable relationship that I could say things like that but it was definitely not an easy thing to do. In many respects, I didn't feel it was my job to be doing that either, but in terms of the children and my role as a facilitator, working towards a better education for these kids, I mean, basically somebody had to do it and nobody else would, nobody else would confront what was happening at the school. (In-school Facilitator 2, 2003)

The lack of safe structures and places that would allow and support openness, honesty and critical questioning of practice was noticed by other participants. Several 
students whom I interviewed noted changes in teachers' practice, although many of these students did not know much about the purposes and/or details of teachers' collaborative partnership work. Some students, however, explained that there had been inconsistencies in the messages they had received about the purposes of teachers' collaborative partnership work, in particular, the activity of in-class observation and feedback. These stories emphasised to me a lack of respect for students, as well as a lack of honesty, transparency and openness within each school community. Again I found myself questioning the underlying but unexamined and unacknowledged values and assumptions that underpinned teachers' practices:

... the teachers told us that that these people were coming into school ... and some told us, 'You have to be all good when they come into class, because we don't want to get kicked out' ... maybe not those exact words but pretty much to that extent, they said people were going to come in and teachers were going to be on edge and that we needed to behave ourselves ... so they just told us about that ... . (Hugh, Yr 11 non-Māori student, 2004)

Interestingly, my other children have said, especially Lauren, that sometimes there have been two teachers in a classroom watching her teachers ... but she didn't know why teachers were there, she didn't know the purpose of this or anything ... . I think the biggest thing was that they were told to behave because someone else was going to be in the classroom ... . But they didn't know why they were there ... . (Mrs Kruger, parent/caregiver of non-Māori child, 2004)

Some students felt that their teachers' teaching behaviour had changed significantly and that they put more effort into their teaching when they were being observed, something which was not sustained over time:

But some of our other teachers really change when teachers come in to watch them. ... there was one teacher, she was really different. Usually, she'd never go around and check up on your work, but this time she was putting in extra effort, so it made you think, 'Why can't you do this all the 
time?' Oh, in that class ... when the observer came, it was like she got struck by lightning. (Marama, Yr 11 Māori student, 2004)

I was interested to note that some of the Year 11 students who were interviewed appeared to be sceptical about whether teachers could really collaborate to improve their practice:

Sometimes when the teacher is observed, like they try harder to teach you, like they're more interested or he'll ask you questions ... that's what I've noticed ... . This year, one of my teachers was observed and he taught differently and then he just went back to how it was before, how he usually was. Most of the times he just sits behind his desk and says, 'Don't bother me’. (Ngawai, Yr 11 Māori student, 2004)

Well, I don't know anything about it, Māori and non-Māori teachers working together at my school ... but like there have been teachers in some of our classes watching other teachers, I'm not sure if this is part of what you're asking about ... they were just sitting in the classroom doing nothing ... it was in my English class and another teacher just came in and sat and watched ... . No, there was never an explanation about it ... . Yeah [I did notice changes] ... the teacher who was teaching us tried harder to be nicer to us and it was like they were acting like we were a better school ... Just that the teacher was trying harder to talk to us and saying 'Hello' and moving around and talking to us about our work ... it was different, like they were trying harder ... . (Tim, Yr 11 non-Māori student)

I don't think you can change teachers if they don't want to learn, it depends of their personalities, ... we had one teacher who was really good, he made teaching fun and he just had a way of making information understandable but he left the school ... . And he sort of knew about the youth problems and just it was like you could relate to him, but the older teachers, you just sort of feel they don't care ... . (Sam, Yr 11 non-Māori student, 2004) 
Some Year 11 students who were interviewed told me that one teacher had stood out for them because he had been open and honest from the start about the purpose of the in-class observation process. These students said that because of his honesty, they had gained more respect for him as a teacher:

Mr Roberts had talked to us ... so he, like, told us what was happening and just to act like it was a normal class when other teachers and people are watching, and that he and other teachers were learning new things and people were watching him teach because it was to improve his learning so he could help us, our learning, but not only us, like future classes, and it was pretty cool because there were heaps of people in our class that had brothers and sisters in the following class, so it was really for their benefit and for, like, you know, brothers and sisters that were coming up from intermediate ... it was good that he explained it pretty well. ... So he made more of an effort about telling us. (Ngawai, Yr 11 Māori student, 2004)

I think it was with Mr Roberts, when somebody came in and they sat down and they were watching him, and it was cool, 'cause he didn't change or anything, he just had the same teaching and I think we got a whole lot of respect out of that for him, because he's not going to change in front of everybody and he didn't change and teach us like a whole different way ... . And we respected him for that. (Hemi, Yr 11 Māori student, 2004)

My analysis of participant stories showed that there were underlying messages within the context of teachers' collaborative partnership work which revealed a lack of trust and respect for students' views. It appeared to me that aspects of teachers' collaborative partnership work could distract students from being engaged in learning activities, if students were not prepared for or informed of the purposes of such work. One student explained that his teacher had appeared nervous whilst being observed, and that this nervousness extended to him and other students in the class:

There was a teacher in class, she was watching the other English teacher and taking notes and stuff. My English teacher, you could tell she was real 
nervous and it made us feel a bit nervous for her. I don't know what it was for or anything - she never told us about what it was for. (Heath, Yr 11 non-Māori student, 2004)

Students sometimes felt distracted from learning if they perceived a falseness in teachers' collaborative partnership work, particularly during the process of in-class observation:

Some of the teachers have been watched in class ... with this teacher who was watched by one of our other teachers and it was like a whole different teacher, because she knew that the other person was there watching, and it was like she knew she had to impress her, she kind of changed which was kind of freaked out - because she was being observed, she changed and we were all thinking, 'What? What's happening?' ... normally she was, like, really laid back, like too laid back, we didn't really like it. Sometimes we had free periods and that was what was wrong with it, and then all of a sudden, like we were so used to not doing work and then when a teacher comes to observe her and suddenly it was all different, like we're doing work, and we're all just kind of freaked out and we didn't know what to do, we weren't used to just getting straight into work in that class, so it was, it was actually weird, we felt kind of weird. (Ngawai, Yr 11 Māori student, 2004)

Many of the students appeared not to have been informed about the purpose or even the occurrence of in-class observation and feedback; some were given misleading information about the process. It occurred to me that honesty may not be a 'nonnegotiable' within the context of teachers' partnership work.

\section{Creating High Trust Environments: School Leadership}

In 2005, as part of the on-going member checking process, 9 of the 17 teachers (3 Māori and 6 non-Māori) from across both schools expressed concerns about senior/middle management and the way they supported (or failed to support) teachers' collaborative partnership work. Some teachers detailed specific concerns about individual senior managers who expected teachers to gather evidence and reflect on their practice without 
modelling the same approach. It was not clear that participants in either school saw the purpose of collaborative reform work as transforming the entire school system for culturally diverse children and young people. During interviews and final member checks, some staff members expressed concern about individual senior managers' commitment to investigating the school as a social system:

Something needs to be done ... but what? There is a hierarchy within our school that I don't feel is respectful of our [the teachers'] issues ... . I felt that often with this type of professional development, the expectation from senior management, is that we, the teachers, are the ones that have to change and improve, while they don't seem capable or willing to reflect on their own practice. I felt in relation to this work, there was that unwillingness and really a lack of respect from our senior management team to work with us on improving the whole practice of the school. (Verna, non-Māori teacher, 2005) ${ }^{38}$

Some earlier participant stories appeared to indicate a lack of principal knowledge about the need for ongoing collective inquiry and dialogue, if the goal was to reform classroom practice and outcomes for culturally diverse learners:

I went to a staff meeting and it was just like general stuff and there was time at the end and the teachers asked if I wanted to say anything and I said, 'Yeah, well actually I would'. I said in the last week I have been counting the number of times that students in this school have been called things like 'little shit' by staff members, and I think it was six times by different staff members. And they all just looked at me with their mouths open and I never heard it again after that. So right at that very basic level, the level of awareness of their own attitudes and behaviour towards our children, those sorts of things changed. ... I just started counting ... . And I didn't have to say to them, 'You can't talk to the kids like that!' ... you just give them the information and I mean that's where the action research comes in 'cause you're not actually telling them anything, you're just

38 This quotation was gathered from a participant during final member checks at this participant's school. 
feeding stuff back in that's happening at school. I remember the Principal saying once about the action research when there was some stuff happening, 'Oh, but you can't take any notice of that. That's just opinion', and I said to him, 'That's exactly why you have to take that on because it is opinion, it's what people are thinking and that matters. We need to be aware of what other people are thinking'. (In-school Facilitator 2, 2003)

Kincheloe has argued that educators must engage in their own critical enquiry into the contradictions of schooling for diverse learners; he stresses that it is important that practice remains "open to the distanced analysis of others who perceive recurrent patterns of unproductive behaviour" that we "don't see" (2003, p. 186). It was not clear to me that the schools' senior managers understood that they needed to conduct critical enquiry into their own or others' leadership practices. As I analysed participant narratives, I felt that there were particular messages and assumptions that were unexamined and unconscious. For example, one principal seemed to acknowledge that teachers had 'seen' what needed to happen through a process of listening to new narratives, but I wondered whether he was also aware that changes to teachers' practice needed to be supported by investigation into the entire culture and structure of the school:

They've, the teachers, certainly seen the need from all of the work and narratives that they've heard from Māori students, that there was definitely a need to improve and a possibility of change on their part so that they could see changes being made to their classroom. (Principal 1, non-Māori, 2003)

A number of theorists have suggested that most serious change initiatives eventually clash with prevailing systems of management within organisations (Fullan, 2005; Johnston \& Bush, 2005; Senge, Cambron-McCabe, Lucas, Smith, Dutton, Kleiner, 2000). These can include managers' commitment to change as long as it does not affect them or their personal reactions to "undiscussable" topics that are too considered too risky to talk about (Senge, Cambron-McCabe, Lucas, Smith, Dutton, Kleiner, 2000, p. 9). Leaders within reforming organisations need to reflect critically on their own contributions to improvement and the work of reform, see that mistakes are inevitable, seek feedback from a variety of sources, and work to improve their own and others' 
performance in the pursuit of moral outcomes (Fullan, 2005; Senge, Cambron-McCabe, Lucas, Smith, Dutton, Kleiner, 2000). If progress is to be made in the development of culturally responsive practice, then all members of the school (including managers) would be expected to learn and contribute positively to the work of change (Johnston \& Bush, 2005). However, this would also mean that participants would need to move beyond superficial understandings of pedagogical ideas and identify their underlying assumptions about student learning (Coburn, 2005). It has been argued that such political factors would need to be investigated, with the aim of transforming the school institution over time, if culturally diverse teachers are to improve classroom practice and outcomes for equally diverse groups of learners (Banks, 2004; Johnston \& Bush, 2005; Shields \& Sayani, 2005). "Creating spaces in which one can be liberated from fear is central to understanding difference and living joyfully together", according to Shields and Sayani (2005, p. 385).

Over the course of a year, I found different participants from across both school communities who believed that considerable fear and insecurity resided in some stakeholder groups who had actively resisted teachers' collaborative partnership work:

I don't think it is easy ... to talk honestly about these issues. I think it's hard, because I think from the outset when Te Kauhua came along it was, you know, this was to improve our teaching and raising Māori student achievement so we had some staff, ... community and board members saying, 'Well what about the other students?' So then we had to change how we described the programme, well, [that] classroom practices that enable Mãori students to achieve will help the achievement of everybody in our classrooms, but the danger is that people go back to their old ways and think that what they are doing is fine and then you've lost that focus on culture ... . I think also it becomes difficult to try and teach identity and culture when you're not sure of your own, and it comes back to Michael King's comments on 'Face to Face' with Kim Hill, and he said that Māoritanga has been found, we know what it is, and he says that is the first indigenous culture of New Zealand, but he said there's another second indigenous culture, and he's right, I agree with him, and that's the Pakeha culture. He said as soon as the British Colony cloak was lifted, then we had Europeans who were unsure about their own culture, and he 
says that we're still looking for that culture. Now, that was a really strong comment, and I thought, 'My gosh, I'd never thought of it like that'. And that's why we start to get these issues and we start to get these problems with the backlash from some parents, and that was from one of our noted historians ... and I thought, yeah, with our Pakeha people and our European culture, some people are still finding out who they are, and then they're wondering whether it's linked with Māori culture as well ... . Maybe it's part of both, and that's fine, you know, there's nothing wrong with it, but that's where the insecurity lies. (Saul, Māori teacher, 2004)

According to Johnston and Bush, school leaders may be "reluctant" to lead conversations which appear "messy and uncertain" around issues of culturally responsive practice, including an analysis of power relationships and evidence of practice related to the race, class and gender of students (2005, p. 294). It appeared to me that a different type of sustained school leadership would be required if teachers' collaborative partnership work was to be developed and instituted over time. Certainly during member checks, some participants appeared reluctant to examine such issues openly and critically:

It's like opening a can of worms ... why would you want to go there? (Verna, non-Māori teacher, 2005)

Different authors have argued that high trust environments are needed if teachers are to work together to create culturally responsive practice for diverse groups of learners, because teachers must first identify, accept, respect and value diversity in the staffroom, before changes can be made across the organisation (Fullan, 2005; Johnson \& Bush, 2005; Shields \& Sayani, 2005). Implementation of whole-school inquiry, that is needed to develop culturally responsive practice, requires all members of the school community to "examine their own issues, biases and cultural differences" in openly supportive yet critically thinking learning environments (Johnston \& Bush, 2005, p. 293). It has been argued that successful organisations explicitly value differences, ensuring reform changes are guided by built-in checks and balances (such as regularly examining evidence for assumptions), and by providing highly supportive yet challenging work environments which allow people to take risks and learn from their mistakes (Fullan, 
2005; Johnston \& Bush, 2005). Fullan has added that staff members working towards collaborative reform must ensure that some commitments are non-negotiable:

Working in a high-trust yet demanding culture, participants take disagreements as normal when undergoing changes, and are able to value and work through differences. Some commitments are non-negotiable, such as raising the bar and closing the gap, ongoing development of professional capacity, and transparency of results. (Fullan, 2005, p. 72)

I learned that valuing diversity and conflict was important for organisational learning because such processes encourage a routine questioning of values alongside inquiry mechanisms which test assumptions, guide organisational actions and generate ownership (Fullan, 1999). However, it did not appear to me that principals and/or teachers had an understanding of the need to agree on such 'non-negotiables' and/or felt safe within their own working environments to discuss their own concerns and/or raise questions about the direction of collaborative partnership work over time. It has been argued that understanding existing social teacher divisions is important for understanding border politics within school communities (Achinstein, 2002; Ball, 1987; Fullan \& Hargreaves, 1996). My analysis indicated gaps in participants' knowledge about the importance of identifying and understanding micro-political processes and how they inhibit or encourage collective learning within the school organisation (Achinstein, 2002). Sources of conflict, border politics and diverse ideologies can offer ways to explore phenomena within teacher collaboration (Achinstein, 2002). Conflict can be viewed as a constructive process in critical thinking and problem-solving which leads participants to question the status quo (Achinstein, 2002; Fullan, 2005). As I have already indicated, participants' emotional responses appeared to me to be signs or messages that something deeper needed to be investigated within the context of collaborative partnership work.

\section{Issues of Teacher Niceness and Unexplored Social Class Values}

My own navigation of participant stories highlighted to me particular, hidden and unacknowledged values which appeared to influence the practice of teachers' collaborative partnership work within each school community. A major challenge, according to some participants who were interviewed, centred around practices of social 
'niceness': unspoken rules about being 'nice' meant that some teachers were not open or honest in their communication:

Maybe some people don't talk straight because we have to be nice ... . But I think you can, you can talk straight ... but you can set it up in such a way that you say to the person, 'Please don't be offended by what I'm going to say', otherwise people take it personally. I'd like to see the staff here really talk openly ... because sometimes the talk is about looking good and being nice and that can really limit us and our relationships and in just achieving our goals ... but it's never stopped me, and as I said to someone this morning, 'I'll be in your face about this'. (Heria, Māori teacher, 2004)

Heria told me that she had become frustrated by some of her colleague's inability to "talk straight". She believed that some of her teaching peers found it hard to be honest and to debate issues due to their upbringing:

... we're raised to be nice. You know, how when a little kid says, 'Oh Mummy, look at that lady's dress', and we all say, 'Ssh, don't say that, it's not very nice'. But it's actually the truth, that dress looks dreadful on the woman and she'd be much better off in a different colour and different style ... but we shut the child up and go away thinking, 'Yeah, she looks pretty gross', so people can't talk straight because we have to be nice. (Heria, Māori teacher, 2004)

Other participants who were interviewed expressed similar feelings:

Some of the challenges [in terms of Māori and non-Māori teachers working together] is you need strong teachers ... probably I mean strong in terms of ones that are more in your face in staff meetings. I call them the 'hard nuts' but I like the hard nuts because you know exactly where you stand with them ... whereas the ones that play 'nicey nice', I would have to say would be more difficult to work with because they're not really fronting up, being straight with you in terms of their position and it's hard to work with 
someone when you don't know their position and maybe that's because they don't know themselves ... . (In-school Facilitator 1, 2004)

Some individual teachers explained that they had chosen not to share concerns or debate issues because they did not want to spoil their relationships with their peers. During my second interview with Richard, he said that while he had some concerns about fading teacher engagement in collaborative work, he had chosen not to talk about these concerns with colleagues ${ }^{39}$ because he did not want people to think ill of him:

... when the whole Te Kauhua project started, just like any new activity, everyone just embarked on it and there was a bit of a hoohaa about it and then I've kind of had the impression that the dust is settling and teachers are getting back to their old habits ... . To be honest, I haven't shared these ideas [with my colleagues] probably because I don't want people to think badly of me ... . How would a teacher who has been teaching for about 20-30 years feel if I stand up to people within my department, and I say, 'Hey, this stuff is really good', and the challenge to me is like scaling a mountain because that teacher has been teacher-oriented for all their life, and all of a sudden a young guy comes along and says, 'Hey, if you really want to see improvement, there is this way ...'. What do you reckon? I am not going to climb up that mountain. (Richard, non-Māori teacher, 2004)

Another teacher who was interviewed explained that she had felt upset and angry after observing a particular incident when her colleague was teaching in class. Although she was convinced that what she was observing was 'poor teaching', she confided that she was not able to be honest about her concerns and was frustrated by her inability to do anything about them:

... I know perfectly well with all the planning that this other teacher hasn't cut it, I know that. ... like yesterday, I walked into her room and saw two girls, fifth form, were sitting on the table, and one boy in the corner with when he experienced 'bullying' teacher behaviour at a previous school. 
his feet up. There was not any paper or any books on the desk, and this other girl was sitting at the front and she was talking to this other girl and I thought, 'Where is the teaching going on?' It was loud in the class and the door was locked, so I just knocked on the door and one of the kids came along and opened it up and it was just straight away, 'Hi, Miss'. They have got that respect, and I just looked at these two girls and they just slid into their seats and I didn't say boo or anything ... and here is an opportunity that she [my colleague] has got with these kids and she is not using that opportunity, you know, that's what I am saying ... . I am not looking at her as a person but as a teacher ... she came up to me afterwards, because I said what I had to say to the kids, I gave them a notice for the hui tomorrow and then when I came out during lunch-time ... she chased me, and she said, 'Oh Whaea, you know that class, they are really doing well with their research work on their marae', and I said, 'Oh, that's good', and she said, 'Yep, they are just about finished' ... . (Barbara, Māori teacher, 2004)

Barbara had felt "horrible" and "mean" about not being able to get her message across to her colleague:

I did say to her that that was good she was trying to please me but I was trying to get a different message across. ... when I see things like that teaching, it's just like baggage ... aren't I horrible? I was mean to that person ... because I refused to acknowledge her. What I was trying to say was, 'It's the kids, you know, it's about the kids' knowledge, not about yours', but that was just my annoyance. ... when I go to talk to her, you know, she's not challenging enough. My way of saying things is to try and get things out of children, get something out of the students, challenge the students, but her response to me is, 'It's, oh, I know this and I know that', like, for example, she'd gone home and she wrote something to give to me as if she was handing in an assignment to me but I didn't want that, I didn't want to test her knowledge, I didn't want to do that. What I was trying to do is say to her, 'Let's challenge the kids', and she came back with this particular work and it had all about her whakapapa on it and I 
said, 'That's good. Now do you reckon you can get the same out of the kids?'. But that's quite frustrating, like I don't think she understood me ... . I am pretty sure that she felt quite hurt that I didn't acknowledge all the work that she had done. (Barbara, Māori teacher, 2004)

I felt that participants' behaviour within the context of new, collaborative partnership work was deeply connected to their own personal values and beliefs, which could impact on their ability to address issues of practice honestly, critically and openly with colleagues. For example, 2/13 (1 Māori and 1 non-Māori) teachers who had engaged in the process of reciprocal in-class observation and feedback explained that they abandoned and/or altered the process because of feelings of care for their colleagues. Julie told me she had dropped the observation process because of her concern for what was happening in her colleague's class. She explained that although she and her colleague had pre-planned Julie's role in the observation process, she had abandoned this role after her peer ran into difficulty. She told me that her feelings of concern impacted on her engagement in the process:

Anne had written down what things she wanted to have me observe in particular, before I went into class. ... I ended up dropping it and stopping, because she was using cooperative expert groups to do some teaching and we both realised that it wasn't actually working as it was expected to work. It was about all we discussed was that it just didn't work the way it was supposed to and that it was just a complete write off, so let's just ignore this observation sort of thing, so that is pretty much what we discussed. I knew she felt bad about it and I didn't see the point in talking about it when it [the lesson] had fallen apart. ... I guess when you are doing a formal observation it does mean you have got to be up front and really be honest which can be difficult when you're not used to it, like with the informal walking in and out of class, as I said before, you don't have to say anything about what you have been seen ... . (Julie, Māori teacher, 2004) 
An in-school facilitator thought that some teachers had not been critical enough which meant that they had not been able to provide a useful critique of their colleagues' practice:

The teachers ... they did the peer observation and they observed each other ... . I felt there were major problems with it because the process was too hit and miss, and it goes back to that thing about teachers wanting to support each other, which is of course incredibly important, but also we found that some teachers were very easy on their buddy. (In-school Facilitator 1, 2004)

It was apparent that some participants were aware that teachers often want the relationships within their school to appear 'nice' and comfortable which would influence their ability to address issues of practice honestly and openly with colleagues. Some of this dynamic was unearthed by a previous study I did on collaborative work, where educators experienced considerable difficulty challenging one another due to issues of social niceness (Hynds, 2000). I searched for other literature and found that Alton-Lee (2003) has warned that existing teacher cultures of 'niceness' provide major challenges to the development of quality teaching for culturally diverse student groups in Aotearoa/New Zealand, because it prevents critical inquiry and a challenge to the status quo. I also found that hooks (2003) has argued that "bourgeois values" within classrooms and schools disrupt the "possibility of confrontation and conflict", a process which she argues teaches us to "maintain order at all costs" (p. 143). According to hooks, studentprofessor discussions may emphasise social niceness which highlights bourgeois values related to social class:

I have found that students ${ }^{40}$ from upper- and middle-class backgrounds are disturbed if heated exchange takes place in the classroom. Many of them equate loud talk or interruptions with rude and threatening behaviour. Yet those of us from working-class backgrounds may feel that discussion is deeper and richer if it arouses intense responses. (2003, p. 148)

40 When she refers to students, bell hooks is making reference to students who are trainee teachers who took part in some of her tutorials. 
hooks maintains that social class is an important but rarely talked about issue in collaborative learning settings, particularly in educational contexts (2003). She argues that class issues in educational settings are "more than just a question of money" as they shape participants' "values, attitudes, social relations, and the biases that informed the way knowledge would be given and received" (hooks, 2003, p. 142). According to hooks, students, and their professors (whether they are from a privileged class group or not) may adopt "a demeanour similar" to that of the dominant group within an institution in order to "advance" or "be deemed acceptable" (2003, p. 143). She argues that, "Although no one ever directly stated that the rules would govern our conduct, it was taught by example and reinforced by a systems of rewards ... [and later] silence and obedience to authority were most rewarded ..." (2003, p. 143). Finally, hooks warns that when participants entering schooling reform contexts (whether as a teacher or as a student) are encouraged to engage in "free speech, most students are not comfortable exercising this right" (2003, p. 143). Fear of "losing face" with one's peers, or of not being liked by such peer groups, undermines all possibility of "constructive dialogue" (hooks, 2003, p. 143).

hooks maintains that culturally diverse participants (students and teachers at all levels) must be challenged and empowered to become conscious of critical assimilation processes within mainstream educational contexts (2003); such an analysis must come from intersections of race, sex and social class. I found myself agreeing with her, in that there appeared to be unexamined values and assumptions which underpinned established teacher relationships and social practices within and across both schools. I found myself wondering whose values counted within each school community. I also realised that if real change was to be sustained that these values would need to acknowledged and examined by participants themselves, particularly since values appeared to influence the way participants chose to define and /or engage in collaborative partnership work over time. Teachers' would need the time and space for such analysis as well as the commitment to engage in critical, collaborative inquiry over time.

\section{A Lack of Listening}

I found other messages and signs embedded within participant stories which emphasised 'learnt behaviours' and the less visible values and beliefs which underpinned them. James had concerns about fading teacher engagement in partnership work at his school, but he believed his concerns were not listened to. In his second interview, he described some of the challenges to teachers' collaborative work which had developed over time and how 
he had noticed a drop in teachers' engagement within the programme of work. He attributed some of this to a lack of collective and critical examination of the school's key beliefs:

Well, there are a number of people who appear to have withdrawn from the Te Kauhua project for whatever reason ... I think a few people maybe have lost the plot, they can't be bothered with the meetings. I do know that there are some people who have sort of said, 'I want to pull out of the project' ... which is a bit sad ... . I'd love to say, yes, that teachers across the school are all working together to try to make a difference for all of our Māori students, but in reality this is not happening. I'd like to think it was an underpinning part of the school's key beliefs, the need to really build effective learning relationships with our kids, Māori kids in particular, but I don't think it is. I've seen too much evidence that doesn't support that and I've probably been guilty of it myself with kids who I'm not teaching, but I think it should be and again I think that's one of those things about the need for refocusing. It's that very question we have to ask ourselves: 'What is it like to be a Màori student in our classes?' ... I don't think as a staff we talk enough about our vision for our school as teachers, Māori and non-Māori teachers all of us, lately anyway. In the last few months, we've been distracted by other things happening in the school. I'm not sure we talk about ... the things that are happening in our rooms, so I think we can always have more of that dialogue and often when we do have that dialogue it is in the morning meetings but it's pretty short and I think we need some more refocusing, maybe some whole staff discussions, just putting the project back in front of the people, reiterating its value and reminding ourselves about what it is like to be, particularly a Māori kid in our school and has it changed. Are we slipping back? What are we doing about this relationship building and all that kind of thing? And that's also a management leadership thing but again it is a time issue too. You've got to make the time to have these meetings. I definitely think we need a refocus. ... we need to flip back to that shared goal and theme for the whole school. (James, non-Māori teacher, 2004) 
I asked James if he had shared his concerns with anyone and he replied, I have raised this, that I feel there is a need for a whole staff discussion on our school vision. Have I suggested that? 'Yes'. Have I been listened to? 'No'. ... I'm having trouble getting anyone to hear me on this so maybe it's me ... . But I do think we definitely need a whole staff discussion about our vision. (James, non-Māori teacher, 2004)

James believed that the lack of listening practices as well as the existing 'tone' of staff relationships had impacted on teachers' willingness and ability to air their concerns about the direction of collective reform work:

I think there's a whole bunch of real good reasons for not wanting to talk through issues, for not wanting to share what's on your mind. Again I think that 90 percent of that is addressed through the tone of your staff relationships, and ... maybe you happen to work in a dysfunctional department ... . I think, yeah, it comes down to tone, I think in the department, or in the school, or in meetings, you know, you feel that it's a trust thing, you feel that you can say what is on your mind without being negatively received, or others pooh-poohing the idea or whatever, that people will listen to you. That even though they might not agree, they'll listen and they'll value your input. But that's a challenge ... . (James, nonMāori teacher, 2004)

Herewini had also attempted to raise his own concerns about the direction of partnership work within his school. During his second interview, he explained how he had tried to raise particular issues:

The key challenge [to Māori and non-Mäori teachers working together] is we've got to really know what the goal is and we've got to be really aware and clear about what the objective is. If you're very clear, and have that clarity, then you know the purpose for what you're working towards and how you're achieving that and I don't think we have that clarity as yet. It's very important that we're all working for that common purpose, but I 
think we've got so many things going on, we've got the koru ${ }^{41}$ here, we've got the literacy and numeracy professional development over there, but what the hell is this for? ... How do they all fit? And where's our whānau voice? ... I think we've lost that ... . So until we pull it all in a bit tighter, we need to decide on our main priorities, this is where we want to go ... . $O K$, at the moment it's too loose ... and there has been an attitude of apathy here towards the cultural component particularly. (Herewini, Māori teacher, 2004)

When I asked him if he had talked through his concerns, he replied,

Yeah, I've shared that at times. I've talked to people. But at this point of time I've been told I need to get my own backyard sorted, so to speak. I have a lot of good ideas for out there but I've got to concentrate on my job. And that's basically what they keep telling me, 'First work on your own job'. So yep, and that's what I'm doing. ... But you know we have Māori and non-Māori teachers here that are at different levels of the change spectrum. In terms of Mäori philosophy, there are some teachers that are ready to embrace like the karakia, the waiata, and the values of tikanga and why people do things. Now, you can't know building relationships, and whānaungatanga, you can't build that until you know and value it yourself and what it means. Otherwise it's a waste of time, you know, just saying, 'We've got values, we've got whakawhānaungatanga, kotahitanga and aroha'. Well, what is it? How do you manifest it? OK, how do you do it, practise it within your community? Yeah, it's a lot to do with walking the talk, I suppose, and more than just lip-service, or tokenism. But ... I need to concentrate on my own job, or so I've been told. (Herewini, Māori teacher, 2004)

One teacher explained that she had concerns about the current appraisal system which operated in the school:

41 By koru, Herewini is referring to the set of teaching beliefs developed by the teachers in his school as part of the Te Kauhua project. 
I think the appraisal system at this school could be better in relation to this work ... . I think it's a bit soft. (Verna, non-Māori teacher, 2004)

I asked Verna if she had shared her concerns with anyone at school, but she felt there was a lack of an appropriate venue to raise her concerns:

I have never done it officially because there isn't an open avenue for scale A's to make their viewpoints heard. (Verna, non-Māori teacher, 2004)

One of the professional development facilitators who was interviewed also believed that established communication practices within the staffroom and school environment had prevented teachers from airing concerns about the direction of collaborative partnership work over time:

There was a lot of talk, teachers talking with me, about how much of a waste of time it was being honest. How people didn't listen, how people didn't respond, you just got hit down every time you came out and said something, so you stopped saying it because you were sort of made to feel like the baddie, or you ended up with more work than you could cope with. But mostly many teachers felt there wasn't anybody who was listening. (In-school Facilitator 2, 2004)

During my second interview with Robyn, she told me that she was going to raise some issues openly within whole staff forums. She had been particularly concerned about how some teachers had self-assessed their knowledge of te reo Māori and tikanga practices:

We all had to rate ourselves, decide for ourselves how comfortable we all felt teaching te reo me ona tikanga and being able to incorporate a Māori dimension into our teaching and it was very surprising and I don't believe it one bit. Like, when I do a scale from 1 to 10, I'm a Māori teacher and I always leave space for me to grow because I believe learning is ongoing ... so I rated myself as an 8 out of 10 , in relation to feeling comfortable teaching te reo and incorporating a Māori perspective or dimension into 
my teaching, but so did many of them [non-Māori teachers]! Now you define that for me. Even their values, you know, values are very deep and very personal, so understanding Māori values I think I gave myself an 8 and so most of them gave themselves a 9. And I thought, 'Wow!' Just where some of them rated themselves I was shocked and surprised ... . (Robyn, Māori teacher, 2004)

Robyn believed there was a big difference between some teachers' assessment of their skills in te reo me ona tikanga and their actual ability in practice:

I was shocked by how high it was. I think it's good for them that they feel that way, but I just know how much they know. I would have rated some of these teachers holistically under 5 and that's about three non-Māori teachers, not all. Because there has been a big shift for some teachers, some of my non-Māori colleagues are now enrolled in Te Ara Reo and they have just really moved, in terms of their learning and understanding, and that's awesome ... but some non-Māori teachers have chosen not to [enrol in the course]. Some are now doing te reo with another Mâori teacher, he is taking classes for them after school, and I think they enjoy what they're doing. But there's a big difference between what they think they know and what they actually do ... but I'm going to bring this to our next hui and we're going to talk about this. (Robyn, Māori teacher, 2004)

However, during my final member check with her, she told me that she had given up trying to speak out because she was not listened to, and her loss of agency was due to recent events which had indicated to her a lack of respect and trust for Māori within her school:

I would like to ask ... where's the review for this? After all we've been through ... it's a disappointment to me ... it is like it is crumbling all over the place ... and it's hard to keep going ... your energy to try and hang in there ... when you're not being listened to. How has it come to this? It's not about the money or not having the resources, it's about basic respect and the need to value the kaupapa. If it's important, then we'll work for it, 
but there have been things that have dropped away and we need to create space and protocols for a review ... . To me we have lost some of that progress we had made. (Robyn, Māori teacher 2005) ${ }^{42}$

Participant stories revealed that existing behaviours and school/staffroom practices could prevent teachers from being heard and openly and critically examining their assumptions and collective actions over time. I wondered why there was a lack of inclusive listening practices and collective inquiry within each school community which would enable culturally diverse participants to speak about their own experiences and interpretations of mainstream schooling practice, particularly since so many teachers had talked about their personal transformations in thinking after engaging in such activities. ${ }^{43}$ Over time, I became more aware of the established power relationships and dominant discourses underpinning school practices which appeared to me to remain hidden, unacknowledged and unexamined by participants within the context of new collaborative partnership work.

Other signs emerged from my analysis of participant stories which pointed to underlying tensions, hidden undertows and currents which seemed to influence the practice of teachers' collaborative partnership work and also its efficacy and acceptance within each school's culture. 


\section{Chapter 6. Warning Signs About the Schooling Environment and Beyond: The External Dynamic}

As I have explained in previous chapters, over time I became more aware of warning signs and messages which pointed to various forms of resistance to teachers' collaborative partnership work. Understanding the causes of resistance is important in any change or improvement context, and teacher resistance can be "interpreted as a problem of the teacher, not the system" (Hargreaves, 1994). If a school adopts a programme that is as fundamental as Te Kauhua, and espouses intentions for reform or renewal, then it is likely that the sorts of changes introduced will threaten the entire school community to different degrees (staff, students and parents/caregivers). Such threats can lead to hardening, resistance and the development of undermining factions, groups that take their energy from a rejection of the reformist intentions. If the system is not held safe and kept open to critical, collective inquiry ${ }^{44}$, then it is likely that the whole culture will become more dysfunctional, and that dysfunctionality will in fact become operative, the raison d'être and catalyst for the existence and development of the culture. Everyone involved will become victims of this - the teachers, all school staff, students and parents/caregivers. Ultimately, too, society will suffer.

But the principal victims will be the children and young people within our mainstream schooling system: not only will they suffer from the silence and their attempts to understand the undercurrents, but they will also not be able to benefit from good role modelling. They and their teachers will fall victim to a system that is closed and subversive rather than open and reformative.

Whereas during my initial fieldwork it appeared that the teachers at these two schools were positive and knowledgeable about collaborative partnership work, during the second interviews and my analysis of the data I became uneasy about the acceptance, application and efficacy of teacher collaboration in these settings. I began to dissect the internal dynamics of collaboration, the beliefs, opinions, learnt behaviours, prejudices and personal values that so deeply affected teachers' adoption of the processes of reform (see Chapter 5). I then started to examine the external factors: established hierarchies and the issue of leadership, staff divisions and disputes, bullying and subversive practices,

\footnotetext{
${ }^{44}$ This is discussed in more detail in Chapter 7.
} 
ways of dealing with diversity in a closed system, systemic transparency and outcomes for students, power relationships and identity formation.

I became more conscious of the influence of the wider schooling environment which had seemed to me to contribute to a lack of preparation and a structural hostility. Some teachers felt that past training experiences and 'fast packages' of professional development had hindered them developing the necessary knowledge, skills and dispositions which would have enabled them to dig deeper into contradictory issues of practice and work together for transformation and reform over time. I felt this lack of knowledge influenced the efficacy of teachers' collaborative partnership work and enabled me to see that influences on the practice of such work stretched well beyond the school gates. In my search for literature, I found that Bronfenbrenner (1979) has argued that to understand the ways in which learning occurs we must move beyond the traits of the individual to examine the dynamic, interactive and influencing nature of the social environments in which that individual is located. This would include the recognition of such influences as family, schooling and society, in other words, the micro and macro social and historical contexts in which learning behaviours are learnt and sustained (Bronfenbrenner, 1979).

During the second interviews, 12/17 teachers (4 Māori and 8 non-Māori) told me that they had chosen not to share particular ideas or concerns openly or honestly with colleagues because of specific incidents that had occurred over time. I became very conscious of the external dynamic and existing power relationships within the schooling environment which could impact on an individual's sense of personal safety and ultimately influence their engagement in collaborative partnership work.

\section{Established Hierarchies and the Issue of Leadership}

I became aware of established hierarchies. Some participants who were interviewed from across both schools explained that individual teachers may not have felt safe discussing issues openly and honestly due to existing hierarchies within the school:

I don't think it's always easy for people to say what they think though in an open forum ... . I think it's hard for some people to speak up because they are worried about who is listening and what's going to be held against them if they say the 'wrong' thing. I think as a staff it would be a really good idea to have a staff meeting when there is no management present where people can 
say what is on their minds and not fear that someone is going to say something or it will be marked down in their log book about them because I do think there is a sense of that sometimes. Because there is a hierarchy in the school, sometimes people are careful about what they say because they are worried about who might hear it. (James, non-Māori teacher, 2004)

A school's existing power structure or hierarchy appeared to me to influence a teacher's ability to discuss issues openly and honestly, as well as exercise choice, something which many teachers had initially told me was important for encouraging their engagement in collective reform activities:

I think it is really important to discuss your values with teachers that you're working closely with and if you are working, but like I am the head of department, so she [the other teacher] basically doesn't have a hell of a lot of choice if I say this is the way I want it done ... . (Ian, non-Māori teacher, 2004)

I became more conscious of the influence of existing power relationships and hierarchies within each of the school's communities, which appeared to remain unacknowledged and unexamined within the context of teachers' collaborative partnership work. Much of what I learnt from listening to the stories of participants talk about their own experiences of teachers' collaborative partnership work over time seemed relevant to Hargreaves' (1994) analysis of contrived teacher collegiality. Hargreaves has argued that this form of collaboration is "typically compulsory" and is not usually voluntary (1994, p. 208). It is "bounded in fixed in time and space"; which has an implementation rather than a development orientation and is "meant to be predictable rather than unpredictable in its outcomes" (1994, p. 208). Hargreaves (1994) stated that contrived teacher collegiality can rob teachers of ownership and may emerge in different forms of collaborative work including "mandated collaboration and joint planning", often at particular stated times, and "required" teacher participation and consultation in such things as "peer coaching programmes" (p. 208). He goes on to say that contrived collegiality can be linked to micro-political issues in schools and broader macro-political attempts to control teachers' lives. As noted in Chapter 2, Hargreaves has added that contrived collegiality may be employed as a strategy for creating collaboration 
amongst teachers, but quickly becomes one for controlling it (1994). This form of teacher culture can suppress teachers' desires and their teaching visions and reduce their motivation to learn from one another (Hargreaves, 1994). I felt that much of what emerged from my analysis of teacher stories pointed to "balkanised teacher cultures" and “contrived collegiality" (Hargreaves, 1994, p. 208). I started to see teachers' collaborative partnership work as largely superficial and impotent.

While some teachers received a lot of support from their heads of department, others did not:

I was really lucky that my head of department really supported the Te Kauhua work ... . I'm not so sure that other teachers had as much support from their heads as we did ... . It really helped with that sustainability, because we have shared planning and resources and we had set tasks that we were discussing as a group. (Julie, Māori teacher, 2004)

It became apparent that there had been mixed reactions to teachers' collaborative reform efforts from middle managers within each of the schools, particularly if new teacher leadership emerged which challenged the status quo:

The other issue ... in terms of the challenges to Māori and non-Mãori teachers working together was the leadership within the ranks of teachers, those that were really working and committed to the kaupapa ... . How do you encourage them in the ways that they can work with others? I think some of the people who are heads of departments, and typical structural leaders ... it was really hard for them to lead or be seen as a leader within the department. More than likely, the teacher who was doing the leading in terms of innovation of instruction and teaching for Māori students probably was one of the assistant teachers, who was probably more the leader in that respect, but that was also potentially very difficult and I think because it's about trying to alter the existing school structure. We had new leaders emerging, ... and this challenged the existing structure in departments and that caused some issues. High schools are quite different in terms of hierarchy and heads of department can hold a lot of power structurally. (In-school Facilitator 1, 2004) 
It has been argued that identifying and understanding conflict and micro-political issues within schools is important within reform activities, because organisations may unintentionally maintain the status quo by seeking changes that are reactive, adaptive and/or produce superficial changes (Argyris \& Schon, 1987). This is called "single-loop learning", in which participants within an organisation undertake incremental changes whilst maintaining norms and practices already established. Double-loop learning, on the other hand, is a particular type of inquiry which "fosters a new sense of the nature of the conflict, of its causes and consequences, or of its meaning for organisations theory" 45 (Argyris \& Schon, 1978, p. 11). Double loop learning requires critical reflection through a process of on-going inquiry and it is this type of learning that produces new insights and practices (Argyris \& Schon, 1978). While there were gaps in participant stories related to teachers' and principals' knowledge of such theories, it interested me that other participants in the wider school community appeared to understand the political complexities of teachers' collaborative partnership work, based on their own personal experiences. However, their voices were not heard within the context of teachers' collective reform activities:

I'd like to know whether all the teachers, Pakeha and Māori, are comfortable ... with this process, whether this process makes their work harder. ... I mean, by working in groups, if they're more interactive, how do they deal with the complexities that sometimes arise with conflict within the groups? ... 'Cause it can be quite political, eh? And I can only imagine that they've been taught conflict resolution 'cause when you're working with groups, and I know that from my own experience with Māori community groups, that's the sort of things you have to expect is conflict 'cause of different people's world-views and perspectives. Because it's complex work ... I'm a community development worker, and it's complex working like that in communities, and I could imagine the same complexities that I deal with are no different ... you just build those mechanisms to be able to deal with it and it's about respect. (Mr Tui, parent/caregiver of Māori child, 2004)

45 This has been described as theory that governs action (Argyris \& Schon, 1978, p. 11). 
Other theorists writing in the area of culturally responsive practices are arguing for the recognition of a new type of leadership: "educational leaders who lead in the midst of diversity" (Shields, \& Sayani, 2005, p. 397). The role of such leadership is "to create appropriate spaces in which meaningful dialogue may occur, dialogue that helps students to make sense of the formal, informal, and/or hidden curricula" (Shields, \& Sayani, 2005, p. 384). This is needed in order to deepen understanding and to acknowledge and reject deficit theorising, reduce disparity in educational outcomes and increase activism for democratic outcomes (Shields \& Sayani, 2005). It has been argued that school leaders who want to be effective inter-cultural leaders will need to listen carefully for implicit and explicit messages being given to children within the school community, by peers, teachers and other members of the community (Banks, 2004; Shields \& Sayani, 2005). Some authors have argued strongly that the process of gathering and listening to voices of culturally diverse participants is necessary for shaping wholeschool reform strategies (Johnston \& Bush, 2005). These authors have stated that teachers can develop culturally responsive strategies only in the context of culturally responsive schools. In order to promote such practices, schools need to adopt socio-cultural inquiry at all levels.

\section{Staff Divisions and Disputes}

Participant stories indicated to me that there were deeper tensions within the context of teachers' collaborative partnership work which highlighted a much bigger but largely hidden political dimension. For example, as I analysed participant stories over time, I became aware of existing staff factions or divisions, as well as personal vendettas which could influence some teachers' willingness to engage in collaborative reform work over time. In some situations, teachers' feelings of personal safety (due to negative past experiences of bullying teacher behaviour, existing dysfunctional relationships and/or communication issues with colleagues) impacted on their engagement in new partnership work.

I became more aware of established divisions and/or disputes within each school. This was particularly evident amongst participants from Rata Primary. Many who were interviewed from this school community explained that at the time Te Kauhua was introduced, there were identifiable staff divisions and factions that actively opposed new partnership work: 
... we had a school that was divided into two camps. They were as aligned as the Balkan states. We had the junior school who was working quite well together and the senior school who really didn't do any planning together, didn't know what the word collaboration meant. They were absolutely divided so we had all of these sorts of problems. We had teachers who said, 'You'll get into my classroom over my dead body'. We had teachers who said, 'Well, what I'm doing is all right so why bother about them, they can sink or swim. It's not my problem - it's the principal's problem'. (Principal 1, 2003)

In fact, Rata Primary appeared to be a completely factionalised school:

... When I first started, I couldn't see that it was possible for Te Kauhua to work in this school because it really was a war zone. There were just little cliques of teachers and everybody was at each other's throat pretty much ... . You couldn't say, well, the syndicates work together or anything like that. It was every man for himself. No, it looked impossible, it seriously looked impossible. (In-school Facilitator 2, 2003)

It appeared from my analysis that some of the existing staff divisions were related to tensions and disputes which had emerged from within the senior management team. ${ }^{46}$ Different participants talked about specific tensions as well as the existence of dysfunctional staff relationships, which impacted on teachers' willingness and readiness to engage in new collaborative reform work. The Te Kauhua facilitator reflected on the turbulence of staff relationships at this early stage. She felt that teachers were divided into factions because of a breakdown in relationships:

To start with in the project, the school was split basically, it was really split. There was a very unpleasant departure of a deputy principal and a whole lot of people who hated the principal and wished it was him that was gone. So there was all this kind of stuff seething away and carrying on

46 In this context, the senior management team was made up of the principal, deputy principal and assistant principal. 
amongst teachers, and there were the ones who were for Te Kauhua and ones who were against and there were ones who were whispering around corners and all of that ... and so at the beginning I spent a lot of time just building relationships with teachers. (In-school Facilitator 2, 2003)

In his interview, the Principal acknowledged difficulties between himself and the last deputy principal and that this "mess" had hindered the start of collaborative reform at his school:

... the last deputy principal resigned, and despite the fact that she resigned in the most horrendous way and left the nastiest mess you could possibly imagine, in some ways it was really good. Because when you're faced with absolute upheaval, it makes you stop and reflect and think, you know, 'Hey, either I go down with this or I survive. Now what do I want to do here? And if I want to continue, how do I make sure that the school is supported to be the best that it can be?'. (Principal 2, 2004)

Stories indicated that teacher emotions were running high within this school during the initial phase of Te Kauhua. The In-school Facilitator believed she learned a lot about the actual politics between staff members:

There was absolute turmoil in that school at that time. ... There was squabbling and fighting and no talking amongst the teachers. The Principal acknowledged that we had a fundamental problem and that we couldn't go anywhere until we sorted all this stuff out ... so an outside consultant came in to do this re-culturing process ... . To begin with, they [the teachers] hated me, all right, 'cause I was another imposition in their lives that they hadn't asked for, and they were just getting used to me and figuring that actually I could be quite useful around the place when we got the outside consultant in who they hated with a vengeance ... and so the feelings they had about me they transferred to him. So they were kind of battered backwards and forwards between the two of us for a while there, but I mean it did take the pressure off me a little bit. And then I got a lot of this knifing because they were criticising him and the Principal and each 
other to me 'cause I was kind of the 'other' person then. I mean, it was a bonus to me in many respects because I picked up a whole lot of stuff that was going on and what the actual politics in the school were and the personal relationships and how it all worked ... but they weren't talking to each other ... this one would talk to me and that one would talk to me but they weren't talking to each other and it was all seething underneath and not actually being brought out into the open. (In-school Facilitator 2, 2003)

A number of participants who were interviewed from this school community acknowledged that the Te Kauhua project took a long time to get established within the school, partly because of the existing staff dynamics:

We had a fairly slow start to the project for various reasons, particularly staff changes and problems within the school ... the dynamics of what was going on. (Verna, non-Māori teacher, 2004)

At the beginning of Te Kauhua, there was a stand-still amongst the teachers, not everyone was on board with the project, the waka wasn't off the beach. (Ms Wilson, parent/caregiver of Māori child, 2004)

Being in the school, you noticed things, like in the school things got quite tense between some of the teachers at one stage. And there was a lot of tension amongst the staff ... . (Mrs Grace, parent/caregiver of Māori child, 2004)

The divisions in staff relationships at Kowhai College were not so pronounced, but I found that there were still undercurrents of subversive and damaging teacher behaviour which had influenced teachers' engagement in new partnership work over time. For example, Heria felt she had fallen victim to an orchestrated campaign in which some colleagues thought she was unsuitable to teach at the school. When she expressed her concerns to me, it appeared that no-one had actually been to see her and address their concerns in her words, "kanohi te kanohi". She had been told by her principal that a letter 
of complaint had been written about her conduct, and there had been accusations of her 'deficit theorising' towards Māori students particularly.

As I listened to participants from Kowhai College tell their stories, I also became aware of largely balkanised teacher groups, particularly as some teachers appeared to associate more closely with colleagues in departments. I knew from my own experience of working in schools and from research literature that teachers may associate more closely with particular groups than with others (Fullan \& Hargreaves, 1996; Hargreaves, 1994). The structure of high schools, with a focus on teacher activities within subject departments, often encourages teachers to form close alliances (Fullan \& Hargreaves, 1996; Hargreaves, 1994; Little, 2001; Stoll, Fink \& Earle, 2003). Teacher activity is more likely to be viewed in terms of subject departments than across the school in most secondary schools (Fullan \& Hargreaves, 1996; Little, 2001). It has been argued that when teachers associate closely with particular groups in school, this may lead to a "balkanised" teacher culture (Hargreaves, 1994; Fullan \& Hargreaves, 1996). A balkanised teacher culture has been defined as,

... a culture made up of separate and sometimes competing groups, jockeying for position and supremacy like loosely connected, independent city states. (Fullan \& Hargreaves, 1996, p. 52)

Balkanisation can create staff divisions, particularly if teachers form close alliances with the teachers in their departments and syndicates (Ball, 1987; Fullan \& Hargreaves, 1996; Hargreaves, 1994). Such divisions can compound difficulties in schools as teachers try to work together to improve practice (Ball, 1987; Fullan \& Hargreaves, 1996; Hargreaves, 1994). McLaughlin and Zarrow (2001) note the difference between the ways teachers work in secondary schools and the way they work in primary schools. They found that teachers in faculty (subject) departments rarely think in whole school terms but rather in departmental terms. Teachers' collaborative behaviour can be very different in secondary schools as compared to primary schools because of different school structures and hierarchical divisions (Ball, 1987; McLaughlin \& Zarrow, 2001). However, Hargreaves (1994) notes that balkanised groups can occur in primary schools between infant and junior teachers who group together and view their work as separate from more senior syndicates. 
It became clear that existing staff divisions within each school community would inevitably have an effect on the acceptance of teachers' collaborative partnership work. I had read that dysfunctional staff relationships can develop through "turf wars", and power struggles and that these can impact on teachers' ability to engage in important reform activities and distract teachers from focusing on improving their classroom practice (Ball, 1987; Fullan \& Hargreaves, 1996; Stoll, Fink \& Earle, 2003). A number of authors have highlighted micro-politics in schools where teacher status, career advancement, resources and influence are at stake, and teacher actions and decisions can be influenced by conflicts between teacher coalitions and alliances within schools (Ball, 1987; Fullan \& Hargreaves, 1996; Little, 2001). Squabbles and destructive conflict amongst teachers can produce poor continuity in monitoring student progress and inconsistent expectations for student performance and behaviour across the school (Fullan \& Hargreaves, 1996; Little, 2001; Stoll \& Fink, 1996; Stoll, Fink \& Earle, 2003). I had read that organisational cultures shape participants' actions and interactions through observable and least observable cultural levels. These cultural levels involve readily identifiable artefacts, such as espoused values through schools' mission statements, and less visible but influential artefacts such as taken-for-granted assumptions, beliefs and social practices which can remain unexamined (Ogawa, 2005, p. 102).

It appeared from my analysis of participant stories that existing social divisions and norms of teacher behaviour within staffrooms across both school communities influenced the practice of teachers' collaborative partnership work. However, I felt from my analysis that such divisions and the values and beliefs underpinning them remained unacknowledged and unexamined by participants themselves over time. There appeared to be gaps in participants' (teachers, principals and in-school facilitators) knowledge about the importance of understanding tensions and conflicts (Shields \& Sayani, 2005), the need to identify the established forms of teacher culture developed through peer relationships and association that exist within the school (Hargreaves, 1994), the presence and nature of border politics, and the need to develop a professional learning community (Achinstein, 2002). 


\section{Bullying and Subversive Practices}

Over time, I became aware of bullying and subversive practices, including personal vendettas, that influenced the practice of teachers' collaborative partnership work, as well as its efficacy and place within each school's culture. It appeared from my analysis of participant stories, from one school community in particular, that there were existing dysfunctional relationships between staff when the Te Kauhua programme was first introduced. Many who were interviewed from this school community explained that there were established patterns of subversive and bullying teacher behaviour. An example of subversive behaviour, according to people who were interviewed, involved teachers "going behind people's backs" and/or not discussing issues within an open forum where staff members could address and debate issues professionally. One participant explained that he had witnessed aggressive and dysfunctional communication practices of teachers within his school community:

There had been that sort of subversive teacher behaviour and it can really damage the staff and it has done a lot of damage in the past ... . Some comments like, 'Why should we do that?' It's almost like saying, 'Up you, you can't make me do it'. Comments at staff meetings, put-downs about Te Kauhua and the work being done, sighs, body language, blatant 'No's', to subversive behaviour, going behind people's backs and saying, 'Let's not do that', 'I'm not handing it in to colleagues', just not being made accountable for their behaviour really ... . And it lets people down sometimes and sometimes it is aggressive. (Resource Teacher of Learning \& Behaviour 2, 2004)

Participant stories indicated that individual staff members from across both school communities had experienced very negative and damaging incidents in their work with colleagues, which in turn impacted on their willingness to engage in new collaborative partnership work, and undermined trust, respect and collegiality.

For example, when I first interviewed Heria, she was very enthusiastic about the possibilities of working collaboratively with colleagues to improve aspects of classroom practice for diverse groups of Māori students. She told me that she was particularly interested in improving practice for those Māori students "who fell through the cracks". She 
believed teachers needed to establish positive relationships with students who were most "at risk" of being suspended from school and she was a real advocate for "power-sharing" strategies. She explained that, in the past, she had upset some of her colleagues (Māori and non-Māori) because of the way she behaved with students, and because she often used students' language in class. ${ }^{47}$ When I interviewed Heria for the second time, she told me that recent events which had occurred at school with individual staff members had made her wary of collaborative reform efforts:

I think at times some people have a problem with fronting up and being honest about what they really think ... . No one came and saw me or talked through their concerns directly with me ... . Another staff member came to me at assembly actually and very quietly said, 'Watch your back', and I said, 'What?', and she said, 'Oh, because there are some people gunning for you', and I said, 'Oh, what have I done?' And she said it was just a personal vendetta, so there was that too, but that really, really upset me, like I was in tears. At the moment she said it I thought, 'Who cares!', but as five, ten minutes ticked by and by the time I got down to the classroom and I looked at these kids and how unruly they were, I just thought, 'Oh, my God, maybe I can't do this. Maybe I'm really not good enough for these kids'. You know, I am doing my very best ... . (Heria, Māori teacher, 2004)

She went on to describe how one of her students ${ }^{48}$ went to get a teaching colleague:

... one of the kids actually went and got Ian. They thought I was upset with them, that they hadn't been listening to me, but it wasn't that ... . Someone went to get Ian and said, 'Whaea's crying', and he came down and said, 'What's the matter?' and I told him and he was great, he reassured me, he

47 Heria said that sometimes she used the language that she believed some students used frequently at home. Some of the language she used with students included swear words and colloquial terms.

48 This quotation forms part of a body of evidence which indicated that some students could be well aware of the emotional states of their teachers. 
said, 'Heria, a lot of people don't appreciate what we do, they don't understand what we do and how we do it'. (Heria, Māori teacher, 2004)

She said that some of the complaints had appeared to come from individual staff members, and she believed some had felt threatened by her expressed beliefs and practices. It seemed that teachers held a variety of beliefs about improved practice for Māori students, and that discussions related to teachers' beliefs could be limited to particular and established teacher groupings within each school community. I had read that cultural divisions can occur within schools when groups of teachers hold very different pedagogical philosophies (Ogawa, 2005). Much of this data appeared to link to research literature on "border politics" within schools, whereby teachers associate with colleagues who share similar ideas and values (Achinstein, 2002; Ball, 1987). Border politics have been described as the process by which teachers define "community borders and/or boundaries" to which people and their ideas "belong" (Achinstein, 2002, p. 426). According to Ball, squabbles can arise as teachers defend their beliefs and their status (1987). It has been argued that teachers may use opportunities in staff and committee meetings to point-score against colleagues and seek revenge for past grievances (Ball, 1987; Fullan \& Hargreaves, 1996).

It also appeared from my analysis of participant interviews that some teachers experienced increased isolation from their peers, sometimes simply because their colleagues had chosen not to work with them. Trust apparently influenced not only the practice of teachers' collaborative partnership work but also the acceptance of such work and its place within each school's culture.

Heria was not the only teacher who was less enthusiastic about the prospect of collaborative partnership work when I interviewed her a second time in 2004. Others were also affected by undercurrents and subversive practices within their school environments. Although Leanne highlighted issues related to "dominant teachers", I found she was reluctant to give any other detail:

I have experienced that dominant teachers get their own way ... . That's been my experience of working with teachers in groups, that there are good and bad experiences .... . (Leanne, non-Māori teacher, 2004)

Richard was another teacher who explained that, since teachers' engagement in the Te Kauhua professional development hui, he had been involved in talking with 
colleagues from across departments, in small groups, about evidence gained during reciprocal in-class observations. He said that the observational data was shared amongst teachers in his group to facilitate discussions regarding the use of strategies to engage Māori students:

We meet once every three of four weeks to talk about our observations ... we get a report on our teaching, a very detailed report from the observer, about where you stand in the room, your use of co-construction strategies, how you work with students, how engaged they are, your use of feedback etc, so basically a report on your own teaching, and then we discuss this report in the group so we can benefit our teaching together as a group. We meet as a group. So everything we share together, we don't say, 'I have got more co-construction strategies', or whatever - that doesn't matter. What matters is coming up with strategies to use in our classrooms that would benefit the Māori kids especially. (Richard, non-Māori teacher, 2004)

Richard explained that while he was quite happy to share his thoughts on practical learning activities with colleagues in this group, he was not happy to share all his thoughts:

... we share practical learning activities, but now as far as my vision, probably not. (Richard, non-Māori teacher, 2004)

I was very interested in his response and I asked him why he had chosen not to share his vision of classroom improvement with colleagues in his group. ${ }^{49}$ He replied that he had experienced very negative reactions from some colleagues at a previous high school in the area when he had tried to talk publicly about improving classroom programmes for diverse learners. It is important to note that Richard had recently arrived at the school and that the events he described did not occur at Kowhai College:

49 Richard indicated that he had attempted to improve his classroom teaching by using co-construction and power-sharing strategies with students. 
I wanted to create a cross-curricular programme at my previous school, and we had a management meeting and we were talking about things, and to me the cross-curricular stuff is of so much value to the kids, and I could see how we could do it. Some kids had to clean up the gutters, so they needed a machine to clean it better, they could work in with the metal work guys and we could create a whole cross-curricular thing. I could see a few eyebrows being raised, and at the end of the meeting someone came up to me and said, 'If you don't like it here, then why don't you leave ...?' ... [and later] so, yeah, I was a bit taken aback, my enthusiasm was dampened after that. I have learned not to say some things to my colleagues ... I got told by a colleague to 'Shut up', and, 'Who the fuck do you think you are?' ... [and later] things like that. I was just trying to do my job as well as I can. (Richard, non-Māori teacher, 2004)

I was shocked by Richard's description: it appeared that he had experienced considerable verbal abuse from a few colleagues at his previous school who had taken an extreme dislike to his suggestions. Richard felt this experience had constrained his ability to talk openly with colleagues about his values and beliefs related to improved classroom practice. Abusive and negative teacher peer pressure was something that he felt was a major barrier to collaborative reform work:

So whatever you do, you are always stepping on someone's values ... . I have found through past experience that there is [teacher] peer pressure not to stand out, because if you stand out, then you bring a shadow on the other teachers. Sad, but that is a reality. I know it is the main hindrance to raising academic achievement amongst our kids in schools, especially the Māori ones. (Richard, non-Māori teacher, 2004)

I was troubled by revelations of racism, alongside of accounts of personal vendettas and of teachers' past experiences of bullying practices. Recent research undertaken in Aotearoa/New Zealand has suggested that bullying is a significant issue for culturally diverse students, because it affects their sense of personal safety and belonging and interrupts their engagement in learning activities (Carroll-Lind \& Kearney, 2004; Gaffney, Higgins, McCormack \& Taylor, 2004). Gaffney, Higgins, McCormack \& 
Taylor (2004) argue that a reduction in bullying practices can occur only through the development of a positive school culture which requires participants (students, teachers, parents/caregivers) to examine critically the relationships that make up their school. However, during my final member checks in 2005, one participant felt one of the teachers had been bullied because he was openly gay. In my reading for this thesis, I discovered warnings that participants may work to uncover racism and prejudice in schools within reform contexts, but still "torment and harm people because of their sexuality" (Unks, 2003, p. 322). A few authors appeared to be arguing that educators must address the intersections of race, gender, social-class, sexuality and (dis)ability within the context of school reform work (Alton-Lee, 2005; Banks, 2006; Fine \& Weiss, 2005; Hooks, 2003; Town, 1996; Unks, 2003). Alton-Lee (2003) has emphasised that an important characteristic of quality teaching in Aotearoa/New Zealand ensures teachers' pedagogical practices enable classes and other learning groupings to work as caring, inclusive and cohesive learning communities. A number of research studies have suggested that sociocultural inquiry into schooling practices are imperative if bullying, prejudice and labelling practices, which can negatively impact on culturally diverse student achievement and outcomes, are to be combated (Banks, 2006; Steele, 2004; Stephens, 1999; Unks, 2003).

Critical theorists have emphasised the discursive underground positioning of students and adults that "flourish within the margins" of public schools (Fine \& Weiss, 2005 , p. 2). These authors have stated that if we are serious in our commitment to multicultural and feminist education, for example, then other voices need to be invited to speak. A few authors have argued that the voices of lesbian and gay adolescents and adults across racial, ethnic and class lines need to be centred and heard if we are serious about schools as democratic spheres and "if we want to understand and interrupt the perversions and pleasures of power, privilege and marginalization in public schooling" (Fine \& Weiss, 2005, p. 2). I wondered about the nature of subversive bullying teacher practices within each of the school communities, fuelled by hidden values, beliefs and unacknowledged attitudes towards difference which seemed to me to influence the acceptance of teachers' collaborative work, as well as its efficacy and place within each school's culture. 


\section{Ways of Dealing with Diversity in a Closed System}

Hierarchies, divisions, disputes, and acts of subversion and bullying are all indicators of cultural malaise that a system is not able to accommodate the openly reflective approaches required by any reform process.

Respect for differences must be considered a non-negotiable factor in the work of culturally responsive practice, as well as ensuring that practice addresses issues of diversity whilst reducing disparity in student outcomes (Johnston \& Bush, 2005; Shields \& Sayani, 2005). During a final presentation of the research data, I observed one of the principals closing the hui by pleading with staff members to listen to the voices of students within their classrooms. However, data indicated that teachers held different beliefs about the importance of power-sharing strategies within each school community and there was a lack of effective listening practices and mechanisms which would engage culturally diverse and previously silenced voices in dialogue over time.

I wondered how teachers could create effective learning programmes and environments for culturally diverse learners without a critical and open investigation into their own established social practices and the values and beliefs which underpinned them. It appeared from participant interviews that the majority of teachers experienced considerable difficulty in challenging colleagues about behaviour and practices which they had witnessed over time:

Like yesterday, I was walking back across the playground and I could see this teacher at the pool with their children lined up at the gate and one of our school runners, a Mâori child, had gone up to the teacher ready to give them the notice and this teacher just snatched it out of her hand, and I could see the look on this child's face. And I felt really shocked and afterwards quite angry. But I haven't said anything to that teacher yet. I'm still fuming, after all the talk about the importance of relationships. I'm not sure that it'll make a difference. (Verna, non-Māori teacher, 2004)

Different questions consumed me: if teachers were unable to 'name and deal' with such situations, how could they encourage and expect the same behaviour from their pupils? It appeared to me that the existing behaviour of school staff in both schools, and the values and beliefs that guided such behaviour, needed to be openly and critically 
examined over time by participants, within the context of collaborative partnership work. The practices of school staff can be interpreted as "the way we do things around here" and relate directly back to the existing school culture (Stoll \& Fink, 1996). The concept of school culture has been described as the guiding values, beliefs and expectations evident in the way a school operates which can be implicit and/or explicitly stated (Stoll \& Fink, 1996). School culture can be evident in the ways that people relate (or fail to relate) to each other (Fullan \& Hargreaves, 1996).

According to noted multicultural theorist James Banks (2004, 2006), grouping practices within schools can create distinctive labels for particular groups of students which can be counterproductive to establishing culturally inclusive and responsive school learning environments. Grouping practices can reinforce stereotypes, lower expectations of particular groups and create social divisions amongst students (Banks, 2004, 2006). Interview evidence indicated that, while Kowhai College had a mission statement about catering for individual student needs, in reality the system itself separated and labelled diverse groups of students. For example, besides the Te Kauhua class, there was also a 'Gifted Class', a 'Special Needs Unit' and an 'Alternative Education Classroom'. I discovered that many Māori students found their way into the 'Alternative Education Class', a class which seemed to me to have a 'watered down' curriculum.

Shields, Bishop and Mazawi (2005) have also argued that mainstream, 'pathologising' schooling practices help to create and perpetuate images of students through labelling practices that can be destructive, particularly to those who are perceived as "different". These authors have stated that deficit thinking related to 'difference' pervades educational thinking and discourse. As I navigated the stories of culturally diverse participants, I started to see the impact of deficit thinking towards difference. Shields, Bishop and Mazawi (2005) have argued that the "root meaning" of pathologising practices is linked to notions of "disease" (p. 17). This suggests that "the cure" is "quarantining the victim"; a pathologising school practice which deems to separate those who are not like 'us'; a process of 'Othering' through the "establishment of separate schools, classes, programmes, or special curriculum" which are often compensatory 'to make up for' the deficiencies within the student (Shields, Bishop \& Mazawi, 2005, p. 17).

I became aware of different social identities which emerged as labels for particular social groups, as well as clearly established social divisions within each school. Consider the following quotations from students at Kowhai College: 
... the Māori kids get their own classroom ... but then most of the Mãori class are pretty good mates and they hang out together, but then so do the White Dudes and the Exchange Students in their special room and then the Màori students on the bottom field doing their own thing ... like with the Exchange Students, we've got quite a few of them at school and they have their own special room and they hang out and it's close to the $7^{\text {th }}$ Form common room and they sit in there and eat noodles .... . (Heath, Yr 11 non-Māori student, 2004)

No, I don't really know about it [Māori and non-Māori teachers working together] and I can't really see it and I've never seen it happen ... like with the kids at school, the Mäoris and the Pakehas are really split, one side is on one side of the school and the other on the other. There's hardly any mixing and maybe only in rugby, but that's sort of different ... . (Sonia, Year 11 non-Māori student, 2004)

... there are little cliques ... . Like, there's the Māoris who want to play touch and the white jokers who want to play touch and then the Marori smokers and the white smokers and then the people who just don't enjoy that sort of stuff ... and then all the Chinese dudes stick together and, yeah, people just stick together in their own groups ... . (Hugh, Yr 11 nonMāori student, 2004)

Banks (2006) has argued that each school must be viewed as a social and cultural learning system which is larger than its interrelated parts. It has been argued that schools can be conceptualised as cultural systems with a specific ethos, and values, norms and shared meanings that develop through grouping practices, actions and interactions amongst school participants:

Among the variables that need to be examined in order to create a school culture which empowers students from diverse cultural groups, are grouping practices (Wheelock, 1992), labelling practices, sports participation and whether there are ethnic turfs that exist in the cafeteria or in other parts of the school ... . (Banks, 2006, p. 16) 
Banks (2006) has argued that any attempt to implement culturally responsive reform in schools requires many different changes in the school, because such organisations are social learning systems. Approaching school reform from a systems perspective is necessary, as many school reform efforts in this area often fail to sustain change over time because the roles, norms and ethos of the school are not critically examined (Banks, 2006; Fullan, 2005). According to Fullan (2005), it is important that change agents, working towards school reform, understand the interconnectedness of the school system and how changes in one area (such as pedagogy) require changes in other areas (such as curriculum and assessment). A systems perspective is needed for empowering classroom practice and outcomes for culturally diverse students because pupils may receive unintended messages from observing interactions amongst staff members (Banks, 2004). An empowering school culture should engage culturally diverse participants (teachers, students, parents/caregivers, community elders) in collaborative, critical inquiry and dialogue to improve aspects of practice for all learners across the school community (Banks, 2006; Johnston \& Bush, 2005; Shields \& Sayani, 2005). Interview evidence revealed large gaps related to teachers' and principals' knowledge of such theories and processes.

An analysis of participant stories indicated that there were existing social divisions and groupings within each school culture which emphasised diverse social identities, and that such divisions were also evident in staffrooms, classrooms, playgrounds and across the wider school communities. Various authors have argued that because schools are unique socio-cultural systems, both teacher and student behaviour is affected by the climate or culture within the school (Banks, 2006; Fullan, 2005; Johnston \& Bush, 2005; Kincheloe, 2003; Ogawa, 2005; Stoll, Fink \& Earle, 2003). I thought it strange that teachers were attempting to work together to improve classroom practice for particular groups of Māori students without being aware of the need to examine critically why they were doing this and/or the existing school practices and the values and beliefs which underpinned them. Nor did teachers, particularly at Kowhai College, appear to be aware of the existing social and turf divisions between student groups which existed within the playground. I became particularly aware of constructions of 'white'-ness, and of the labelling practices some students used which emerged from their interviews: 
Teachers should be working together to improve all the kids' achievement, not just the Māori ones, because some of our teachers need to teach better for the white kids as well. (Lucy, Year 11 non-Māori student, 2004)

Well, pretty much the Māori kids stick with the Māoris and, well, the white kids stick with the white kids, why would you want to get any closer? (Sonia, Year 11 non-Māori student)

I searched for further literature and found recent warnings from Alton-Lee about short-term "democratic" processes in schools which attempt to meet the needs of particular groups of students. I was interested to read her warnings of a "backlash effect" (2005):

The 'democratic' process can result in an intensive focus for a period of time on a particular group who have an effective lobbying impact. This kind of approach can provide important intensification of resources and knowledge for particular groups of learners but is at risk of not permeating mainstream practice, and/or can even create a backlash effect. Of most concern is that this approach can lead to a kind of bandwagon approach that fails to address the teacher's challenge to manage the learning of all the students at the same time. (Alton-Lee, 2005, p. 10)

In observing the entrenched resistance to teachers' collaborative partnership work, based on the dominant discourses of identity and equity, and bolstered by the undercurrents of deficit thinking, prejudice, racism and forced identities (Chapter 5), I began to see that there was little that was healthy in the attempts to maintain and sustain such work in these two schools. While sometimes difference was upheld, at other times it was undermined. There was no indication of holistic acceptance and inclusiveness, either at the level of the classroom or in the wider community. While some positive new identities seemed to emerge (such as "school achiever"), there was a blindness towards the existing identities that maintained a conservative stranglehold on school culture.

I therefore started to see teachers' collaborative partnership work as a largely superficial process, tinkering with the edges of practice but not really challenging the status quo. I also found myself questioning the purpose of teachers' collaborative 
partnership work, and particularly what counted as improved practice for culturally diverse learners and their teachers.

\section{Transparency and Outcomes for Students}

I wondered about the messages (intended or unintended) that students may receive from observing their teachers' interactions over time. It interested me that a number of writers speaking about the development of multicultural education highlight the importance of teachers modelling appropriate behaviour in multicultural settings (Banks, 2006; Bishop \& Glynn, 1999; Cochran-Smith, 2004; Ladson-Billings, 2001). Banks argues that the behaviour of school staff must be examined in order to determine "the subtle messages it gives the students about racial, ethnic, cultural and social class diversity" (2006, p. 16).

Classrooms are not neutral territories. All of my fieldwork indicated that students are often preternaturally aware of dynamics, power struggles, hidden agendas and undercurrents within relationships throughout the school. If a school operates with subterfuge, subversion, ostracisation, and autocratic systems of power and control, students are bound to be aware of many of these dynamics, at least at the level of dis-ease if not at the level of full understanding. They are also usually aware of a lack of commitment, of hypocrisy and dishonesty:

I like to ask the teachers if they are really serious about this, about their collaboration ... because I don't think all the teachers are doing this work ... . I don't think they're all working together. (Marama, Māori student, Year 11, 2004)

Many participants ${ }^{50}$ who were interviewed believed it was important for teachers to model appropriate collaborative behaviour, because teachers were role models for children:

50 Fifteen parents/caregivers (13 parents/caregivers of Māori children and 2 parents/caregivers of nonMāori children), 18 students (13 Māori and 5 non-Māori), 9 teachers (2 Māori and 7 non-Māori), 2 principals (both non-Māori), and 2 facilitators (1 Māori and 1 non-Māori) told me that it was important for teachers to model appropriate collaborative behaviour because teachers act as role models for children in cross-cultural settings. It is also important to note that 14 parents/caregivers (13 parents/caregivers of Māori children and 1 parent/caregiver of a non-Māori child) and 6 teachers (2 Māori and 4 non-Māori) thought it was important for teachers to work in partnership because it models a commitment to the Treaty of Waitaingi. 
... we also recognised that if we were going to have certain expectations of the children, then we had to have the same expectations of ourselves, so one of the big complaints by staff was the number of put-downs that kids were using out in the playground, and so we said, 'But yes, what about ourselves?', and when we looked at some data taken at meetings, there were put-downs all over the place. There was staff using put-downs about the children and put-downs about each other, so we agreed we had to go right back and have a look at our philosophy of values, and rights and responsibilities for ourselves before we could look at them for the children, and although we should encompass the kids in it, we needed to go through it ourselves. (Principal 2, 2004)

I think this had been an important aspect of this work that teachers are modelling cooperative learning to their students and I think that is one of the real strengths of this programme. (Principal 1, 2004)

It's essential for the kids to see teachers modelling cooperative behaviour ... and they are seeing that when we [teachers] are working in each other's room and through the trialling of cooperative learning strategies ... . (Leanne, non-Māori teacher, 2003)

Although the majority of participants who were interviewed believed teachers should model effective cross-cultural learning relationships or partnerships, there appeared to me to be considerable gaps and contradictions between how they believed they should behave, and the way they actually modelled behaviour within the context of their collaborative partnership work. Over time, I became aware of just how sensitive some students were to changes in teachers' behaviour but also that some sensed the unease and lack of acceptance of teachers' collaborative partnership work within their own school communities.

For example, 4/6 Māori students who were interviewed from Rata Primary School appeared concerned about teacher and/or parental resistance to the practice of teachers working together to improve the use of te reo me ona tikanga: 
Umm, I think it's good [Māori and non-Māori teachers working together], but some teachers might not want to learn Māori and I don't think you can force them. Maybe they just don't want to learn it ... umm, not sure why. (Keriana, Yr 5 Māori child, 2004)

Keriana explained that some people might not want to learn te reo because of their parents' reaction:

Some people might not want to learn te reo because they might think it's bad for them ... because they might think their parents might growl at them if they learn it, the Māori, and if they don't tell their parents they're learning it, they might get an even worse growling.

Q: Why do you think some parents might growl?

Because they don't like Màori stuff. Umm, I'm not sure really, maybe they just don't understand the words. (Keriana, Yr 5 Māori child, 2004)

Groups of students appeared sensitive to changes, debates and the emotional states of teachers and parents/caregivers within the context of new collaborative reform work. This seemed to reinforce some theorists' arguments that students receive and interpret messages from observing interactions between adults within the school's community (Banks, 2001a, 2006; Cochran-Smith, 2004; Hawk, Tumama Cowley, Hill \& Sutherland, 2002; Ladson-Billings, 2001). For example, 19/30 students (12 Māori and 7 non-Māori $)^{51}$ told me that they had noticed their teachers being helped or watched by other adults or teachers in their classrooms.

It was also clear that many of the students appeared not to have been informed about the process of in-class observation and feedback, and/or were given misleading information about the process. It occurred to me that 'honesty' may not be a 'nonnegotiable' within the context of teachers' partnership work. Data indicated that if teachers acted differently in class during in-class observations, then the students would definitely be aware of this, and if they did not know why teachers were acting in this

51 Eleven/18 Year 11 students from the high school and 7/12 children from the primary school told me that they had noticed other adults/teachers in their classrooms, working with or watching their own classroom teacher. 
way, they could feel that it was something to do with them (as the earlier example of Ian being brought to Heria's classroom also indicates).

Evidence gathered through participant interviews suggested that diverse groups of students were keen observers of their teachers and were sensitive to changes within their classroom and school environments: ${ }^{52}$

There were some changes in the school and I think that was brought about by the whole concept of just trying to keep Māori students at school and also teachers being made really aware of the cultural difference ... . I think it really pulled teachers in line by saying, 'You know, you have to respect these kids ... you can't bellow at them in class', and from that I really did notice a difference, and also my son, he was coming home and saying, 'Oh, the teachers aren't yelling at us as much'. He actually came home and said that to me, and from that aspect it was good to see that change. (Mrs Gambie, parent/caregiver of non-Māori child, 2004)

According to a number of theorists writing in the area of culturally responsive/multicultural education, appropriate teacher modelling must include activism and challenging the status quo to highlight issues of prejudice, racism and bullying which impact on culturally diverse student engagement and achievement in school (Banks, 2001a, 2006; Cochran-Smith, 2004; Ladson-Billings, 2001; Sleeter \& Delgado-Bernal, 2004). According to these theorists, an important part of the development of culturally responsive pedagogy requires teachers to encourage their students to raise critical questions, and to investigate knowledge construction, pathologising practices, and power relations both within the school community and outside in society (Banks, 2001b, 2006; Bishop \& Glynn, 1999; Cochran-Smith, 2004; Ladson-Billings, 2001; Shields, Bishop \& Mazawi, 2005; Sleeter \& Delgado-Bernal, 2004). Cochran-Smith (2004) has argued that teachers need to encourage their students to think critically about information they are exposed to and to speak out honestly and openly about issues of injustice:

52 Heria told me that students within her class went and got Ian when she broke down and cried in class (see p. 215 in this chapter): 
Part of this means helping students name and deal with individual instances of prejudice as well as structural and institutional inequities by making these practices 'discussible' in school. This also means challenging some of the practices and assumptions that are taken for granted. (Cochran-Smith, 2004, p. 77)

I could find no evidence from participant interviews that indicated that teachers were helping students to speak out about prejudice and racism and/or to investigate and identify power relationships within either school community.

There appeared to be a lack of collective, critical inquiry and listening practices which would enable culturally diverse participants to talk about their experiences of teachers' collaborative partnership work. The impact of existing social practices and customs within each school community became an important influencing theme which emerged from data analysis. Issues of trust and respect between teachers also emerged within the data, as evidence indicated that teachers' prior experiences of collaborative partnership work could influence the way they chose to define and/or engage in partnership reform work. ${ }^{53}$ Although a number of authors have stressed that collaborative partnership work must be underpinned by mutual trust and respect (Bishop, Berryman, Tiakiwai \& Richards, 2003; Fullan, 2005; Timperley \& Robinson, 2002), participant stories highlighted subversive, bullying and damaging teacher behaviour which could undermine participant trust and respect.

Evidence gathered through participant interviews indicated the complexity and interconnectedness of cultural and emotional issues related to power and politics. It appeared from an analysis of participant interviews that there was a growing resistance to teachers' collaborative partnership work from diverse participant groups, within and across both school communities. The next section continues to explore political themes associated with resistance which emerged from analysis as impacting on the development of teachers' collaborative partnership work within and across both school communities.

\section{Power Relationships and Identity Formation}

As I listened to different participants tell me about their experiences of teachers' collaborative reform work, I became more aware of forced and lost identities. These

53 This is covered in more depth in Chapter 7. 
identities appeared to me to have been constructed through our own colonial history, through deficit thinking and pathologising practices, and the imbalance of power relationships between Māori and Pakeha as described by many Māori academics (Bishop \& Glynn, 1999; Shields, Bishop \& Mazawi, 2005; Smith, L. T., 1999). For example, many Māori participants who were interviewed believed that teachers needed to engage in collaborative partnership work in order to improve their understanding of mainstream schooling and teaching practice and its negative impact on the cultural identity of Māori families and on language loss:

Many families have missed out on learning and appreciating their cultural identity, they missed out ... so you've got a lot of people going to sea who aren't sure where they belong ... a lot of them can't actually speak Māori, and I've got a fluent father, I'm not fluent but I can understand some of our language, so ... that's something I'd like to state openly ... . I think we were wrongly or rightly pressured into thinking that was the way we had to bring our children up and so it means that for my daughter, she has lost a bit of her own culture ... and I think teachers play a part in teaching children to respect and value our culture and our language ... so it's great to see this [Māori and non-Māori teachers working together]. (Mr Tumu parent/caregiver of Māori child, 2004)

Some of the parents have said to me, 'My kids won't speak Māori', 'I didn't put my kids into school to learn Mâori!' They don't mind the counting, counting numbers, but they're not even that keen on the waiata. They say, 'My kids are here to learn how to read and write and not learn how to speak Māori!' And that was their answer, and I got a little bit hurt over that. Because to me it is part of our culture, I've learned a lot through the Te Ara Reo, about New Zealand as a whole. I'm not English and I'm not Scottish - that's some of my heritage, sure, but I've never been to those countries, I wouldn't know what they look like ... . My real heritage is here in New Zealand, and that means learning about Māori and Pakeha. For me, we're all New Zealanders and a big part of our culture is Māori language and it's sad to see it not being spoken or valued and children not knowing it. A lot of Māori kids don't know their own 
culture and language, and that's sad, and I think that's touched our family too. I think it's important to learn about both cultures, Māori and Pakeha. That's what is unique about New Zealand and we should be proud of that. (Mrs Tumu, parent/caregiver of Māori children, 2004)

Casey was one young Māori student who was interviewed who appeared to me to be acutely sensitive to the cultural loss within her own family. When I talked to her mother, she told me that Casey's father had felt embarrassed that he was unable to speak te reo:

... they [Māori and non-Māori teachers] should work together, because if they don't then they couldn't do things for their kids, like teach them te reo, and that's important to learn at school. ... Because it's our history and, like, maybe some parents might not have learned te reo at school and they maybe feel ashamed about that ... . (Casey, Yr 6 Māori student, 2004)

Māori academics have extensively documented the impact of the colonial education system which considered Māori language and culture to be a prime obstacle to the educational progress of Māori children (Bishop \& Glynn, 1999; Smith, L. T., 1999; Walker, 1991). Bishop and Glynn (1999) note that Māori were encouraged to "abandon their culture ... in order to learn the ways and process of the dominant culture" (p. 16). Between 1844 and 1960, assimilation was official government policy (Bishop \& Glynn, 1999; Smith, L. T., 1999). Bishop and Glynn add that such policies were based on racist beliefs, that "colonists knew what was best for Māori people" (1999, p. 16). I wondered about the ongoing effect and reality of our colonial history and its impact on teachers' collaborative reform efforts. Some participants emphasised the pain and damage which had been inflicted on their local Māori community, and reinforced through past injustices that were connected to historical events:

There has been so much hurt and damage in our community. People are hurting, families are hurting and there is a history here that goes back generations. I think it's awesome that the teachers are trying to improve their teaching for our mokopuna, but it's going to take time for some 
healing and an acknowledgement of that needs to happen first ... . Not all our families are involved in what is happening here at school. (Mrs Huia, Māori parent/caregiver, 2004)

Some authors writing in the area of culturally responsive practice have argued that collaborative development can occur only when diverse participants engage in respectful dialogue and collective inquiry, whilst actively and critically examining beliefs and values underpinning existing social practices and rejecting deficit theorising which marginalises particular groups (Cochran-Smith, 2004; Johnston \& Bush, 2005; Shields \& Sayani, 2005). Shields and Sayani note that participants engaged in collective discussions must work hard to examine the values and beliefs underpinning the practices of classrooms and schools and those of the homes of diverse groups of children. Citing Macedo (1995), these authors argue that,

... the dominant curriculum is designed primarily to reproduce the inequality of social classes, while it benefits the interests of the dominant class ... [this] emphasises the role of power in defining what counts as knowledge and, hence, in shaping the official curriculum. Macedo urges that power in education be examined through a discussion of the politics of 'what content gets taught, to whom, in favour of what, of whom, against what, against whom' (p. 43). These are other conversations in which educational leaders would want to engage if the curriculum of our schools is to make sense of all children. (Shields \& Sayani, 2005, p. 392)

It seemed to me that there was a lack of sustained leadership and political will to investigate hidden and less visible aspects of practice. I started to see that teachers were 'tinkering' around the edges and that real transformation of mainstream schooling practice for cultural diverse students, particularly Māori students, was not possible, until a critical collective inquiry which investigated dominant discourses and established power relationships within each school community took place.

As I navigated my way back and forth through the complex messages embedded in participant stories and across the different theories within the research literature, I found myself asking questions about the purpose of teachers' collaborative partnership work. I also came to see large gaps within my analysis of teachers' and principals' stories 
which indicated that they were unaware of many of the theories which may have helped them to 'dig deeper' and make sense of their own situation. I came to interpret this too as a warning sign, a message that highlighted to me the impact of the wider schooling environment which extended well beyond the school gates.

\section{The Impact of the Wider Schooling Environment on Teachers' and Principals' Knowledge}

Some participant stories emphasised to me the presence of hidden identities which had been forced and lost, and I was interested that these remained unacknowledged and unexamined by teachers themselves within the context of their collective reform work. It also became apparent that there were gaps within participant stories, which led me to the conclusion that teachers, principals and those supporting the reform work were unaware of important theories related to the development of culturally responsive practices as described by key theorists. This lack of knowledge appeared to me to influence the practice of teachers' collaborative partnership work as well as its efficacy.

For example, it has been argued that, in order to develop culturally responsive practice, the curriculum ${ }^{54}$ in schools must be transformed to enable all students to view concepts, themes and problems from diverse ethnic, cultural and critical perspectives (Banks, 2001b, 2004, 2006; Shields, Bishop \& Mazawi, 2005; Sleeter \& Delgado-Bernal, 2004). Some theorists have argued that many young children arrive at school with negative racial attitudes which mirror those of adults around them (Banks, 2001a; Stephens, 1999). Schools can help students to develop more positive inter-group attitudes and beliefs through critical examination of stereotypes (Banks, 2001a; Stephens, 1999). However, a number of authors writing in the area of multicultural education have warned against tokenistic and trivialising classroom activities which misrepresent or provide stereotypes of diverse cultural groups as foreign, exotic or isolated from usual classroom activities or events, and do not actively promote a critical analysis of knowledge construction and power relationships (Banks, 2004; Bishop \& Glynn, 1999; Kincheloe, 2003; Ladson-Billings, 2001; Shields, Bishop \& Mazawi, 2005; Sleeter \& DelgadoBernal, 2004).

54 By curriculum, I am referring to 'bodies of knowledge' that societies expect teachers to teach and students to learn; to the state-mandated curriculum and unintended or hidden curriculum within classrooms; to the knowledge referred to, used and valued by the teacher in the classroom; and to the interactions between curriculum (intended and unintended), assessment and pedagogy. 
Banks (1993) identifies four approaches and discrete levels that teachers can use in the pursuit of more responsive classrooms. These are contributions, additives, transformation and social action. The contributions approach focuses on including discrete cultural elements, holidays, and heroes and heroines into the curriculum. When using the additive approach, teachers append ethnic content, themes and perspectives to the class curriculum without changing its basic structure. In the transformation approach, the structure of the curriculum is altered to enable students to view concepts, issues, events and themes from the perspective of various ethnic and cultural groups and to help students investigate how knowledge is constructed. In the social action approach, which is an extension of the transformation approach, students make decisions on important social issues and take action to solve them (Banks, 1993, 2001b, 2004, 2006):

The knowledge construction process consists of the methods, activities, and questions teachers use to help students to understand, investigate, and determine how implicit cultural assumptions, frames of reference, perspectives, and biases within a discipline influence the ways in which knowledge is constructed ... [and later] Positionality is the term used to describe the ways in which race, social class, gender, and other personal and cultural characteristics of knowers influence the knowledge they construct and produce. (Banks, 2006, p. 9)

There were gaps which emerged from my analysis of teacher stories regarding their knowledge of such theories as they worked together for change. Descriptions of improved classroom practice from participant stories suggested that teachers had been working together to include a cultural dimension within teaching practice. This included tikanga Māori practices, such as teachers' use of karakia and waiata and more emphasis on including te reo and correct pronunciation by non-Māori teachers in classrooms. Some teachers referred to the importance of valuing and using Māori students' cultural capital, including an emphasis on connecting to students' prior knowledge, using collaborative teaching methodologies in class and raising teacher expectations. Other teachers talked about colleagues working together to use co-construction and power-sharing strategies, such as allowing students to have more say in class. However, I felt these changes in teachers' practices appeared to fit within the first two lower levels of Banks' approaches to integrate ethnic content into the curriculum, and to reflect his warnings of a "tourist" or 
"tokenistic" effort (Banks, 1993). Banks asserts that educators need to recognise multicultural education but notes that it involves much more than content integration (Banks, 2001b, p. 8). My analysis of participant interviews indicated that teachers' pedagogical approaches did not empower culturally diverse groups of children to examine the curriculum critically from various cultural and critical perspectives. Teachers who were interviewed did not appear to be encouraging their students to investigate critically how knowledge is constructed in ways which benefited particular groups in society.

I felt disturbed that teachers' existing social practices remained unexamined and unacknowledged over time. I had read that there are inherent dangers in attempting to get teachers to function as colleagues, unless attention is placed on the development of internal school conditions which foster critical discussion and a commitment to shared responsibility for improvement in practice over time (Fullan, 2005; Lieberman \& Miller, 1999; Little, 2001; Stoll, Fink \& Earle, 2003). A number of authors have stated that in collaborative work, participants must establish clear processes and protocols which allow them to learn from one another, share responsibility for improvement, gather evidence, and reflect on how effective their working relationships are for achieving particular tasks or outcomes (Forest, 1998; Fullan, 2005; Fullan \& Hargreaves, 1996; Hynds, 2000; Lieberman \& Miller, 1999; Senge, Cambron-McCabe, Lucas, Smith, Dutton, Kleiner, 2000; Timperley \& Parr, 2004; Timperley \& Robinson, 2002):

\footnotetext{
Most complex tasks are not fully knowable in advance - understandings of the tasks are always partial, evolving and incompletely shared ... Partners may enjoy working together and report improved relationships; but unless the quality of their working together is critically examined one cannot assume that those improvements will serve the partnership task. (Timperley \& Robinson, 2002, p. 21)
}

My analysis of participant stories revealed a lack of trust, respect and openness along with a lack of sustained critical inquiry and dialogue. I had read that culturally responsive practice can occur only in culturally responsive schools (Johnston \& Bush, 2005), and that to develop such practice teachers must be able to identify, accept and value their own cultural differences (Shields \& Sayani, 2005). According to Shields and Sayani, creating spaces of encounter for culturally diverse groups of students requires a 
critical examination of established school practices as locations for inclusion, respect and acceptance of difference or spaces of exclusion, despair and marginalisation (2005, p. 385). There were gaps in teachers' knowledge about the importance of such processes and the need to investigate critically their own personal theories related to difference, as well as existing social practices and spaces within the school community. It appeared to me that established social customs (and the beliefs and values which underpinned them) within and across both school communities remained unacknowledged and unexamined by participants, even though evidence indicated that such factors impacted on the development of teachers' collaborative partnership work over time.

According to different authors, an important part of the development of culturally responsive pedagogy requires teachers to encourage their students, colleagues and parents/caregivers to raise critical questions about their own experiences in school as well as the information they are exposed to within the school community and outside in society (Banks, 2001a; Bishop \& Glynn, 1999; Cochran-Smith, 2004; Ladson-Billings, 1995; Sleeter \& Delgado-Bernal, 2004). However, it appeared from my analysis of participant stories that these were not practices that were actively encouraged over time within either school community.

\section{What Counts as Culturally Responsive Practice?}

Other authors have argued strongly that "our professional training has not prepared us to address emotionally and socially charged issues" related to the politics of identity, culturally responsive practice and the pursuit of social justice (Bell, Washington, Weinstein \& Love, 2003, p. 464). Achinstein (2002) has drawn on research case studies of two urban, public middle schools in the United States that indicated the emergence of conflict as teachers enacted collaborative reforms. She argues that conflict is central to the development of professional learning communities, but also adds that the ways in which teachers manage conflict, particularly whether they suppress or embrace their differences, not only define community borders but also impact on the potential for ongoing organisational learning and change. Individual participant beliefs and/or reactions to conflict may prevent group collaborators extending appropriate levels of challenge (Achinstein, 2002; Forest, 1998; Hynds, 2000). Learning to deal with conflict is critical, as no community or group seeking reform will achieve their quest unless they are able to function effectively (Fullan, 2005; Johnson \& Bush, 2005). 
It has been argued that conflict should be viewed as a natural by-product of collaborative learning communities, and collaborators need to identity, accept and value conflict through appropriate protocols of respect for difference, whilst focusing on 'nonnegotiables' such as reducing disparity in achievement for diverse groups of learners in environments of trust and respect (Forest, 1998; Fullan, 1999; Johnston \& Bush, 2005; Stoll, Fink \& Earle, 2003). These authors argue that teachers need to understand that conflict of ideas and respect for difference and diversity in thinking are necessary for growth, critical thinking and ongoing development (Forest, 1998; Fullan, 1999, 2005; Johnston \& Bush, 2005; Stoll, Fink \& Earle, 2003). However, Hooks maintains that students and their teachers enter a schooling system which demands that they "accept without question" the assumptions and values held by "privileged classes", and that those who do express their opinions loudly or often enough are censored, silenced and "deemed to be trouble-makers" (2003, p. 143).

Many participants appeared to me to be unprepared for the intensity of emotional responses and the political, intellectual awareness that would be needed if culturally diverse teachers were to work together over time within their school communities. I tried to find literature which would provide directions to enable participants to navigate their differences and value their diversity in a system that was closed to such processes. I discovered that Denzin (1984) has argued that teaching is an emotional practice, which requires emotional understanding because of the social dimensions involved in teaching and learning. Similarly, Hargreaves has argued that teaching and learning to teach are also "emotional practices". I discovered that Hargreaves has called for more inclusive and open definitions of collegiality in schools "where educators engage in learning partnerships with pupils, parents and others that are politically reciprocal, morally guided and emotionally rich" (2000, p. 47). It appeared from my reading of this literature that teachers' emotional connections and interactions with pupils, parents/caregivers and colleagues are viewed as important emerging and impacting factors in collaborative reform work, although little is known about the contribution of teachers' emotional intelligence within change contexts (Bascia \& Hargreaves, 2000; Fullan, 2005; Little, 2001; Senge, Cambron-McCabe, Lucas, Smith, Dutton, Kleiner, 2000).

Shields, Bishop and Mazawi (2005) have called for a recognition of the fact that learning occurs in social groupings. These authors have argued for a new type of learning community within schools, whereby culturally diverse participants (students, teachers, parents/caregivers) develop reciprocal learning relationships of care and empathy which 
allow them to explore issues of difference and diversity in respectful, trusting and inclusive ways. Askew and Carnell (1998) have also argued that emotional literacy is needed if teachers are to understand and develop more responsive and effective classroom programmes, programmes that are responsive to children's varied cultural identities. They argue that emotional literacy involves the creation of learning relationships centred on activities such as listening, and being able to negotiate and value differences, empathise and repair relationships. Empathy for others is considered to be one of the five domains of emotional intelligence (Goleman, 1998).

I found that there were gaps in participants' stories which highlighted a lack of knowledge and understanding of the need for 'emotional literacy' and the pedagogy of care within the context of teachers' collaborative partnership work. However, I also became aware of other hidden dangers that appeared to me to be far more subversive and dangerous, and which influenced the practice of teachers' collaborative partnership work and its acceptance within each school's culture. I found myself thinking that teachers would need to be more than just good listeners if they were to transform mainstream schooling practice for Māori children and young people.

During interviews, a number of participants reflected that teachers were not used to grappling with the types of ideas or theories needed to engage them in critical thinking and open, collective inquiry into issues of practice for culturally diverse groups. Participant stories also indicated that teachers were expected to sustain aspects of their collaborative work in addition to their other teaching responsibilities, and that there was no time and space that would enable teachers to sustain their critical, collective inquiry. Their statements also seemed to me to portray a deficit view of teachers as professionals. It appeared that teachers were reading about 'strategies' for learning, rather than theories of learning and engaging in collaborative partnership activities which would have enabled them to continue critical inquiry into their teaching beliefs:

Some teachers are reading now, ... but it has really only got to do with the strategies they're doing in class ... . I think as teachers we gravitate towards the strategies first - someone shares a template as a handout, we don't want to fill it in with a pen or paper because we want to photocopy it later. We want to use it later in a class as a resource. We always check we've got the second copy and most of us, we're happy to pass it around. 
... anyway, you know, we've always had the practical stuff, but we've never had the big ideas before. (In-school Facilitator 2, 2004)

During interviews and final member checks, it appeared to me that there was a dependency and learned helplessness in the thinking of some participants, that they hoped 'experts' would provide them with the 'right answer':

Well, my hope is that someone will give us the Master Plan to follow. (Ian, non-Māori teacher, 2005) ${ }^{55}$

While I was reading for this thesis, I discovered that some authors had argued strongly that human experience is shaped by context (Hooks, 2003; Kincheloe, 2003; McLaren, 2003). A critical inquiry into forces which shape participant knowledge and experience must include teacher training processes, school reform and curricular renovation alongside an analysis of power relationships and unexamined economic interests (Fielding, 1999; Kincheloe, 2003; McLaren, 2003). According to a number of theorists, there are hidden forms of control over teachers' practical thinking, and current educational reforms often specify what is to be taught, how it is to be taught and what constitutes teacher competence (Elliott, 1993; Fielding, 1999; Kincheloe, 2003; Lieberman \& Miller, 1999; Parker, 1997). This 'technicalisation' of teachers' work is viewed as a direct threat to the authentic professionalism of teaching. It is seen as a 'deskilling' process for teachers, whereby outside experts are considered best able to deliver the essential skills, knowledge and attitudes to 'fix' the problems of inequality in learning and then hold teachers accountable. Technical rationality assumes that teachers are 'rationalist' problem-solvers who readily apply such scientifically-tested procedures to classroom problems (Elliott, 1993; Fielding, 1999; Kincheloe, 2003; Parker, 1997).

According to different theorists, traditional approaches to teachers' professional development are inadequate if teachers are going to learn to respond more effectively to culturally diverse groups of learners (Bishop, Berryman, Tiakiwai \& Richards, 2003; Bishop \& Glynn, 1999; Cochran-Smith, 2004; Darling-Hammond, 1997; Elliott, 1993; Gay, 2001; Kincheloe, 2003; Lieberman \& Millar, 1999; Sleeter, 2005; Tsianina Lomawaima, 2004). Usually, professional delivery focuses on an inservice or INSET

55 This quotation was gathered through the final member check with this participant. 
approach, whereby teachers attend training workshops. These types of courses have often emphasised successful 'techniques' or the 'best method' (Darling-Hammond, 1997; Lieberman \& Miller, 1999). In theory, the application and ready transfer of such techniques should enable the teacher to cope with any demand the postmodern classroom presents, but such approaches are grossly inadequate (Kincheloe, 2003). The majority of my teacher training in Aotearoa/New Zealand was delivered in this fashion, and as a past facilitator I, too, have been guilty of delivering 'fly-by-night workshops' to other teachers in short-term professional development contracts. I found this to be a confronting message. I too had perpetuated a dependency on 'quick-fix' ideas during my time as a School Adviser, employed to support the transfer of new policy reforms into teachers' practice. As I listened to different participants talk about their own experiences, I came to question the impact of past professional development 'workshops' on teachers' capacity for collaborative critical inquiry:

It took us back to this thing about treating teachers as professionals ... and I sometimes think we exist in a context which doesn't encourage that and I'm thinking about traditional or normal professional development. Normal professional development would be to do it after school ... shoving everyone into the staffroom for an hour and be talked to non-stop about what things you should do with students which ironically is often the total opposite of what is being presented, you know. For example, 'learning to learn' and all this sort of stuff, being told about this during a meeting that's happening after a long day of teaching at 1/2 past 3 until 5 o'clock and teachers ... it basically kills them. (In-school facilitator 1, 2004)

Other participants believed their own training and preparation interrupted the process of co-construction with their students, because teachers were trained to take control in the classroom:

... that is the way we have been taught. I think there are a lot of teachers, they have been trained in that way [not to engage in co-construction with their students], it's not their problem, it's not their fault, but that's how 
we've been trained, that's how primary school and secondary school teachers are trained. (Barbara, Māori, teacher, 2004)

During interviews and final member-checks, some teachers expressed fears about their ability to engage in deep thinking about the nature of their collaborative reform work due to past professional development experiences. Some teachers who were interviewed were concerned about Te Kauhua as a 'pilot project', and explained that in their experiences such 'projects' came and went:

Well, one problem is that other things come along and take your focus away. An example is the whole staff did courses on cooperative learning, we spent a lot of time doing that, and we came back and tried it out with our classes, we discussed with each other how we were getting on, that was good, then it faded away [and then] something else comes along and takes your attention away ... . We've had to cope with the numeracy and literacy professional development ... so we don't actually get a lot of choice. (Verna, non-Māori teacher, 2004)

My concern is another item in professional development will become the latest fashion before this one [Te Kauhua] becomes embedded in our school. (Max, non-Māori teacher, 2004)

According to Cochran-Smith (2004), conventional training and preparation programmes have failed to prepare teachers for culturally diverse classrooms, and current discourses on outcomes, achievement scores and measurements of effectiveness ignore the complexity and uncertainty of teachers' work:

Linear models of teaching will not suffice, nor will approaches to the outcomes question that push only for clarity and certainty. Someone once said that "those who have been forced to memorise the world are not likely to change it'. It may also be true that those who measure the outcomes of teaching only with pluses and minuses are not likely to see the value of question marks, concentric circles and arrows that point both ways and sometimes double back. (Cochran-Smith, 2004, p. 115) 
As I listened to teachers and principals talk about their experiences of collaborative partnership work, I felt they lacked preparation for and knowledge about theories related to culturally responsive practice as defined by key authors (Alton-Lee, 2003; Banks, 1993, 2001a, 2004, 2006; Bishop \& Glynn, 1999; Ladson-Billings, 2001; Penetito, 2001), the political, intellectual skills and dispositions needed if participants were actively and collaboratively to inquire into contradictions of schooling practice for culturally diverse groups of Māori and non-Māori students (Bishop \& Glynn, 1999; Hooks, 2003; Johnston \& Bush, 2005; Kincheloe, 2003; Shields, Bishop \& Mazawi, 2005; Smith, L. T., 1999) as well as the time and space to sustain such intensive critical and collective work (Stoll, Fink \& Earle, 2003; Kincheloe, 2003). I found myself reflecting on the many contradictory messages which had emerged from participant stories highlighting issues of participant mindsets, trust, respect, openness, ownership, voice, inclusion, difference, diversity and power relationships within and across both school communities. It occurred to me that many teachers were reluctant to share power with their students because these processes were traditionally denied to them in their own learning contexts. According to Kincheloe, "knowledge in contemporary education is still something that is produced far away from the school by experts in a rarefied domain", and critical inquiry is not seen to be the domain of teachers (2003, p. 18). Education is often viewed as a transmission of knowledge by trained technicians, rather than an interactive process through which problems are posed and answers collaboratively sought (Bishop \& Glynn, 1999; Elliott, 1993; Kincheloe, 2003; Parker, 1997). Fielding has argued that the "lobotomised discourse of delivery" has "effectively colonised teachers" daily work" within an environment of "fundamental dishonesty" created by education policies and practices that debilitate teachers as professionals, whilst requiring teachers to 'own' what they “do not want or really need” (1999, p. 22).

In the process of reading for this thesis, I have been warned that multicultural programmes which emphasise tolerance towards cultural diversity as an outcome are not enough to combat barriers of racism, prejudice and disparity in educational outcomes for diverse groups of learners (Banks, 1997, 2006; Ladson-Billings, 2001; Sleeter, 2005). During the process of inquiry, I became aware of gaps in participants' knowledge of such important themes. I agreed with the arguments put forth by Cochran-Smith (2004) who states that relatively few authors writing in the area of teachers' professional development appear to be calling for partnership work around issues concerned with race, identity, diversity and social justice. Gaps which emerged from my analysis indicated to me a lack 
of participant knowledge, skills and dispositions (particularly in teachers and principals) related to such theories, but also a lack of time and space to sustain their engagement in this important work. I felt that these things also influenced the practice of teachers' collaborative partnership work, as well as its efficacy and acceptance within each of the school's communities. 


\section{Chapter 7. Charting the Journey: A Slow and Careful Navigation of the Collaborative Dynamic}

As I write this final chapter, I feel a certain weariness as little appears to have changed. The promise of teachers' collaborative partnership work lies 'dead in the water' within and across both school communities, while race-relationship headlines within Aotearoa/New Zealand still dominate the news. Don Brash's ${ }^{56}$ latest accusation that there are "few", "if any" full-blooded Māori left and that because of this Māori are no longer a distinct indigenous group appears to have caught the imagination of potential voters, as media sources report that his political party is now surging ahead in recent telephone polls. As I pick up a recent copy of New Zealand Education Review (October 2006), I find an article written by Loper who argues that "rescue-type" "kura kaupapa" and "kotahitanga" educational programmes "employ" "inefficient learning" models and that in order to address the current education gap, "teachers" and their "trainers" must be "reprogrammed" and more "positive reinforcement" methods utilised (2006, p. 7). These arguments appear simplistic, while teachers' voices are largely absent from any of these discussions. Although I am tired, much has been learnt and I remain hopeful of the promise of teachers' collaborative partnership work and the potential for real transformation and change. This last chapter outlines my final reflections and recommendations, related to the context of teachers' collaborative partnership work and the future directions of such work within Aotearoa/New Zealand.

\section{Searching Out and Interpreting Different Signs and Messages within the Context of Teachers' Collaborative Partnership Work}

I believe that my own learning journey described in this thesis emphasises the need for partners who engage in collaborative work to be good sailors and navigators, skilled practitioners who can work together to search out and interpret different signs and messages over time both internally and externally, and to use them to uncover and break through the dominant, largely hidden, taken-for-granted discourses, assumptions and values which underpin our mainstream schooling system. As explained in earlier

56 At the time of writing this thesis, Don Brash was Leader of the National Party (the major opposition party). Towards the later part of 2006, these statements were reported widely in the news media. In the following few weeks, other events and revelations led to his stepping down as leader. 
chapters, several tohu emerged which perplexed me as I navigated the theories and practices which underpinned teachers' collaborative partnership work. The contradictory nature of the signs enabled me to dig deeper into meanings embedded within participant stories, highlighting less conscious beliefs, values, identities, assumptions and experiences which needed to be brought into the light and collectively and critically explored in contexts of trust and mutual respect. Some of these messages pointed to social divisions between 'them' and 'us' and could have been explored in the context of “Othering” (Shields \& Sayani, 2005, p. 389):

I would have liked to ask some questions about it [Māori and non-Māori teachers working together], of teachers working together to raise Māori student achievement. Was it going to have a negative impact on the nonMāori students, like was this enormous amount of money going to be poured into catering for Māori students at the detriment of non-Māori ? Or the time and energy of teachers - were they going to spend more time and energy on the Māori students to the detriment of non-Māori ? I suppose initially it was don't let it be to the detriment of the non-Mãori because they spent a lot of time on how to teach them, and catering for them. (Mrs Smith, parent/caregiver of non-Māori child, 2004)

Over time I started to see warning signs about the acceptance of teachers' partnership work within and across both school communities. These signs highlighted different forms of resistance, fuelled by the influence of the internal dynamic: for example, the less visible, hidden and submerged beliefs, values, identities, learnt behaviours and practices, including damaging deficit theories, racism and prejudices that those involved brought into the context of reform. As I listened, I found evidence of pathologising practices (Shields, Bishop \& Mazawi, 2005) which suggested that many participants wanted to fix, cure, isolate or ignore cultural and ethnic difference and diversity, rather than acknowledge and value it as fundamental to enhancing our collective thinking and extending our learning opportunities. Other warning signs highlighted resistance which stemmed from beyond the schooling environment - the external dynamic, which also influenced the acceptance of teachers' collaborative partnership work and its efficacy and place within each school's culture. Messages contained within participant stories enabled me to see the influence of the external dynamic: the established hierarchies and issues of 
leadership; the presence of staff divisions and disputes, and bullying and subversive practices; the problems of dealing with diversity in a closed system; the lack of systemic transparency and the outcomes of this for students; and the endemic fundamentalism of power relationships and identity formation. I started to see the interplay between the internal and external dynamics which worked in hidden, unexamined and less visible ways to influence the practice of teachers' collaborative partnership work.

I found literature which identifies the sorts of messages and signs which highlight contradictory practices of schooling (Darder, Baltodano \& Torres, 2003; Kincheloe, 2003; McLaren, 2003). Darder, Baltodano and Torres emphasise the power of human activity and human knowledge as "both a product and force in shaping the world, whether it be in the interests of domination or liberation" (2003, p. 13). According to McLaren, we "inhabit a world rife with contradictions and asymmetries of power and privilege" (2003, p. 69). McLaren argues that political contradictions exist in mainstream schooling practice which seeks to promote shared decision-making practices whilst actually functioning to limit some participants' access to information and/or to deprive them of such responsibilities. I discovered that dialectical thinking ${ }^{57}$ is needed to search out contradictions in educational practice whereby the system aspires to help all students reach their potential whilst inadvertently oppressing particular groups (McLaren, 2003). Kincheloe (2003) has warned that it is only through critical, collective inquiry into contradictions of schooling practice that we begin to lay the foundations for the sophisticated form of knowledge work that is needed for citizens to operate in a knowledge society. It became apparent that critical, social research calls all of us to become both critical consumers and producers of knowledge (Bigelow, 2001; Kincheloe, 2003; Sachs, 2003). Some authors have stated that teachers can improve classroom practice and outcomes for culturally diverse groups of children only through a process of developing socio-cultural consciousness (CochranSmith, 2004; Shields \& Sayani, 2005; Villegas \& Lucas, 2002):

By socio-cultural consciousness, we mean awareness that one's worldview is not universal but is profoundly shaped by one's life experiences, as mediated by a variety of factors, chiefly among them is race/ethnicity, social class and gender. (Villegas \& Lucas, 2002, p. 27)

57 McLaren argues that analysis must start with human existence and the "contradictions and disjunctions" that both shape and make meaning problematic (2003, p. 21). 
Different writers in the area of culturally responsive pedagogy describe the development and expansion of cultural consciousness as a journey across a life-time of learning (Cochran-Smith, 2004; Villegas \& Lucas, 2002); one which requires participants to acknowledge and unlearn the social practices that restrict and constrain our engagement in democratic practice (Hooks, 2003). I believe the issue of time is central to this story because the process of navigation required me to double-back, start again and re-chart my own course several times. This necessitated a commitment, and a leap of faith, to critically examine my own thinking, biases and assumptions which I too carried into this work. I had to learn to listen and search out the messages and signs contained within participant stories and within different sources of research literature. In navigating the collaborative dynamic, I found that teachers' experiences of collaborative partnership work changed and declined over time within and across both school communities. I found it took time to develop trusting and respectful relationships, and that these did not just happen over night, as many teachers shared more intimate stories of their experiences in collaborative partnership work within their second interviews. I also become aware of how little time teachers had within their schools to sustain their collective inquiry work. However, time by itself will not be enough to encourage the change and transformation that is needed within our mainstream schooling system.

\section{A Return to the Blessings}

Although I was confronted by the contradictory nature of these different signs and messages contained within the stories of teachers' collaborative work, I return to those tohu (the blessings) which signalled to me a safe way of moving forward in the context of teachers' collaborative partnership work, but which were largely ignored and unacknowledged by participants themselves. These were:

- exploring mindsets, beliefs and values

- establishing the right environment

- awakening understanding and the contribution of listening practices towards learning

- telling and hearing real/honest heart-felt stories

- examining contradictions of practice in a context of collaborative inquiry

- ownership, voice and choice

- valuing voices not usually heard. 
It appeared to me that these signs contained much promise in the context of teachers' collective reform work. At the end of this stage of my own journey of learning, I have also come to understand that the blessings highlighted the potential of different forms of teacher collaborative partnership work and that these forms are essential if teachers are to work with others to transform the mainstream schooling system for culturally diverse groups of children and young people (Māori and non-Māori ). I found that the validity of these forms of partnership was backed up by some authors. For example, Penetito (2001, 2004) warns that conversations and rethinking of current mainstream teaching practice for Māori children and young people must involve collaborative work and participatory learning between teachers, schools and local whānau, hapū and iwi. It is the knowledge of these local Māori communities that will enable teachers to develop more improved practice and outcomes for Māori students through place-based, context-specific stories (Penetito, 2004).

Of course, as a result of this study I understand that one of the challenges of such work undertaken in mainstream schools lies in ensuring culturally diverse (Māori and nonMāori) teachers, students, parents and caregivers enter such conversations in respectful ways and re-position themselves as learning partners. Pinar (2004) echoes this point by stating that schools can fulfil their promise as democratic public spheres only if we engage in complicated and inclusive conversations about curriculum, teaching and learning. Shields and Sayani have also argued for a new type of curriculum based on "sense-making conversations and relationships" which educators could use to connect the content, knowledge, values and perspectives of the "formal curriculum" to the "lived experiences" of diverse groups of students (2005, p. 392). Such conversations could enable students, teachers, parents/caregivers, elders and community members to examine how particular groups are advantaged in mainstream schooling practices, because their prior experiences and cultural capital are most likely to be represented and valued within the existing curricula and mainstream schooling practices (Shields \& Sayani, 2005). Both the content and process of community dialogue must address such issues if schools are truly to embrace difference and develop culturally responsive and inclusive practice which enables diverse groups of children and young people to achieve (Shields, 1999; Shields \& Sayani, 2005). 


\section{Developing New Types of Collective Consciousness and Political}

\section{Activism}

I have come to the realisation that transformation and change are possible only if we develop a new form of collective critical consciousness, that can only begin to be approached through the rigorous study of power (at an individual and collective level); a process which engages all participants in careful consideration, inquiry and dialogue to uncover contradictory, dishonest schooling practices and the production of knowledge, meanings and values (Kincheloe, 2003; McLaren, 2003; Penetito, 2001). According to Kincheloe, a "cardinal feature" of critical collective "conversation" within schools must be, "The unequal distribution of power and the way it privileges the privileged and silences the dis-privileged" (2003, p. 186).

It has been argued that a critical consciousness developed through de-colonisation is needed if teachers, students and parents/caregivers are to examine the way historical power relations have shaped schooling practice, cultural identity, thought processes and legitimate knowledge in Aotearoa/New Zealand (Bishop \& Glynn, 1999; Shields, Bishop \& Mazawi, 2005; Smith, L. T., 1999). The mainstream schooling system within this country has been developed through colonising processes (Durie, 2005; Bishop \& Glynn, 1999; Smith, L. T., 1999) and perpetuates deficit thinking and images of Māori children and young people that are destructive (Shields, Bishop \& Mazawi, 2005).

According to Giddens' (1984) theory of structuration, individuals play a significant role in maintaining and/or challenging and changing social systems through their interpretation of such systems. Giddens argues that social systems are essentially patterns of human behaviour. In relation to teachers' work, it has been argued that it is heavily routinised and difficult to change, partly because teachers rationalise and help to maintain the social systems of schooling through their own interpretations of such work (Elliott, 1998; Giddens, 1984). In order to transform teachers' "practical consciousness" and change the social systems of schooling, teachers must develop "discursive consciousness" through open, critical discussion and examination of the present systems of schooling (Elliott, 1998; Giddens, 1984). Kincheloe (2003) echoes these points by stating that we are constrained by assumptions and habits built up from the past, from historical traditions of authority and power, and because of this, critical reflection, discomfort and a desire to act must sit with uncertainty and a restless sense of inquiry. Kincheloe argues that critical consciousness develops only through a critical examination 
of contradictory schooling practices for diverse groups that moves "the discourse of multi-culturalism away from the study of race as only a black and non-white conundrum to a new locale where it involves the enigma of whiteness as well" (2003, p. 203). In this context, teachers as critical researchers understand political forces that shape constructions of "human needs and desire" and develop heightened awareness of expressions of "racism, sexism and homophobia" (2003, p. 203).

The 'blessings' which emerged from my initial analysis of participant stories signalled an awakening in many teachers' consciousness, within and across both school communities. Some teachers described their eyes opening in ways which allowed them to see previously hidden aspects of their teaching practice. It was through teachers' stories of awakening that I saw the signs of transformation that promised so much hope. Saul was one teacher who had described the changes in his own thinking, and despite the challenges of working collaboratively, of his renewed hope for change:

... all kids are born with magic, and somewhere along the way, you know, the flame has been put out, and you have to try and find that flame again, and try ... you know, to bring the magic back to them, so for us, we're having to do that, and to try and just get out of that thinking that they're only local Māori kids, but to get into the thinking of higher expectations. (Saul, Māori teacher, 2004)

During final member checks, some teachers reaffirmed that although they were disappointed with the outcomes of teachers' collaborative partnership work within their own school community, they themselves had undergone a transformation which meant they had changed. Andrew was one such teacher:

I'm disappointed ... [that] some teachers have pulled out of this work [Te Kauhua]. However, for me ... it's not possible to return to where I was ... before those hui ... . My teaching is not perfect and there's a lot to learn ... but when you've been through a learning experience as profound as that ... you can't go back. (Andrew, non-Māori teacher, 2005) ${ }^{58}$

58 This quotation was gathered during the final member check in 2005. 
Different authors have argued that education is political and that political work is accomplished through education because "existing social relations" can be "reproduced, legitimated, challenged, or transformed" (Ginsburg, 2003, p. ix). At the end of this inquiry, I have found myself agreeing with such authors who warn that culturally diverse participants must be encouraged to engage in knowledge production through a process of sustained critical enquiry and dialogue into the way ideology shapes political and cultural practices in the classroom, the playground, the staffroom and society (Cochran-Smith, 2004; Fine \& Weiss, 2005; Ginsburg, 2003; Kincheloe, 2003; Penetito, 2001; Smith, L. T., 1999; Smith, 2004):

In this context students appreciate the impact of, say, dominant Western modes of thinking on the knowledge produced in such a context. They understand what it might mean to discuss gendered ways of knowing. Such insights are possible only by studying diverse historical and cultural modes of knowing and learning. With such epistemological dynamics in mind, students are asked to explore the social epistemological construction of their own consciousness. Here they trace the effects of their cultural value systems upon the frame of reference and perception of the world around them. Along lines of race, class, gender, geographic place, national origin, sexuality, generation and other factors, students gain personal epistemological insights and understandings of how similar dynamics construct the epistemological orientations of others. Such awareness holds profound pedagogical consequences, as teachers who are aware of the epistemological influences of diverse social and cultural backgrounds gain deep insight into invisible forces that shape student performance in school. (Kincheloe, 2003, p. 231)

A number of authors have called for a process of transforming education through politically-guided practice which struggles for justice (Bishop, Berryman, Tiakiwai \& Richards, 2003; Fielding, 1999; Ginsburg, 2003; Kincheloe, 2003; Ladson-Billings, 2001; Sachs, 2003; Sleeter \& Delgado-Bernal, 2004). However, evidence from this study indicated that critical discussion and inquiry into contradictions of practice for culturally diverse children and young people were not natural activities that teachers and principals were prepared for. There were gaps in data analysis related to teachers' and principals' 
knowledge of these important theories which they would need to prepare them to work with others and address contradictions of practice for culturally diverse groups of Māori and non-Māori children and young people within and across our different school communities.

\section{Engaging Culturally Diverse Participants in Dialogue and Critical Collective Inquiry}

I have come to the realisation that facilitated dialogue and an adherence to agreed principles and protocols must underpin teachers' collective partnership work which seeks to transform mainstream schooling practice for culturally diverse children and young people. The principles of teachers' learning relationships and the protocols which will be needed to sustain them will require new forms of leadership because of the pain and conflict that participants often experience through engaging in very new conversations and joint work (Johnston \& Bush, 2005; Shields \& Sayani, 2005). Durie has called for the recognition of particular principles which should underpin "research at the interface" which involves Māori and non-Māori participants (2005, p. 143). These include principles of "mutual mana enhancement" whereby researchers recognise the validity of various knowledge systems and accept that each needs to "be given its own space" (2005, p. 142). Other principles identified by Durie include shared benefits (2005, p. 142), human dignity - 'aroha ki te tangata' - and the principle of discovery (p. 143). Durie emphasises that such principles ensure that "personal integrity, cultural identify and associated bodies of knowledge" are not "devalued or lightly dismissed" (2005, p. 143).

Some authors writing in the area of culturally responsive and multicultural practice argue strongly that inclusive conversations regarding diversity and difference within the school community must be viewed as central to classroom and school reform, and should not be added as an afterthought or viewed as something to be avoided (Johnson \& Bush, 2005; Sheilds \& Sayani, 2005). However, it has been noted that dialogue is not just talk or ordinary conversation (Bohm, 1987; Hooks, 2003) but is underpinned by a genuine desire to know, understand, value and respect other people (Shields \& Sayani, 2005).

Dialogue is identified within this research as a key navigational tool for encouraging collective engagement and interpretation over time. It has been argued that "in the long run dialogue and participation by a wide range of stakeholders produce better and 
more relevant educational research, policy and practice" (Ginsburg, 2003, p. x). "Good judgement" has been described as a result of "intersubjectivity", whereby we examine the same world from other's viewpoints (Ginsburg, 2003, p. x). It has been argued that such a process not only enhances the quality of our collective judgements when viewing school practice but also advances a commitment to more "public" democratic processes, rather than "privatised/professionalised/expert" forms of collaborative work (Ginsburg, 2003, p. $\mathrm{x})$. Ginsburg calls for a process of active participation in the work of reform which engages diverse participants in a study of the politics of education:

... the issue is not whether education should be taken out of politics, nor whether politics should be kept out of schools, nor whether educators should be apolitical. Rather the concerns are toward what ends, by what means, and in whose interests educators and other worker-consumercitizens should engage in political work in and about education. (Ginsburg, 2003, p. x)

Messages contained within the stories of participants, particularly teachers, alerted me to the importance and impact of listening to culturally diverse and previously silenced voices telling their own stories. I heard teachers give their interpretations and experiences of mainstream schooling practices as they related their experiences of hearing with new ears and seeing with new eyes. As I have highlighted previously, I had interpreted these as 'blessings', as ways of moving forward and finding safe passage, because the process of listening had encouraged a re-visioning, an awakening and a sense of dissonance in many teachers' thinking, with unexamined beliefs and practices starting to emerge. This in turn seemed to open these teachers to ideas and feelings they had not countenanced before in their professional, and possibly their personal, lives. It has been argued that an important component of using stories is not just the telling of them, but involves a process whereby participants learn to listen and hear the messages contained within them (Hooks, 2003; Jones, 1999; Sleeter \& Delgado-Bernal, 2004). Issues of voice, of storying and counterstorying and dialogue are considered important pedagogical tools if teachers are to transform practice and outcomes for culturally diverse student groups, according to these theorists (Hooks, 2003; Johnston \& Bush, 2005; Kincheloe, 2003; Shields, Bishop \& Mazawi, 2005; Shields \& Sayani, 2005; Sleeter \& Delgado-Bernal, 2004): 
Counterstorying is a methodological tool that allows one to tell the story of those experiences that are often not told (i.e. by those on the margins of society) and to analyse and challenge the stories on those in power ( $\mathrm{p}$. 247). ... learning to listen to counterstories and then making those stories matter in the educational system is an important pedagogical practice for teachers and students. (Sleeter \& Delgado-Bernal, 2004, p. 248)

Kincheloe argues strongly that "one of the quickest ways to apply teacher research to the pursuit of good teaching involves, simply, teachers listening to students" (2003, p. 39). However, he also warns that listening processes must extend inquiry into an analysis of "the social context into which student and teacher consciousness are formed and education takes place" (2003, p. 39). Fine and Weiss posit that educating for social justice requires a process of listening hard to young people and collaboratively raising questions that simultaneously "haunt and invigorate" us (2005, p. xi). As a result of their findings, I agree with their argument that if we are truly concerned with educating for change, this requires a belief "in the power of educators to think broadly and work intimately and a belief in the power of youth to wrestle with questions of intellect, power, voice, dissent and hope in schools and community" (Fine \& Weiss, 2005, p. xi). These were not the findings that I expected when I first started out on this research journey.

I found other authors who agree, who state that dialogue must move beyond simply hearing multiple perspectives on educational issues, to a critical collective analysis that uncovers hidden political interests involved in schooling and classroom practice (Fine \& Weiss, 2005; Kincheloe, 2003; McLaren, 2003). A critical consciousness, developed through an examination of power relationships in social systems, is necessary alongside a political agency which empowers participants (teachers, students and their parents/caregivers) to act for change and social justice (Bigelow, 2001; Friere, 2000; Giroux, 1985; Hooks, 2003; Kincheloe, 2003; McLaren, 1993; Penetito, 2001; Sleeter \& Delgado-Bernal, 2004; Smith, L. T., 1999). Kincheloe puts forward the view that teachers must engage in scholarly work, researching multiple viewpoints about practice and appreciating the insights of parents, community members and students who are "traditionally silenced" and excluded from "conversations about education" (2003, p. 185). I found his arguments compelling and his description of pragmatic/catalytic validity a useful model of a key characteristic of critical teacher inquiry. Such validity occurs when teachers researching issues of practice "struggle with issues of interpretation within 
a socio-educational context" in order to understand better the forces impacting on practice so that confrontation and transformation can occur (Kincheloe, 2003, p. 184). This "pragmatic approach", according to Kincheloe, raises questions of "intellect and ethical reasoning" as teacher researchers wrestle intellectually in order to uncover the values and assumptions used to support their actions in schools (2003, p. 184). It was these theories which gave me courage.

\section{The Need for Preparation}

The theories highlighted above were very new to me, as most of the readings that I found to be available on the study of teacher collaboration and partnership largely ignored dialectical theory, ideology and critique, and the dynamics of dialogue and conscientisation. In my own experience as a student in mainstream schools and later as a teacher, I have had very limited access to te ao Māori (the Māori world) (Durie, 2005) or to de-colonising practices (Smith, L. T., 1999), and culturally responsive pedagogy or critical pedagogy as described by some key theorists ${ }^{59}$ (Bishop \& Glynn, 1999; Darder, Baltodano \& Torres, 2003; Fine \& Weiss, 2005; Hooks 2003; Kincheloe, 2003; McLaren, 2003; Shields, Bishop \& Mazawi, 2005). Most of my own work as a teacher and teacher educator has been consumed by professional development issues primarily concerned with teacher 'effectiveness' and classroom practices of 'effective' teaching; mainly literacy, numeracy and assessment practices. I found myself disturbed by Hooks' (2003) warnings regarding hidden class values and associated censoring processes which determine social behaviour and undermine the democratic exchange of ideas within schooling settings.

Through the process of engaging in collaborative inquiry, I found myself thinking about the lack of teacher and principal knowledge (as well as my own before I engaged in this process) about such theories. How well prepared are we, as educators, to navigate and interpret the collaborative dynamic as we engage in critical collaborative inquiry with multiple and culturally diverse participants about complex and contradictory issues of practice? My whole understanding of what counts as collaborative partnership work has been challenged through the processes involved in engaging in this research. This

59 I am not suggesting that all these theorists agree on what constitutes critical pedagogy, because disagreements and debates were evident in my reading of this literature. However, the bulk of literature that was readily available to me, and/or that I had been familiar with as a teacher and as a teacher educator, did not touch on the issues promoted in these texts. 
enabled me to see that much of the available research literature on teacher collaboration and many of the teacher education programmes promoted in my own institution are currently inadequate for empowering educators to engage intellectually, morally, emotionally and politically with such issues of cultural identity, difference and diversity. I came to realise that as an educator I needed to be careful about the categories I use and to become more conscious of how individual members of a social group can experience oppression in multiple and diverse ways. I have come to see the hidden dimensions of such work. Throughout this thesis journey, I have felt disturbed and puzzled about my own knowledge and the experiences and contexts which helped shape my own thinking processes. I have been forced to think about the hidden values and assumptions below the surface of my consciousness that remained as yet unexamined.

Many of the assumptions and questions expressed by participants could have been used as a basis for critical, open enquiry into contradictions of schooling practice for culturally diverse indigenous and non-indigenous participants (students, teachers, parents/caregivers). If students had been encouraged to raise their own questions and critically research such issues, perhaps they would have seen an overlap and/or connections between their own 'dull and boring' experiences of classroom life, and the impact of previous 'quick fix' professional development on the learning capacity of their teachers. If culturally diverse teachers and principals had sustained their engagement in open, critical enquiry with children and young people, their parents/caregivers and their community elders about mainstream schooling practice, perhaps they would have seen the contradictory messages that emerged and revealed racism, prejudice and deficit theorising within an environment and schooling system which holds no tolerance for difference.

It can be argued that different types of knowledge are needed, developed through culturally responsive and inclusive learning communities which conduct critical inquiry into schooling practice, if we are to solve the problems inherent in mainstream teaching practice and to meet the needs of all our children and young people (Bishop \& Glynn, 1999; Penetito, 2001, 2004; Shields, Bishop \& Mazawi, 2005). The principle of discovery, noted by Durie, appears relevant here:

The principle of discovery ... emphasises both exploration and invention. The discovery of new knowledge is at the heart of all research. In 'research at the interface', however, discovery owes its innovation to 
insights drawn from two knowledge systems that have moved together in directions not possible with recourse to one system only. In addition to the notion of breakthrough, discovery also carries the concept of the future. (2005, p. 143).

At this end of my own learning journey, I have come to understand that it will only be through more radical ${ }^{60}$ and inclusive forms of teachers' collective reform work (Fielding, 1999, 2004) that Durie's (2005) principle of discovery can be achieved. Such a breakthrough will require new forms of collaborative partnership work in which teachers will re-position themselves as learners and engage with culturally diverse groups (indigenous and non-indigenous teachers, students, parents/caregivers) and those supporting the work of reform (kaumatua, kuia, facilitators, researchers) in uncovering the unexamined, hidden and submerged values, beliefs, identities and practices which "saturate" our mainstream schooling practices as well as our own collective actions (Fielding, 1999, p. 16). It is clear that a particular type of conversation and joint inquiry must now occur if we are to reframe the mainstream schooling experience for Māori children and young people. I started to see that this type of work required political activism and encapsulated Durie's (2005) concept of breakthrough and of a future form of citizenship within Aotearoa/New Zealand. Other authors have also noted the importance of this:

Whether or not we want to be, all teachers are political agents because we help shape students' understanding of the larger society. That is why it is so important for teachers to be clear about our social visions. Toward what kind of society are we aiming? (Bigelow, 2001, p. 299)

Many teachers who were interviewed had personal social visions which developed over time, yet these were rarely shared with colleagues, students, or parents and caregivers:

Unless teachers answer this question with clarity we are reduced to performing as technicians, unwittingly participating in a political project

60 Fielding has called for more radical and inclusive forms of teacher collegiality which reposition teachers as co-learners with students and their parents/caregivers. 
but with no comprehension of its objectives or consequences. Hence teachers who claim 'no politics' are inherently authoritarian because their pedagogical choices act on students, but students are denied a structured opportunity to critique or act on their teachers' choices. Nor are students equipped to reflect on the effectiveness of whatever resistance they may put up. (Bigelow, 2001, p. 299)

In the face of this scholarship, it was apparent to me that in the schools where I conducted research there was a lack of teacher and principal knowledge about the need for political community activism, a process which engaged culturally diverse groups (students, teachers, parents/caregivers, kaumatua and kuia) in "mutual mana enhancement" (Durie, 2005), sustained dialogue and collective critical inquiry over time.

The point at which change can occur, where the status quo is seen to be disabling and intransigent, is the point where it is apparent that stasis is not giving a sense of stability and efficacy, but is instead holding a system in place that perpetuates the dishonesty, the power base, the unreflective practice, the measures that hold and protect the status quo. Recognition of this point is a way of seeing that instead of holding the balance of power, it is crucial that those involved need to take part in a conversation about powerful, hidden, privileging and pathologising discourses. This cannot be a one-off event but rather a series of critical and public (honest) investigations about the less visible, hidden and unexamined values and beliefs which guide practices in our classrooms and schools within Aotearoa/New Zealand. In other words, it will become a process that allows and encourages breakthroughs and new discoveries.

I believe that if we are serious about reframing the educational experience for indigenous and culturally diverse learners (Māori and non-Māori ), we need to develop a very different type of school curriculum and classroom practice through political and dialogical community. It will require a very different power structure, which (re)positions teachers, principals, students, parents/caregivers and community elders as co-researchers and co-inquirers. This will be the process that will create new learning opportunities and structural change. Such collaborative research could be guided by Kaupapa Māori research protocols of initiation, representation, benefits, legitimisation and accountability as described by Bishop and Glynn (1999) or by the principles of "research at the interface" as described by Durie (2005), including mutual mana enhancement, shared benefits, 'aroha ki te tangata' and the principle of discovery. Freire $(1998,2000)$ had also 
called for a dialogic 'problem-posing' method of education, whereby teachers, students and their parents/caregivers become actors in figuring out the world through a process of mutual communication and inquiry. Questions - not answers - are at the core of this curriculum, according to Freire, stimulating an open, critical analysis of social situations and a development of collective agency to change them (1998). This will require us to be open to analysis, experience and feedback, and to have an understanding of what influences the collaborative dynamic over time.

The messages and stories presented within this research highlight the need for an education system that is strategic in its purpose by ensuring access to and participation in te ao Māori as well as other knowledge systems. While I believe that participants, other than teachers, must join this work, I found little literature which called on educators to reposition themselves as learners to research the worlds of their students and communities, and even fewer authors who acknowledged that students and their parents/caregivers could aid critical inquiry by investigating the cultural activities and worlds of their teachers.

It appeared to me that teachers were not prepared for and had no understanding of the need for pedagogical approaches which empower culturally diverse groups of learners to examine curriculum critically from various cultural perspectives. Teachers who were interviewed did not seem to be encouraging their students to investigate critically how knowledge is constructed in ways which benefit particular groups in society. I felt concerned about this, particularly since Giroux (1985) has pointed out that some progressive, multicultural education discourses have attempted to reduce power and domination to simple misunderstandings between oppositional groups. Such discourses ignore the complexity and sweat of social change, according to Giroux, because they displace attention from structural power relations to more comfortable concepts such as tolerance. There were gaps in the interview data related to teachers' understanding and knowledge of such theories as they worked together for change over time, but it became apparent that issues such as power and domination and the entire political perspective of teachers was limited and tended to be held safe within a dialogue of inclusiveness and recognition of difference that was belied by practice and story.

Most of the research literature I have read on teacher collaboration and partnership as mechanisms for improving classroom practice remains silent on the importance of collaborative engagement in critical collective inquiry with others (particularly students, parents/caregivers and community elders) as a way of actively 
investigating our own 'taken-for-granted' knowledge, our 'unexamined' values and beliefs which underpin the social practices of mainstream schooling. Evidence analysed in the context of this study revealed important gaps in participants' knowledge particularly related to the development of culturally responsive practice. However, I have come to realise that gaps in our knowledge will be addressed only if participants engage in critical inquiry and dialogue themselves. I came to realise that 'I' was in a privileged position. 'I' had the time and space to undertake this journey of inquiry; it was 'I' who read the many research texts and grappled with the complexity of research themes and contradictions of practice emerging from an analysis of multiple perspectives on teachers' collaborative reform work. Through the process of engaging in this enquiry, I have been challenged to think deeply about the context and purpose of teachers' collaborative reform work. I now firmly believe that it will be through participants' engagement in collaborative critical inquiry that teachers, students and their parents/caregivers will be encouraged positively to address institutional constraints to improvement in practice and outcomes for culturally diverse groups. I agree with various authors that it will be through new collaborative partnership work in change efforts at multiple levels (in the classroom, within the school, within the education system and in society) that democracy will be envisaged and democratic outcomes achieved (CochranSmith, 2004; Ginsburg, 2003; Kincheloe, 2003; Villegas \& Lucas, 2002). I believe this is the basis for effective citizenship and democratic practice.

Such a process would not treat culturally diverse participants as 'objects' for study, but as co-learners in the co-construction of the knowledge, a knowledge that is needed to transform our education system and to improve practice and outcomes for culturally diverse learners (teachers, students, parents/caregivers). However, at the end of my journey I also feel it would be naïve of me to think that such changes will be welcomed, even in my own institution. Kincheloe warns that "Questioning the unquestionable has never been a picnic in the park" (2003, p. 19) as it involves the struggle and sweat of social justice work. This is work that can be developed only through engagement in the practice of it. Durie (2005) reminds me of the need to develop resilience, a disposition necessary for those attempting to sustain navigational work over time. Resilience, according to Durie, “... is an expression of the effort needed to steer a steady course. It recognises both adversity and triumph, and celebrates strength of purpose, determination and a capacity to survive ..." $(2005$, p. 1$)$. It is a reminder that strengthens my resolve. 
I have come to realise that teachers' collaborative partnership work must be reconceptualised as political community work; a process which encourages breakthroughs and discoveries through political activism and participation through collective, critical examination of schooling practice from multiple and culturally diverse perspectives. This is the type of learning community which must be developed and sustained over time, if we are truly to work in collaborative partnership to transform our mainstream schooling practice and our society.

\section{Recommendations}

There are a number of recommendations which I would like to make for practice, policy and further research. I consider the most important to be further research and development on processes which encourage the participation and stories of culturally diverse participants, particularly indigenous and non-indigenous teachers, students, parents/caregivers, whānau and community elders (kaumatua and kuia), as they engage in critical examination of the contradictions of mainstream schooling practice for culturally diverse learners. Such inquiry would need to ascertain participant experiences, beliefs and perceptions of the impact over time. I found a lack of longitudinal research which tracked the process of change and discovery within the context of teachers' collaborative partnership work, from culturally diverse perspectives.

Further research and development is needed which outlines participants' navigational journeys of the collaborative dynamic as indigenous and non-indigenous teachers work together for change and transformation over time. Currently, there is a lack of stories in practice which would help prepare partners for engaging in such work.

I also found a lack of recognition in the research literature on the hidden, unacknowledged and unconscious beliefs, values, identities and practices that those involved bring into the collaborative dynamic over time.

\section{Teachers' Professional, Personal and Learning Identities}

Further research is needed on the professional, personal and learning identities that teachers (indigenous and non-indigenous) bring into the context of collaborative partnership work. There is a lack of research within Aotearoa/New Zealand regarding the multiple identities that teachers carry into collaborative partnership work, how such 
identities influence teachers' sustained engagement in such work and/or how teachers' identities change over time.

\section{The Development of Non-negotiable Principles and Protocols in Practice}

Much of the scholarship highlighted the need for non-negotiable principles, such as the need for mutual mana enhancement, shared benefits, human dignity and the principle of discovery (Durie, 2005); or protocols of mutual trust, respect and a focus on student outcomes underpinning collaborative partnership work (Fullan, 2005; Johnston \& Bush, 2005; Shields \& Sayani, 2005; Timperley \& Wiseman, 2003). However, I found that there was a lack of research literature which described how Māori and non-Māori participants (particularly teachers and principals) developed and sustained such principles and protocols in actual practice. Further research and development work in needed which describes the experiences of culturally diverse (particularly indigenous and nonindigenous) participants' experiences as they developed the principles, protocols and practices needed to sustain their engagement in collaborative partnership work over time.

\section{Knowledge, Skills and Dispositions Needed as well as the Time and Space to develop these}

Evidence highlighted important gaps in participants' (particularly teachers, principals, inschool facilitators, researchers, consultants) knowledge of:

- culturally responsive practice (as identified by key authors referred to throughout this study);

- "research at the interface" (Durie, 2005); and

- the notion of a dialogic problem-solving and learning community.

Further research and inquiry needs to be undertaken at all levels of our schooling system within Aotearoa/New Zealand to identify the types of theories and practices currently promoted. Evidence from this study would indicate that adding a 'cultural dimension' is not enough to transform mainstream schooling practice for culturally diverse groups of learners. Data analysis highlighted gaps in participant knowledge, skills and dispositions which would be needed for sustained engagement in dialogue and ongoing critical inquiry with others across the school community. However, I also 
became conscious of the lack of time and space for participants to sustain their collaborative, partnership work. I believe further research is required in the practice of such work from culturally diverse participant perspectives.

\section{The Cultural, Emotional, Political and Spiritual Dimensions of Collective Reform}

\section{Work}

Participant stories emphasised different and less visible dimensions of collective reform work. Some of the stories, particularly those of teachers who were awakened through the process of collaborative inquiry and listening practices, signalled cultural, emotional, political and spiritual dimensions of collective reform work. I believe that this is an area that warrants further research and scholarship.

\section{Racism, Prejudice and Bullying Practices in the Context of Reform}

I was particularly disturbed by accounts of racism, prejudice and of bullying behaviour within schools. These accounts really disturbed me, particularly as some teachers' experiences of peer behaviour made them wary of engaging in collaborative partnership work. There is a need to name such practices in schools, alongside other forms of oppression and tyranny. Further research is needed on teachers' experiences of racism, prejudice and bullying practices within schools and within the context of educational reform.

\section{The Internal and External Dynamics of Teachers' Collaborative Partnership Work}

There appeared to be a complex, interrelated dimension which influenced teachers' collaborative partnership work. For example, messages contained within participant stories revealed micro-political and macro-political influences on the dynamic of such work. Messages containing deficit theorising and pathologising practices within the context of teachers' collaborative partnership work, and within and across both school communities, were difficult to separate from the macro-political context occurring at the time of interviewing participants. Race-relationship issues dominated news headlines between 2004-2006, and more recently the Leader of the Opposition at the time, Don Brash, questioned the right of contemporary Māori to call themselves indigenous, due to their 'mixed blood-lines' and 'diluted blood' histories. When she won the national election, our Prime Minister, Helen Clark, noted the deep divisions within our country and it was this external (macro) environment which I also felt influenced the acceptance 
and efficacy of teachers' collaborative partnership work within and across both school communities. Further research needs to be undertaken which outlines the relationship between the micro-political and macro-political dimensions of teachers' collaborative partnership work within Aotearoa/New Zealand.

\section{In My Own Educational Practice}

I have come to realise that I must continue to engage in critical, collective inquiry into issues related to professional practice within Aotearoa/New Zealand. As an educator working in the context of teachers' professional development, I now see that many of the programmes in which I currently work are inadequate for preparing teachers to engage intellectually with issues related to culturally responsive and inclusive practice in this country. I personally believe that many of the programmes I have engaged in either as a teacher or as a teacher educator have ignored the need for critical theory and/or critical race theory in the work of collective reform. Through engaging in this inquiry journey, I realise that educators at all levels must be rigorous scholars of power and that I too will need to undertake collaborative research on my own professional practice that is informed through dialogue and on-going critical inquiry with others. I, too, must work to uncover the hidden and less conscious values and 'taken-for-granted' assumptions which underpin my own practice. This will require a continued navigation, a journey across a life-time of work.

Through the process of engaging in this inquiry, I have come to acknowledge aspects of my own personal vantage point. I understand now that I need to be clearer about articulating my social vision, one committed to addressing issues of social justice, and be prepared to investigate contradictions in my own practice that interrupt the occurrence of democratic processes. I know that it will be through engaging in critical collective inquiry that I will understand first-hand the promise and challenges involved in undertaking such work; and gain a deeper understanding of the internal and external influences on the collaborative dynamic which promote and/or disrupt the development of a critical collective consciousness, agency and activism.

So finally I end this stage of my own learning journey by referring to a whakatauki that was given to me by a participant during one of my final member checks:

\section{E kore te tangate e pakari I runga I te wai marino}

A person who remains in calm waters will never get strong. 
I have found it useful as a reminder of the importance of taking up the challenge with others, and of leaving behind safe and familiar harbours on an exploration of new, unexplored and uncharted waters. Such a journey requires courage, resilience and wholeheartedness, as well as new forms of leadership which commit to modelling a way forward so that others can be inspired and encouraged to join our collective struggle. In the context of this thesis, this whakatauki also encapsulates a vision of schooling that is dedicated to issues of social justice and democratic practice, by ensuring and celebrating our access to te ao Māori alongside other bodies of knowledge and knowledge systems.

To fellow navigators, Kia kaha!

Anne Hynds 


\section{References}

Achinstein, B. (2002). Conflict amid community: The micro-politics of teacher collaboration. Teachers College Record, 104 (3), 421-455.

Alejandra Elenes, A. (2003). Reclaiming the borderlands: Chicana/o identity, difference and critical pedagogy. In A. Darder, M. Baltodano \& R. Torres (Eds.), The critical pedagogy reader. London: Routledge Falmer.

Alton-Lee, A. (2003). Quality teaching for diverse students in schooling: Best evidence synthesis. Wellington: Ministry of Education.

Alton-Lee, A. (2005). Quality teaching for diverse learners: How an evidence-based approach can help. Keynote address to ACSA (Australian Curriculum Studies Association) Forum, Quality teachers: Quality teaching - Creating a new agenda for action by practitioners, researchers and policy makers. Melbourne, 23-24 May.

Arygris, C., \& Schon, D. (1987). Organisational learning: A theory of school organisation. New York: Routledge.

Askew, S., \& Carnell, E. (1998). Transforming learning: Individual and global change. London: Cassell.

Ball, S. J. (1987). The micro-politics of the school. Towards a theory of school organisation. London: Routledge.

Bandura, A. (1997). Self-efficacy: The exercise of control. New York: Freeman.

Bandura, A. (2000). Exercise of human agency through collective efficacy. Current Directions in Psychological Science, 9 (3), 75-78.

Banks, J. (1993). Approaches to multi-cultural curriculum reform. In J. A. Banks \& C. A. Banks (Eds.), Multi-cultural education: Issues and perspectives ( $2^{\text {nd }}$ ed.). Boston: Allyn and Bacon.

Banks, J. (1997). Educating citizens in a multi-cultural society. New York: Teachers College Press.

Banks, J. (2001a). Cultural diversity in education: Foundations, curriculum and teaching. Needham Heights: Allyn \& Bacon.

Banks, J. (2001b). Multi-cultural education: Historical development, dimensions and practice. In J. Strouse (Ed.), Exploring socio-cultural themes in education. Readings in social foundations ( $2^{\text {nd }}$ ed.). New Jersey: Merrill Prentice Hall.

Banks, J. (2004). Multi-cultural education: Historical development, dimensions, and practice. In J. A. Banks \& C. A. McGee Banks (Eds.), Handbook of research on multi-cultural education ( $2^{\text {nd }}$ ed.). San Francisco: Jossey-Bass. 
Banks, J. (2006). Cultural diversity and education. Foundations, curriculum and teaching $\left(5^{\text {th }}\right.$ ed.). New York: Pearson Educational.

Bascia, N., \& Hargreaves, A. (2000). Teaching and leading on the sharp edge of change. In N. Bascia \& A. Hargreaves (Eds.), The sharp edge of educational change. London: Routledge Falmer.

Bell, L., Washington, S., Weinstein, G., \& Love, B. (2003). Knowing ourselves as instructors. In A. Darder, M. Baltodano \& R. Torres (Eds.), The critical pedagogy reader. London: Routledge Falmer.

Bigelow, W. (2001). Inside the classroom: Social vision and critical pedagogy. In J. Strouse (Ed.), Exploring socio-cultural themes in education. Readings in social foundations ( $2^{\text {nd }}$ ed.). New Jersey: Merrill Prentice Hall.

Bishop, R. (1996). Collaborative research stories: Whakawhānaungatanga. Palmerston North: Dunmore Press.

Bishop, R., Berryman, M., Tiakiwai, S., \& Richards, C. (2003). Te kotahitanga: The experiences of Year 9 and 10 Māori students in mainstream classrooms. Hamilton: University of Waikato, Māori Education Research Institute (MERI), School of Education.

Bishop, R., \& Glynn, T. (1999). Culture counts: Changing power relations in education. Palmerston North: Dunmore Press.

Bishop, R., \& O'Sullivan, D. (2005). Sustaining educational reform: Towards a model for promoting and ensuring sustainability of educational reforms. A monograph prepared with the support of Nga Pae o te Maramatanga, The National Institute for Research Excellence in Māori Development and Advancement.

Bloor, D. J. (1996). The workloads of Mãori secondary school teachers. A national survey. Palmerston North: Massey University, Educational Research and Development Centre.

Bohm, D. (1987). Unfolding meaning. A weekend of dialogue with David Bohm. London: ARKS Paper-backs.

Bronfenbrenner, U. (1979). The ecology of human development. Experiments by nature and design. Cambridge, MA: Harvard University Press.

Bruner, J. (1990). Acts of Meaning, Cambridge, Mass: Harvard

Caprara, G. V., Barbaranelli, C., Borgogni, L., \& Steca, P. (2003). Efficacy beliefs as determinants of teachers' job satisfaction. Journal of Educational Psychology, 95 (4), 821-832.

Carr, W., \& Kemmis, S. (1986). Becoming critical: Education, knowledge and actionresearch. London: Falmer Press. 
Carroll-Lind, J., \& Kearney, A. (2004). Bullying: What do students say? Kairaranga, 5 (2), 19-24.

Charmaz, K. (2000). Grounded theory. Objectivist and constructivist methods. In N. K. Denzin \& Y. S. Lincoln (Eds.), Handbook of qualitative research ( $2^{\text {nd }}$ ed.). London: Sage Publications.

Coburn, C. (2005, July). Shaping teacher sense-making: School leaders and the enactment of reading policy. Educational Policy, pp. 476-509.

Cochran-Smith, M. (2004). Walking the road. Race, diversity and social justice in teacher education. New York: Teachers College Press.

Corson, D. (1998). Changing education for diversity. Buckingham: Open University Press.

Cram, F., Smith, G., Smith, L., \& Tunks, M. (1999). A report of workload issues for Māori secondary school teachers. Wellington: Ministry of Education.

Darder, A., Baltodano, M., \& Torres, R. (2003). Critical pedagogy: An introduction. In A. Darder, M. Baltodano \& R. Torres (Eds.), The critical pedagogy reader. New York: Routledge Falmer.

Darling-Hammond, L. (1997). The right to learn: A blue-print for creating schools that work. San Francisco: Jossey-Bass.

Denzin, N. (1984). On understanding emotion. San Francisco: Jossey-Bass.

Durie, M. (2003). Whānau capacities: A framework for measuring whānau outcomes. Paper presented at the Whānau Development National Hui held at Te Wananga-oRaukawa, Otaki, 24 March 2004.

Durie, M. (2005). Ngā tai matatū. Tides of Māori endurance. Melbourne: Oxford University Press.

Elliott, J. (1993). Academics and action research: the training work-shop as an exercise in ideological deconstruction. In J. Elliott (Ed.), Reconstructing teacher education. London: Falmer Press.

Elliott, J. (1998). The curriculum experiment: Meeting the challenge of social change. Buckingham: Open University Press.

Fatiu, Indrei, \& Rodgers, Irene (1984). The iceberg concept of nature. In American Field Scholarship Orientation Handbook, Vol. IV.

Fielding, M. (1999). Radical collegiality: Affirming teaching as an inclusive professional practice. Australian Educational Researcher, 26 (2), 1-34.

Fielding, M. (2004). 'New wave' student voice and the renewal of civic society. London Review of Education, 2 (3), 197-217. 
Fine, M., \& Weiss, L. (2005). Introduction. In L. Weiss \& M. Fine (Eds.), Beyond silenced voices. Class, race and gender in United States schools. New York: State University of New York Press.

Forest, L. (1998). Cooperative learning communities: Expanding from classroom cocoon to global connections. In C. M Brody \& N. Davidson (Eds.), Professional development for cooperative learning. New York: State University Press.

Freire, P. (1998). Pedagogy of freedom. Boulder, CO: Rowman \& Littlefield.

Freire, P. (2000). Education for critical consciousness. In A. M. A. Freire \& D. Macedo (Eds.), The Paulo Freire reader. New York: Continuum.

Frost, D., Durrant, J., Head, M., \& Holden, G. (2000). Teacher-led school improvement. London: Routledge Falmer.

Fullan, M. (1999). Change forces: The sequel. London: Falmer.

Fullan, M. (2005). Leadership and sustainability. Systems thinkers in action. California: Corwin Press.

Fullan, M., \& Hargreaves, A. (1996). What's worth fighting for in your school? New York: Teachers College Press.

Fullan, M., \& Hargreaves, A. (1998). What's worth fighting for out there? New York: Teachers College Press.

Fullan, M., \& Stiegelbauer, S. (1991). The new meaning of educational change. New York: Teachers College Press.

Gaffney, M., Higgins, N., McCormack, J., \& Taylor, N. (2004). Developing a more positive school culture to address bullying and improve school relationships: Case studies from two primary schools and one intermediate school. Wellington: Ministry of Social Development.

Gay, G. (2001). Curriculum theory and multi-cultural education. In J. A. Banks \& C. A. Banks (Eds.), Handbook of research on multi-cultural education. San Francisco: Jossey-Bass.

Giddens, A. (1984). The constitution of society. Cambridge: Polity Press.

Ginsberg, M. (2003). Series editor's introduction: Dialogue isn't necessarily more efficient, but it's more democratic and therefore more effective. In M. B. Ginsberg and J. M. Gorostiaga (Eds.), Limitations and possibilities of dialogue among researchers, policy makers and practitioners. International perspectives on the field of education. New York: Routledge Falmer.

Giroux, H. (1985). Critical pedagogy, cultural politics, and the discourse of experience. Journal of Education, 167 (2), 22-41. 
Goddard, R. (2001). Collective efficacy: A neglected construct in the study of schools and student achievement. Journal of Educational Psychology, 93 (3), 467-476.

Goddard, R., Hoy, W., \& Hoy, A. (2004). Collective efficacy beliefs: Theoretical developments, empirical evidence and future directions. Educational Researcher, 33 (3), 3-13.

Goleman, D. (1998). Working with emotional intelligence. New York: Bantam Books.

Goodman, J., Baron, D., \& Myers, C. (2005). Constructing a democratic foundation for school-based reform: The local politics of school autonomy and internal governance. In F. W. English (Ed.), The Sage handbook of educational leadership. Advances in theory, research and practice. London: Sage Publications.

Gradous, B. D. (1991). The development and validation of a transfer of training system (Project No. 45). St Pauls, Minnesota: Minnesota University, Department of Vocational and Technical Education.

Hammersley, M. (1993). On the teacher as researcher. Educational Action Research, 1 (3), 425-445.

Hargreaves, A. (1994). Changing teachers, changing times: Teachers' work and culture in the post-modern age. London: Cassell.

Hargreaves, A. (2000). Professionals and parents: A social movement for educational change? In N. Bascia \& A. Hargreaves (Eds.), The sharp edge of educational change. Teaching, leading and the realities of reform. London: Routledge Falmer.

Hargreaves, A., \& Fink, D. (2004). The seven principles of sustainable leadership. Educational Leadership, 61, 8-13

Hattie, J. (2003). Teachers make a difference: What is the research evidence? Melbourne: Australian Council for Educational Research on Building Teacher Quality.

Hawk, K., Tumama Cowley, E., Hill, J., \& Sutherland, S. (2002). The importance of the teacher/student relationship for Māori and Pasifika students. SET, 3, 44-49.

Head, G. (2003). Effective collaboration: deep collaboration as an essential element of the learning process. Journal of Educational Enquiry, 4 (2), 47-61.

Heifetz, R. (1994). Leadership without easy answers. Cambridge, MA: Harvard University Press.

Henderson, J. G., \& Hawthorne, R. D. (1995). Transformative curriculum leadership. Englewood Cliffs, NJ: Merrill Prentice Hall.

Hooks, B. (2003). Confronting class in the classroom. In A. Darder, M. Baltodano \& R. Torres (Eds.), The critical pedagogy reader. London: Routledge Falmer. 
Hynds, A. S. (2000). Airing our dirty laundry - a case study of collaboration within an action research project. Unpublished MA thesis, Wellington: Victoria University of Wellington.

Janesick, V. (2000). The choreography of qualitative research design. Minuets, improvisions and crystallisation. In N. K. Denzin \& Y. S. Lincoln (Eds.), Handbook of qualitative research ( $2^{\text {nd }}$ ed.). London: Sage Publications.

Jenkins, K. (1994). Māori education: A cultural experience and dilemma for the state - A new direction for Māori society. In E. Coxon, K. Jenkins, J. Marshall \& L. Massey (Eds.), The politics of learning and teaching in Aotearoa/New Zealand. Palmerston North: Dunmore Press.

Jones, A. (1999). The limits of cross-cultural dialogue: Pedagogy, desire and absolution in the classroom. Educational Theory, 49 (3), 299-316.

Jones, A. (2001). Difference and desire. Dividing classrooms by ethnicity. SET (1), 2932.

Johnson, R., \& Bush, L. (2005). Leading the school through culturally responsive inquiry. In F. W. English (Ed.), The Sage handbook of educational leadership. Advances in theory, research and practice. London: Sage Publications.

Kincheloe, J. (2003). Teachers as researchers. Inquiry as a path to empowerment $\left(2^{\text {nd }}\right.$ ed.). London: Routledge Falmer.

Kincheloe, J. \& McLaren, P. (1994). Rethinking critical theory and qualitative research. In N. Denzin and Y. Lincoln (Eds.), Handbook of qualitative research. London: Sage Publications.

Ladson-Billings, G. (1995). Toward a theory of culturally relevant pedagogy. American Educational Research Journal, 32 (3), 465-491.

Ladson-Billings, G. (2001). Seeing colour, seeing culture. In J. Strouse (Ed.), Exploring socio-cultural themes in education. Readings in social foundations $\left(2^{\text {nd }}\right.$ ed.). New Jersey: Merrill Prentice Hall.

Lather, P. (1986). Research as praxis. Harvard Educational Review, 56, 257-277.

Laugesen, R., (2005, January 16). The big issues facing the nation. Sunday Star-Times, Focus, p. C2.

Lieberman, A., \& Miller, L. (1999). Teachers transforming their world and their work. New York: Teachers College Press.

Lieberman, A., \& Wood, D. (2001). When teachers write: of networks and learning. In A. Lieberman \& L. Miller (Eds.), Teachers caught in the action. New York: Teachers College Press. 
Lincoln, Y., \& Denzin, N. (2000). The seventh moment. Out of the past. In N. K. Denzin and Y. S. Lincoln (Eds.), The handbook of qualitative research $\left(2^{\text {nd }}\right.$ ed.). London: Sage Publications.

Little, J. (1990). The persistence of privacy: Autonomy and initiative in teachers' professional relations. Teachers College Record, 91 (4), 509-536.

Little, J. (2001). Professional development in pursuit of school reform. In A. Lieberman \& L. Miller (Eds.), Teachers caught in the action. New York: Teachers College Press.

Little, J., \& McLaughlin, M. (Eds.). (1993). Teachers' work. Individuals, colleagues and contexts. New York: Teachers College Press.

Loper, L. (2006, October 13). Closing the education gap. New Zealand Education Review, 11 (40), p. 7.

Louis, K. S., \& Ingram, D. (2003). Schools that work for teachers and students. In B. Williams (Ed.), Closing the achievement gap. A vision for changing beliefs and practices $\left(2^{\text {nd }}\right.$ ed.). Alexandria, VA: Association for Supervision and Curriculum Development.

Louis, K. S., \& Marks, H. (1998). Does professional community affect the classroom? Teachers' work and student experiences in restructured schools. American Journal of Education, 106 (40), 532-575.

Marzano, R. (2003). What works in schools. Translating research into action. Alexandria, VA: Association for Supervision and Curriculum Development.

McCreanor, T. (2005). 'Sticks and Stones may break my bones ...' Talking Pakeha identities. In J. Liu, T. McCreanor, T. McIntosh \& T. Teaiwa (Eds.), New Zealand Identities. Departures and Destinations. Wellington: Victoria University Press.

McDonald, B. L. (2001). Transfer of training in a cultural context: A Cook Islands study. Unpublished $\mathrm{PhD}$ thesis, Victoria University of Wellington.

McDonald, P. (2001). Students' work and teachers' learning. In A. Lieberman \& L. Miller (Eds.), Teachers caught in the action. New York: Teachers College Press.

McFarlane, A. (2004). Kia hiwa ra! Listen to culture - Māori students' plea to educators. Wellington: NZCER.

McInerney, D., \& McInerney, V. (2002). Educational psychology. Constructing learning (3rd ed.). Sydney: Prentice Hall.

McIntosh, T. (2005). Māori identities: Fixed, fluid, forced. In J. Liu, T. McCreanor, T. McIntosh \& T. Teaiwa (Eds.), New Zealand identities. Departures and destinations. Wellington: Victoria University Press.

McLaren, P. (1993). Border disputes: Multicultural narrative, identity formation and critical pedagogy in post-modern America. In D. McLaughlin \& W. G. Tierney 
(Eds.), Naming silence lives: Personal narratives and the process of educational change. New York: Routledge.

McLaren, P. (2003). Critical pedagogy: A look at the major concepts. In A. Darder, M. Baltodano \& R. Torres (Eds.), The critical pedagogy reader. New York: Routledge Falmer.

McLaughlin, M., \& Talbert, J. (2001). Professional communities and the work of high school teaching. Chicago: University of Chicago Press.

McLaughlin, M., \& Zarrow, J. (2001). Teachers engaged in evidence-based reform: Trajectories of teacher inquiry, analysis and action. In A. Lieberman \& L. Miller (Eds.), Teachers caught in the action. New York: Teachers College Press.

Metge, J. (1976). The Māoris of New Zealand (Revised ed.). London: Routledge \& Kegan Paul.

Mitchell, H., \& Mitchell, M. (1993). Māori teachers who leave the classroom. Wellington: New Zealand Council for Educational Research.

Oakes, J., Wells, A., Yonezawa, S., \& Ray, K. (2000). Change agentry and quest for equity: Lessons from detracking schools. In N. Bascia \& A. Hargreaves (Eds.), The sharp edge of educational change. London: Routledge Falmer.

OECD (2001). Knowledge and skills for life: First results from PISA 2000. Programme for International Student Assessment. Paris: OECD. Retrieved December 10, 2006 from http://www.miranda.sourceoecd.org

OECD (2002). Education at a glance. OECD indicators 2002. PISA 2000. Paris: OECD.

Ogawa, R. (2005). Leadership as social construct. The expression of human agency within organisational constraint. In F. W. English (Ed.). The Sage handbook of educational leadership. Advances in theory, research and practice. London: Sage Publications.

Parker, S. (1997). Reflective teaching in the post-modern world: A manifesto for education in postmodernity. Buckingham: Open University Press.

Penetito, W. (2001). If we only knew ... Contextualising Māori knowledge. Early childhood education for a democratic society. Wellington: New Zealand Council for Educational Research.

Penetito, W. (2004). Theorising a 'place-based' education. Ahakoa kai tahi, tera a roto te hahae ke ra. Keynote address to the New Zealand Annual Research in Education Conference, Westpac Stadium, Wellington, November 24-26.

Pinar, W. (2004). What is curriculum theory? Mahweh: LEA Associates.

Poskitt, J. (2001). Schools doing it for themselves. Successful professional development. Set, 1, 4-7. 
Rosenholtz, S. (1989). Teachers' workplace: The social organisation of schools. New York: Longman.

Roth, W. M., \& Tobin, K. (2002). At the elbow of another. Learning to teach by coteaching. New York: Peter Lang.

Rubin, H. (2002). Collaborative leadership. Developing effective partnerships in communities and schools. California: Corwin Press.

Sachs, J. (2003). The activist teaching profession. Buckingham: Open University Press.

Sarason, S. (1996). Revisiting 'The culture of school and the problem of change'. New York: Teachers College Press.

Senge, P., Cambron-McCabe, N., Lucas, T., Smith, B., Dutton, J., \& Kleiner, A. (2000). Schools that learn. A fifth discipline fieldbook for educators, parents, and everyone who cares about education. London: Nicholas Brealey Publishers.

Sewell, W. (1992). A theory of structure: duality, agency and transformation. The American Journal of Sociology, 98 (1), 1-29.

Shields, C. (1999). Learning from students about representation, identity and community. Educational Administration Quarterly, 35 (1), 106-129.

Shields, C., Bishop, R., \& Mazawi, A. (2005). Pathologizing practices. The impact of deficit thinking on education. New York: Peter Lang.

Shields, C., \& Sayani, A. (2005). Leading in the midst of diversity: The challenge of our times. In F. W. English (Ed.), The Sage handbook of educational leadership. Advances in theory, research and practice. London: Sage Publications.

Shultz, J., \& Cook-Sather, A. (2001). Preface. In our own words. Students' perspectives on school. New York: Rowman \& Littlefield.

Sleeter, C. (2005). How white teachers construct race. In C. McCarthy, W. Crichlow, G. Dimitriads \& N. Dolly (Eds.), Race, identity and representation in education ( $^{\text {nd }}$ ed.). New York: Taylor Francis Group.

Sleeter, C., \& Delgado-Bernal, D. (2004). Critical pedagogy, critical race theory and antiracist education. Implications for multi-cultural education. In J. A. Banks \& C. A. McGee Banks, Handbook of research on multicultural education ( $2^{\text {nd }}$ ed.). San Francisco: Jossey-Bass.

Smith, G. (1990). Taha Māori: Pakeha capture. In J. Codd, R. Harker \& R. Nash (Eds.), Political issues in New Zealand education (pp. 183-197). Palmerston North: Dunmore Press. 
Smith, G. (2002). Kaupapa Māori theory: Transformative praxis and new formations of conscientisation. Paper presented at the Sconed International Conference on Cultural Policy Research, Te Papa, Wellington.

Smith, L. T., (1999). Decolonising methodologies: Research and indigenous peoples. Dunedin: University of Otago Press.

Smyth, J. (1999). Researching the cultural politics of teachers' learning. In J. D. Loughram (Ed.), Researching teaching: Methodologies and practices for understanding pedagogy. London: Falmer Press.

Steele, C. M. (2004). A threat in the air: How stereotypes shape intellectual identity and performance. In J. A. Banks \& C. A. McGee Banks (Eds.), Handbook of research on multi-cultural education ( $2^{\text {nd }}$ ed.). San Francisco: Jossey-Bass.

Stephens, W. (1999). Reducing prejudice and stereotyping in schools. New York: Teachers College Press.

Stoll, L. (2000). School culture. SET, 3, 9-14.

Stoll, L., \& Fink, D. (1996). Changing our schools: Linking school effectiveness and school improvement. Buckingham: Open University Press.

Stoll, L., Fink, D., \& Earle, L. (2003). It's about learning (And it's about time). What's in it for schools? London: Routledge Falmer.

Strauss, A., \& Corbin, J. (1998). Basics of qualitative research. Techniques and procedures for developing grounded theory ( $2^{\text {nd }}$ ed.). London: Sage Publications.

The Concise Oxford Dictionary (9 ${ }^{\text {th }}$ ed.). (1995). Thompson, D. (Ed.), Oxford: Clarendon Press.

Thrupp, M. (1999). Schools making a difference: Let's be realistic. Buckingham: Open University Press.

Timperley, H. (2003). School improvement and teachers' expectations of student achievement. New Zealand Journal of Educational Studies, 38 (1), 73-88.

Timperley, H., Fung, I., Wilson, A., \& Barrar, H. (2006). Professional learning and development: A best evidence synthesis of impact on student outcomes. Paper presented to the annual meeting of the American Educational Research Association, San Francisco, California, April.

Timperley, H., \& Parr, J. (2004). Using evidence in teaching practice: Implications for professional learning. Auckland: Hodder-Moa Publishers.

Timperley, H., \& Robinson, V. (2002). Partnership: Focusing the relationship on the task of school improvement. Wellington: New Zealand Council for Educational Research. 
Timperley, H., \& Wiseman, J. (2003). The sustainability of professional development. Report to the Ministry of Education. Wellington: Ministry of Education

Torre, M. (2005). The alchemy of intergrated spaces. Youth participation in research collectives of difference. In L. Weiss \& M. Fine (Eds.), Beyond silenced voices. Class, race and gender in United States schools. New York: State University of New York Press.

Town, S. J. H. (1996). 'Is it safe to come out yet?' The impact of secondary schooling on the positive identity development of ten young gay men. Paper presented to the New York Meeting of the American Educational Research Association, April 1996, pp. 132.

Tsianina Lomawaima, K. (2004). Educating Native Americans. In J. A. Banks \& C. A. McGee Banks (Eds.), Handbook of research on multi-cultural education $\left(2^{\text {nd }}\right.$ ed.). San Francisco: Jossey-Bass.

Tuuta, M., Bradnam, L, Hynds, A., Higgins, J., \& Broughton, R. (2004). Evaluation of the Te Kauhua Māori mainstream pilot project: Report to the Ministry of Education. Wellington: New Zealand.

Unks, G. (2003). Thinking about the gay teen. In A. Darder, M. Baltodano \& R. Torres (Eds.), The critical pedagogy reader. London: Routledge Falmer.

Vasil, R. (1988). Biculturalism: Reconciling Aotearoa with New Zealand. Wellington: Institute of Policy Studies.

Villegas, A. M. \& Lucas, T. (2002). Educating culturally responsive teachers. A coherent approach. Albany: State University of New York Press.

Waitere-Ang, Hine Tu Whiria O Te Rangi, (1999). Te kete, the briefcase Te tuara: The balancing act - Mãori women in the primary sector. Palmerston North: Massey University, Unpublished Masters in Education thesis.

Walker, R. (1991). Liberating Māori from educational subjection. Auckland: Research Unit of Māori Education, University of Auckland.

Welmond, M. (2002). Globalization viewed from the periphery: The dynamics of teacher identity in the Republic of Benin. Comparative Education Review, 46 (1), 37-65.

Wenger, E. (2005). Cultivating communities of practice. The art of learning together. Conference Presentation for the Ministry of Education, Duxton Hotel, Wellington, July 29. 
Appendices 


\title{
Appendix A. Consent Forms and Participant Information Sheets
}

\author{
VICTORIA UNIVERSITY OF WELLINGTON \\ Te Whare Wānanga o te Ūpoko o te Ika a Māui
}

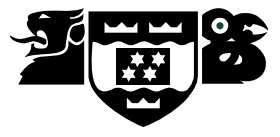

June 2003

\section{Participant Information Sheet}

\section{TITLE: WE'RE WORKING ON THIS TOGETHER ...? An investigation into participants' experiences of Mäori and non-Mäori teachers working together within a school reform project}

\section{Kia Ora (name)}

My name is Anne Hynds and I am a Pakeha researcher who currently works in teacher professional learning and development programmes, here in Aotearoa/New Zealand. As part of my own professional learning I am undertaking research for a $\mathrm{PhD}$ thesis, which will be supervised through Victoria University of Wellington. I want to find out about different peoples' experiences of Mäori and non-Mäori teachers' collaborative partnership work, when teachers work together to improve teaching classroom practice and learning outcomes for their Mäori students. This letter gives you some information about my research.

\section{The purpose of my research}

You are probably aware that (name of school) has been involved in a professional development programme, Te Kauhua/Mäori in the Mainstream Project, for the past two-three years. This project set out to improve teachers' knowledge, their teaching practice and Mäori students' learning outcomes. An important part of this pilot project required Mäori and non-Mäori teachers at the school to work together for change and improvement. I was one of the evaluators of the Te Kauhua/Mäori in the Mainstream Project, responsible for writing a series of research reports on the impact of Te Kauhua/Mäori in the Mainstream Project for the Ministry of Education. However, it is important to note that my involvement in that evaluation process has now finished. I now what to find out more about what happens when Mäori and nonMäori teachers work together for change and improvement over time. I will be undertaking my own research in (name of school) and one other school which had also previously been involved in Te Kauhua/Mäori in the Mainstream Project.

I have been given permission by the Ministry of Education and by both schools' boards of trustees to use information gathered in the Te Kauhua/MMP evaluation process for my own separate research. However, I am really interested in finding out about culturally diverse peoples' experiences of Mäori and non-Mäori teachers' collaborative/partnership work, when teachers work together to improve teaching practice and learning outcomes for Mäori children and young people. 


\section{Who will be involved in the research?}

I am interested in different people's experiences and their thoughts/beliefs when Mäori and non-Mäori teachers' work together for change and improvement, and so I will be interviewing:

- Mäori and non-Mäori teachers from two different schools (which were both involved in the Te Kauhua/Mäori in the Mainstream Project);

- the principals from both these schools;

- Mäori and non-Mäori in-school facilitators (who have been involved in the Te Kauhua professional development pilot at these two schools);

- Mäori and non-Mäori students (from these teachers' classrooms); and

- parents and caregivers of these students.

I am interested in interviewing teachers, in-school facilitators and principals over the course of a year, to see if and how teachers' collaborative/partnership work changes over time. I will be interviewing students and their parents/caregivers only once and that will be towards the end of next year.

\section{What would your involvement mean?}

If possible, I would like to interview you. Here are some of the questions that I will ask you. Please note that I may ask you to explain something that you say during your interview. I am very interested in your own experiences, beliefs and perceptions.

- Can you tell me about your own experiences of Mäori and non-Mäori teachers working together to improve their classroom practice and Mäori students' learning outcomes. Have you seen Mäori and non-Mäori teachers working together? What were they doing? Where were they working? What were they talking about/discussing? How many teachers were involved?

- What did you think about when you saw Mäori and non-Mäori teachers working together in such ways? What do you think about this idea of Mäori and non-Mäori teachers' working together to improve their classroom practice and Mäori students' learning outcomes? What are your own beliefs about these teachers' collaborative or partnership work?

- What were your perceptions of the impact when Mäori and non-Mäori teachers worked together to improve their classroom practice and Mäori students' learning outcomes? What do you think has changed as a result of teachers' collaborative/partnership work? What hasn't changed?

- What questions would you like to ask about Mäori and non-Mäori teachers working together to improve their classroom practice and Mäori students' learning outcomes? Why is this question important to you?

- What information would you like about Mäori and non-Mäori teachers working together to improve their classroom practice and Mäori students' learning outcomes? Why is this information important to you? 
The interview will be taped electronically and should take between 20-25 minutes. I can interview you at a time and at the place that is most suitable for you (for example, at your house or at the school). You will receive a copy of your own interview transcript and you can make changes to this if you wish. Once you are happy with your interview, I will ask you to sign it and send it back to me. The analysed findings from this research will be also be made available for you to comment on.

The information you provide will be strictly confidential and you will not be identified in any way (unless you want this). Information collected from the interview will be used for research and publishing purposes and will be kept secure in a locked filing cabinet at Victoria University of Wellington. Access to the cabinet will be available only to me, and will then be destroyed after five years.

Please note that you may withdraw from participating in this project at any stage up until and including the point at which you have checked for accuracy any transcripts of interviews I have had with you. If you decide to withdraw, you don't have to:

- give me a reason; and/or

- fear any penalty.

I will seek your written permission to participate before the interview starts.

If you would like any more information or have any questions about this research, please do not hesitate to contact me. I can be reached by phone (04) 4721000 (work), Mobile phone: 029924 2043, or by email: anne.hynds@wce.ac.nz. I will contact you soon to see if you would like to take part in this research process.

Thanks again for your time. Your involvement in my research is highly valued .

Yours sincerely

Anne Hynds 


\section{VICTORIA UNIVERSITY OF WELLINGTON}

Te Whare Wānanga o te Ūpoko o te Ika a Māui

\section{Teacher Consent Form}

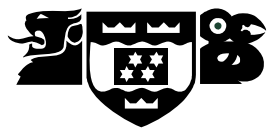

\section{RESEARCH PROJECT}

\section{We're working on this together ...? An investigation into participants' experiences of Māori and non-Māori teachers working together within a school reform project}

I agree to take part in the above research. I have had the project explained to me and I have had a chance to ask any questions. I understand that agreeing to this means that I will be willing to the following: (please tick box)

- I agree to take part in this research project and to be interviewed by researcher, Anne Hynds.

- I agree the interviews can be audio-taped.

- I agree to make myself available for further interviews and discussio be required.

- I agree to allow Anne Hynds' access to to my learning goals and act which I have developed as part of my involvement in the Te Kauhua school.

- I agree that information I have supplied in the Te Kauhua/MMP eval (including interview data, questionnaires) can be used by the resear Hynds for this separate research.

- I understand I don't have to take part in this research and that I can withdraw my consent for participation in this research, without havin reason, up to and including the final point of data collection.

- I understand that any information I provide is confidential and that I identified in the research or any reports on the project or to any part

- I understand that I will have a chance to comment on the research fi check the accuracy of any interviews.

Name:

Date:

Signature:

I understand that the tapes and research data will be destroyed after five years.

Would you like your tape returned to you?

$$
\text { Yes }
$$

No 


\section{VICTORIA UNIVERSITY OF WELLINGTON}

Te Whare Wānanga o te Ūpoko o te Ika a Māui

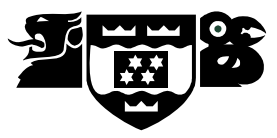

\section{Student Consent Form}

\section{RESEARCH PROJECT}

\section{We're working on this together ...? An investigation into participants' experiences of Māori and non-Māori teachers working together within a school reform project}

I have had the project explained to me and I have had a chance to ask any questions. I understand that agreeing to take part means that I will be willing to: (please tick box)

- I agree to take part in this research project and to be interviewed by the researcher, Anne Hynds.

- I agree the interviews can be audio-taped.

- I understand that I don't have to take part in this research and that I can che withdraw my participation in this research, without having to give a reasor and including the final point of data collection.

- I understand that any information I provide is confidential and that I will not identified in the research or any reports on the project, or to any party.

- I understand that I will have a chance to comment on the research finding check the accuracy of any interviews.

Name:

Date:

Signature:

I understand that the tapes and research data will be destroyed after five years.

Would you like your tape returned to you?

$$
\text { Yes }
$$

No 


\section{VICTORIA UNIVERSITY OF WELLINGTON}

Te Whare Wānanga o te Ūpoko o te Ika a Māui

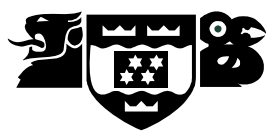

Parent/Caregiver Consent Form for their Child

\section{RESEARCH PROJECT}

\section{We're working on this together ...? An investigation into participants' experiences of Māori and non-Māori teachers working together within a school reform project}

I agree for my child (name) to take part in the above research. I have had the project explained to me and I have had a chance to ask any questions. I understand that agreeing to this means that I will be willing to the following: (please tick box)

- I agree for my child to be interviewed by the researcher, Anne Hynds.

- I agree the interviews can be audio-taped.

- I agree that my child can take part in further interviews should that be requil

- I understand that my child doesn't have to take part in this research and the chose to withdraw my consent for their participation in this research, withe having to give a reason, up to and including the final point of data collectic

- I understand that any information my child provides is confidential and that will not be identified in the research or any reports on the project or to any

- I understand that my child will have a chance to comment on the research $f$ and check the accuracy of any interviews.

Name:

Date:

Signature:

I understand that the tapes and research data will be destroyed after five years. 
VICTORIA UNIVERSITY OF WELLINGTON

Te Whare Wānanga o te Ūpoko o te Ika a Māui

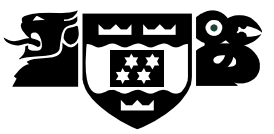

\section{Parent/Caregiver Consent Form}

\section{RESEARCH PROJECT}

\section{We're working on this together ...? An investigation into participants' experiences of Māori and non-Māori teachers working together within a school reform project}

I have had the project explained to me and I have had a chance to ask any questions. I understand that agreeing to take part means that I will be willing to: (please tick box)

- I agree to take part in this research project and to be interviewed by the researcher, Anne Hynds.

- I agree the interviews can be audio-taped.

- I understand that I don't have to take part in this research and that I can che withdraw my participation in this research, without having to give a reasor and including the final point of data collection.

- I understand that any information I provide is confidential and that I will not identified in the research or any reports on the project, or to any party.

- I understand that I will have a chance to comment on the research finding check the accuracy of any interviews.

Name:

Date:

Signature:

I understand that the tapes and research data will be destroyed after five years

Would you like your tape returned to you?

$$
\text { Yes }
$$

No 
VICTORIA UNIVERSITY OF WELLINGTON

Te Whare Wānanga o te Ūpoko o te Ika a Māui

June 2003

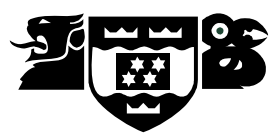

\section{RESEARCH PROJECT}

\section{TITLE: WE'RE WORKING ON THIS TOGETHER ...? An investigation into participants' experiences of Māori and non-Māori teachers working together within a school reform project}

Kia Ora (name)

Your child's school has been involved in a professional development programme, Te Kauhua/Māori in the Mainstream Project, over the past two years. This project has set out to improve teachers' knowledge and classroom practice with a view to improving teaching practice and raising Mäori student achievement. Māori and non-Māori teachers have been working together to conduct this work.

I am a Pakeha researcher currently undertaking a $\mathrm{PhD}$ thesis and would like to find out about peoples' experience of Māori and non-Māori teachers working together to improve teaching classroom/school practice and the learning outcomes of Mäori students. I have been given permission by the Ministry of Education and by the school's board of trustees to use the information gathered in the Te Kauhua/MMP evaluation process for my research.

I am interviewing Māori and non-Māori teachers at your child's school to find out about their own experiences about working together in the Te Kauhua programme, in order to improve teaching practice and raise Māori student outcomes. I am also interested in the views and experiences of Māori and nonMāori students from teachers' classrooms and the views of their parents/caregivers.

I would like to invite you and your son/daughter (name) to a hui to talk about this research. The purpose of the hui is to share information about this study and to find out if you and your son/daughter would like to be involved. At the hui I will:

- explain the purpose of the research

- explain how you and your son/daughter could be involved and what your involvement would mean

- answer any questions you may have.

The hui will be held the school's whare-nui at

Kai and tea/coffee will be provided. 
I am interested in interviewing you and your child (name) to find out about your own experiences of Māori and non-Māori teachers working together to improve classroom practice and outcomes for Māori students. I am also interested in any questions that you and your child may have about Māori and non-Māori teachers' partnership work and whether there is any information you would like from the school about this collaborative work.

The information gained through this research will be used to improve teacher professional development programmes. I will also be informing the school of the results of this study. However, the school will not know that you and your child have taken part in this study.

If you would like any more information or have any questions about this research, please do not hesitate to contact me. I can be reached by phone (04) 4721000 (work), Mobile phone: 029924 2043, or by email (anne.hynds@wce.ac.nz).

I look forward to meeting you soon.

Yours sincerely

Anne Hynds 


\section{Principal/Facilitator Consent Form}

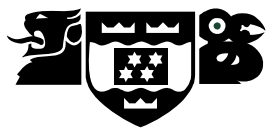

\section{RESEARCH PROJECT}

\section{We're working on this together ...? An investigation into participants' experiences of Māori and non-Māori teachers working together within a school reform project}

I agree to take part in the above research. I have had the project explained to me and I have had a chance to ask any questions. I understand that agreeing to this means that I will be willing to the following: (please tick box)

- I agree to take part in this research project and to be interviewed by the researcher, Anne Hynds.

- I agree the interviews can be audio-taped.

- I agree to make myself available for further interviews and discussion sho be required.

- I agree to allow Anne Hynds access to to my learning goals and action pli which I have developed as part of my involvement in the Te Kauhua proje my school.

- I agree that information I have supplied in the Te Kauhua/MMP evaluatior process (including interview data, questionnaires) can be used by the researcher, Anne Hynds, for this separate research.

- I understand I don't have to take part in this research and that I can chose withdraw my consent for participation in this research, without having to $\mathrm{g}$ reason, up to and including the final point of data collection.

- I understand that any information I provide is confidential and that I will nc identified in the research or any reports on the project or to any party.

- I understand that I will have a chance to comment on the research finding check the accuracy of any interviews.

Name:

Date:

Signature:

I understand that the tapes and research data will be destroyed after five years.

Would you like your tape returned to you?

$$
\text { Yes }
$$$$
\text { No }
$$ 
Appendix B. Characteristics of Participants

Table 1

Characteristics of Teacher Participants

\begin{tabular}{|c|l|l|l|l|c|}
\hline & Gender & Position of Responsibility & $\begin{array}{l}\text { Age } \\
\mathbf{2 0 - 2 8}\end{array}$ & $\begin{array}{l}\text { Age } \\
\mathbf{2 9 - 3 7}\end{array}$ & $\begin{array}{c}\text { Age } \\
\mathbf{3 8 - 5}\end{array}$ \\
\hline Māori & $\begin{array}{l}2 \text { male } \\
5 \text { female }\end{array}$ & $\begin{array}{l}2 \text { positions held: } \\
1 \text { of these included a senior } \\
\text { management team member, } \\
1 \text { middle management }\end{array}$ & $\mathbf{3}$ & $\mathbf{2}$ & $\mathbf{2}$ \\
7 & Non-Māori & 6 male \\
10 & 2 female & management & $\mathbf{1}$ & $\mathbf{3}$ & $\mathbf{6}$ \\
\hline
\end{tabular}


Table 2

Characteristics of Student Participants

\begin{tabular}{|c|c|c|c|c|c|}
\hline & Gender & Year group & $\begin{array}{l}\text { Age } \\
9-10 \text { yrs }\end{array}$ & $\begin{array}{l}\text { Age } \\
15\end{array}$ & $\begin{array}{l}\text { Age } \\
16\end{array}$ \\
\hline $\begin{array}{r}\text { Māori } \\
15\end{array}$ & $\begin{array}{l}4 \text { male } \\
5 \text { female } \\
4 \text { male } \\
2 \text { female }\end{array}$ & $\begin{array}{l}9 \text { students } \\
\text { were Yr } 11 \\
6 \text { students were Yr } 6\end{array}$ & 6 & 6 & 3 \\
\hline $\begin{array}{c}\text { Non-Māori } \\
15\end{array}$ & $\begin{array}{l}6 \text { male } \\
3 \text { female } \\
3 \text { male } \\
3 \text { female }\end{array}$ & $\begin{array}{l}9 \text { students were } \operatorname{Yr} 11 \\
6 \text { students were } \operatorname{Yr} 6\end{array}$ & 6 & 5 & 4 \\
\hline
\end{tabular}


Table 3

Characteristics of Parent/Caregiver Participants

\begin{tabular}{|c|c|c|c|c|c|}
\hline & Gender & $\begin{array}{l}\text { Position of } \\
\text { responsibility within } \\
\text { the school community }\end{array}$ & $\begin{array}{l}\text { Age } \\
20-28\end{array}$ & $\begin{array}{l}\text { Age } \\
29-37\end{array}$ & $\begin{array}{l}\text { Age } \\
38-56\end{array}$ \\
\hline $\begin{array}{r}\text { Māori } \\
10\end{array}$ & $\begin{array}{l}7 \text { female } \\
3 \text { male }\end{array}$ & $\begin{array}{l}5 \text { people working within } \\
\text { their child's school } \\
\text { (4 paid \& } 1 \text { unpaid) }\end{array}$ & & 6 & 4 \\
\hline $\begin{array}{c}\text { Non-Māori } \\
20\end{array}$ & $\begin{array}{l}19 \text { female } \\
1 \text { male }\end{array}$ & $\begin{array}{l}4 \text { people employed within } \\
\text { child's school } \\
\text { ( } 2 \text { paid \& } 2 \text { unpaid) }\end{array}$ & 2 & 5 & 9 \\
\hline
\end{tabular}




\section{Appendix C: Interview Questions}

\section{Participant Interview Questions - Adults}

- Can you tell me about your own experiences of Māori and non-Māori teachers working together to improve their classroom practice and Māori students' learning outcomes. Have you seen Māori and non-Māori teachers working together? What were they doing? Where were they working? What were they talking about/discussing? How many teachers were involved?

- What did you think about when you saw Māori and non-Māori teachers working together in such ways? What do you think about this idea of Māori and non-Māori teachers' working together to improve their classroom practice and Māori students' learning outcomes? What are your own beliefs about these teachers' collaborative or partnership work?

- What were your perceptions of the impact when Māori and non-Māori teachers worked together to improve their classroom practice and Māori students' learning outcomes? What do you think has changed as a result of teachers' collaborative/partnership work? What hasn't changed?

- What questions would you like to ask about Māori and non-Māori teachers working together to improve their classroom practice and Māori students' learning outcomes? Why is this question important to you?

- What information would you like about Māori and non-Māori teachers working together to improve their classroom practice and Māori students' learning outcomes? Why is this information important to you? 


\section{Interview questions - Students}

- Warm up questions: Who are the Māori teachers in your school? Who are the non-Māori teachers in your school?

- Can you tell me about your own experiences of Māori and non-Māori teachers working together to improve their classroom practice and Māori students' learning outcomes. Have you seen Māori and non-Māori teachers working together? What were they doing? Where were they working? What were they talking about/discussing? How many teachers were involved?

- What did you think when you saw Māori and non-Māori teachers working together in such ways? What do you think about this idea of Māori and non-Māori teachers' working together to improve their classroom practice and Māori students' learning outcomes? What are your own beliefs about these teachers' collaborative or partnership work? Some people might say that Māori and non-Māori teachers working together is a good or a bad thing? What do you think about this? Why do you think this?

- What were your perceptions of the impact when Māori and non-Māori teachers worked together to improve their classroom practice and Māori students' learning outcomes? What do you think has changed as a result of teachers' collaborative/partnership work? What hasn't changed? Do you think things are the same or do you think things are different? Why do you think this?

- What questions would you like to ask about Māori and non-Māori teachers working together to improve their classroom practice and Māori students' learning outcomes? Why is this question important to you?

- What information would you like about Māori and non-Māori teachers working together to improve their classroom practice and Māori students' learning outcomes? What do you want to know about Māori and non-Māori teachers working together to improve their classroom practice and Māori students' learning outcomes? Why is this information important to you? Do you have anything that you would like to say to your teachers? Why do you want to say this? Why don't you want to say anything? 


\section{Appendix D: Summary of Research Design, Methods \& Findings}

\section{Summary of Research Design, Methods \& Findings \\ Final Research Questions}

- What are the beliefs, values and experiences that precede the collaborative activities, when Māori and nonMāori teachers work together on a school reform project?

- What are the identities that those involved bring into the collaborative dynamic, when Māori and non-Māori teachers work together on a school reform project?

- What influences the acceptance and practice of teachers' collaborative partnership work, when Māori and non-Māori teachers work together on a school reform project?

Subset research questions which also guided data analysis include:

- What are the visible activities/aspects of teachers' collaborative partnership work, as Māori and non-Māori teachers work together on a school reform project?

- What are the less visible activities/aspects of teachers' collaborative partnership work, as Māori and nonMāori teachers work together on a school reform project?

It is important to note that themes that emerged were interrelated, multi-faceted and interdependent. For example, in the first set of interviews teachers talked about the importance of open, honest and/or respectful talk between Māori and non-Māori teachers during the professional development activities facilitated as part of the Te Kauhua PD hui, whānau hui, and/or marae visits/stays. However, in order to speak honestly/openly and respectfully it was also important that Māori and non-Māori teachers felt safe and/or encouraged to explore their teaching beliefs in open, honest and respectful ways. My interpretation of this first set of data indicated that certain environmental features encouraged Māori and non-Māori teachers to feel safe and engage in such discussions. I found that teachers' experiences, beliefs and perceptions were often interrelated and interdependent.

However, in the second set of interviews and through the process of conducting member checks I found particular contradictions (mixed messages) that were related to open, honest and/or respectful talk between Māori and non-Māori teachers. I also found that many teachers did not feel safe and/or felt encouraged to explore their teaching beliefs in open, honest or respectful ways within their own school environments. It appeared to me, as a qualitative researcher, that there were visible and less visible influences, activities and aspects related to teachers' collaborative partnership work. 
Interpreting Signs and Messages

First Set of Participant Interviews - 2003
24 participants (8 Māori and 16 non-Māori)
17 Teachers (7 Māori and 10 non-Māori)
2 School Principals (both non-Māori)
2 Resource Teachers of Learning and behaviour (both non-Māori)
2 Te Kauhua In-school Facilitators (1 Māori and 1 non-Māori)
1 Consultant (non-Māori)

\section{The Blessings}

\section{Findings from the Evidence}

Certain activities/processes/conditions/experiences influenced the acceptance and practice of teachers' collaborative partnership work

These activities/aspects were visible to me (as researcher) as influencing Māori and non-Māori teachers' initial commitment to work together.

\section{Exploring Mindsets, Beliefs and Values}

Māori and non-Māori teachers talking openly, honestly and/or respectfully about my/our current teaching practice for Māori students.

Māori and non-Māori teachers collectively exploring Mindsets, Beliefs and Values

- about my/our current teaching practice for Māori students

- through exploring evidence of current teaching practice for Māori students

- by asking questions

- by listening/hearing other people's perspectives

- by being encouraged to do this (in culturally appropriate and safe environments)

\section{Establishing the Right Environment}

Culturally inclusive settings for Māori and non-Māori participants (responsive to Māori and non-Māori teachers' needs)

Collective environments include other Māori stakeholders' views about current teaching practice for Māori students

Includes teachers' access to resource people who have cultural expertise

Which is connected and representative of the local Māori community

Is interpreted as safe, inclusive of Māori and nonMāori teachers, respectful of cultural differences

Includes time and space (for formal professional development activities and informal activities which encourage teacher interaction)

Encourages Māori and non-Māori teacher interaction and participation individually and collectively in professional development activities

\section{Real, Honest Heartfelt Stories}

- Personal revelations (open and honest/heartfelt) touched me/us and led to a change in thinking/led to a change that enabled me/us to work with other teachers for change and improvement

- Being in an environment which encouraged personal revelations (open and honest/heartfelt) from culturally diverse perspectives

- Came from real people in my/our school community

- Humbling to listen to - enabled me to/us to see my/our values, beliefs, mindsets, practice, judgements more clearly

- Challenged my/our thinking about my/our current teaching for Māori students

- Enabled healing/enabled further sharing

- Enabled reconnection to important spiritual/cultural values non-Māori teacher ownership

\section{Ownership, Voice and Choice}

- Having personal and/or collective input into professional development goals and/or processes encourages Māori and non-Māori teacher shared ownership

- exercising choice and being able to take part in decision-making in professional development goals and/or processes encouraged Māori and

- Having an individual/collective voice and feeling heard/valued in professional development activities and/or processes encourages Māori and non-Māori teacher ownership

\section{Valuing Voices not usually Heard}

Valuing/acknowledging culturally diverse voices not typically heard in schools (new and different experience for Māori and non-Māori teachers) enables Māori and non-Māori teachers to develop a commitment to work together for change and improvement

- New situation for Māori voices/ perspectives/ experiences to be valued, acknowledged, listened to, heard, respected, trusted, consulted

- New roles and responsibilities for Māori stakeholders

- Valuing/acknowledging te reo me ona tikanga in classrooms/schools

- Hearing/supporting the language in classrooms/schools (new situation)

\section{Awakening, Understanding and Listening}

Listening to/Hearing the voices, stories, perspectives and/or experiences of culturally diverse participants not typically heard in their schools (Māori students,

parents/caregivers/whānau, Kaumatua, Kuia, Māori teachers, non-Māori teachers) led to a change in Māori and non-Māori teachers' thinking

Enabled Māori and non-Māori teachers to see/view their teaching practice for Mãori students in a new and different way

- led to a change in Māori and non-Māori teachers' thinking

- led to a commitment to work together for change and improvement

Enabled Māori and non-Māori teachers to become more aware/connected to their values, beliefs, practices and/or vision for teaching

\section{Examining Contradictions of Practice in a Context of Collaborative Inquiry}

Examining evidence of current teaching practice and/or learning outcomes for Māori students whilst reflecting on individual/collective values, mindsets and beliefs about teaching practice encourages Māori and non-Māori teachers to develop a commitment to work together for change and improvement

- Māori and non-Māori teachers' analysis of classroom data/evidence of Māori students' experiences during collective discussions

- Evidence/data that challenges/confronts Māori and non-Māori teachers' thinking (shocking, humbling, fascinating, healing, exciting)

- Māori and non-Māori teachers are encouraged to analyse and/or reflect on classroom data/evidence of Māori students' experiences in safe and inclusive learning environments A facilitated process, Māori and non-Māori teachers have access to expertise 


\section{The Gathering of the Blessings}

Participants' perceptions of change - the visible activities that influenced the acceptance and practice of teachers' collaborative partnership work (as Māori and non-Māori teachers work together)

17 (7 Māori and 10 non-Māori) teachers $-2003\left(1^{\text {st }}\right.$ set of teacher interviews) 2 School Principals (both non-Māori - 2003

2 Resource Teachers of Learning and Behaviour (both non-Māori) - 2003

2 Te Kauhua In-school Facilitators (1 Māori and 1 non-Māori) - 2003

15 parents/caregivers of Māori students - 2004

15 parents/caregivers of non-Māori students -2004

15 Māori students - 2004

15 non-Māori students - 2004

- The observed excitement and enthusiasm of Māori and non-Māori teachers for their new collective reform work

- The observed incorporation of Māori language, cultural values and practices in classrooms/schools

- A focus on improving relationships (teacher-student, student-student, teacherparent/caregivers)

- Valuing and using Māori students' prior knowledge

- Teachers' use and/or experimentation with new teaching strategies (co-operative learning, co-construction/power-sharing)

- Raising teachers' expectations

- Teachers seeking support from colleagues to make changes and/or experiment with new teaching strategies in classrooms

Teachers' Collaborative Partnership Work helps to

Shape New Identities for

Some Māori Students

New identity: School achiever

New identity: Te Kauhua class member 


\section{Mixed Messages: Different, Contradictory Signs within the Context of Teachers' Collaborative Partnership Work}

\section{The Warnings}

Data set from Interviews with Different Stakeholder Groups from Both School

$$
\text { Communities - } 2004
$$

7 Māori and 10 non-Māori teachers - 2004

2 School Principals (both non-Māori) - 2004

2 Resource Teachers of Learning and Behaviour (both non-Māori) - 2004

2 Te Kauhua In-School Facilitators (1 Māori and 1 non-Māori) - 2004

15 Māori students - 2004

15 non-Māori students - 2004

15 parents/caregivers of Māori students -2004

15 parents/caregivers of non-Māori students -2004

Changes to teachers' collaborative partnership work: The warning signs

Less Visible Influences

- Underlying issues of trust and a lack of respect underpinning teachers' collaborative partnership work

- Established power relationships and hierarchies which resulted in privileged and silenced voices

- Deficit thinking, stereotypes, racism and prejudice

- A lack of acknowledgement and valuing of cultural difference, identity and diversity; and

- A lack of participant knowledge, skills and dispositions which would enable change and improvement

Signs and messages: emotionally charged discussions

- Rubbing up against less visible values and beliefs about teaching

- New roles and responsibilities provoke participant feelings, passions and/or emotions

- Less visible and/or acknowledged identities and deeply held values and beliefs

Trust and respect: less visible and/or examined beliefs and practices

- Choosing a peer who is a 'credible'/'trustworthy' role model highlights less visible/acknowledged values and beliefs of 'good'/'effective' teaching

- Differences in teachers' values and beliefs influence the decisions that they make in collaborative partnership work - who teachers choose to watch/observe/feedback

Submerged beliefs/reveal prejudice

- Submerged teacher beliefs/expectations of Māori students: "When Māori students leave school they are going to be going into workshops"

- Submerged teacher beliefs/expectations of fellow teachers: "As is typical - maths isn't a strong point of female teachers"/"Female teachers can be fragile in observation processes"

- Submerged teacher beliefs/expectations of fellow teachers: "She is not my idea of a trained teacher ... she hasn't been to Teachers' College."
Differences in Teachers' Beliefs: Trust, Respect, Status, Leadership and Mana (Similarities and differences in Māori teachers' beliefs and values which influenced their participation in collaborative partnership work over time)

Diversity of identities, beliefs and values

Diversity of Māori identities

Radical teacher identity

Effective/good teacher identity

Trained teacher identity

Stereotypes: lazy Māori teacher identity (forced identities)

Stereotypes: female, maths teachers' identities (forced identities)

Different beliefs about the goal of reform: what counts as improved teaching practice and outcomes for Māori students? Less visible disagreement about the use of power-sharing and co-construction activities with students

Messages about established listening and partnership practices with culturally diverse stakeholder groups

Listening practices and partnership practices with culturally diverse stakeholder groups that were not sustained 


\section{Warning signs about Resistance to Collaborative Partnership Approaches: The Internal Dynamic}

Resistance to Teachers' Collaborative Partnership Work

- Emerged over time

- Different stakeholder groups resisted the work over time

- Particular stakeholder groups voiced their concerns

- Particular stakeholder groups' concerns are heard/privileged

\section{The Dominant Discourses of Resistance:} Identity and Equity

Resistance tied to participant beliefs and values and identities

- Reject/ignore cultural differences (everyone the same)

- Reject/ignore cultural differences (racist treatment) Reject/ignore cultural differences (special treatment/threatens own child's identity/educational achievement

- Reject/ignore cultural differences (influenced the way participants chose to view/engage in teachers' collaborative partnership work

The Undercurrents of Resistance: Deficit thinking, prejudice, racism and identity

- Submerged/hidden/less visible beliefs, values and practices reveal lack of respect and trust for cultural differences

- Submerged/hidden/less visible beliefs and identities: stereotype - lazy/greedy/ undisciplined/thieving, underachieving/dumb/ privileged Māori

- Submerged/hidden/less visible teacher interactions (face-pulling, whispered conversations, attempt to hide true feelings/beliefs, reveal lack of trust and respect

- Submerged/hidden/less visible beliefs and identities: stereotype - fag

- Submerged prejudices - homosexuals and marriage
Resistant and Automatic Learnt Behaviour

- Unconscious/less visible beliefs and values - fue resistance

- Unconscious/less visible beliefs and values underpin learnt behaviour

A lack of openness, transparency and honesty and the presence of subterfuge

Specific challenges and dilemmas in developing honest, specific. and constructive communication practices between teachers - reveal less visible beliefs and values, reveal learnt behaviour

- Lack of open, honest, constructive questioning

- Lack of honesty and openness: in-class

observations

- Hiding the purpose of in-class observations

Creating high trust environments: school

leadership

- Less visible belief: hierarchy in school does not model process of partnership

- Less visible belief: school senior management unwilling/reluctant to reflect on/inquire into own practice/lead collaborative partnership work in school

- Less visible belief: school senior management lack knowledge, skills and/or disposition to support teachers' collaborative partnership work within school

- Less visible belief: hierarchy in school create less trusting/safe environments for teachers

Issues of teacher niceness and unexplored social class values

- Unexamined/less visible practices/beliefs and values: teacher niceness

- Unexamined/less visible practices/beliefs and values: teacher niceness and lack of openness/honesty/presence of subterfuge

- Unexamined/less visible practices/beliefs and values: teacher niceness and lack of critique

- Unexamined/less visible practices/beliefs and values: teacher niceness and unexplored family values/practices

Learnt behaviour: a lack of listening

- Unexamined/less visible beliefs/values/practices a lack of listening practices and lack of respect/lack of trust for cultural differences

- Unexamined/less visible beliefs/values/practices a lack of listening practices in the staffroom

- Unexamined/less visible beliefs/values/practices a lack of listening practices and the hierarchy/roles/responsibilities of teachers

- Unexamined/less visible beliefs/values/practices a lack of listening practices and the perception that teachers who raise issues are trying to cause problems/trouble 


\section{Warning signs about the Schooling Environment and}

\section{Beyond: The External Dynamic}

\section{Established Hierarchies and the Issue of Leadership}

- Less visible/hidden beliefs, values and practices: lack of safety: teachers don't feel safe discussing issues openly and honestly because of existing school hierarchies

- Less visible/hidden beliefs, values and practices: lack of voice/choice: teachers are not able to exercise voice/choice due to existing school hierarchies

- Less visible/hidden beliefs, values and practices: lack of consistency and support for teachers' collaborative partnership work across school senior managers/syndicate leaders/heads of department

- Less visible/hidden beliefs, values and practices: new teacher leadership threatens established school hierarchy

- Less visible/hidden beliefs, values and practices: reveal influence of existing power relationships

\section{Staff Divisions and Disputes}

- Less visible/hidden beliefs, values and practices: reveal existing staff relationships - the presence of staff factions, divisions and/or disputes

- Less visible/hidden beliefs, values and practices: the presence of staff factions divisions and/or disputes reveal resistance

- Less visible/hidden beliefs, values and practices: personal vendettas and existing dysfunctional relationships

- Less visible/hidden beliefs, values and practices: staff factions/divisions and/or disputes - reveal lack of trust, respect and issues related to individual teachers' sense of personal safety

Bullying and subversive practices

- Less visible/hidden beliefs, values and learnt behaviours/practices: established patterns of subversive and bullying teacher behaviour

- Less visible/hidden beliefs, values and learnt behaviours/practices: established patterns of personal vendettas

- Less visible/hidden beliefs, values and learnt behaviours/practices: established patterns and dominant teacher behaviour

Ways of dealing with diversity

- Learnt behaviour and established practices: a lack of open questioning

- Learnt behaviour and established practices: a lack of open challenge

- Learnt behaviour and established practices: a lack of listening

- Learnt behaviour and established practices: established ways of dealing with diversity create group identities, group labels and divisions within the school (staffroom, playground, classroom, school community

\section{Systemic transparency and outcomes for students}

- Less visible/unexamined practices: messages students receive from observing teachers/teacher interactions and tensions within the school

- Less visible/unexamined practices: messages students receive from observing parent/caregiver interactions and tensions within the school

- Less visible/unexamined practices: contradictions related to teacher modelling of collaborative partnership approaches and actual practice

\section{Power Relationships and Identity Formation}

- Less visible practices, identities and power relationships: understanding mainstream schooling practices and the loss of cultural identity

- Less visible practices, identities and power relationships: understanding mainstream schooling practices and the hurt and damage in the Māori community

The impact of the wider schooling environment: lack of teacher preparation/past professional development experiences

- Less visible beliefs, values, practices and learnt behaviour: Teachers' principals lack of knowledge and experience of past professional development workshops

- Less visible beliefs, values, practices and learnt behaviour: teacher/principal beliefs about culturally responsive practice and experience of past professional development workshops

- Less visible beliefs, values, practices and learnt behaviour: teachers'/principals lack of preparation and experience of past professional development workshops

- Less visible beliefs, values, practices and learnt behaviour: teachers'/principals' lack of knowledge and past experience of training

- Less visible beliefs, values, practices and learnt behaviour: teachers'/principals' lack of choice/voice/ownership of past professional development workshops and training 
